Portland State University

PDXScholar

$1-1-1981$

\title{
FORTEL, a telecommunications forecasting system
}

James Leslie Black

Portland State University

Follow this and additional works at: https://pdxscholar.library.pdx.edu/open_access_etds Let us know how access to this document benefits you.

Recommended Citation

Black, James Leslie, "FORTEL, a telecommunications forecasting system" (1981). Dissertations and Theses. Paper 80.

https://doi.org/10.15760/etd. 80

This Dissertation is brought to you for free and open access. It has been accepted for inclusion in Dissertations and Theses by an authorized administrator of PDXScholar. Please contact us if we can make this document more accessible: pdxscholar@pdx.edu. 


\title{
FORTEL: A TELECOMMUNICATIONS FORECASTING SYSTEM
}

\section{By}

James Leslie Black

\begin{abstract}
A dissertation submitted in partial fulfillment of
the requirements for the degree of

\section{DOCTOR OF PHILOSOPHY}

in
\end{abstract}

SYSTEMS SCIENCE

Portland State University

James Leslie Black (C) 1981 
TO THE OFFICE OF GRADUATE STUDIES AND RESEARCH:

The members of the committee approve the dissertation of James Leslie Blffek presented May 29, 1981.

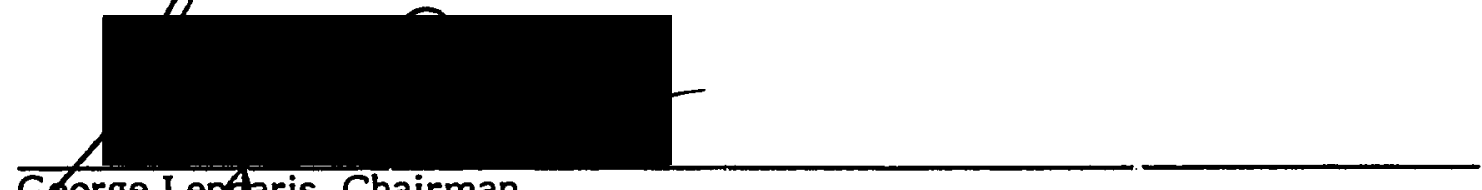
George Lendaris, Chairman

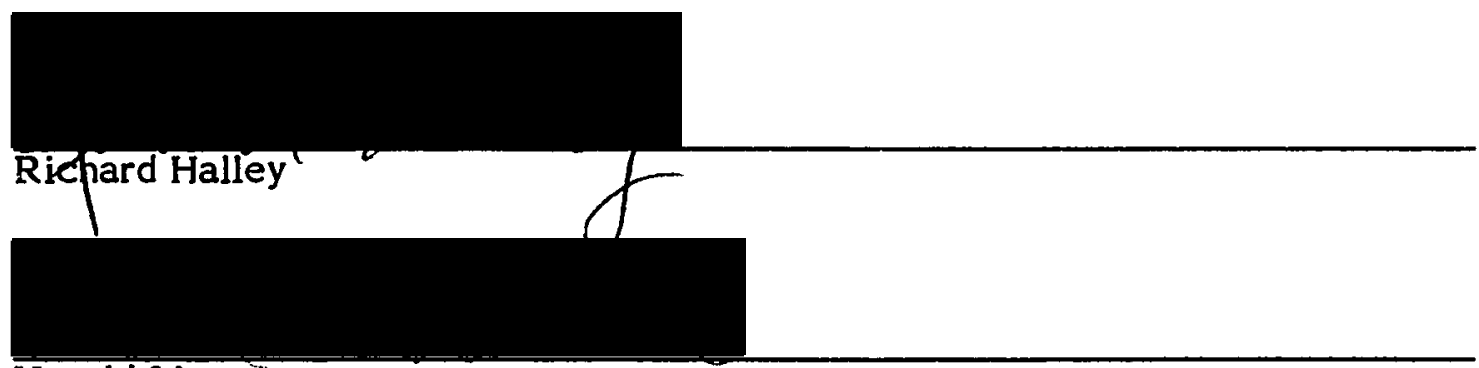

Harold Linstone

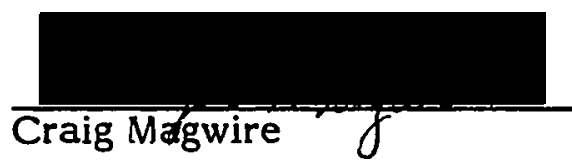

APPROVED:

Stanley-Rauck, Deah of Graduate Studies and Research 
AN ABSTRACT OF THE DISSERTATION OF James Leslie Black for the Doctor of Philosophy in Systems Science presented May 29, 1981.

Title: FORTEL: A Telecommunications Forecasting System

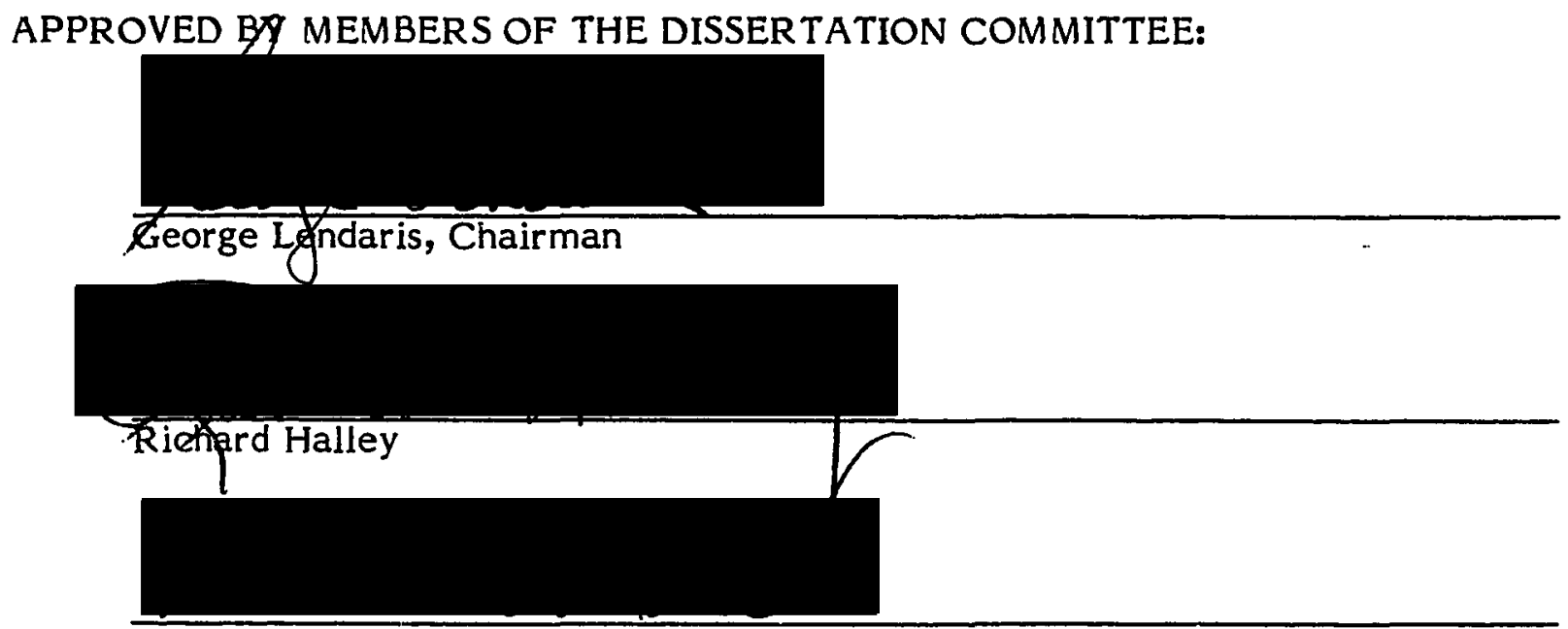

Harold Linstone

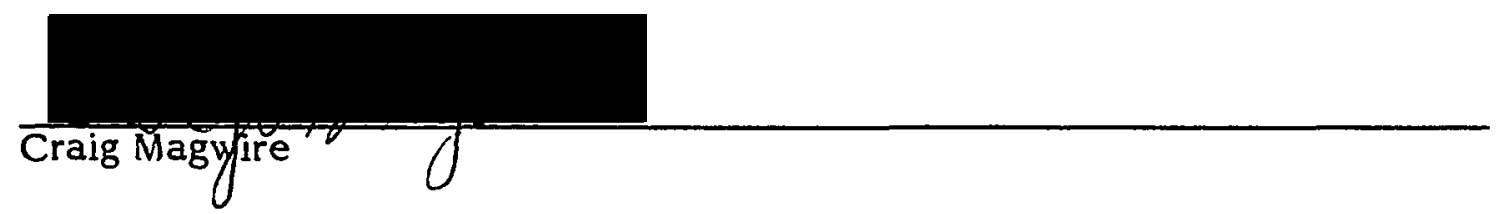

The telecommunications industry is undergoing a metamorphic change. New technologies have made possible a vast panorama of new services. Electronic newspapers, videotelephones, and computer-mediated conferences are but a few of the possibilities. In contrast to technology, most of the other factors affecting the industry (and its infrastructure) have not changed. Government regulations, for example, are based on the 1934 Communications Act. These factors (e.g., consumer behavior, corporate philosophies, energy, and competition) are beginning to change. The Congress is considering a rewrite of the 1934 Communications Act. Competition 
Competition has become a dominant factor (note that the industry by and large has been a government-regulated monopoly). The outcome of these changes will determine which services will be offered and the extent to which they will be demanded. The problem is to determine which changes will actually occur and, then, forecast their effect. The problem is further complicated by the fact that those individuals and institutions involved in making changes do not know which changes to make. For them, a forecasting system is needed to evaluate the outcome of various changes.

A review of the literature was conducted to determine the extent to which the problem was solved. Several forecasts have been generated, but none address the proilem in its entirety. Some have examined, in great detail, one or two of the pertinent factors, but ignored the others. Other forecasts have been more global. These assume certain changes will be made. Forecasts are then developed. The problem is that users do not have the option of changing the assumptions. Moreover, most of these forecasters have not specified their assumptions. Following the literature search, an overview of the FORTEL System is given.

FORTEL is designed to forecast service and terminal equipment demand. The system synthesizes forecasters' assumptions about industry change with quantitative demand models. The system also provides the forecaster with the ability to change assumptions and evaluate the outcome; i.e., test alternative scenarios.

There are three major components: model, user assumptions, and the computer program. The model component consists of four demand models. For each market (residential and business), there are service and terminal models. User assumptions reflect the forecaster's outlook on the future of the 
telecommunications industry. The assumptions are divided into five categories. The general category reflects assumptions about the industry in general, the economy, societal change, and energy. Technology assumptions deal with the future of a variety of new (and existing) technologies. There are several assumptions about services and terminals. These cover a broad range of factors which will directly affect implementation and demand of a particular service or terminal. The final category includes assumptions about the forecasting technique (quantitative techniques) to be used.

The computer program is the synthesizing component of the system. It combines the user assumptions with the models to produce the forecast. It also contains the scenario testing facit of the system.

Following a detailed description of each component, an output comparison is given. The author has selected three different sets of user assumptions. The forecasts generated from these sets are compared. The three range from a pessimistic outlook (economic recession and energy crisis) to a very prosperous outlook (exponential growth).

The thesis concludes with a chapter on follow-on research and a conclusion. 


\section{PREFACE}

The Systems Science Ph.D. Program offers both theoretical and applied research options. The student selecting the applied option is required to spend a period of time working with a company or a government agency. The intention of this (internship) is to gain experience in a real-world setting. The author's internship was with the General Telephone Company of the Northwest, Incorporated. This dissertation is the product of research the author conducted during his internship and continued association with the company. 


\section{ACKNOWLEDGMENTS}

During the course of this project, a spiritual dimension has been added to the author's life. Without this dimension, the author would have given up in despair long ago. It is to the glory of God and His Son, Jesus Christ, that this research has been brought to the point of completion.

I would like to express my gratitude to the members of my dissertation committee. Dr. George Lendaris, chairman, has been of the greatest help with his invaluable insights and gentle prodding at the appropriate moments. I also want to thank Dr. Harold Linstone, Dr. Richard Halley, and Dr. Craig Magwire for thier considerable efforts.

I would like to especially thank the General Telephone Company of the Northwest, Incorporated for making available to me the resources necessary to conduct this research.

To Jerry Pound, a special note of gratitude is in order for his personal interest in my progress as well as his invaluable help with the computer program. I also want to thank Dr. Selmo Tauber for his motivation and encouragement during my moments of despair. In addition, I would like to thank Bob Black, Albert Chen, Alan Eaker, Bob Fugate, Terry McCoy, Joyce Sieminski, and Dennis Trimble for their comments and ideas.

Last, but not least, I want to thank Kim Fenton for typing the thesis. Her kind patience with my numerous revisions is greatly appreciated. 


\section{TABLE OF CONTENTS}

PAGE

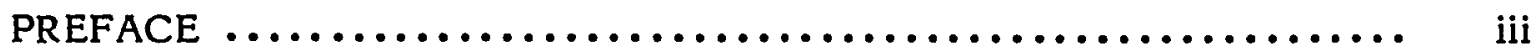

ACKNOWLEDGMENTS $\ldots \ldots \ldots \ldots \ldots \ldots \ldots \ldots \ldots \ldots \ldots \ldots \ldots \ldots$, iv

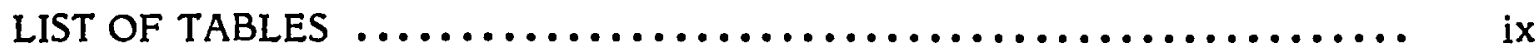

LIST OF FIGURES $\ldots \ldots \ldots \ldots \ldots \ldots \ldots \ldots \ldots \ldots \ldots \ldots \ldots \ldots \ldots \ldots, \quad \mathrm{x}$

\section{CHAPTER}

I. INTRODUCTION $\ldots \ldots \ldots \ldots \ldots \ldots \ldots \ldots \ldots \ldots \ldots \ldots \ldots \ldots \ldots, \ldots \ldots \ldots$

II. THE PROBLEM AND CONTEXTUAL BACKGROUND $\ldots \ldots \ldots \ldots \ldots 3$

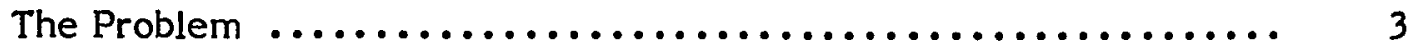

Services and Terminals $\ldots \ldots \ldots \ldots \ldots \ldots \ldots \ldots \ldots \ldots \ldots \ldots, \quad 5$

Contextual Background $. \ldots \ldots \ldots \ldots \ldots \ldots \ldots \ldots \ldots \ldots \ldots, 10$

Literature Search $. \ldots \ldots \ldots \ldots \ldots \ldots \ldots \ldots \ldots \ldots \ldots \ldots \ldots, \quad 36$

III. FORTEL--AN OVERVIEW $\ldots \ldots \ldots \ldots \ldots \ldots \ldots \ldots \ldots \ldots \ldots \ldots, 38$

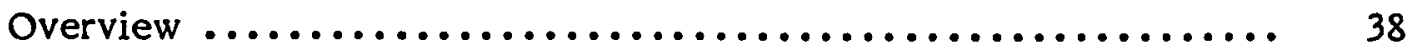

User Assumptions............................. 39

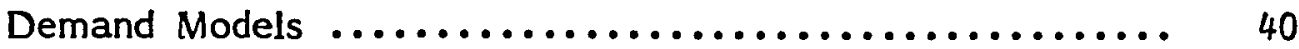

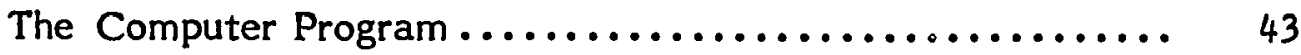

The Forecasting Process $\ldots \ldots \ldots \ldots \ldots \ldots \ldots \ldots \ldots \ldots \ldots \ldots, 45$ 
PAGE

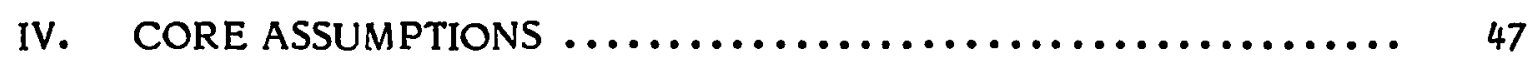

Introduction $\ldots \ldots \ldots \ldots \ldots \ldots \ldots \ldots \ldots \ldots \ldots \ldots \ldots \ldots \ldots \ldots \ldots . \ldots \ldots$

Selection Criterion ............................. 49

Core Assumptions ............................ 52

V. DEMAND MODELS ........................... 59

Introduction $\ldots \ldots \ldots \ldots \ldots \ldots \ldots \ldots \ldots \ldots \ldots \ldots \ldots \ldots \ldots \ldots$

Residential Demand Models ........................ 61

Service Demand Model ......................... 61

Terminal Equipment Demand Model $\ldots \ldots \ldots \ldots \ldots$

Business Demand Models ......................... 76

Service Demand Model ....................... 76

Terminal Equipment Demand Model ............... 79

VI. USER ASSUMPTIONS ............................ 82

Introduction $\ldots \ldots \ldots \ldots \ldots \ldots \ldots \ldots \ldots \ldots \ldots \ldots \ldots \ldots \ldots \ldots . \ldots \ldots$

Creating An Assumption Set ....................... 83

Assumption Set I--Economic Colapse $\ldots \ldots \ldots \ldots \ldots \ldots \ldots \ldots \ldots$

General Assumptions ....................... 85

Technological Assumptions ..................... 91

Service Assumptions .......................... 94

Terminal Equipment Assumptions ............... 106

Forecasting Technique Assumptions ............... 107

Assumption Set II--Modest Growth ................... 113

General Assumptions ......................... 113 
Technological Ãssumptions .................... 117

Service Assumptions ......................... 119

Terminal Equipment Assumptions ................. 128

Forecasting Technique Assumptions $\ldots \ldots \ldots \ldots \ldots \ldots . \ldots . \ldots 128$

Assumption Set III--Exponential Growth .................. 134

General Assumptions ......................... 134

Technological Assumptions ...................... 139

Service Assumptions ......................... 141

Terminal Equipment Assumptions ............... 148

Forecasting Technique Assumptions $\ldots \ldots \ldots \ldots \ldots \ldots . \ldots . \ldots 149$

VII. THE COMPUTER PROGRAM .................... 155

Introduction $\ldots \ldots \ldots \ldots \ldots \ldots \ldots \ldots \ldots \ldots \ldots \ldots \ldots \ldots \ldots \ldots \ldots$

Running The Program .......................... 156

Entering A New Assumption Set.................. 156

Running The Reports $\ldots \ldots \ldots \ldots \ldots \ldots \ldots \ldots \ldots \ldots$

Testing Alternative Scenarios .................... 164

Program Overview--A Data Processing Perspective ............ 165

Data Base ................................... 167

Reports................................... 170

Program Structure .............................. 172

VIII. APPLICATIONS $\ldots \ldots \ldots \ldots \ldots \ldots \ldots \ldots \ldots \ldots \ldots \ldots \ldots \ldots \ldots \ldots \ldots$

Example Session $\ldots \ldots \ldots \ldots \ldots \ldots \ldots \ldots \ldots \ldots \ldots \ldots \ldots \ldots \ldots$ 
Resultant Forecasts $\ldots \ldots \ldots \ldots \ldots \ldots \ldots \ldots \ldots \ldots \ldots \ldots \ldots \ldots \ldots$

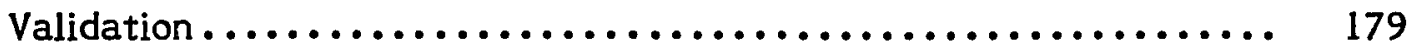

Comparison To Other Forecasts $\ldots \ldots \ldots \ldots \ldots \ldots \ldots \ldots \ldots \ldots \ldots$

IX. FOLLOW-ON RESEARCH ......................... 184

Technology $\ldots \ldots \ldots \ldots \ldots \ldots \ldots \ldots \ldots \ldots \ldots \ldots \ldots \ldots \ldots \ldots \ldots \ldots . \ldots \ldots$

Financial Analysis ............................... 184

Social Benefit $\ldots \ldots \ldots \ldots \ldots \ldots \ldots \ldots \ldots \ldots \ldots \ldots \ldots \ldots \ldots \ldots \ldots$

Elasticity Survey .............................. 185

X. CONCLUSION ............................... 186

REFERENCES .................................. 189

\section{APPENDIX}

A Description of Services $\ldots \ldots \ldots \ldots \ldots \ldots \ldots \ldots \ldots \ldots \ldots \ldots \ldots \ldots \ldots . \ldots \ldots$

B Regression Results .............................. 196

C Sample Reports ............................... 197

D User Assumption Work Sheets ...................... 207

E Service and Terminal Forecasts $\ldots \ldots \ldots \ldots \ldots \ldots \ldots \ldots \ldots \ldots \ldots$

KEY TO ABBREVIATIONS $\ldots \ldots \ldots \ldots \ldots \ldots \ldots \ldots \ldots \ldots \ldots \ldots \ldots \ldots \ldots \ldots \ldots$ 


\section{LIST OF TABLES}

TABLE

PAGE

I Transmission Requirements $\ldots \ldots \ldots \ldots \ldots \ldots \ldots \ldots \ldots \ldots \ldots \ldots, 19$

II Transmission Characteristics $\ldots \ldots \ldots \ldots \ldots \ldots \ldots \ldots \ldots \ldots \ldots .26$

III Service Assumption Categories $\ldots \ldots \ldots \ldots \ldots \ldots \ldots \ldots \ldots \ldots . \quad 95$

IV Forecasting Technique Assumptions For Set I--General ......... 108

V Forecasting Technique Assumptions For Set I--Services ......... 109

VI Forecasting Technique Assumptions For Set I--

Terminal Equipment $\ldots \ldots \ldots \ldots \ldots \ldots \ldots \ldots \ldots \ldots \ldots \ldots, 112$

VII Forecasting Technique Assumptions For Set II--General $\ldots \ldots \ldots \ldots 129$

VIII Forecasting Technique Assumptions For Set II--Services ......... 130

IX Forecasting Technique Assumptions For Set II--

Terminal Equipment $\ldots \ldots \ldots \ldots \ldots \ldots \ldots \ldots \ldots \ldots \ldots \ldots, 133$

X Forecasting Technique Assumptions For Set III--General ......... 150

XI Forecasting Technique Assumptions For Set III--Services ........ 151

XII Forecasting Technique Assumptions For Set III--

Terminal Equipment ........................ 154

XIII Data Base Summary $\ldots \ldots \ldots \ldots \ldots \ldots \ldots \ldots \ldots \ldots \ldots \ldots \ldots . \ldots \ldots$

XIV File Organization $\ldots \ldots \ldots \ldots \ldots \ldots \ldots \ldots \ldots \ldots \ldots \ldots \ldots \ldots, 167$

XV Resserv.dat File Record Description .................... 168

XVI Resterm.dat File Record Description .................... 169

XVII Busserv.dat File Record Description .................... 169

XVIII Busterm.dat File Record Description .................... 169 


\section{LIST OF FIGURES}

FIGURE

PAGE

1 The Telephone Network $\ldots \ldots \ldots \ldots \ldots \ldots \ldots \ldots \ldots \ldots \ldots \ldots \ldots$

2 A Cellular Mobile System ........................... 29

3 A Schematic For Discussing The Process of Using FORTEL . ...... 39

$4 \quad$ The Forecasting Process $\ldots \ldots \ldots \ldots \ldots \ldots \ldots \ldots \ldots \ldots \ldots \ldots \ldots \ldots$

$5 \quad$ The Development Process $\ldots \ldots \ldots \ldots \ldots \ldots \ldots \ldots \ldots \ldots \ldots \ldots . \ldots . \ldots . \ldots$

$6 \quad$ Residential Service Demand Model ...................... 65

$7 \quad$ Residential Terminal Equipment Demand Model .............. 71

$8 \quad$ Business Service Demand Model ....................... 75

9 Business Terminal Equipment Demand Model ................. 80

10 The Computer Program Flowchart .................... 166

11 Forecast Comparisions $\ldots \ldots \ldots \ldots \ldots \ldots \ldots \ldots \ldots \ldots \ldots \ldots \ldots \ldots$ 


\section{CHAPTER I}

\section{INTRODUCTION}

The purpose of the research underlying this dissertation was to develop a system which forecasts residential and business demand for a variety of telecommunication services ${ }^{1}$ and terminals. An important feature of the resulting system is the ability to incorporate the effects (upon demand) of changes in governmental regulations, technology, competition, society, and energy. Although elusive, an important goal has been to incorporate (into the system) a capacity to test alternative scenarios and utilize the "wisdom" of the users--be they telecommunication forecasters, decision makers, or whoever. The forecast period designed into the system is twenty years; e.g., 1980 to 2000 . The demand forecasted is for the "entire" United States.

This type of forecasting system is virtually necessary at present because of the explosive technological growth which has taken place. Technological innovations have made possible a vast panorama of possibilities. Electronic newpapers, videotelephones, and Turoff's (Hiltz and Turoff, 1978) Electronic Information Exchange System are but a few examples. This has caused an imbalance in the industry for, while technology has grown exponentially, the other aspects have grown linearly--or not at all. Regulation, for example, is based on 1934 legislation and must now be updated. When done, this will fundamentally change the industry's infrastructure. Hence, a requirement of the system is the ability to reflect these changes.

${ }^{1}$ The majority of these services are new and have never been offered to the public; e.g., electronic newspaper. See Appendix A for descriptions. 
Chapter II provides a definition of the problem. Included is background information on the factors that affect demand. The chapter closes with a review of the literature.

Chapter III is an overview of FORTEL. The system's components are discussed along with their relationships to each other. A summary of the forecasting process is also provided.

Chapter IV discusses core assumptions. These are fundamental assumptions about the future. Based on these assumptions, the demand models were developed (Chapter V). The demand models, in turn, require input from the user. These inputs (called user assumptions) are discussed in Chapter VI. In addition, three sets of assumptions are delineated.

Chapter VII delineates the computer program. This includes descriptions of input requirements, output documents, and the process flow.

A sample forecasting session is documented in Chapter VIII. The resultant forecasts (based on the three assumption sets of Chapter VI) are also discussed.

Chapter IX indicates follow-on research. Chapter $\mathrm{X}$ is the conclusion. References are then cited. After the references are the appendixes. The dissertation concludes with a key to the abbreviations. 


\section{CHAPTER II}

\section{THE PROBLEM AND CONTEXTUAL BACKGROUND}

Following a description of the problerri, the services and terminals to be forecasted are delineated. The next section is the contextual background in which the factors affecting demand are outlined. The chapter closes with a review of the literature.

\section{THE PROBLEM}

Metamorphosis is the hallmark of today's telecommunications industry. The multifaceted cacoon of government regulations, monopolies, electromechanical technologies, and consumer satisfaction with existing telecommunication services is shedding. Emerging is an industry of manifold beauty. "Light" cables, satellites, videotelephones, electronic newspapers, and computer-assisted meetings are but a few of the possibilities. Martin (1978) envisions a wired society in which every citizen is connected to centralized computers. The machines will send mail, switch telephone calls, order merchandise from stores, and even allow citizen input into the political process via remote voting. Martino (1979) foresees a universal mobile communication service. Satellites would relay signals from wristwatch transmitters. In addition, services such as disaster communications, educational broadcasting, and telemedicine could be offered.

Turoff's computerized conferencing system (Hiltz and Turoff, 1978) has the potential to fundamentally alter the business world. This system (called EIES) eliminates the need for face-to-face meetings. Using a computer, businessmen (or 
anyone for that matter) can hold a meeting while being geographically and temporarily dispersed.

New technologies are not the only factors causing the metamorphosis. The Federal Communications Commission, Congress, and state commissions are all reevaluating their roles in the industry. Many regulators feel the existing regulatory structure is an inhibiting process. A president was elected whose main platform was to reduce governmental intervention into our lives (regulation, taxes, etc.). Terms like "competitive edge," "market force," and "deregulation" have become very common among government regulators. The government has established the industry's infrastructure. Deregulating the industry will substantially impact the outcome of the metamorphosis.

This is not the only factor. Changing social mores, energy shortages, the economy, and changes in corporate philosophies will also affect the metamorphosis. An analysis of each is provided in the Background Section.

The ultimate goal of the metamorphosis is to provide many more highquality telecommunications services to both residential consumers and businesses. These services range in sophistication from plain old telephone service (POTS) to Turoff's conferencing system. Forecasting the demand for these services is the purpose of this dissertation.

Concomitant with demand for services is the demand for terminals. In order to access these services, the consumer must have a terminal--a telephone is necessary in order to make a telephone call. Thus, terminal demand, being a function of service demand, is also include herein.

The problem of forecasting service and terminal demand has been greatly complicated by the metamorphosis. No one knows the degree to which the emerging industry will be regulated, whether or not data processing and 
telecommunications will merge or the extent to which new technologies will be implemented. Each of these factors, as well as many others, will have a tremendous impact. Thus, the forecast must include inferences about the industry's infrastructure.

The timing of the present research is opportune. Corporations investing billions of dollars are in need of decision-support systems with which they can determine the effects of various investment scenarios. The government has equal need for these forecasts. In order to determine policies that best serve the people, it must be able to evaluate the effects of several different possibilities. This illustrates yet another facet of the problem. In addition to forecasting demand, there is a need for scenario testing.

It will be helpful to digress for a moment to discuss scenario testing and user assumptions. Alternative scenario testing is, in fact, the process of testing different sets of assumptions about the future. Business will want to find the set which will result in the best financial posture. Government will want the set which best serves the population. Any solution to the problem, then, should have this facet. Otherwise, the decision makers will not be able to test their assumptions.

To summarize, the problem can be designated as the need to develop a system capable of forecasting the demand for telecommunication services and terminal equipment under a range of scenarios specified by the user.

\section{SER VICES AND TERMINALS}

The services and terminals that emerge from the metamorphosis may be very different than those offered today. This is especially true of the new services, where a vast potential exists. There are twenty-five potential services and three terminal types forecasted herein. Of these, only three services are 
currently offered (on a widespread basis). Several companies are field testing a few of the remaining twenty-two; however, most of them have yet to be introduced. ${ }^{1}$ The terminals, on the other hand, already exist. The devices will undergo technological improvements, but their basic function will remain the same. A description of the services and terminal is given below.

Innovative Services

Speculation about future services has come from several quarters. Ironically, these quarters do not substantially differ in their outlook. Outside the industry, speculation is generally liberal. Martino (1979), as described above, has written an article which forecasts Dick Tracy wristwatch radios, centralized data banks for crime control, video telephone, and automated offices. The "Wired Society," (Martin, 1978) talks of a society completely revolutionized by telecommunications--medical examinations by computers, travel replaced by telecommunications, EFT completely replacing paper money, and a return to the cottage industry (office in the home).

Within the industry, speculation runs a little more conservative. Like Martino, Theodore Brophy (1979) (Chief Executive Officer of GTE) argues the industry must offer data and video as well as voice services. W. Rowland (1979) (Vice President--Telephone Operations, GTE) feels home services such as remote control of appliances, security, video entertainment, and access to data-bases will emerge in the 1980s. In the office, he envisions video conferencing, electronic information services, and data base systems. However, they stop short of predicting wristwatch radios or centralized crime control data banks.

${ }^{1}$ GTE, for example, is field testing a version of electronic newspaper. See Fay (1980, page 44). 
Listed on the next page are the services to be forecasted. These are organized into five categories. Descriptions are given in Appendix A.

General Information

- Electronic Newspapers

- Electronic Mail

- Travel Reservations

- Airlines, Bus, Trains, Hotel, Car Rentals, Night Clubs

- $\quad$ Plain Old Telephone Service (POTS)

- Cellular Mobile System

- Consumer Advisory Service

Entertainment

- Video Library (Plays, Movies, Etc.)

- Restaurant Guide, Reservations, and Menus

- Video Games

- Network Television Transmission (Superstations)

- Electronic Library (Books, Magazines, Etc.)

Health Services

- Outpatient Treatment

- Diagnosis

- Emergency Services

Education

- $\quad$ Computer Tutoring

- Correspondence School

Business

- $\quad$ Electronic Meetings (EIES)

- Electronic Funds Transferring 
- Message Recording (Answering Service)

- Call Forwarding

- Video Conference Calls

- Appointments Calendar

- Data Base Access

- Government Documents

- Industry Statistics

- Corporate Data Bases

- Stock Market

- Word Processing

- Computer-To-Computer Communications

$\underline{\text { Terminal Equipment }}$

Terminals are the devices that reside on the customer's premise. There are several types; telephones, computers, computer terminals, televisions, video telephones, PBXs, and mobile radios. These devices fall into three basic categories; voice, data, and video. As with most categories, the boundaries are somewhat fuzzy. Video telephones, for example, use both video and voice. Nevertheless, it is helpful to use this organization scheme. A description of each category follows.

Voice Terminals. The most ubiquitous voice terminal is the telephone. There are 175 million telephones in the United States. The telephone is also the oldest terminal. It has been in use for over 100 years. ${ }^{2}$

2 Alexander Graham Bell invented the telephone in 1877. 
Over the past century, the telephone has undergone several changes. What began as an electromechanical contraption has evolved into an electronic device complete with state of the art, integrated circuitry. Many new styles have emerged. These range from the ultramodern GTE flip telephone to the antique candlestick.

What has not changed, however, is the basic function of the telephone. It remains today as it did in 1880, a device designed for person-to-person voice communication. The changes have been of an evolutionary nature. They are enhancements (improvements) to the basic concept. Thus, today's telephone can be considered the product of 100 years of refinement.

Mobile radios are another type of voice terminal. Their popularity, in the recent past, has grown substantially through the citizens band (CB) market. Mobile radios, however, suffer from a frequency allocation problem. This is true whether the radio operates on citizens bands or those allocated to the telephone companies for their mobile systems. The Federal Communications Commission (FCC) has allocated an extremely small portion of the frequency spectrum to mobile radios. As a result, there is not enough capacity (bandwidth) to meet the demand. Overcrowding has resulted. One solution to this problem is a cellular mobile system (discussed in the Technology Section). Until this problem is resolved, mobile radios will have limited use.

Data Terminals. While the telephone was evolving, the data terminal has undergone a series of revolutions. What began as a device which connected man to a computer has gone way beyond the need for man or computers. Many terminals collect data automatically; e.g., data satellites. Other terminals are intelligent. With the advent of digital technology and packet switching, computers can talk directly to each other. In this case, the terminal has been eliminated. 
With the advent of data terminals, many new services have been developed; e.g., computer conferencing, electronic newspaper, and EFT. But more than that, data terminals may revolutionize the industry. At this time, telephony is a voice communications system. The demand for data may very well force the "voice" to become "data." The reason this may happen is that voice can be digitalized to data transmitted over the data system and decoded at the receiving end. Thus, a data system can also transmit voice. This is further discussed in the Technology Section. This will have a tremendous impact on terminal demand. The data terminal may well become the most ubiquitous device.

Video Terminals. Television receivers are the most common examples of video terminals. With very little modification, these devices can provide two-way voice and video communications. Moreover, they could be linked with computer terminals to provide endless possibilities.

The demand for terminals, as well as services, is dependent on several factors. These are discussed below.

\section{CONTEXTUAL BACKGROUND}

As stated above, the telecommunications industry is in the dawn of a new era. The factors causing the metamorphosis are discussed in this section. Several other factors--not part of the metamorphosis but which, nevertheless, affect demand--are also discussed.

Particular attention has been given to the interaction among the factors. New technologies, for example, have forced changes upon the regulatory structure. The economy will most assuredly affect corporate investment decisions. An energy crisis may very well change society's values. The importance of these interactions, to the forecaster, lies in his selection of user assumptions. As stated above, 
assumptions will have to be made. It is essential that these assumptions are consistent. It would not be realistic to assume corporations would undertake costly programs during a severe recession.

The factors, described below, are:

- Government Regulations

- The Network

- Technology

- $\quad$ Energy

- Societal Change

- Competition

- The Economy

- Corporate Change

\section{Governmental Regulation}

In that telephony is a regulated industry, no other area will play as crucial a role as governmental regulations. The government established the industry's infrastructure; dictates what services the telephone companies can offer; determines how much a company can earn; defines where companies can operate. In short, the regulators totally dominate the industry. Thus, any user assumption will have to include regulation.

From its inception (circa 1870) until 1934, telephony was left free of governmental intervention. The result was chaos. Thousands of telephone companies sprung up, none of which had any interconnection. Customers have several telephones. One for each company. To place a call, both customers have to have service from the same company. This resulted in unnecessary duplication.

The: problem was solved when Congress passed the 1934 Communications Act. This legislation established the industry's infrastructure. Congress felt 
telephony was a "natural monopoly." Each company was given a serving area in which no other company could operate. A complex set of regulations was established to ensure that customers were not overcharged and that everyone could get a telephone. ${ }^{3}$ Telephone companies, on the other hand, were given an opportunity to earn a profit allowing a fixed rate of return on their investment (rate base). Also, a procedure was established to share long-distance revenues. The procedure (called division of revenues) was necessary in order to ensure universal service. Rural companies must invest more per customers than city companies. In some cases, the rural investment is quite high, division of revenues tends to offset this cost.

Natural monopolies, universal service, rate of return, and division of revenues play a crucial role in telephony. A change in any one of them will alter the infrastructure of the industry.

During the 1950s, the government began to change its attitude towards natural monopolies. The impetus for this change began in 1957. In its landmark hush-a-phone decision, the FCC ruled customers could add any attachment that wasn't electrically connected to the telephone system. Prior to this ruling, only telephone companies could provide equipment. New technologies were forcing open the door to competition.

The Carterphone case is generally considered the beginning of competition. After a lengthy court battle, the Supreme Court upheld the FCC's ruling that the Carterphone could be connected to the network. That 1968 decision marked a significant change in the regulator's posture. Martin (1976, page 37) quotes the FCC conclusion:

${ }^{3}$ This is known as the universal service concept. 
A customer desiring to use an interconnecting device ... should be able to do so, so long as the interconnection does not adversely affect the company's operations.

This opened the door to a flood of activity. The next year, the FCC gave Microwave Communications Incorporated (MCI) permission to establish a microwave system between Saint Louis and Chicago. This marked the beginning of competition in the long-distance portion of the network. Shortly after $\mathrm{MCI}$, several companies sprung up to offer long-distance service.

In 1977, the FCC completely deregulated the telephone market. Anyone could connect any telephone to the network as long as the device met certain electrical standards. In 1980, the FCC generalized this in its Computer Inquiry II decision. All terminals, not just telephones were deregulated. In addition, long distance was also completely deregulated. With this decision, the terminal equipment and long distance markets were flung open wide.

In 1977, the Congress began a rewrite of the 1934 Communications Act. The spirit of the rewrite was to let competitive forces (not the FCC) regulate the industry wherever possible. A "competitive edge" will do more to stimulate new technologies and services than more regulations, according to the legislators.

In late 1979 , the FCC began preliminary investigations into a cellular mobile system. This system may replace the telephone wire to the home (or business) with mobile radios.

Thus, what began with the hush-a-phone decision has evolved into a complete rewrite of the 1934 Communications Act. In that time span, the infrastructure has undergone a major change--telephony is no longer a natural monopoly. 
While sweeping changes have been made to the natural monopoly concept, very little has been changed elsewhere. Universal service is still the government's goal for the telephone industry. The financial aspects, rate of return, and division of revenues have not changed either. This has caused part of the technological problem. The reward mechanisms have promoted the development of expensive, highly reliable, and very long-life equipment. At one time, central offices (discussed in the next section) were designed to last 40 years. Thus, telephone companies are rewarded for keeping equipment in service for long periods of time, not for frequently replacing them with new technologies.

To summarize, in 1934, the Congress established the industry's infrastructure. This structure was based on natural monopolies providing universal service. In the last 20 years, regulators have moved towards competition as a means of providing better service. The "competitive edge," regulators feel, will stimulate new technologies better than governmental regulation. On the other hand, financial rewards are still based on a system which inhibits new technologies.

The final outcome of this paradox will have a substantial impact on terminal equipment demand. If the financial system is changed to stimulate new technologies, demand will shift towards more sophisticated services and terminals. If it is not changed, demand may remain the same. Another alternative is that (under the no-change assumption), new technologies will spread outside telephony. Demand will grow for more sophistication, but it will be supplied by the data processing industry not telephony.

Technology is forcing a merger of the two industries. Within telephony, all new central offices use computers to switch the telephone calls. Many PBXs are microprocessors which have a variety of computing capabilities. Data processing, 
on the other hand, is relying more and more on remote computing (teleprocessing). In fact, IBM and Xerox have proposed satellite systems to facilitate teleprocessing. The barrier to the merger is the FCC. In that telephony is regulated and data processing is not, regulators have kept the two industries separate. At this time, telephony can transmit "nonenhanced" data. That is, telephony can transmit data but cannot change its (the data) meaning. Data processing can transmit data and enhance it but only in the long distance portion of the network. Throughout most of the world, this distinction does not exist. In fact, IBM is one of the world's largest telephone suppliers.

The FCC is in a dilemma. If they allow the merger, telephone companies may use capital generated from their monopolies to underprice the data processing competitors. On the other hand, data processing companies will have an advantage in that they are not subject to restrictive regulations. The problem with not allowing the merger is that many new services will not come into being. Some of these services, for example, would replace travel by teleconferencing. In an era of energy dependence, this is a critical service. The Computer Inquiry II decision has addressed this dilemma by deregulating long distance. ${ }^{4}$ All enhancements to the data, the FCC argues, can be done there. Thus the services will be offered without a complete merger.

The future of this decision is uncertain. Most major telephone and data processing companies are opposed to the decision. A lengthy court battle is ahead. The final outcome will have a tremendous impact on demand.

${ }^{4}$ It is interesting to note computer Inquiry II was necessary because new technologies made computer Inquiry I obsolete only months after it was issued. 
The Network

The North American telecommunication network is beyond a shadow of a doubt the most sophisticated in the world. Virtually all the electronic switching facilities are in North America. It is also the largest. Half of all the telephones in the world are in the United States.

The network, like the telephone, has evolved over the last 100 years. The direction of the network's evolution was dominated by the two governmental regulations; universal service and rate of return. Universal service forced the telephone companies to develop a highly reliable and widespread voice network. The rate of return profit system (as previously discussed) encouraged the telephone companies to install costly equipment with extremely long lives.

What has evolved, then, is a very costly, reliable, widespread, long-lasting voice network. The problem with this type of network is that it is slow to change. In the wake of new technologies (see the next section), this has become a substantial problem. There are many new technologies which are not being offered because of the existing network. Before describing these technologies a description of the existing network is in order.

The network has three components (see Figure 1). The local loop connects the subscriber to the switching facility. The "switch" is designed to connect the subscribers to each other. Without the switch, every telephone would have to be connected directly to every other telephone. In that there are 136 million telephone customers, this would require $10^{16}$ connections. The third element is long-distance transmission. This portion of the network interconnects switches.

The local loop is a pair of wires connecting the subscriber (customer) to the switch. Every subscriber has his own pair of wires, except in the case of party lines. The United States has several hundred million miles of subscriber loops. 
These loops, like the entire network, were designed to transmit voice signals. The wire pairs are an excellent medium for voice. Unfortunately, wire has a low transmission capacity. Multiplexing will improve the capacity, but this is expensive. A wire pair can handle approximately $70 \mathrm{~K}$ bits per second. With multiplexing, it can be increased to 2 million bits per second. Even at this increased rate, it will require 46 pairs to transmit one television channel. This is one of the major factors inhibiting change. Many new services require wide-band capacity. The network was designed around narrow band. Thus, a significant change will have to be made to accommodate the new services. Various capacity requirements are given in Table $\mathrm{I}$.

The vast majority of switching facilities (called central offices) are electromechanical. Each call is routed through the switch in a sequential fashion. In a local call, seven numbers must be dialed. The first number must be processed before work can begin on the second. A long-distance telephone call (ten numbers) requires 20 seconds for a complete connection. In an era of computers, 20 seconds is an eternity. Another problem is with dedication. Once the connection has been made, no one else can use the circuit. In the case of on-line computer interaction, this results in tremendous waste. Only 5 percent of the time the circuit will be used to transmit data; the other 95 percent will be inactive while the programmer determines what to do next.

The new electronic central offices have reduced the time to connect a call but are still faced with dedication problems. Moreover, at the current rate of replacement, it will be the end of the century before all the step-by-step offices are replaced.

In a communications network there is a trade-off between long-distance transmission and switches: The more the switches, the less the long-distance 
facilities. A hierarchy of switches has been established to deal with this problem. There are five levels ranging from Class 5--End Office (connected to the subscriber) to a Class 1--Regional Center. In the United States there are 20,000 end offices and only 10 regional centers. A long-distance telephone call will move up the hierarchy until it finds a circuit available to the desired destination. An intracity call may not go up the hierarchy at all. The end offices involved, in this case, may have a direct connection. A telephone call from New York to Los Angeles, on the other hand, may go through regional centers.

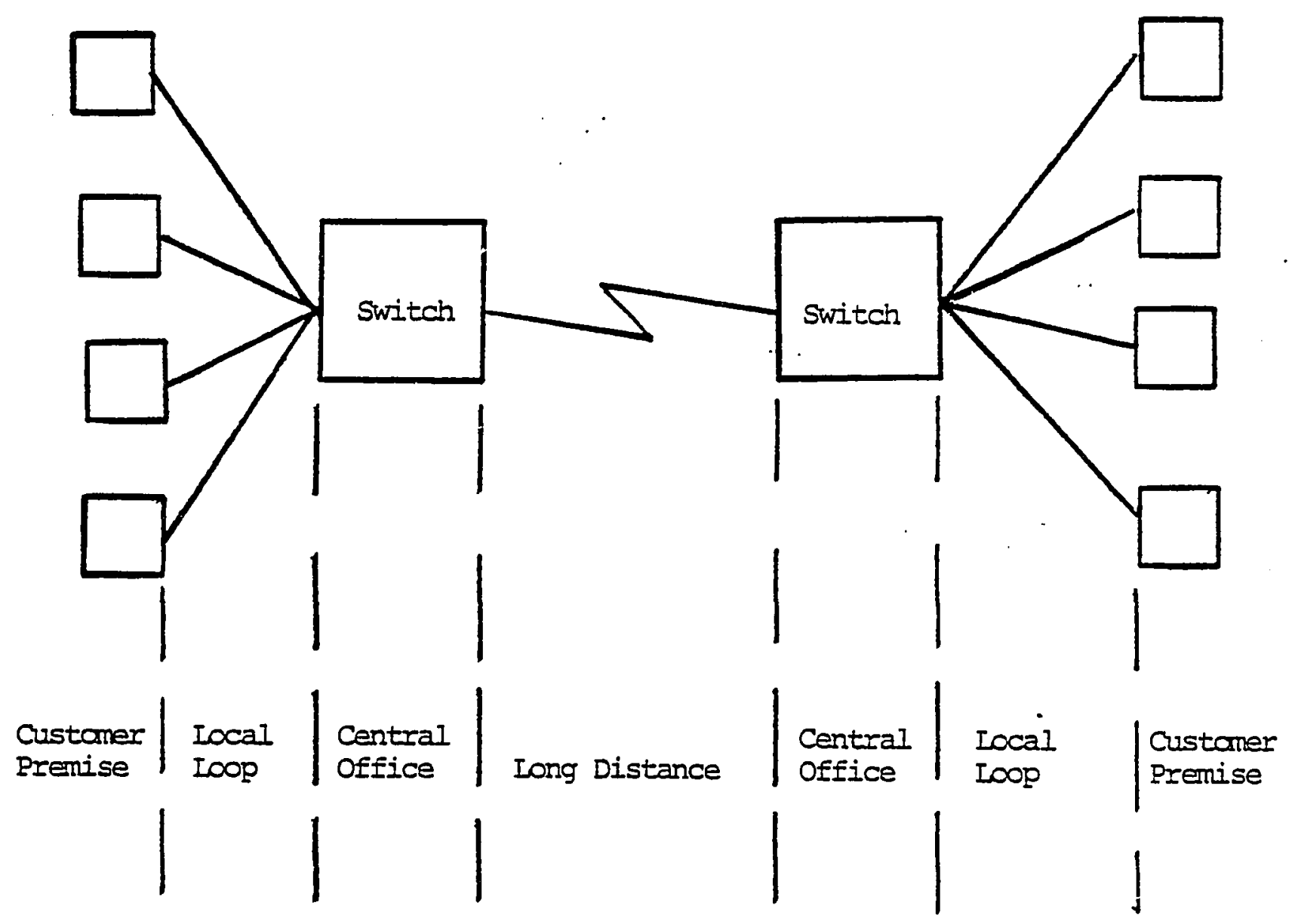

Figure 1--The telephone network 
TABLE I

TRANSMISSION REQUIREMENTS 5

Type

Bits Per

Telex

Second

Telephone

55

Hi Fi Music

$64 \mathrm{~K}$

Picture Telephone $400 \mathrm{~K}$

Color Television

6.3 Million

92 Million

Since long-distance facilities are expensive, they have been designed to handle a large capacity. A variety of transmission media are used; wire, coaxial cable, microwave, fiber optics, and satellites. These media range in capacity from 1.5 million bits per second (wire pair using time division multiplex) to 100 million bits per second (fiber optics using light frequencies). The key to capacity is bandwidth. Shannon (1948) has proven that the capacity cannot exceed his wellknown equation:

$$
C=W \log _{2}(1+s / n)
$$

Equation 1

Where:

$$
\begin{aligned}
& \text { C--Channel Capacity In Bits Per Second } \\
& \text { W--Bandwidth } \\
& \text { s/n--Signal To Noise Ratio }
\end{aligned}
$$

The thrust in long-distance transmission development is to devise systems with higher frequencies (hence, large bandwidth) and higher signal to noise ratios. In the recent past, this has led to the development of fiber optics. Fiber optics is

$$
{ }^{5} \text { Martin, 1976, page } 151 .
$$


one of the new technologies to impact telephony. The next section describes these technologies.

\section{Technology}

The importance of technology cannot be overemphasized. In fact, technology is to the regulators as the regulators are to the telephone industry. The regulators effect change on the industry. Technology effects change on the regulators. The regulators' adoption of the "competitive forces" strategy, for example, is a direct result of technology. Since World War II, new technologies have been born at an explosive rate. Unfortunately, the telephone industry has been slow in adopting these technologies. This is due in part to governmental regulations and in part to the industry. The government now feels competitive forces will drive the industry into offering these technologies. It is ironic that regulators cite data processing as an example of an industry where competitive forces constantly stimulate the introduction of new and improved technologies. The component which underlines all data processing, the transistor, was born at Bell labs. They invented the transistor. The irony is that Bell is forbidden to enter the data processing industry.

There are several new technologies which may impact telephony. The decision maker will have to select (as part of his user assumption set) the technologies he feels pertinent. The technologies are described below.

Satellites. Satellites can enhance the existing network by significantly increasing long-distance capacity at a much lower rate. Six of NASA's ATS-6 satellites (1974 technology) could handle all the long-distance traffic in North America. The cost of each was estimated at $\$ 150$ million (1975 dollars). This cost is considerably less than an equivalent terrestrial system. Increased capacity will allow more services at a lower rate. 
Satellites could transmit directly to the subscriber or through a local earth station. Wide-band capacity would be available for video and data as well as voice. Picture telephone, international television, and high-speed data transmission are examples of what satellites could provide. Several corporations have proposed satellite systems for data communications. Many cable television companies use satellites to distribute television.

Currently, there are two barriers. Technologically, there is a problem with capacity. Satellites operate at quite high frequencies $4-30 \mathrm{GHZ}$. This is necessary in order to provide enough capacity (recall Shannon's equation). At these frequencies, weather becomes a major factor. A heavy rainstorm can cause a $50 \mathrm{DB}$ loss. In the past, it was not economically possible to overcome the loss problem. The only solution was to use more powerful satellites. This, however, required bigger power supplies and transponders. The additional weight requires much larger launch vehicles, hence a prohibitive cost. Martin (1977) has proposed this problem may be overcome with launch vehicles such as the space shuttle. Governmental regulations form the second barrier. For a variety of reasons, the FCC has kept the telephone industry from fully developing satellite systems. This may be overcome by the "competitive forces" strategy.

Electronic Publishing Technologies. Electronic newspapers, magazines, and mail are provided by these technologies. Some of the technologies also are interactive, allowing the consumer to access electronic libraries, data bases, etc.

There are two basic types; teletext and view data. Both send information to the consumer's television set. The difference lies in the transmission medium. Teletext transmits over conventional television signals. On any television channel, a certain amount of the signal is left blank (the vertical blank interval). This is the 
black bar that appears on the screen when the set is out of adjustment. Teletext is transmitted on this portion of the signal.

Since teletext is broadcasted, it is one way only. The viewer cannot interact with the transmitter. The only latitude the consumer has is to select individual pages. Up to 400 pages can be transmitted over the vertical blanking interval.

View data, unlike teletext, does have an interaction capability. ${ }^{6}$ This is due to the fact that it is transmitted over the telephone lines. The same telephone line can be used to both transmit and receive messages.

Electronic Information Exchange System (EIES) is a view data type technology. Developed by Turoff (Hiltz and Turoff 1978), it has already been used in thousands of electronic "meetings." EIES is a computer conferencing system. Using ordinary telephone lines, the participant can access the system any time of the day or night. Messages are sent to other participants via the computer. The messages are stored on the machine until the recipient requests them. It is particularly interesting to note that the computer (called HAL) is a full fledged participant. HAL can send and receive messages just as any other member. EIES has had a provocative effect on the sociology of meetings. This is discussed in the social change section.

These technologies, if widely used, will have a tremendous impact on demand.

Digital Transmission. The two transmission modes of telephony are digital and analog. Analog has been the dominant mode since telephony was first founded. In recent years, however, the move has been towards digital. This is especially pronounced in the wide-band transmission of long distance. There are several

${ }^{6}$ View data is currently being implemented in both England and France. It is being tested in the United States. 
advantages of the digital mode. First, digital can capitalize on large-scale integration to reduce the cost of multiplexing equipment; analog cannot. A second advantage is regeneration. When a signal is transmitted, it becomes distorted. With analog transmission, the signal, distortion and all, is amplified. Digital, on the other hand, regenerates the signal without the distortion. It is for this reason that digital is hailed as "distortion free."

A third advantage with digital is that computers could connect directly to the network. Analog interfaces (modems) would not be necessary. This, of course, would require the network to be all digital. Another factor is that digital switching is faster (see Packet Switching).

In terms of demand, digital transmission will provide much more wide-band capacity. This, in turn, will make it technically possible to offer many more services to the home and business. Since these will be wide-band, terminals will be more sophisticated.

Digital has one disadvantage. It requires more bandwidth. Voice traffic, for example, operates at $56 \mathrm{~K}$ bits per second. Anyone using a time share computer knows the local loop cannot transmit that fast. Three hundred (300) bits per second is common with 9,600 as an absolute maximum (beyond that requires special equipment), yet analog can be used to transmit voice with almost no distortion over the same local loop.

Packet Switching. Packet switching is a digital technology which greatly reduces switching times and channel use. Recall that the network can take up to 20 seconds to connect a telephone call. Moreover, once the call is connected, the circuit cannot be used by others. In some instances, the circuit is used only five percent of the time. With the proliferation of computer terminals and distributive processing networks, these problems have become quite costly. 
Packet switching is a digital network designed to transmit data (although it could transmit voice and video). Data, originating from a terminal or computer, is sliced into 1,008 bit packages. Attached to the front and rear of the package are destination and end-of-packet records. The packet is then switched through the all-electronic network. At the receiving end, the records are removed, the data is assembled and sent to the end user's terminal.

This solves the switching time problem because all switches are electronic, connect time is in milliseconds. Since data is sent in packages, the same circuit can be used by several different subscribers during the same period. In addition to these advantages, the network can change the protocol allowing incompatible equipment to "talk" to each other.

There are several wide-band mediums over which the digitalized information could travel. In addition to satellites, there are fiber optics, lasers, waveguides, and radio.

Transmission Media. There are several new media technologies. These are solutions to a common problem--capacity. Each has been developed to handle higher and higher frequencies. Recall, high frequencies provide greater bandwidths, and (from Shannon's equation) capacity is a linear function of bandwidth; thus, the higher the frequency, the more the capacity. The impact on demand will be similar to the digital impact--more sophistication. Each of the transmission media is discussed below. The descriptions are summarized in Table II.

Fiber Optics. This medium has received the most attention within the telephone industry. Fiber optics are silicone cables which transmit light. Since silicone (sand) is quite abundant, it will be cheap to produce. Light frequencies are five orders of magnitude higher than satellites. Thus, the capacity is large. In 
fact, along with lasers, it has the highest capacity of any medium. Another advantage is its low loss. At Bell labs, fibers have been developed with a loss of 1 $\mathrm{DB} / \mathrm{KM}$. This is 28 times better than some of the conventional cables. It is for these reasons fiber optics has received so much attention.

Currently, fiber optics development is in the final stages of experimentation. Field trials are being conducted using fibers in the local loop and interoffice (central office) trunks. The interoffice trucks are transmitting voice while the local loops also transmit video (television).

Lasers are also in the experimental stage. Unlike fiber optics, however, they have received little attention. This is primarily because of their point-topoint nature. Although in some cases, lasers have been used as light sources for fiber cables. Operating at light frequencies, lasers have high capacity. Also, due to parallel transmission, the loss is quite low.

Waveguides. Frequencies up to $100 \mathrm{GHZ}$ can be transmitted through this medium. Experimental waveguides have transmitted $1.644 \times 10^{10}$ BPS. This is equivalent to 257,000 telephone calls. The primary advantage of waveguides lies in its economies of scale. Large amounts of information can be transmitted for a relatively low cost. Attenuation is quite low, $4 \mathrm{DB} / \mathrm{KM}$. Amplifiers are required every $40 \mathrm{KM}$.

The primary disadvantage is that waveguides must be relatively straight. They cannot have sharp bends. Due to this, right-of-way clearances are often two to three times the cost of the waveguide and its electronic equipment.

In the recent past, waveguides have been set aside in favor of fiber optics. This is because fibers are much smaller, easier to install, and have more capacity. In the future, this trend may reverse. It may be that frequencies higher than light 
(X-rays and gamma rays) will be used. If they are, waveguides will most certainly receive attention. At this time, however, work with $\mathrm{X}$ rays and gamma rays are primarily confined to university laboratories.

Other Media. Coaxial cable has been used in both long-distance and intercity trunks. However, its primary use has been with cable television. It will be further discussed in the cable television section.

TABLE II

TRANSMISSION CHARACTERISTICS

\begin{tabular}{|c|c|c|c|c|c|}
\hline Medium & $\begin{array}{c}\text { Capacity } \\
\text { (BPS) }\end{array}$ & $\begin{array}{c}\text { Frequency } \\
(\mathrm{HZ})\end{array}$ & $\begin{array}{c}\text { Attenuation } \\
(\mathrm{DB} / \mathrm{KM})\end{array}$ & Cost & $\begin{array}{c}\text { Number Of } \\
\text { Simultaneous } \\
\text { Telephone } \\
\text { Calls } \\
\end{array}$ \\
\hline Fiber Optics & $\begin{array}{c}10^{14} \\
\text { (Theoretical } \\
\text { Maximum) }\end{array}$ & $\begin{array}{l}300-600 \\
\text { Tetra HZ }\end{array}$ & 4 & Medium & $1.5 \times 10^{9}$ \\
\hline Lasers & $10^{14}$ & $\begin{array}{c}300-600 \\
\text { Tetra HZ }\end{array}$ & $\begin{array}{l}\text { Very Low-- } \\
\text { Sunny Day } \\
\text { High-- } \\
\text { Heavy Rain }\end{array}$ & High & $1.5 \times 10^{9}$ \\
\hline Waveguides & $1.644 \times 10^{10}$ & $40-110 \mathrm{GHZ}$ & 4 & Low & 257,000 \\
\hline Satellites & $5 \times 10^{11}$ & 4-30 GHZ & $\begin{array}{c}\text {.1--Sunny Day } \\
50-- \text { Heavy Rain }\end{array}$ & High & $2 \times 10^{6}$ \\
\hline Microwave & $2 \times 10^{9}$ & $1-10 \mathrm{GHZ}$ & $\begin{array}{l}.01-- \text { Sunny Day } \\
1 \text {--Heavy Rain }\end{array}$ & Medium & 28,224 \\
\hline $\begin{array}{l}\text { Coaxial } \\
\text { Cable }\end{array}$ & $\begin{array}{c}6.9 \times 10^{9} \\
\text { (Multiplexed) }\end{array}$ & $70 \mathrm{MHZ}$ & 28 & Low & 10,800 \\
\hline $\begin{array}{l}\text { Local Loop } \\
\text { Wire }\end{array}$ & $64 \times 10^{3}$ & $4 \mathrm{KHZ}$ & 3 & Low & 1 \\
\hline
\end{tabular}

Wire pairs are used exclusively in the local loop. Although this is the oldest medium, it is not something that can be ignored. For every mile of fiber cable, 
there are millions of miles of wire. Several billion dollars have been invested in wire. Although new media have much more capacity at a lower price, they are not already installed, wire is. An analogy can be drawn from physics to illustrate the importance of wire. Imagine the local loop portion of the network as mass and the investment as its momentum. It becomes readily apparent it will take a monumental force to change the direction of the mass. It is for this reason wire cannot be ignored.

The last form is microwave. This is one of the primary medium of longdistance transmission. It is a line of sight radio medium operating between 1 and $10 \mathrm{GHZ}$. Due to its ubiquity, microwave has a "momentum" similar to wire.

Due to the existing network's "momentum," new systems have developed in parallel to it. Rather than change the system, it is sometimes easier to develop a new system in addition to the old. Cable television is such a system.

Cable Television began in 1949 as a technological solution to a television reception problem. According to Martin (1977), an Appalachian radio dealer realized the mountains were spoiling television reception. Hence, his sales were low. He erected an antenna on a mountain top and connected subscribers to it via a coaxial cable. Cable television (CATV) rapidly grew during the 1950 s and 1960 s in spite of FCC regulations and lobbying by the three major networks. They feared competition from CATV. Broadcasting, like telephony, is a regulated industry. In 1968, the Justice Department (Antitrust Division) urged the FCC to let CATV develop as a competitive medium. It is interesting to note that the decision did not significantly impact the growth rate. It was exponential before and after 1968 . Moreover, the parameter in the exponent did not significantly change.

In 1977, 11 million homes had CATV. In 1980, this had risen to 20 million. If this trend continues, all homes will be connected in the early 1990s. 
After the 1968 decision, CATV companies were encouraged to originate programming as well as distribute the national networks. This opened the door for considerable enhancements. In addition to 20 channels of television, CATV companies could provide music, weather, and news reports, as well as a multitude of business information. In 1972, the FCC took an even broader perspective. CATV was required to provide two-way communications. Although this has had very little use, many subscribers do have two-way broadband communications.

What has evolved is a wide-band local loop system outside the telephony network. A system capable of up to 81 television channels; any one of the channels could transmit 100 channels of high-fidelity stero music. In terms of telephone calls, one television channel could simultaneously transmit 600 conversations or 15 picture telephone calls. Most CATV systems operate at a lower capacity. The effective capacity ranges from 20 to 40 channels.

The importance of CATV (upon demand) is its high capacity and presence.

Cellular Mobile System. This is another technology, like CATV, that is outside the network. Unlike CATV, however, it has not been developed and implemented. Moreover, it could be developed by telephone companies and made a part of the network. Although this type of system has been discussed for several years, it has not received much attention until a recent request for information by the FCC.

The cellular concept is a mobile telephone system which operates in cells. One version (Martin, 1977) divides the area in which the system resides into hexagonal cells, see Figure 2.

Each cell (a few miles wide) has three radio telephone base stations at alternate corners. These will be connected to a mobile telephone switching office. The person placing the call will transmit to the base station in his cell. The call is then switched through the mobile switch to a conventional switch and then through 
the network to the destination. When the caller moves from one cell to another, the system detects the boundary crossing and switches his call to the base station in the cell.

The primary advantage of this approach is frequency use. Since the transmitter power is low, cells several miles apart can use the same frequencies. This helps solve the frequency management problem.

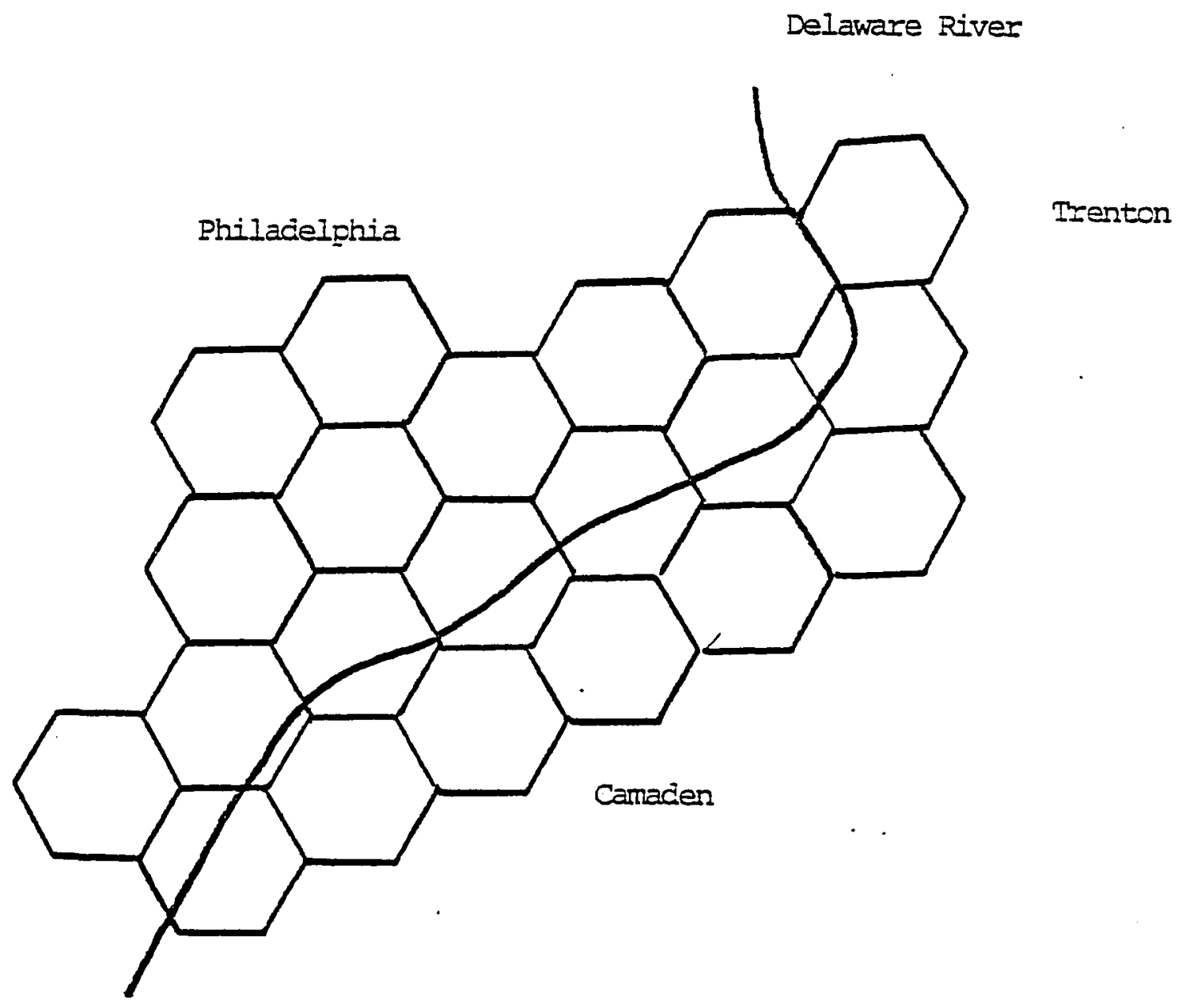

Figure 2--A cellular mobile system ${ }^{7}$

${ }^{7}$ Martin, 1977, page 200. 
The impact on terminal equipment will be a demand for mobile telephones. If a wide-band system is used, the terminals will have video and data as well as voice capacity.

Technology has (or can) produced a variety of communication forms. As previously stated, new technologies have been the force behind governmental changes in the industry's infrastructure. These forms, if allowed by governmental changes can provide a vast panorama of new services.

\section{Energy}

Energy has recently been the topic of much debate. Dwindling petroleum supplies and rising prices have spurred much research and development. Developing new resources of energy is one solution to the energy crisis. Another is to reduce the demand. Many energy conservation programs have already been undertaken. It is within this area that telecommunications can be of benefit. Teleconferencing, for example, could replace some travel. According to Brophy (1979), a one percent reduction in business travel over the last decade would have saved 25 million barrels of fuel. Electronics Funds Transfer is another area which would reduce the demand for energy. First, EFT would reduce the demand for paper. An energy savings would be realized because energy is required to make the paper. Second, energy would be saved because the paper would not have to be transported. In fact, this could be generalized to all forms of mail, not just that relating to EFT.

Home entertainment is yet another area where energy could be saved. The CATV Home Box Office, for example, provides first run movies. Thus, it is not necessary to drive to the theatre. An expansion of this type of service would offer the consumer even more incentive to stay at home. 
Although these services will save energy, their overall impact on the energy problem is minimal. Twenty-five million barrels is a very minimal savings when amortized over a 10 year period.

What may make the energy crisis an important factor is its popularity. Because it commands public attention, decisions may be made based on public reaction as opposed to economic incentives. Consider the following scenario. Nuclear energy, as we all know, is very contraversial. Suppose a reactor's core melted down killing the entire population of some small town, say 1,000 people. The ensuing public reaction would be so strong, consumers would demand that all nuclear plants be shut down. Conservation would be absolutely necessary since the nuclear power supply system is inoperative. The environment is now very conducive for the energy saving telecommunication services described above.

Under this scenario, it was the nuclear tragedy that precipitated the demand for these services. If the tragedy had not occurred, neither would the demand.

Another scenario comes from the dependence on foreign oil. In our effort to become energy independent, the government may provide special incentives to capatilize on conservation methods. Another oil boycott would certainly stimulate the government and general public to conserve.

These are just two of many scenarios that could happen. In selecting user assumptions, this aspect of the energy problem will certainly have to be addressed.

\section{Social Change}

Societal change will affect demand in a variety of ways. In a symbiotic way, telephony, will also have its impact on society. Anyone with teenage children knows how the telephone has impacted that segment. Turoff's (Hiltz and Turoff 1978) recently developed electronic information system has two symbiotic impacts on society. First, EIES has altered the sociology of discussion. No longer are 
factors such a physical appearance, accent, or ability to speak in front of people important. Through EIES, all members are equal. Each may say whatever he/she wants without being "shouted down." This impersonality, or freedom to be one's self, has the potential to make "meetings" much more productive. The ideas of many, as opposed to the ideas of the dominant personalities, will provide much richer solutions. The second impact is on travel. EIES allows the participants to be geographically dispursed.

One area where society will impact demand is the consumers' increasing demand for sophistication. Gone are the days when a telephone was a luxury. 8 Business consumers are even more demanding. Teleprocessing places ever increasing demands upon the network for more sophistication.

Demographic changes in the society will also impact demand. One of the major demographic factors is the mass migration to the suburbs between 1950 and 1975. Fifteen of the eighteen largest cities in the US have had declining populations. Normally this would not affect terminal demand. The overall population is not changing. More people in the suburbs simply means less in the cities. The impact on demand would occur in conjunction with an energy shortage. It is the automobile that has made the suburban migration possible. Petroleum shortages, resulting in higher prices, will spur the demand for more service which allows people to work, shop, and play at home. This, in turn, will result in terminal demand.

Another demographic factor is households. The number of households is one of the major determinants of demand. In the case of telephones, almost every household has at least one. Changes in the number of households are affected by population changes. Thus assumptions will have to be made about birth, death, and

${ }^{8}$ The acronym POTS (Plain Old Telephone Service) is reflective of present consumers' attitudies. 
immigration rates. Another factor is the size of the average household. Over the past 25 years this has dropped from 3.37 to 2.81 people per household. The drop is a result of a desire for smaller families as well as the divorce rate. In the latter case, more families will have only one parent. Yet another factor is dwelling size. Larger houses will have more extension type terminals. Assumptions will also have to be made about theese factors.

Thus, social change may impact demand in a variety of ways. In addition, telecommunications has the potential to affect change on society.

\section{Competition}

Twenty years ago, no one believed competition could ever be a part of telephony's infrastructure. Today, no one doubts it is. Competition dominates the subjects discussed in telephony trade journals (Dobbs, 1976; Graham, 1977; Hosselwonder, 1978). All major telephone companies are reorganizing to meet the competitive challenge (Henson, 1980). Already, competition has made substantial inroads in telephone company market share of the PBX and long-distance markets. Moreover, most telephone company executives (Brophy, 1979; Rowland, 1979; Henson, 1980) feel competition will become even more encompassing. Some feel telephony will become completely deregulated. Thus, telephony will be open to competition in every aspect. Others believe the deregulation will be only partial. They argue the government's commitment to universal service will not allow total deregulation. Telephone companies will provide POTS under regulation. All other markets will be deregulated. In this case, the telephone companies may be prohibited from entering these markets. Currently, this is the situation. The FCC argues telephone companies will use revenues generated in its monopoly sector to offset competitive expenses. Telephone companies can compete, but they must 
establish "separate entities" completely divorced from the monopolistic operating companies.

Another effect of competition is the stimulation of new technologies. The monopolistic environment, according to the regulators, does not stimulate the development of new technologies. This was previously discussed in the Technology Section.

To summarize, competition may affect both market share and development of new markets. The effect on the market share will be a function of the operating companies' "competitive edge" as well as government regulation. New markets will emerge as a result of competitive forces.

\section{The Economy}

During the next twenty years, the economy, as measured by GNP, may follow any of a number of paths. In the past, it has had cyclical growth. This may continue. Forrester (1971), on the other hand, forecasts exponential growth up to a crisis point. At that point, the economy takes a dramatic nose dive. Kahn (1976) has a optimistic outlook. He sees a future without any catastrophies.

In forecasting demand assumptions about the economy will have to be made. This is because the economy affects demand in two ways. First, per capita income is correlated to demand. Thus, increase in income implies increase in demand. It is interesting to note that demand for POTS is income inelastic (.15). This is probably due to the belief that telephone service is a necessity. More sophisticated terminals and services may be perceived as luxuries, hence higher elasticities. Thus, an assumption will have to be made about income elasticities.

The second effect is upon the business market. Business grow:th, of course, is highiy correlated to the economy. Growth, as measured by fixed business 
investment, will impact demand for services and terminals. Fixed business investment (the amount of money firms will spend on new plant and equipment) can be quite high during times of prosperity. However, due to inflation, the investment may be misleading. Therefore, inflation will also have to be considered.

\section{Corporate Changes}

There are two types of corporate changes that will impact demand. Within the telecommunications industry, corporations are realigning their goals. Brophy (1979, page 108) states, "We must set a new goal: the provision of universal, affordable total telecommunications." By "total telecommunications," he means a wide-band network with voice, data, and video capacity. One which can provide electronic mail, word processing, EFT, video conferencing, and intelligent terminals. Brophy, then, is looking to provide almost all the possible services-quite a change from POTS. These changes will impact demand through the offering of new services and equipment. Assumptions will have to be made as to which of these services and terminals will be offered. If, for example, the electronic restaurant reservations service is not offered, then there cannot be any demand. A point of clarification is in order. To the economist, demand is present whether the service is offered or not. In the above example, there would still be demand for the restaurant service. What there would not be is consumption. Thus changes in corporate goals will affect consumption.

The other corporate change is a result of the postindustrial society. According to many (Ferris, 1980, Martin, 1978, and Strassmann, 1980) the United States has become (or is becoming) an information society. A society in which more people are employed in handling information than on farms, in industry or personal services. Strassmann (1980) believes this will continue. In fact, he argues 
that an even larger percentage of the work force will be information handlers. If this is true, the demand for information services will grow.

\section{LITERATURE SEARCH}

The forecasts described in the literature focus on various aspects of the problem. None, however, have addressed it in its entirety. Some are of a telescopic nature. These utilize the knowledge and opinions of experts. The forecasts focus more on the "big picture." Others are microsopic. For them, the key element is a quantitative technique. Emphasis is placed, for example, on an econometric demand model. The key factors are price, income, consumer behavior (elasticities), and their quantitative relationship. Expert opinions are not utilized. The result is a forecast which focuses, in great detail, upon a very narrow area. This is in contrast with the telescopic approach which focuses on breadth at the expense of deptin.

There are five "telescopic-type" forecasts. The most comprehensive was developed by Baran and Lipinski (1970). In all, 210 "experts" were asked in excess of 500 multiple-part questions. The questions were organized into five major categories: regulation, social change, existing network and services, new networks and services, and characteristics of the labor force. The Delphi technique (Linstone and Turoff, 1975) was the forecasting technique employed. Using the data collected in this study, Baran (1971) prepared a companion paper on services to the home. There were six major categories of service: education, business conducted from the home, general information, shopping facilitation, entertainment, and person-to-person communications.

Hiltz and Turoff (1978) have extensively examined human communication via computers. In their avant-garde work, they review the nature of computeriztd 
conferencing and explore applications and their impact, as well as project its future. Martin (1977) has also written an extensive work. His work, however, focuses primarily upon technology. He examines the existing technology and new technologies and their applications.

The last of the "telescopic" forecasts (Davenport, 1978) concentrated on telecommunications for metropolitan. The report was based on existirig technology. Given this assumption, it examined opportunities for public services (e.g., education, health, emergency help, etc.), mobile services, community security, and energy conservation.

The "microscopic" forecasts are primarily econometric in nature. Davis, Caccappolo, and Chaudry (1973), Dobell (1972), Dunn and Spivey (1971), Ehlin and Trimble (1977), and Mahan (1979) have all developed econometric models. The focus has been on POTS and long distance. The other services, described above, have not been considered. In terms of terminal demand, these econometricians have focused exclusively on the telephone.

Two other forecasts, Volante (1978) and Chadda and Chitgopekar (1971), have relied upon the logistics curve as their forecasting technique. Although Volante has forecasted several services, the focus has been restricted to upper limits and growth rates. 


\section{CHAPTER III}

\section{FORTEL--AN OVER VIEW}

The first section outlines the FORTEL System. Following introductory comments, the system's components are discussed. The forecasting process is outlined in the last section.

\section{OVERVIEW}

It is the purpose of this chapter to outline the FORTEL System and summarize the process of using the system. The next chapter complements this overview by explaining the basis (core assumptions) upon which FORTEL was predicated and the process used to develop the system.

FORTEL is an integrated man/machine system designed to forecast telecommunication service and terminal demand. It is a system which synthesizes the logic of quantitative forecasting techniques with the forecaster's wisdom, intuition, and "gut feelings." In addition to forecasting, the system has the feature of scenario testing.

The system requires, as input, the forecaster's user assumptions. ${ }^{1}$ It outputs twenty-year forecasts of service and terminal equipment demand. There are two distinct markets, residential, and business. The system generates forecasts for each.

FORTEL has three major components (see Figure 3). The user assumptions specify the forecaster's outlook on the future of the industry. The demand models generate the service and terminal forecasts. The computer program is the

${ }^{1}$ These are discussed in Chapter VI. 
synthesizing agent. It translates user assumptions into variable forecasts. These are used as inputs to the demand models. The program then "runs" the models, generating the forecast.

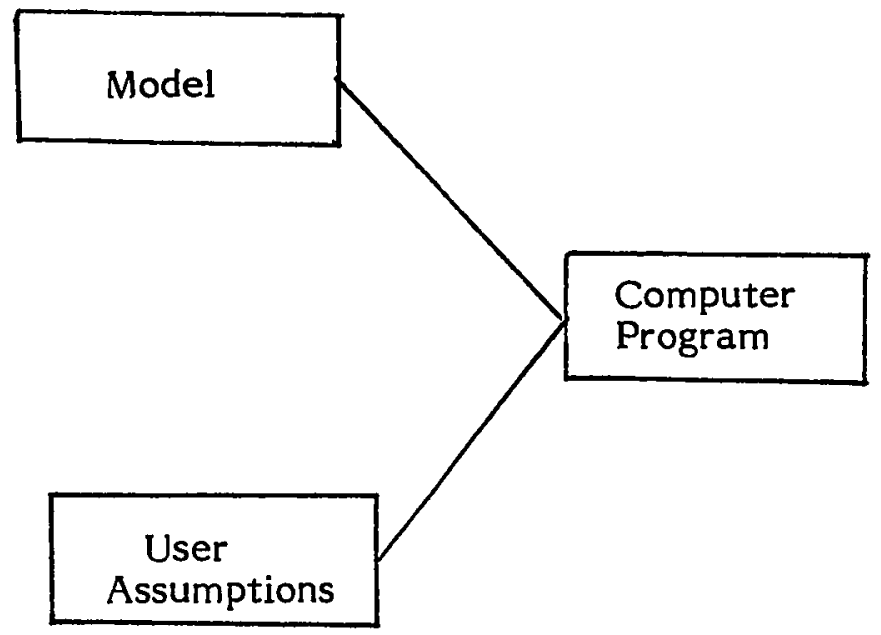

Figure 3--A schematic for discussing the process of using FORTEL

An overview of each component is given below.

\section{User Assumptions}

User assumptions, as stated before, represent the forecaster's outlook on the future of the telecommunications industry. These assumptions are organized into five categories.

General Assumptions. These assumptions reflect the forecaster's outlook on those factors which affect both services and terminals. These include assumptions about the economy, energy, societal change, and governmental regulations.

Technological Assumptions. There are eight technologies about which assumptions must be made. These are: satellites, electronic publishing 
technologies, digital transmission, packet switching, transmission media, CATV, cellular mobile systems, and electronic switches.

Service Assumptions. For each service to be evaluated, fifteen user assumptions are necessary. Eight pertain to the residential market. The remaining seven are for the business market. Of these seven, five are about the rate at which the service will be implemented. The remaining two are price and price elasticity. These assumptions must also be made for the residential market. It may seem redundant to make the same assumptions for both markets; however, it is necessary for a variety of reasons. For example, the price of POTS in the residential market is approximately one-third of the business market. Some of the other reasons are different price elasticities and different implementation rates. The residential market also has an income elasticity assumption.

Terminal Equipment Assumptions. These assumptions are about prices and elasticities for the three terminal types. The residential market has an additional assumption about the number of terminals per household.

Forecasting Technique Assumptions. This last category deals with the choice of forecasting technique. Each of the above assumptions must be translated into a forecast (the rationale behind this is discussed in the computer program section below). The forecasting technique assumptions are specifications of the quantitative technique to be used.

\section{Demand Models}

There are four demand models. Both markets (residential and business) have service and terminal models. A summary discussion of each model is given below.

Residential Service Demand Model. This model consists of two major components: households and usage rate. Households represents the market size; 
i.e., number of households. Usage rate is the percentage of total customers (households) that will subscribe to a given service. The product of the two components, then, is service demand.

The household component is a function of several variables. These are: population, children per household, divorce rate, and changing life styles. Migration is a variable with a somewhat different impact. While the others determine the number of households, this variable determines the location. The household element is segmented into those households located in the urban core and those in the suburbs or country.

The usage rate is more complex than households. It has three elements, each of which is a function of several variables. The implementation element is the percentage of households that will have access to the service. Recall most of the services are not offered. It will take time to implement them. There are five variables that affect the implementation rate. These are: technology, government, cost, energy, and competition. Although this element determines the percentage of households having access to the service, it does not determine demand. This is done with the price and income elements. These follow standard economic theory; i.e., both have elasticities as well as price (income) variables. It is assumed that the elasticities may change over time; therefore, they also are considered variables.

To summarize, the usage rate is the product of implementation, price, and income. The usage rate element is the percentage of households subscribing to a particular service. The household element, on the other hand, is the total number of households; i.e., market size. The product of these two elements, then, is the residential service demand for a given service. 
Residential Terminal Equipment Demand Model. This model also has two components: mainstations and extensions. A mainstation is a customer's first or primary terminal. Since a terminal is necessary in order to access a particular service, mainstation demand is generally considered to be synonymous with service demand. Thus, service demand is one of the mainstation variables. Many of the services, however, may be accessed by the same type of terminal. Therefore, a second variable service per household is also included.

The second component, extensions, have more econometric-type variables; i.e., price and income and their elasticities. The terminal demand is the sum of extension and mainstation demands.

Business Service Demand Model. The general form of this model is similar to its residential counterpart. It also has market size and usage rate components. Market size (number of mainstations) is the number of business customers. This, in turn, is a function of the economy (business growth) and market composition. Over the past century, the percentage of employees handling information has greatly increased. If this trend continues, the business market will be almost exclusively composed of information handlers. If this happens (Strassmann, 1980, believes it will), the demand for business services will increase even if the market size does not change. Thus, this variable is incorporated in the mainstation forecast.

The usage rate has the same variables as the residential model, with the exception of income. Due to its nature, income is a consumer--not business-variable. Usage rate, then, has implementation and price variables.

Business Terminal Equipment Demand Model. In that the relationship between terminal and service demand is the same (terminals access the service) for both markets, this model has mainstatin and extension, as does the residential model. The mainstation component is a function of service demand and a 
distribution factor; i.e., number of services per mainstation. Extensions (called terminals per mainstation) is a function of price and fixed business investment and their elasticities. Fixed business investment is a business counterpart to the income variable.

\section{The Computer Program}

The program is the synthesizing agent in the FORTEL System. It combines the user assumptions with the demand models to produce the forecasts. The program first translates user assumptions into a form usable as input to demand models. It then runs the models producing the forecasts.

The actual process involves two forecasting efforts. The first is a series of "variable" forecasts. Recall, the demand models were, in fact, functions of several variables. The program is designed to generate a twenty-year forecast for each of the variables. This is done in an interactive session with the forecaster. For each variable, the program requests the forecaster's user assumptions (about the variable). These assumptions are used to generate the variable forecast. Each forecast is stored on a file for later use.

The second forecast is of demand. This is accomplished by using the variable forecast as input to the demand models which generate the demand forecasts.

If the forecaster chooses to test an alternative scenario, he simply changes the appropriate user assumptions, generates new variable forecasts, and, then, runs the model again to obtain a new demand forecast. The forecasting process is illustrated in Figure 4 and delineated in step form in the next section.

The program generates as output nine reports (see Appendix C). These are briefly discussed below. 
Service Demand Forecast. This report specifies the residential, business, and total service demand. For each of the twenty-five services. In order to run this report, the forecaster must select a user assumption set.

Terminal Equipment Demand Forecast. This is the terminal counterpart of the service demand forecast. For each of the three terminal type, residential, business, and total demand is forecasted. The report also specifies mainstation and extension demand.

Service Segment Analysis. The residential demand for services is segmented between urban and suburban/rural customers in this report. It provides a total residential demand. The report is based on the user assumption set selected by the user.

Terminal Segment Analysis. This is similar to the service segment analysis report. It specifies the segment demands for terminals.

User Assumption Comparison--Services. The previous reports are based on a particular user assumption set. This report compares different assumption sets. The total service demand for each assumption set is delineated. This provides a means by which the forecaster can compare the various user assumption effects upon demand. As with the other service reports, this is available for only one or all services.

User Assumption Comparison--Terminals. This is a terminal version of the User Assumption Comparison--Services Report.

Service Assumptions. Recall, there were eight residential and seven business assumptions for each service. The program translated each into a variable forecast. This report specifies these forecasts. 
Terminal Assumptions. This is the terminal counterpart to the Service Assumption Report. Four residential variable and three business variable forecasts are delineated for each terminal type.

Demographic and Business Forecasts. This report delineates the forecasts of those variables applicable to all services and terminals. These variables are: population, children per household, divorce rate, and urban and suburban/rural segments. These variables pertain to the residential market. There are two others--fixed business investment and information handlers. These are used in the business models. They are also included.

\section{THE FORECASTING PROCESS}

There are four steps in the process (see Figure 4). It begins with a selection of a set of user assumptions. As stated above, these assumptions reflect the forecaster's outlook. The next step is to forecast the input variables. This step translates the forecaster's assumptions (about the variables) into individual forecasts. In the third step, the models use the variable forecasts to produce demand forecast. The final step is an analysis of the demand forecast. As a result of the analysis, the forecaster may choose to test alternative scenarios. In this case, the process begins again at the first step; if not, the process ends. 


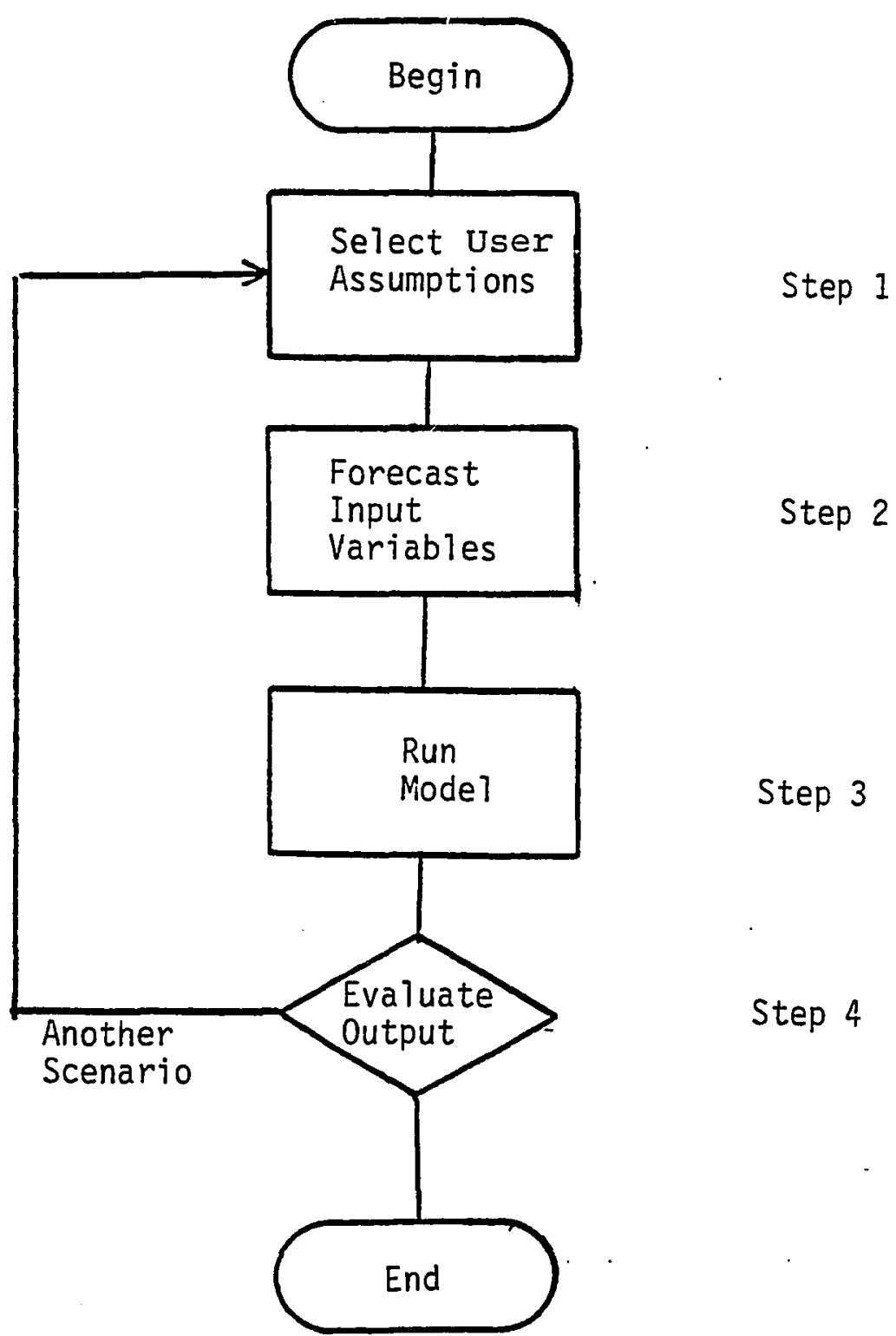

Figure 4. The forecasting process 


\section{CHAPTER IV}

\section{CORE ASSUMPTIONS}

The first section defines core assumptions. In addition, the relationship between the assumptions and methodology is specified. The criterion, by which core assumptions were selected, is provided in the second section. The chapter concludes with a description of the selected assumptions.

\section{INTRODUCTION}

Underlying any forecast is a set of fundamental or "core" assumptions. According to Ascher (1978, page 199), core assumptions "represent the forecaster's basic outlook on the context within which the specific forecasted trend develops...." In other words, they represent the forecaster's belief in how the world works.

Core assumptions impact several aspects of a forecast. The primary impact is upon accuracy. Ascher has found these assumptions are the major determinant of accuracy. If the forecaster selects the correct set, the resultant forecast will be reasonably accurate. If an incorrect set is chosen, Ascher (1978, page 199) stated, "Other factors such as methodology generally makes little difference; tiley cannot "save" the forecast."

Another impact of core assumptions is forecast use. If a user agrees with the forecaster's core assumptions, it is much more likely that the resultant forecast will be used. Few economists, for example, would use Forrester's (1971) forecast because it does not follow standard economic theory. 
Yet another area core assumptions impact forecasts is methodology. Ascher (1978, page 199) argues "methodologies are basically the vehicles for determining the consequences or implications of core assumptions that have been chosen more or less independently of the specific methodologies." The relationship between the core assumptions and the methodology is illustrated in the FORTEL development process (Figure 5).

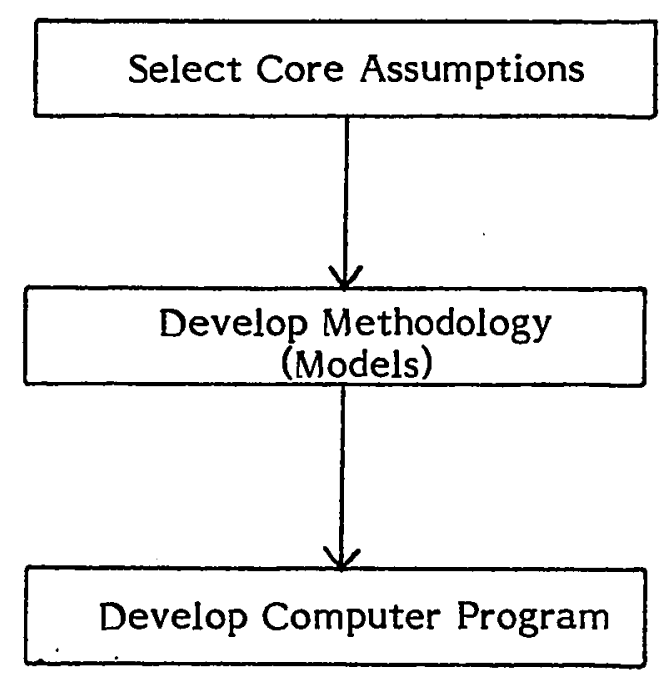

Figure 5. The development process

The process of developing the FORTEL System began with the selection of a core assumption set (discussed below). Based on the selected assumptions, the methodologies (demand models) were determined. These models provide the means of translating the core assumptions into quantitative forecasts. Within the FORTEL System, then, methodologies quantify the core assumptions. It is important to note that this may not always be true. Some forecasts are qualitative. With this type of forecast, methodologies would translate rather than quantify. 
The final step in the development process was to code the computer program which performs the calculations.

To summarize, every forecast has underlying core assumptions. 1 These assumptions, which reflect the forecaster's belief in how the world works, impact accuracy and usability. Methodologies are related to core assumptions in that they determine the consequences of the assumptions. ${ }^{2}$

Before discussing the criterion by which the assumptions were selected, it will be helpful to compare core assumptions and user assumptions.

Core assumptions determine the form of the demand models. Each of FORTEL's models consist of several variables (see Chapter V). User assumptions are assumptions about the future values of these variables. The residential service demand model, for example, has fourteen variables. Population is one of the variables. The user makes assumptions about the future population--from which a population forecast can be generated. Thus, user assumptions determine the future values of the variables. Core assumptions are much more general. They determine which variables are to be included in the demand models as well as the mathematical relationship of the variables with demand.

\section{SELECTION CRITERION}

The FORTEL System is predicated on a rather special set of core assumptions. It is the purpose of this section to explain why these particualr assumptions were chosen and, on a more general level, discuss why a set was chosen at all--as opposed to allowing the user the option of selecting his own.

$1_{\text {It }}$ is interesting to note that although every forecast is based on core assumptions, very rarely are they clearly specified.

${ }^{2}$ Core assumptions are to methodology as the metamorphosis will be to the new infrastructure. 
The fundamental criterion upon which core assumptions were selected was forecast use. The intent was to select the assumption held by prominent industry and governmental leaders. This, of course, will not guarantee the forecast will be used. Mathematically speaking, it is necessary but not sufficient.

The reason for selecting this criterion follows from the original intent of FORTEL. The forecasting system is intended to assist telecommunication decision makers with the restructuring of the industry. If the system is not used (because of disagreement with core assumptions), the effort would be in vain.

This being the case, it could be argued FORTEL should have been designed in such a way as to let the user select his own assumptions. This would most obviously satisfy the forecast use criterion. For some areas (where the users have widely varied core assumptions) this is necessary. Within the telecommunications field, however, it is not. Contrary to what one might expect, most of the industry leaders have quite similar core assumptions.

This conclusion was drawn from the following industry leaders: Brophy (1979), CEO of GTE; Brown (1980), CEO of AT\&T; Ferris (1980), Chairman of the FCC; Geller (1980), National Telecommunications and Information Administration, Department of Commerce; Henson (1980), CEO of United Telecomm; Martin (1977), computer and telecommunications author; Martino (1979), professor at the University of Dayton; Rowland (1979), vice president of telephone operations, GTE; Van Deerlin (1980), chairman of the United States House of Representatives subcommittee on communications; and Wheeler (1980), president of National Cable Television Association.

Although they disagree on minor issues, such as degree of government involvement, all agree there will continue to be a government. Moreover, they all agree it will continue to support a capitalistic system. 
Strictly speaking, widespread agreement of core assumptions makes it possible but does not mandate that the assumptions be preselected. In fact, to do so tends to foster a narrow outlook of the future (see below). The advantage is that it makes the system easier to use.

As stated in the background chapter, industry leaders are very concerned about issues such as degree of government involvement, which technologies will be implemented, and consumer behavior. If a telecommunication forecasting system is to be used, it will have to address these issues. They are incorporated in the FORTEL System via user assumptions (see Chapter VII). In all, eight hundred sixteen (816) assumptions are required to forecast the twenty-five services and three terminal types (the author has preselected three user assumption sets for convenience). The point is, users will want to address these issues. Doing so will require a considerable effort on their part. If, in addition, users are required to input their core assumptions, the system may very well become too demanding. Users will look for a simpler approach. It is for this reason the assumptions were preselected.

The disadvantage of preselecting core: assumptions is that it limits the scope of the forecast. Alternative assumptions cannot be analyzed. ${ }^{3}$ This is a serious problem given Ascher's finding that core assumptions are the major determinant of accuracy. As a partial solution to this problem, alternative assumptions are given with the discussion of the preselected core assumptions. Another aspect that may tend to minimize this problem follows from the industry consensus. The industry as a whole has a considerable amount of power and influence. Sincer the leaders are in common agreement that power will be directed toward making the assumptions

${ }^{3}$ Strictly speaking, alternatives can be analyzed. This, however, requires changes at the system level. The user would have to reprogram the demand models. 
come true; i.e., a self-fulfilling prophecy. Only time, of course, will tell the extent to which this will occur.

Now that the criterion has been established, the selected core assumptions (and alternatives) can be discussed.

\section{CORE ASSUMPTIONS}

As a general rule, the selected core assumptions are of a status quo nature. They assume the future will continue to follow the trends of the past. Each of the specific assumptions are discussed in the succeeding sections (along with alternatives).

Before proceeding, however, some further general comments concerning the FORTEL modeling strategy are in order.

As the user proceeds to consider the arena in which the forecasts are to be made, it will be clear that interactions among the various variables (including feedback) are clearly inherent in such a complex enterprise, as will be seen later. Such feedback does not appear explicitly in the FORTEL models. If FORTEL 'ere to demand sufficient explanation of the intricies of interconnection of the many variables involved, the user would likely think in mire winile attempting to use the system. Therefore, in designing FORTEL, it was decided to utilize the welideveloped heuristic capabilities of the user to mientally and/or intuitively take account of interactions when creating the hypothesis and inputs to the FORTEL models. The most obvious of these types of interactions occur among the variables "feeding" the implementation variable of the FORTEL model (which will be discussed in Chapter V; the reader may look ahead to Figure 7. The user is expected to take account of interactions when formulating the "what if" conditions 
to be input into the FORTEL models, which will then compute the forecast accordingly.

This approach was chosen, as were many implementation decisions, to provide a useful balance between versatility and model complexity.

\section{Technological Assumptions}

Following the status quo philosophy, one would expect the technology assumption to be based on exponential growth. Given the past trends, the assumption should reflect the real possibility of new (yet to be discovered) technologies that will revolutionize the industry in an even more profound fashion than the existing technolgies (which caused the metamorphosis).

Technology, however, is the only assumption contrary to the past trends rule. Industry leaders have assumed only those technologies described in the background chapter will significantly impact the future of telephony.

Alternative assumptions can be placed into two broad categories: those dealing with existing technologies and those addressing yet-to-be-discovered technologies. It is important to note the word "technology" is not restricted to telecommunication technologies. It is applicable to any technology which could impact the industry.

The yet-to-be-discovered technologies can be classified into three types: those that would eliminate the industry, those that would significantly alter its structure, and those that would enhance the existing structure. The first type would be on the order of teleportation. In this case, telecommunication (communicating over a distance) would not be necessary. Objects (both living and nonliving) could be transported instantaneously to any location, thus communication could be face to face. Strictly speaking, this does not imply the 
industry will be eliminated. The impact on the industry depends on the form of the technology. If, for example, this technology used "electronic" highways, the industry would most likely expand.

The second type of yet-to-be-discovered are those one would assume from the past trend rule. These types of technologies will have a similar metamorphic impact as those described in the background chapter. For example, new longdistance transmission technologies (which operate frequencies several orders of magnitude higher than light) would significantly increase the long-distance capacity. Another example would be new transmission modes which would combine the distortion-free characters of digital with the low-capacity requirement of analog.

The third type enhances existing technologies. These would, for example, reduce the satellite-to-earth distortion problem. They would increase the speed of computing, which would increase the speed of switching a call.

The second broad category deals with existing technologies. There may be technologies (other than those described herein) which could be adapted for use in telecommunications. Assumptions could also be made about the impact of existing technologies. In FORTEL, the impact is upon demand for services and terminals. Governmental decision makers, for example, may be more interested in the social impact. In this case, the models would be restructured to forecast the social impact.

\section{Governmental Assumptions}

There are three governmental core assumptions. It is assumed that the government will not change its existing form ${ }^{4}$ (democracy), rather, that it will

4 e.g., it will not become totalitarian. 
continue to support a capitalistic system, and the degree of regulatory involvement may change. There are also specific assumptions about the form of the new infrastructure (which will, in part, be determined by the government) and how the impact of this structure (upon demand) is incorporated into the models.

The new infrastructure, it is assumed, may take any of a number of forms. 5 The system is designed to allow the user (via a heuristic process) to select his own assumptions about the new structure. Once done, the user can then enter the speculated impact (upon demand) into the computer program.

It is important to point out that the impact of the restructure has been assumed to not directly affect consumer (and business) demand for services and terminals. Rather, it is assumed the impact will be upon the rate at which a particular service is implemented, and this, in turn, will impact demand.

The government, for example, may choose only to regulate only telephone service, while deregulating all other activities. Under this hypothesis, the new infrastructure would have limited governmental regulations. All new telephone services would be deregulated and, therefore, could be offered to the consuming public without governmental constraints. This, in turn, would make it easier (and faster) to implement. ${ }^{6}$ For these reasons, the impact of the new structure upon demand is incorporated in the model through an increase in the implementation rate.

Some of the more severe alternative assumptions deal with governmental stability. It could be assumed, for a variety of reasons, that the government will loose its ability to function. This could be due to such a factor as civil strife--

\footnotetext{
${ }^{5}$ Ranging from strict governmental control (regulated monopoly) to laissez faire.

${ }^{6}$ Implementation is the degree to which a service is offered (see Chapter V).
} 
leading to an overthrow of the government. It could also be caused by the loss of a war. In this case, the government would (after a period of time) be controlled by the victorious country.

Other assumptions address the issue of change in structure, but the government continues to function. The past trend of governmental growth could lead to the assumption of more and more control until the government nationalizes the industry for national defense reasons.

\section{Competition Assumptions}

Competition is here assumed (as for the government variable) to impact demand indirectly through the implementation rate. Again, this approach is used here to provide a balance between user versatility and model complexity.

Analyzing competition, to say the least, is a very complex problem. Such analysis includes determining the competitive strategy of each participating corporation. There is usually no direct knowledge of this so the decision maker/planner is forced to make knowledgeable guesses. The latter will incorporate what is known about other corporations' activities, ${ }^{7}$ governmental regulations, the economy, perceived consumer demand, etc.

Once the hypothesized strategies have been determined, they must be translated into the effet upon total United States demand. As mentioned above, this occurs in FORTEL via the implementation variable.

\section{Feedback Assumptions}

As mentioned in the introductory portion of this section on core assumptions, feedback is not explicitly specified in the demand models. Rather,

${ }^{7}$ Degree of market penetration, extent of marketing, pricing, etc. 
the feedback/interaction which occurs among the variables is assumed to be taken account of by the user. For example, when selecting the values for the governmental and competitive variables, the users are assumed to think through (via some heuristic process) the consequences of the effects, say, of governmental regulations on competition and vice versa. Another method of feedback, of course, occurs between the output of the computer program (reports) and user assumptions. This is the scenario-testing feature.

\section{Economic Assumptions}

It is assumed that the economic system will continue to function as it currently functions. It is further assumed price, income, and fixed business are major determinants of demand.

Alternative assumptions fall into two categories: those that assume the economic system will cease to exist and those which assume it will remain, but the structure will change. Examples of the first category are connected to the alternative government assumption of a controlled economy. Under a totalitarian government, the economy would be controlled by governmental decision makers, not Adam Smith's invisible hand.

The second category addresses possible change within the economic system. It has been proposed, for example, to replace money with energy. Ergs would replace the dollar; people would have energy banks instead of money banks.

\section{$\underline{\text { Social Assumptions }}$}

There are two types of social assumptions: demographic and consumer behavior. The demographic assumptions assume there will be a large middle class. That is, it is assumed the population will not be polarized into the very rich and the very poor. It is also assumed the household is the basic unit of consumption. It is 
further assumed children per family and the divorce rate are the major determinants of households.

The consumer behavior assumption is that basic consumer trends will not change. Consumers may, for example, demand more or less of a service but the scciety will not totally reject all telecommunication services. Consumers will continue to demand services and terminals.

One alternative demographic assumption is that the society would be polarized in to the very rich and the very poor. Another is that the notion of a household may become obsolete. Cummunal living is one example. Schumakers' "small is beautiful" philosophy could restructure consumer behavior. If his philosphy comes to pass, the demand for high technology products would subside.

With the core assumptions specified, the next logical step is to develop the methodologies. This is done in the next chapter. 


\section{CHAPTER V}

\section{DEMAND MODELS}

Core assumptions were specified in Chapter IV. In this chapter, demand models are developed based on the core assumptions. There are two sets of models; one for the residential market, the other for the business market.

\section{INTRODUCTION}

In specifying demand models, it is appropriate to start with the relationship between services and terminal equipment demand. The ultimate goal of the telecommunications industry is to provide communications services. Terminals are the means by which consumers can access the services. Thus terminal demand is a function of innovative services.

Other relationships are those between the assumptions discussed in the previous chapter and demand. The author has developed four models specifying these relationships. It was necessary to develop several models because of the overall structure of the telecommunications market. Within the market, there are two distinct submarkets--each has a service demand model and a ierminal equipment demand model. The residential submarket has demands for those services and terminals one would normally use in the home. The business submarket demands more data and videoconference-oriented services. However, there is a considerable degree of overlap. Every household as well as every business has a telephone. In the future, many offices may be actually be in the home. Most of the assumptions described in the previous chapter will be involved 
in both submarkets. However, the relationships between these and demand are not the same for both submarkets. For this reason, each submarket will be addressed separately.

Yet, a third set of relationships are those between the models and the resultant forecasts. In the overall forecasting process, the firsi: step is to select a user assumption set. From the set, individual forecasts are generated for elements such as population, price, income, etc. These elements become inputs to the models. The models combine these forecasts into a resultant forecast inr each service and terminal.

The system approach (Churchman, 1968; Hall, 1962; Bloch, 1970) was used to develop the models. To an individual trained in a specific discipline, this may prove to be somewhat confusing. The economist, for example, will find portions of the models following traditional econometric theory. In other sections, the models radically deviate from the standard theory.

The point being, the models cannot be understood in terms of traditional disciplines. Rather, the models must be viewed as systems. Each system has elements which interact with each other. In some cases, these elements and interactions will follow traditional discipline theories, in other cases they will not.

Another area of confusion may be with the manner in which the author quantified the interactions. In some cases, especially with those of an econometric nature, several different mathematical functions could have been used. In these cases, the author selected the functional forms which provided the greatest flexibility. This broadens the forecaster's horizon in terms of his ability to test various different scenarios.

One of the fundamental aspects of the systems approach is scenario testing. Any "systems" model has to have this ability. The models described herein have 
been developed to maximize this aspect. The forecaster may change the parameters of the models, select one of three user assumption sets (see next chapter), or develop his own, or make changes to an assumption set. With each change (or combination of changes), the models can be rerun, thus testing various scenarios.

Inflation is a factor which affects all the models. The author has elected to make the forecast based on 1980 dollars. In this manner, real growth will be forecasted.

\section{RESIDENTIAL DEMAND MODELS}

The following section focuses on the mathematical representation of the residential models. Recall there are two residential models: service and terminal. Each model is developed in separate subsections. The mathematical forms are given at the end of each subsection. In that it is often difficult to "visualize" relationships from an equation, the demand models are graphically illustrated in Figures 6 and 7 (located at the beginning of each section).

\section{$\underline{\text { Residential Service Demand Model }}$}

The residential service demand model has two major components. Households represent the market size. Usage rate is the percentage of the total number of households that will subscribe to a particular service. This percentage times the number of households results in the demand for the service.

Households. This factor is both market size and composition. The market size is the number of households in the United States. The household was selected as the basic unit of consumption of residential services because every household has the potential to subscribe to a given service; yet, it is unlikely the household would subscribe to the same service more than once. For example, every household 
has the potential to subscribe to CATV. Moreover, it is highly unlikely the household would have a second cable connected providing the same service.

As stated above, the systems approach may deviate from traditional theory. This is the case with market composition. The author has divided the market into two segments; those households in the urban core and those outside the central cities (suburbs and country). This division was selected over the traditional divisions (income, race, educational level, etc.) because it would best illustrate the impacts of energy and social change upon migration. Recall that many of the larger cities have had declining populations over the last 25 years. There has been a mass migration to the suburbs. This, of course, has been made possible by the automobile. With rising energy costs and petroleum shortages, suburbanites may encounter substantial transportation problems. As stated in the Background Chapter, telecommunications services may help solve this problem. Thus, energy conservation type services may have a higher demand in the suburbs and country, especially those that replace travel. It is for this reason the author chose to divide the market into the urban and nonurban segments.

Beginning with the Market Size Section, a detailed discussion of the household portion of the residential service demand model follows.

The market size (number of households) is the first portion of the service model. This is illustrated in Equation 2.

Number of Households $=$ Pop $(.823 \text { Child }+1.57 / \text { Divorce }+1.77)^{-1}$

Equation 2

The approach taken herein is to first determine the total population (Pop), then divide by the average household size. The average household size is a function of the number of children per family and the divorce rate. These two factors were 
regressed on household size, using the United States Bureau of Census (1979) data. The resultant "R" square value was .999 (see Appendix B for complete results).

The elements "Pop, Child, and Divorce" are inputs to the model. Recall that in the overall forecasting process, these elements are forecasted (based on specific user assumptions), and the forecasts are the inputs to the model.

Market composition, as previously stated, consists of those households in the urban core and those outside the cities. A forecast of the percentage of urban households will be made. This percentage multiplied by the number of households will result in the urban market size. Similarly, one minus the percentage multiplied by the number of households produces the suburban/rural market. This is designated in Equation 3 as segment(i).

Usage Rate. As illustrated in Figure 5, Usage Rate has three major components; implementation, price, and income. Implementation addressed the issue of whether or not a service will be offered to consumers; also, if the service is offered, the degree to which it will be offered. Although the services delineated in the Background Chapter are the most likely candidates, it is not certain all of them will be implemented. Some will require huge expenditures of capital. Others will need governmental approval. Still others will require new technologies. The outcome of ths component is the percentage of the households that can subscribe to a given service.

The other two components follow standard econometric theory.

Each of the three components are percentages. The latter two are different from implementation in that they are the percentage of households that will actually subscribe to a given service. The product of the three percentages is the usage rate.

A detailed discussion of each component is given below. 
The implementation component is quantified as the following expression: $\operatorname{Min}(\operatorname{Min}($ Tech, Gov, Cost $)(1+$ Energy \%)(1+Comp \%) 1)

Expression 1

The first three variables (technology, government, and cost) determine the percentage of households to which a particular service will be offered. ${ }^{1}$ The technology variable is the percentage of households to which the appropriate technology is available. Thus, a value of .75 means 75 percent of all households have the technology available to access the service. As illustrated in Figure 6, there are several elements which impact the technology variable. First, the government must allow the technology to be implemented. Satellites, for example, require governmental approval before they can be launched. The economy is another element. Recall, satellites cost $\$ 500$ million each. A prosperous economy (with a low cost of money) is essential to finance such an enterprise. The last component is energy. As described in the Background Chapter, an energy crisis may very well cause a technology to be implemented.

Governmental regulations play a twofold role in implementation. In addition to approving technologies, approval will also be necessary for many services.

Cost, like regulation, has a twofold role. The cost element of the technology variable is in fact the start-up cost. The other cost is daily operations. As illustrated in Figure 6, the economy (specifically the availability and cost of money) will play a crucial role.

User assumptions will be made about each of the elements affecting these variables. From the assumptions, forecasts will be generated. The forecasts are the inputs (technology, government, and cost) to the model. Recall, these forecasts are in percentages.

${ }^{1}$ The values of these variables range between 0 and 1. 


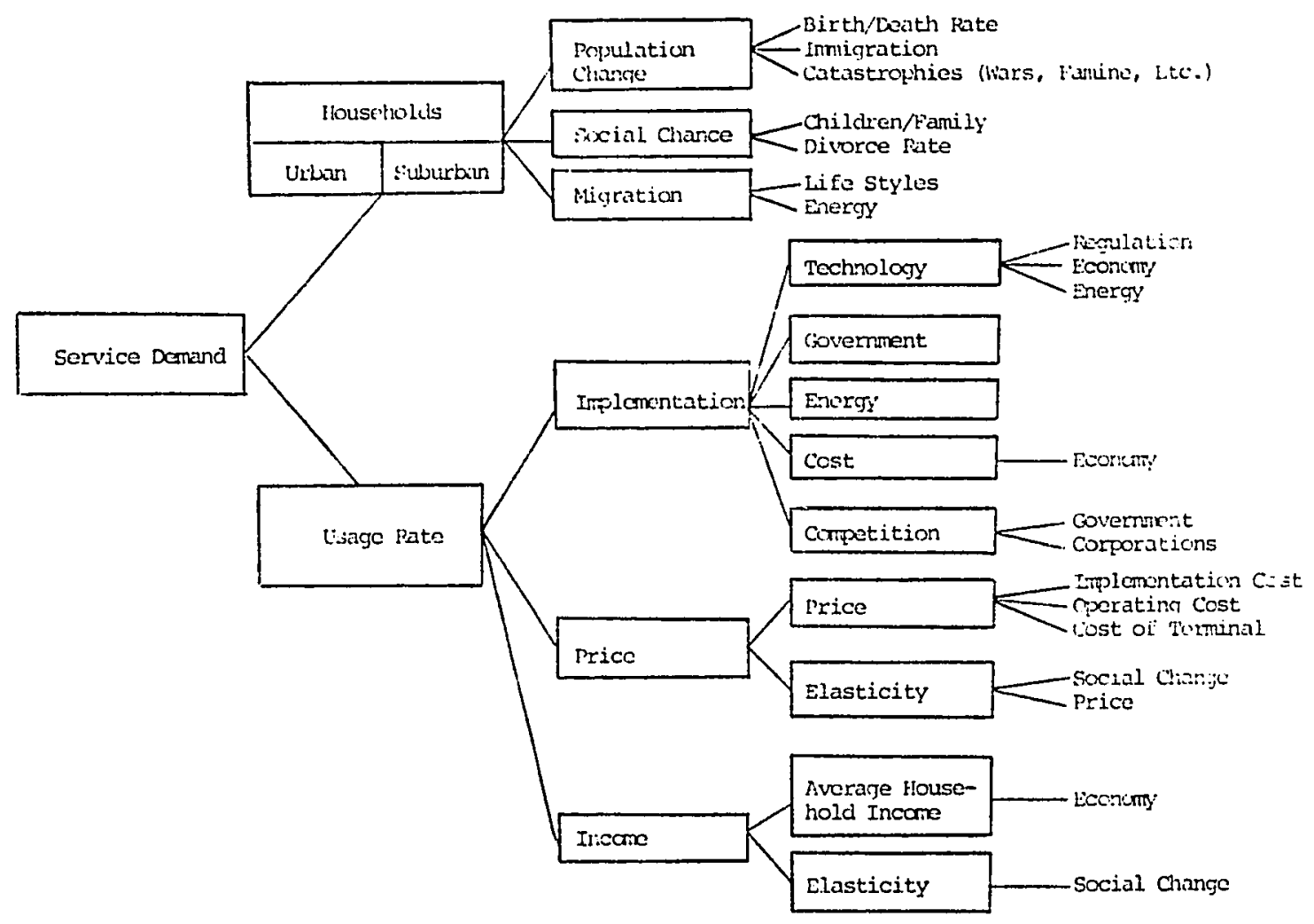

Figure 6. Residential Service Demand Model 
The model then selects the smallest percentage; Min (Tech, Gov, Cost). This is done because implementation cannot exceed the smallest percentage of the three variables.

The two remaining variables (energy and competition) are multiples of the above-resultant percentage. These variables are also in percentages. ${ }^{2}$ In this case, however, they are percentage increase (or decrease). The rationale behind selecting them as multipliers is based on their natures.

The nature of a company's decision to offer a service (not currently offered by any company) is based on a cost and benefit analysis. If the service proves to be profitable, the company will offer it, assuming the government approves and the appropriate technology exists. Once the service is offered, competition comes into play. Other companies will try to offer the service at a lower price. They will also offer it to households that are not served. Thus, the nature of competition is to affect the degree to which a service is offered. It will not, however, affect whether or not the service is offered in the first place. Thus, competition is a multiplier of existing services.

The competition variable has two elements. The effect of one company upon another is described above. The other is government. In order to foster competition, the government may encourage some services (and specific companies) while inhibiting others.

The energy variable has an impact similar to competition. Petroleum shortages, for example, will stimulate the implementation of several services.

Returning to Expression 1, the reader will notice there are two minimums (Min). The second is to ensure the implementation component does not exceed 100 ${ }^{2}$ They also range between 0 and 1. 
percent. It could be the product of the energy and competition variables with Min (Tech, Gov, Cost) exceed 100 percent, which is not realistic.

The second usage rate component is price. The econometric approach was used in that it provides the greatest flexibility for scenario testing. This component has two variables; price and price elasticity. The price variable, in turn, is a function of the implementation cost, operating cost, and the cost of the terminal. The first two elements reflect the cost of offering the service. The latter reflects the consumer's perspective. It may be that the cost of offering a service is quite low. However, the terminal (necessary to access the service) could be very expensive. Consumer behavior will be affected by the terminal cost and, therefore, must be included in the price variable.

Assumptions about the price elasticity are critical in that they determine the functional form of the price variable. The author conducted a review of the literature to see if there was a consensus on the form. The only service for which price elasticities were determined was POTS. Some, Davis, Caccappolo, and Chaudry (1973), found the elasticity to be constant. Others, Ehlin and Trimble (1977), found it to vary with changes in price; still others, Mahan (1979) and Dobell (1972), found it not even to be significant. In light of the diversity in the findings, it was not possible to use consensus as the criteria for determining the elasticity.

Following the systems approach philosophy, the author selected Ehlin and Trimble's findings. This was done because a variable elasticity allows price to affect both demand and the elasticity, resulting in more versitility.

Another element that will affect the elasticity is social (behavioral) change. The telephone, for example, was a luxury in the 19th Century. Today it is a necessity. Demand has become inelastic. User assumptions will have to be made about these elements from which a forecast of the elasticity can be generated. 
Income is the third usage rate variable. As with the price variable, an econometric approach is used. Most of the previous studies (Davis, Caccappolo, and Chaudry, 1973; Mahan, 1979; and Dobell, 1972) concluded the income elasticity was constant. However, there was a problem due to the nature of the elasticity's sign (positive). Recall, the three usage rate variables must be percentages. Since the income elasticity (exponent of the income variable) is positive, the income variable is greater than one. In order to overcome this problem, the author utilized the scaling constant (C). The constant is determined by taking the largest income to the laragest elasticity power. This ensures the income functin will always be less than or equal to one. The functional form of the income variable is represented as:

$I^{\mathrm{b}} \mathrm{C}$

Expression 2

Where:

b--Income elasticity of demand.

C--Scaling constant.

I--Income.

This form is consistent with the theory that an increase in income will increase demand. It also allows one to make assumptions about income and elasticities. In the case of elasticity, the author has allowed for the inclusion of social change, as in the case of the price elasticity. The process of forecasting income and the elasticity (which become inputs to the model) are described in the following chapters.

To summarize, the residential service model has two major components. Market size in a function of population and social changes. The usage rate has three variables; implementation, price, and income. The product of usage rate and 
market size results in the number of households that will demand a given service. This is expressed mathematically in Equation 3.

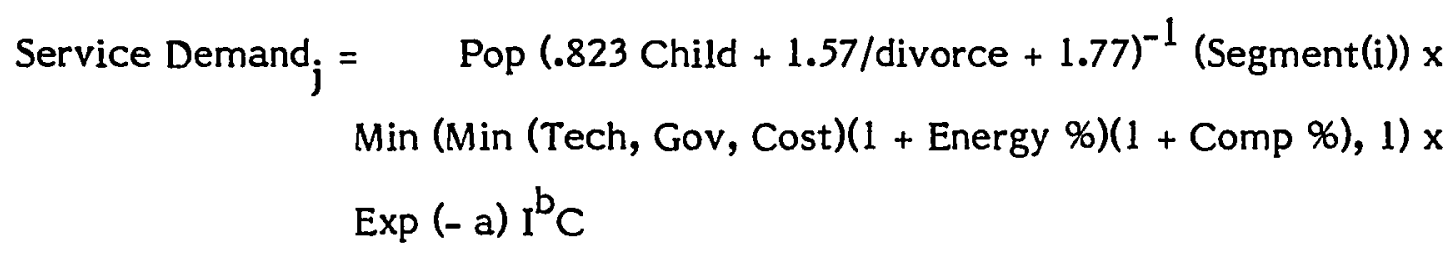

Equation 3

Where:

Service Demand ${ }_{j}$--Number of households subscribing to service ${ }_{j}$.

Pop--United States population.

Child--Number of children per family.

Divorce--Divorce rate.

Segment(i)--Percent of total population residing in urban core segment or outside urban core.

Tech--The percentage of households that have access to the technology required to provide the service. (A value of .75 means 75 percent of the households have access to the technology necessary to provide the service.) Gov--The percentage of households the government regulators will allow to subscribe to the service.

Cost--The cost of some services is quite high. Therefore, the services may be initially offered in only limited areas. This variable is the percent of households offered the service due to this variable.

Energy \%--The percentage increase (or decrease) of the number of subscriber households due to energy impacts.

Comp \%--The percentage increase (or decrease) of households offered the service due to competition. 
a--Price elasticity of demand. This is a function of price and social change. p--Price.

I-- Income per household.

b--Income elasticity of demand.

C---Constant

\section{$\underline{\text { Residential Terminal Equipment Demand Model }}$}

This model produces two forecasts; mainstation and extensions. The mainstation is a customer's "main" or primary terminal. In the case of telephones, it is the customer's first telephone. Additional telephones are classified as extensions. It is necessary to make the distinction between mainstations and extensions because the components of demand are different.

Mainstation demand is synonymous with service demand. If a customer subscribes to POTS, for example, then that customer must have a telephone; the customer could not access the service otherwise. Thus, service demand is also mainstation demand.

Extension demand, on the other hand, is for additional terminals. The factor affecting this type of demand are more related to price and income and less related to service demand.

The demand model is quantified in Equation 5 and "visually" illustrated in Figure 7. A detailed explanation of the model is given below.

Mainstation Demand. The primary factor affecting mainstation demand is service demand. In that this (service demand) was discussed at some length in the previous section; it is not necessary to discuss it here. What is necessary, however, is to modify the output of the service model. 


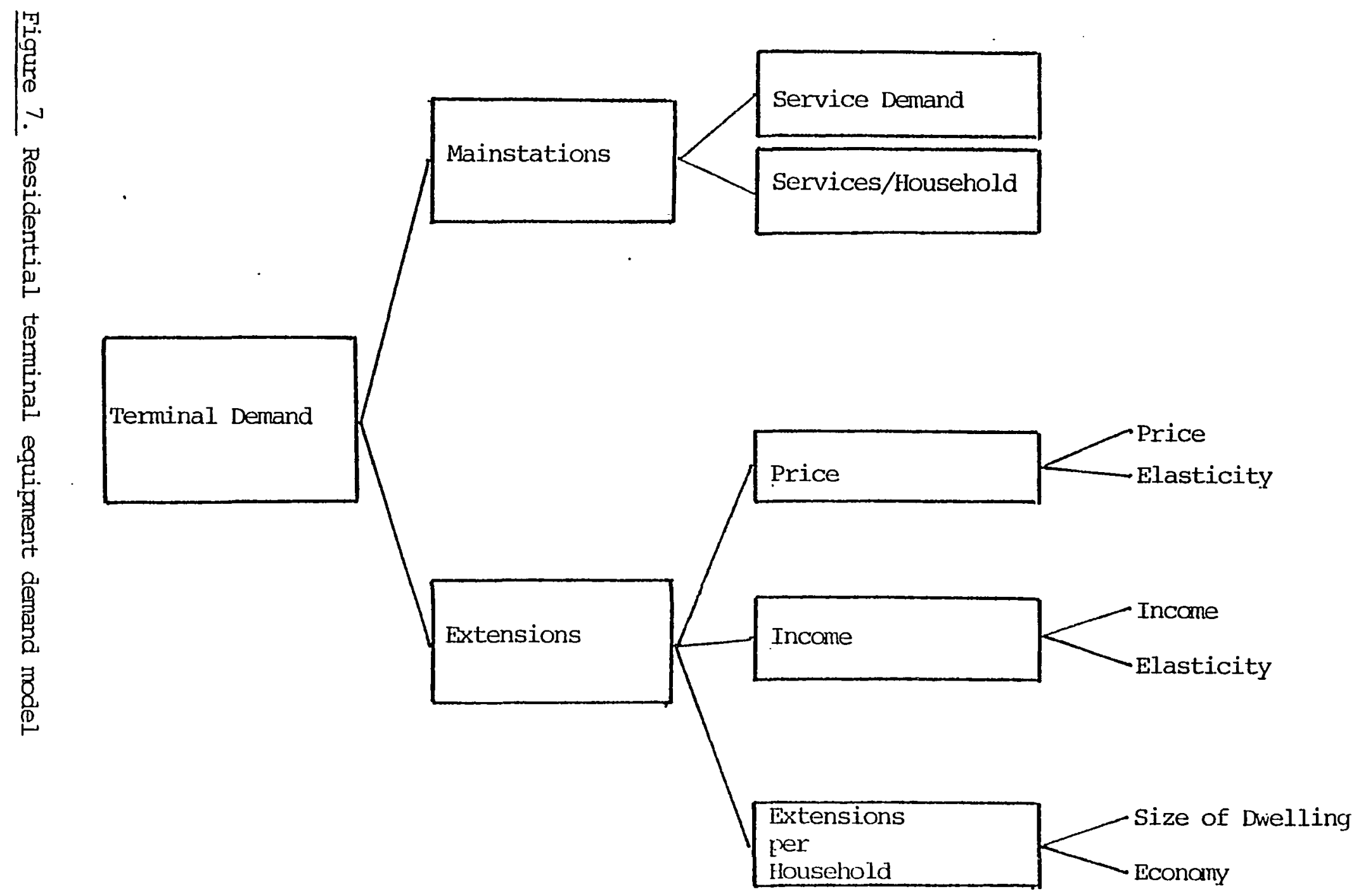


In its raw form, the service model generates the number of households that will subscribe to the services described in the Background Chapter. Many of these services can be accessed by the same terminal. Electronic newspapers, travel reservations, and correspondence schools, for example, can all be accessed by a data terminal. Thus, there is not one-to-one correspondence between service and terminal demand.

The approach taken herein was to determine the number of services to which a household will subscribe. This, divided into the total number of services demanded will result in mainstation demand.

The number of services per household is determined from the ratio of actual to potential subscription. This is illustrated as the following expression:

$N \underset{i}{\sum_{i} \text { Service }_{i} / \text { Imp }_{\mathbf{i}} \text { (Market Size) }}$

Expression 3

The numerator (inside the summation) of Expression 3 is the demand for the "i"th service. The denominator is the maximum (potential) demand for the service. The implication of the summation is that when only a few services are offered, only a few households will subscribe to more than one service. As the number of service offerings increases, so does the number of services per household.

The author considered including price and income as components of the number of services per household variable. However, after discussing the nature of the impact of these components with various forecasters and economists (Black, 1980; Trimble, 1980), the author elected not to explicitly include them. The impact of these components is upon the number of households subscribing to a particular service, as opposed to the number of services per household. Increasing demand, however, will increase the number of services per household to a certain 
extent. Thus, there is an indirect impact. Expression 3 quantifies this impact; thus, it is not necessary to explicity include the price and income components.

Extension Demand. Several econometric models have been developed (Ehlin and Trimble, 1977; Irish, 1974; Mahan, 1979) to forecast extension demand. The primary advantage of this approach is that social and behavioral changes can be incorporated through the elasticities. ${ }^{3}$

The forecasting process (like the service process) is to make user assumptions about the prices of the terminals and elasticities. Recall, the income variable has already been forecasted. Next, forecast prices and elasticities. This is the input to the extension model.

The model, which follows classical econometric theory, is given below: $D_{j}=g$ (Market Potential) Exp $(-c)\left(I^{d}\right)$,

Equation 4

Where:

$\underline{D}_{j}$--Extension demand for Terminal Type $j$.

g--Scaling constant

Market Potential--h (market size), see below.

c--Extension terminal price elasticity of demand.

I--Income per household.

d--Extension terminal income elasticity of demand.

The market potential variable is the maximum number of extension terminals. The Variable " $h$ " represents the number of terminals per household. This variable, in turn, is a function of household size. Larger households will most likely have more extensions. On the other hand, there may be a future trend toward smaller dwellings. Thus, an assumption will also have to be made about "h."

${ }^{3}$ The disadvantage is that it requires the traditional econometric approach to be valid in the future. 
To summarize, the residential demand forecast has two major components; mainstations and extensions. Demand is the sum of these two components. The mathematical form is given in Equation 5.

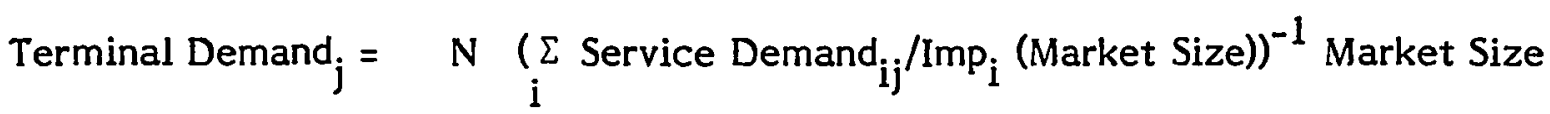

$$
\text { g (Market Potential) Exp (-c)(I) }
$$

Equation 5

Where:

Terminal Demand;--Demand for terminal Type $j$.

$\mathrm{N}$--The number of services that require a Type $\mathrm{j}$ terminal.

Service Demand ${ }_{i j}-$-Is the demand for service $i$ (which requires a Type $j$ terminal).

Imp ${ }^{-}$-Implementation factor for service $\mathrm{i}$ (see Equation 2). $\operatorname{Min}(\operatorname{Min}(T e c h$, Gov, Cost $)(1+$ Energy \%)(1+Comp \%), 1)

Market Size--Total number of households (see Equation 2).

Pop $(.823 \text { Child }+1.57 / \text { divorce }+1.77)^{-1}$

g--Scaling constant.

Market Potential ${ }_{j}-$-Maximum number of extension terminals (Type $j$ ) that could be sold.

c--Price elasticity of terminal demand, this like service demand, is a function of price.

I--Income per household.

d--Income elasticity of terminal demand. 


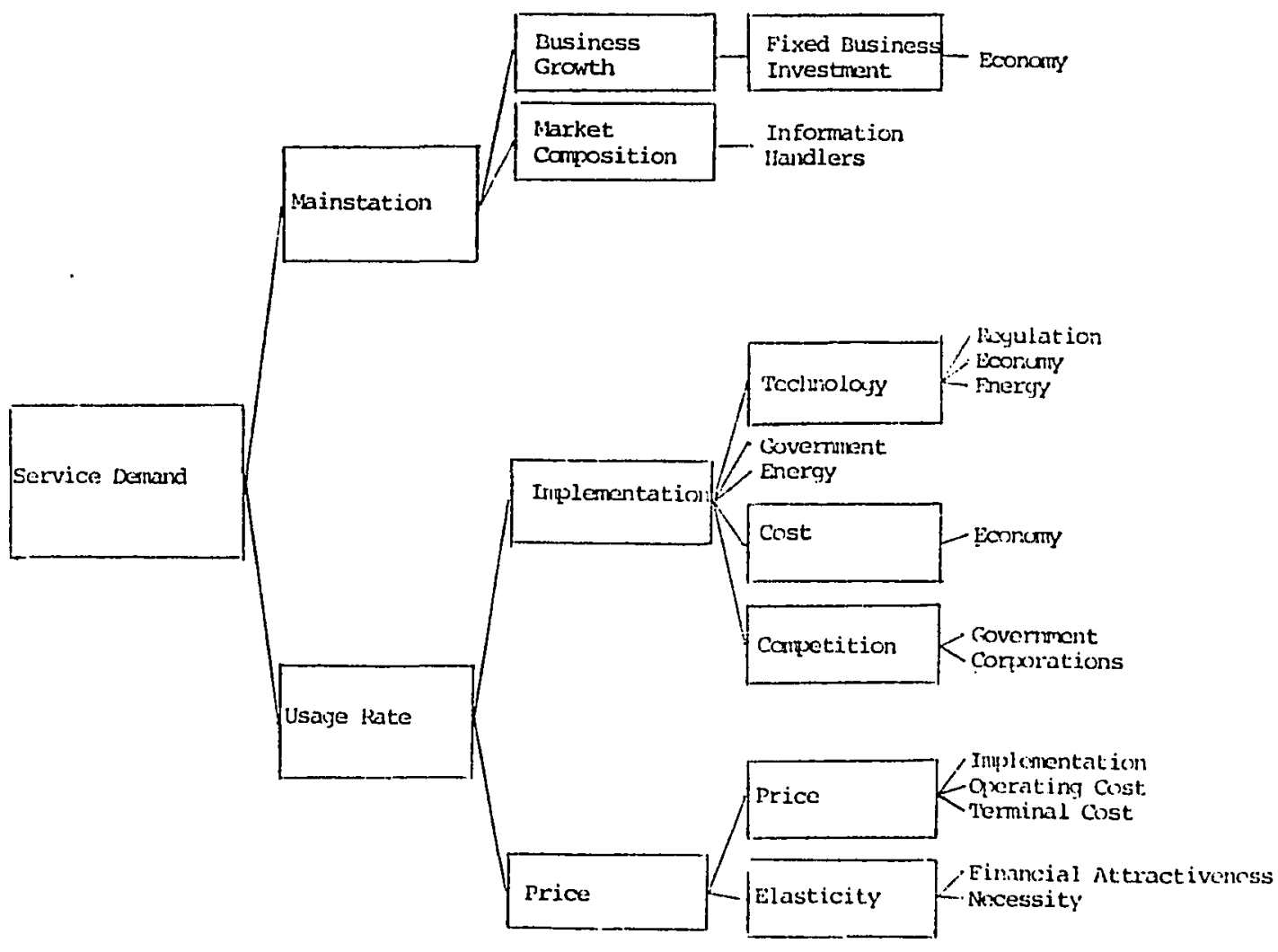

Figure 8. Business service demand model. 


\section{BUSINESS DEMAND MODELS}

The business market sector is similar to its residential counterpart in that there are also two demand models: service and terminal. The discussion of these models parallels the residential format. Each model is described in a separate subsection with the mathematical form specified at the end. Figures 8 and 9 have been provided to help "visualize" the models.

\section{Business Service Demand Model}

This model is similar to the residential model in that there are two major components; market size and usage rate. Beyond the components, however, the similarity begins to breakdown. A detailed discussion of these components follows.

Mainstations. This component represents the market size. Before discussing its composition, a few general comments are in order. To begin with, there may be some confusion as to why mainstations were used. Recall, in the residential models, a mainstation was defined as a household's primary (or first) terminal. There was only one mainstation per household. On the business side, there could be several mainstations--large corporations may have in excess of 10,000. The reason for this conflict lies in the fact that for each mainstation there is a unique "telephone" number. Each household, it was assumed, would have only one telephone number. In the business market, each management-type employee will have a unique telephone number. Thus, there will be several mainstations per business. Each management employee, it is assumed, has the potential to subscribe to the business-type services. Strictly speaking, there will also be some nonmanagment personnel that have a need to access the services. It is for this reason mainstations were used as the primary unit of consumption, instead of management employees. 
The above definition keyed on the telephone. In the future, a mainstation may not be a telephone, it may be a data or video terminal. Thus, for each mainstation there will be a unique "terminal" number.

The mainstation component has two variables; business growth and type of business. Business growth is represented as fixed business investment. This is the amount of money (deflated to 1980 dollars) corporations will spend on new plant and equipment. This, in turn, is dependent on the general economy. An investment forecast can be generated. This becomes input to the model. The functional form of this variable is specified as:

$$
6,103+25 \text { Businv }
$$

Expression 4

A linear form was used because of the extremely good $R$ square value (.998)-see Appendix B for complete results.

The second mainstation variable addresses changes in the market composition. As Strassmann (1980) has pointed out, more and more workers are involved in information handling. If this trend continues, demand will increase even if the market size remains the same. This variable is incorporated in Equation 6 as a percentage. The Variable Infor $\%$ represents the percentage increase (decrease) in the number of mainstations subscribing to a given service.

Usage Rate. This section of the business model is quite similar to its residential counterpart. Both models have implementation and price variables. Moreover, the mathematical structures of the variables are the same. In the case of implementation, this makes sense in that any service will have to go through the same process, regardless of the end user. That is, the appropriate technology must exist, government must approve, and the economy must be able to support the cost before a service can be implemented. It does not matter whether the service is for a business or household. 
This is not to say that the resultant implementation percentage will be the same for all services. In fact, a sarvice offered to both markets will most likely have different implementation percentages. Word Processing, for example, will most likely have a much higher implementation rate in the business market. Even though the percentages are different, the process is the same, and, therefore, the same mathematical form is used.

Recall, the functional form of the price variable is determined from the elasticity. The author assumed the elasticity would vary with price and economic benefit. This lead to an exponential form--the same as in the residential model. These assumptions were made because they provided the greatest flexibility for scenario testing.

The economic benefit is, in part, the financial attractiveness and, in part, the necessity of the service. A company's decision to subscribe to a particular service is generally based on some type of a cost benefit study. If the service generates (or saves) more money than it costs, the company will subscribe. Services that are highly profitable will be inelastic. Over time, however, they may become less financially attractive, hence more elastic.

In the business market, some services are necessities. POTS, for example, is never subjected to a cost benefit study. It is a necessity. No business could operate without a telephone. Thus, at this time, POTS is inelastic, with an almost zero elasticity. In the future, this may change. Other services may become necessary. ${ }^{4}$ User assumptions will have to be made about this as well as the financial attractiveness. From these assumptions, an elasticity can be forecasted.

This concludes the decision on the service demand model. As discussed below, the service demand is part of the input to the terminal demand model.

${ }^{4}$ Electronic mail may become the POTS of tomorrow. 
Service Demand De $_{\mathrm{j}} \quad(6,013+25 \times$ Businv $)(1+$ Info $\%) \times$

$$
\begin{aligned}
& \text { Min (Min (Tech, Gov, Cost) }(1+\text { Energy \%)(1+Comp \%), 1) x } \\
& \text { Exp (-ap) }
\end{aligned}
$$

Equation 6

Where:

Service Demand $j^{--N u m b e r}$ of mainstations subscribing to Service $\mathbf{j}$.

Businv--Fixed business investment.

Info \%--Percentage increase (decrease) of market size due to increase (decrease) of information workers.

Tech--The percentage of business mainstations that have access to the technology required to provide the service.

Gov--The percentage of business mainstations the government regulators will allow to subscribe to the service.

Cost--The cost of some services is quite high. Therefore, the services may be initially offered in only limited areas. This variable is the percent of business mainstations offered the service due to this variable.

Energy \%--The percentage increase (or decrease) of the number of business mainstations offered the service due to energy impacts.

Comp \%--The percentage increase (or decrease) of business mainstations offered the service due to competition.

a--Price elasticity.

$\mathrm{p}$--Price of the service.

Business Terminal Equipment, Demand Model

This model (Equation 7 and Figure 9) has two major components; mainstations an terminals per mainstation. 


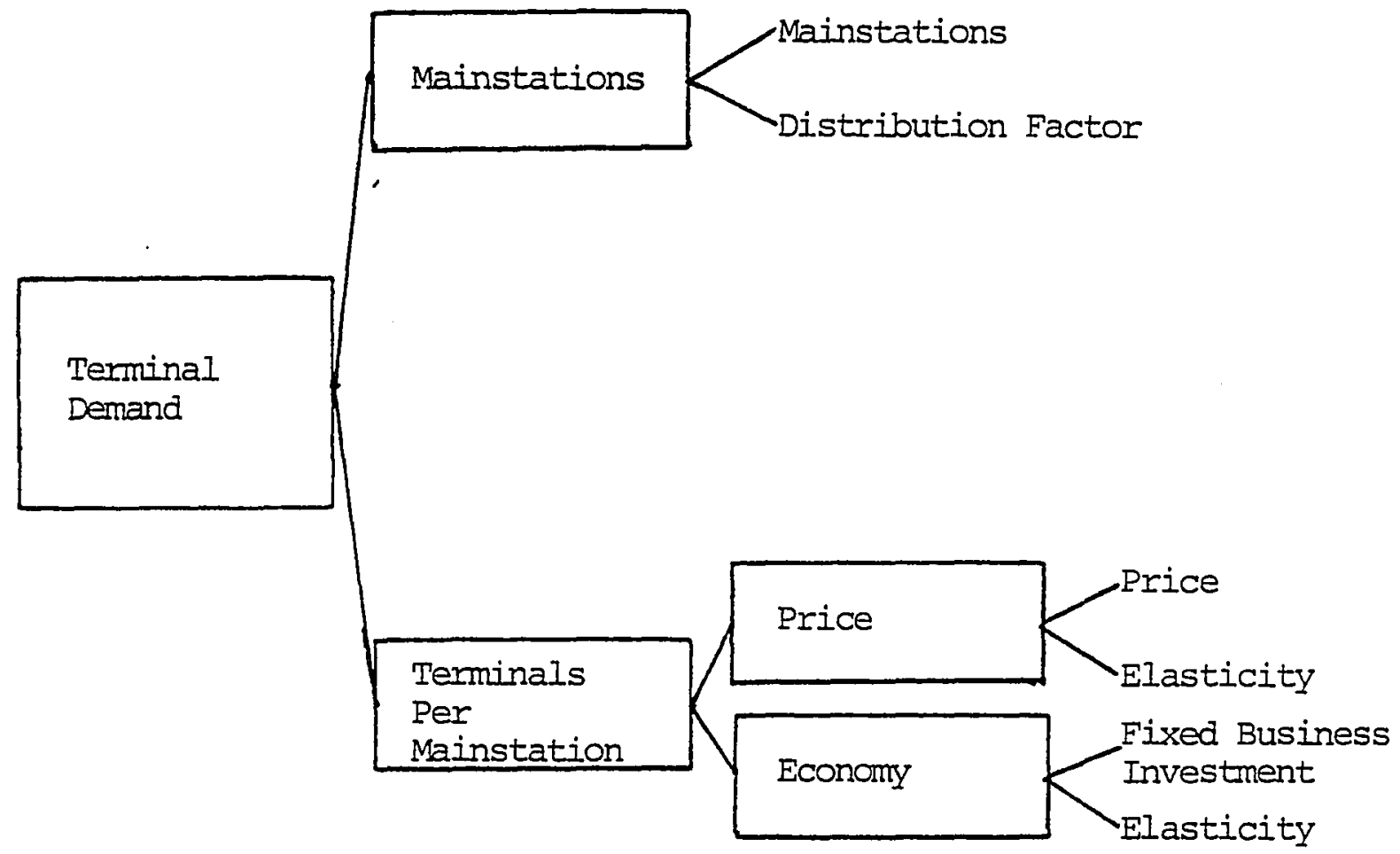

Figure 9. Business terminal equipment demand model 
Mainstations. This component results in the number of mainstations for a given terminal type. Recall, there are three types; voice, data, and video. The approach taken herein is to distribute the total number of mainstations (determined in the business service model) by type. Recall the total number of mainstations was determined from the expression "6,013 + 25 Businv." The distribution factor is represented in Equation 7 as:

$\sum_{\mathrm{i}}{\text { Service } \text { Demand }_{\mathrm{ij}}}$

Expression 5

$\sum_{i} \sum_{j}$ Potential Demand ${ }_{i j}$

Terminals Per Mainstation. An econometric approach was taken in developing this component. The fixed business variable is analogous to the income variable in the residential models. As with those models, assumptions will have to be made about fixed business investment and its elasticity.

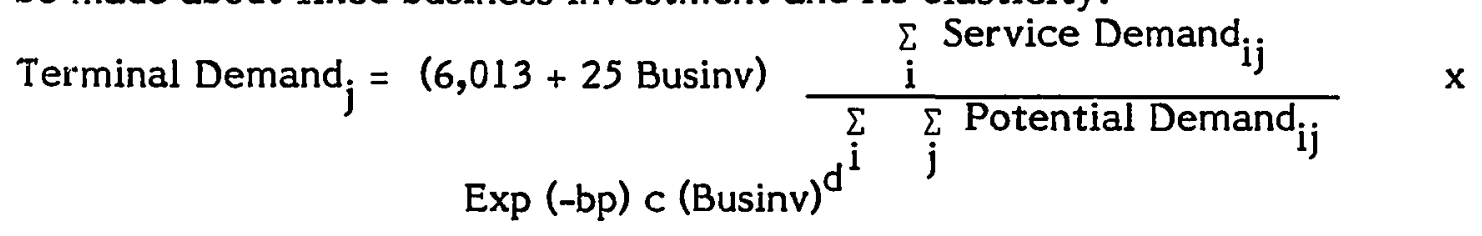

Equation 7

Where:

Terminal Demand $_{\mathrm{j}}$--Demand for terminal Type $\mathrm{j}$.

Potential Demand $_{\mathrm{ij}}$--Market size multiplied by implementation rate for Service i.

Businv--Fixed business investment.

Service Demand $_{\mathrm{ij}}$--Demand for Service $\mathrm{i}$ (which requires a Terminal Type $\mathrm{j}$ ). b--A function of price elasticity.

C--Scaling constant.

d--Businv elasticity of demand. 


\section{CHAPTER VI}

\section{USER ASSUMPTIONS}

User assumptions are developed in this chapter. These are the means by which users input their ideas into the system. Following the introduction, the process of selecting a set is given. The chapter concludes with three sets preselected by the author. 1

\section{INTRODUCTION}

FORTEL was designed to combine the rigor of quantitative models with intuition and experience of the decision maker. The previous chapter addressed the models. This chapter outlines the user's input.

Users may input their ideas (assumptions) on a variety of factors. In fact, each of the variables (in the demand models) are designed to incorporate user input.

A word of caution is in order here. In selecting assumptions, the forecaster must ensure they are consistent. For example, it is not consistent to assume expensive technologies (e.g., satellites) will be implemented when the economy is in a deep recession. If the money is not available, the technology cannot be implemented. Thus, the assumptions must be analyzed for inconsistencies.

The author has selected three different sets of user assumptions. These sets range from a pessimistic to an optimistic outlook. The forecaster has the option of

${ }^{1}$ It is extremely important to note that the preselected sets reflect the bias of the author. They are not based on industry consensus as are the core assumptions. 
selecting one of the sets or selecting his own. Following a discussion of creating an assumption set, the three preselected sets are described.

\section{CREATING A USER ASSUMPTION SET}

The essence of a user assumption set is the forecaster's belief about the future. This belief becomes the guiding principle by which the specific assumptions are determined. Some forecasters believe there will be an economic and social colapse. For them, the society will revert from its industrialization back to an agrarian form. Optimists, on the other hand, believe in exponential growth. New technologies will be discovered at ever-increasing rates. Industrial expansion will continue.

Thus, the process begins with a statement of the forecaster's belief. Once done, specific assumptions can be selected.

There are five categories of specific assumptions. ${ }^{2}$ These categories (summarized in Chapter III) are:

- General

- Technology

- $\quad$ Service

- Terminal

- Forecasting Technique

The categories were determined from the factors that impact demand (see Chapter II). In all, these categories contain 816 specific assumptions. The service and forecasting technique categories are the largest with 375 and 403, respectively.

${ }^{2}$ There may be a considerable degree of interaction (feedback) between the categories. This will depend on the user's outlook. If there is feedback, its effect will have to be explicitly considered. 
Within each category, there are two types of assumptions. Most of the assumptions will be about the variables of the models. These were discussed in the previous chapter. The other assumptions are necessary in order to make the variable assumptions. This is best illustrated with the technology assumptions. In order to provide computer conferencing, the electronic publishing technology must exist. Thus, an assumption will have to be made about the technology before assumptions can be made about the service's implementation.

Recall that the variable assumptions must be translated to variable forecasts. In order to do this, the assumptions must be about the future values of the variables. Specifically, assumptions must be made about the starting values and rate of change for each variable. In addition, the forecasting method must be identified. For example, an optimistic forecaster may assume the population will grow linearly while disposable income grows exponentially.

To summarize, assumptions must be made about each variable. The assumption must specify a starting value, growth, and forecasting technique. Nonvariable assumptions are also necessary. They are necessary in order to make the variable assumptions. Work sheet (Appendix D) have been developed to help the forecaster specify his variable assumptions. The work sheets, however, do not clearly specify the forecaster's basic belief or the nonvariable assumptions. A comprehensive format, which delineates all the assumptions, is exemplified in the following sections. These sections describe the three assumption sets selected by the author.

It is recommended that any new assumption sets first be specified in this comprehensive manner, then they can be translated to the work sheets. 


\section{ASSUMPTION SET I--ECONOMIC COLAPSE}

The assumptions in this set reflect an economically depressed outlook. It is assumed the economy will enter a recession during the late 1980s. This will be further exasperated by an energy crisis. These two events will cause a social shift back to traditional moral values. Families will grow larger. Divorces will decline. The number of traditional households--husband, wife, and children--will increase.

Within the telecommunications industry, the 1934 Communications Act will not be rewritten. The FCC will continue to regulate with outdated legislation. Each time the FCC issues a major ruling, it will be challenged in the courts. This will result in a feeling of uncertainty on the part of industry leaders. Many services will not be implemented either because of the FCC, courts, or not offered by companies.

\section{General Assumptions}

The assumptions described in this section are applicable to all services and terminals. These assumptions are delineated in a list format (below). An analysis follows the list.

\section{Economy}

- A recession will occur in the late 1980 s.

- Disposable income per household will increase at an annual rate of $\$ 75$ prior to the recession, drop at a rate of $\$ 375$ per year during the recession, and modestly grow at a rate of $\$ 42$ per year after the recession.

- Fixed business investment will grow at an annual rate of $\$ 26.5$ trillion prior to the recession, drop at a rate of $\$ 200$ trillion per year during the recession, and grow at a rate of $\$ 16.67$ trillion per year after the recession.

- The percentage of information-handling employees will not change. 


\section{Energy}

- A severe energy shortage will occur in 1987.

- The shortage will reverse the migratory trend to the suburbs.

- The shortage will have a tremendous impact on implementation. Energy conservation-type services will be implemented rapidly.

\section{Social Change}

- The economic recession will cause a change to conservative moral values.

- The population (birth, death, and immigration) will continue to grow at a rate of 2.2 million prior to 1988 . Thereafter, the rate will increase to 5 million per year.

- The number of children per household will decrease (at a rate of .02 per year) until 1988, then increase to 4 children per household.

- Divorces will increase at a rate of .19 million per year. After the recession, it will drop to 1 percent of the total population.

- Dwelling size will remain the same prior to 1988. Afterward, it will drop by 20 percent.

- Prior to 1988 , migration (from the central cities) will continue at a rate of .27 percent. The trend will reverse during the recession with a rate of 5 percent, tapering off to .5 percent by 1995.

- Consumers will demand less sophistication.

\section{Government Regulations}

- The 1934 Communications Act will not be rewritten.

- Most interexchange services and technologies will be deregulated.

- The terminal market will be partially deregulated.

- Competition will be vigorously promoted. 
- $\quad$ Regulated services will be priced low.

- Regulations will grow.

There are two major assumptions in this set. These assumptions--an economic recession and an acute energy shortage--will impact many of the other assumptions. The recession will occur in the late 1980s. Compounding its effect will be the energy crisis. The greatest impact of these events will be upon the economic variables; fixed business investment and disposable income.

Prior to the recession, it is assumed disposable income (per household) will increase for two reasons. First, a growing economy will generate larger disposable incomes. The other growth factor is due to second incomes. It is assumed there will be an increase in the number of households which have more than one person earning an income. As wives, for example, enter the work force, the family income will substantially increase. During the recession, most of these workers will be layed off. Moreover, many of the primary earners will have their salaries reduced or be layed off altogether. Hence, the substantial drop in disposable income.

Fixed business investment will undergo an even larger drop than disposable income. The economic downturn will substantially reduce the number of business opportunities. Many smaller businesses will go bankrupt. The cost of money will rise to the point where most new business ventures are not financially viable.

Another factor driving down fixed business investment will be the energy shortage. First, shortages will drive up the price. Higher energy costs will force up the price of products. Demand, in turn, will drop, reducing the company's profits and need for employees. Secondly, residential customers have priority over businesses. Thus, energy will be less available as well as more expensive. 
The reductions in disposable income and fixed investment will precipitate a societal change. Society, it is assumed, will undergo a transition from liberal to conservative moral values. Following the theory that "the more affluent the society, the more liberality" prior to the recession, society will move in a liberal direction. Most of the current trends in divorces, children per family, dwelling sizes, and migration will continue. These trends will reverse during the recession. The divorce rate will decline, children per family will increase. Households will migrate to urban center in search of work.

After the recession, the intensity of these trends will slacken. However, the trends will not revert to the prerecession directions.

Up to this point, the economic assumptions have affected society. The author has made one assumption where this trend is reversed. Disposable income per household will be reduced due to societal change. The change to conservative values will result in less working wives. Even after the recession, fewer wives will return to work. This will reduce the disposable income.

Another major factor is the government. The major assumption in this area is that the 1934 Communications Act will not be rewritten. The rationale behind this assumtion lies in industry disunity. In the mid 70 s, industry executives became worried about the way the FCC was changing its direction. Most of these executives felt the FCC was responding to the problem in an ad hoc fashion. As a result, they approached the Congress. Their hope was that the 1934 Communications Act would be rewritten. Congress agreed to initiate legislation, provided the industry would reach a consensus of opinion. To date, this has not happened. As a result, no bills have reached either the House or Senate floor. Hence, the "no rewrite" user assumption. 
Without a rewrite, the burden of regulatory changes falls on the FCC and state commissions. Most of the changes will emanate from the FCC since the state commissions have no authority on a national level. It must be pointed out that the changes affecting demand are primarily on the national level; e.g., satellites and network television. The FCC's decisions, however, will affect state commissions. For example, deregulating long-distance carriers will impact division of revenues. State commissions, therefore, will take many of the FCC's rulings to court. Actually, this issue is a symptom of a deeper problem. Recall that the FCC was originally established to carry out the legislative mandate of the 1934 Communications Act. Also, recall that very little of the act is applicable to today's technology. It is not possible for the FCC to solve today's problems with yesterday's regulations. The FCC is forced to exceed its limits of authority in order to solve these problems. Each time it does, the opposing factions (be it state commissions, telephone companies, Justice Department, etc.) will challenge the decisions in the courts. Many of these decisions will be reversed. Uncertainty will prevail. Executives will be reluctant to engage in ambitious programs for fear of lengthy litigation. Each time a substantially new service or technology is developed, it will have to go through a court battle before it can be implemented. This will result in lengthy delays, and in many cases, implementation will never occur. A more devastating effect is that many new ideas will never be developed. The unlikelihood of success will prevent many new ideas from ever leaving the minds of the inventors.

The environment of uncertainty is exactly what the FCC does not want. Uncertainty will have the same effect as industry complacency--lack of new services. Following the competitive edge philosophy, the FCC will continue to press for more competition. All interexchange communications will be 
deregulated. All terminal equipment will be deregulated. Only the local loop and central office portion of the network will remain regulated.

Outside the network, CATV companies will be encouraged to compete with broadcasters. This includes program origination as well as distribution. Several entertainment services will emerge.

The network will continue to evolve as it has in the past. The local loop and switches will be upgraded on a replacement basis. By the end of the century, most of the switches will be electronic. Some wire in the local loop will have been replaced by optical fibers. This, however, will be on a very limited basis. Thus, the local loop and switches will be predominantly narrow-band. There are both financial and regulatory reasons for this slow evolution. The local loop and switch will continue to be regulated in order to ensure universal service. The financial reward system will remain the same. Thus, telephone companies are rewarded for long life and reliable equipment. This will keep this portion of the network evolving at a slow rate. The recession will also impact the rate because money will not be available. This will also keep the evolutionary rate low.

A faster evolution rate will occur in the interchange (long distance) portion. Here the capacity will be modestly increased. Fiber optics will be common. Satellites will also be used more. Most of this growth will be a result of deregulation. Many new interexchange carriers will emerge. They will provide both voice and enhanced nonvoice services. Data networks will also emerge. These networks will interconnect to the switch. The local telephone companies will then provide the link to the customers. In some cases, direct connect will occur. These, however, will most likely be dedicated circuits through the switch. Thus, the network will, for all practical purposes, be split into two separate, 
but connected, entities. The switch and local loop will be regulated while long distance will be totally deregulated.

\section{Technology Assumptions}

Technolgy is the one area in this user assumption set with an optimistic future. Several of the technologies will be used to enhance the existing network. These technologies will be implemented--regardless of the recession. Although the other technologies (outside the network) will be affected by the recession, they will continue to be implemented.

The author has assumed the technologies will develop similar to those in the computer industry. Price will drop while capabilities increase. Network-related technologies will be implemented on a replacement basis; as old devices wear out, they will be replaced by newer technologies. Thus, the implementation rate will follow the replacement schedule--independent of the recession. Nonnetwork technologies will also drop in price. Unlike the network types, however, they cannot replace existing technology. Recall, most of these technologies are not currently implemented.

Listed below is a specific analysis of each technology.

Satellites. This technology falls in both network and nonnetwork categories. As stated in the Background Chapter, it can be used in the interexchange portion of the network or bypass it altogether, transmitting directly to the customer's premise. Another aspect is the high implementation cost. This, coupled with the fact tht there are several interexchange transmission modes, will keep the implementation low. Telephone companies will seek other (cheaper) long-distance technologies. Some corporations and CATV companies will rely on satellites for private communication systems and distribution of television programs. The 
government will also use satellites for military, research, and navigation. Overall, however, satellites will be modestly implemented.

Electronic Publishing Technology. There are several components of this technology. Many have already been implemented. The distribution systems (television broadcasting and telephone network) are available to virtually every residential and business customer. Moreover, almost every residential customer has a terminal (television). Actually, this terminal will work for the teletext technology. View data (which is transmitted over the network) will require a "data-type" terminal. The originating company will also have to obtain some type of computer to compose and store the text. In terms of implementation, this will be the major problem. Thus, for all practical purposes, the implementation of this this technology is linked to the originating computer.

Digital Transmission. By the end of the century, all transmission will be digital, with exception of portions of the local loop. This is one of the network technologies which will grow independent of the recession. Due to its distortionfree characteristic and computer compatibility, digital will completely replace the analog mode. The replacement rate in the interexchange portion of the network will be high. By the early 1990s, virtually all long distance will be digital. The rate within the central offices is keyed to the electronic switch. This technology (discussed below) will take longer to jully implement.

Within the local loop, many business customers will have digital. This, however, will require wide-band capacity. Due to the cost of replacing the wire in the local loop, it is assumed only business customers will have digital. Residential customers will remain with analog.

Packet Switching. Like the electronic publishing technology, the distribution system is already implemented. Recall, packet switching uses the 
existing network. It also has an advantage in that it enhances the network. Packet switching requires less capacity. With this, more data can be transmitted over the network.

Strictly speaking, not all of the distribution system has been implemented. Nodes (computer processing centers) will have to be developed. Moreover, these nodes are subject to governmental regulation. Under the "no rewrite" assumption, the FCC and state commissions will have to approve the establishment of these nodes (in fact, of the entire system). This will tend to reduce the degree of implementation. Nevertheless, the advantages of this technology will be sufficient to foster widespread implementation.

Transmission Media. Fiber optics and coaxial cable are the two media which will grow. By the mid-1990s, all interexchange wire will be replaced by fiber cables. Some larger business customers will have fibers directly to their premises. Most residential customers, however, will not be connected via fiber optics.

Coaxial cable will continue to be used by CATV companies. Since this is an integral part of the CATV technology, it will be discussed in that section (below).

The other media--lasers, waveguides, wire, and microwave--will not be significant factors.

CATV. Prior to the recession, CATV will continue to grow as it has in the past. By 1988, almost every urban and suburban household will be connected.

The recession will halt CATV growth. No new customers will be connected to the system. After 1991, the growth will start up, but at a very low rate. This follows from two assumptions. First, the assumption about the economy determines the availability of money. This, in turn, drives the CATV companies' ability to expand. Second, by 1988, most of the profitable (urban and suburban) households will already be connected. Growth must come from the rural market. 
However, due to a low population density, the connection cost per household will be high. This, coupled with a sluggish economy, will keep the growth quite low.

Cellular Mobile System. This system will not be developed. It is assumed this will not occur because of governmental indecision and the economy.

Prior to the recession, several corporations will begin studying the feasibility of implementing a cellular system. However, governmental approval will be slow. By the time the FCC finally approves, the recession will occur. The drastic change in the economy will make the system no longer financially sound. After the recession, there will be some talk of implementation. A sluggish economy and a lengthy approval process, however, will keep the system from being implemented.

Electronic Switches. This technology will be implemented on the replacement basis. As the old mechanical type switches wear out, they will be replaced by electronic offices. By the end of the century, virtually every central office will be electronic. During the recession, the replacement rate will slow, but not significantly.

\section{Service Assumptions}

The assumptions in this section are about specific services. Each service will have a unique price, elasticity, and implementation rate. In fact, many of the services will have unique values for each market. Recall, there are two markets; residential and business. The price, for example, of POTS is higher for business than residential customers.

In terms of the demand models, the assumptions in this section determine the usage rates. The specific areas (for which assumptions must be made) are listed in Table III. 
TABLE III

SERVICE ASSUMPTION CATEGORIES

\begin{tabular}{ll} 
Residential & Business \\
Model & Model \\
\cline { 2 - 2 } Technology & Technology \\
Government & Government \\
Cost & Cost \\
Energy & Energy \\
Competition & Competition \\
Price & Price \\
Price Elasticity & Price Elasticity \\
Income Elasticity &
\end{tabular}

The assumptions about each service are given below.

Electronic Newspaper. The following assumptions are applicable to both the residential and business markets. Most of the technology is already in place. Only the origination computers are missing (see Technology Section). Most newpapers will view the profitability of this service as quite low. As a result, they will very slowly implement the computers. The technology variable will grow at an annual rate of .01 . The government variable will have a value of 1 . This follows from the assumption that this will be an unregulated service. Initially, the cost of offering the service will be moderate. The cost variable will increase by 5 percent a year, until the recession. During the recession, the scarcity of money will keep the cost variable from growing. Afterward, the cost variable will grow at an annual rate of 1 percent.

Energy will have a substantial impact on implementation. During the recession, energy costs will rise dramatically. This, coupled with petroleum shortages, will force newpapers to pursue the "electronic" option. Transmitting electronically removes the necessity (and cost) of physically delivering the paper. In some cases (due to petroleum shortages), the electronic option will, in fact, be the only option. The energy variable will be 50 percent during the recession. Before and after, energy will not be significant. 
Competition, the last implementation variable will not be significant either. Initially, the price will be $\$ 15$ per month--two to three times the cost of "hard copy" delivery. The price will rise to $\$ 17$ per month during the recession, reflecting the higher cost of money. Thereafter, it will drop. Reflecting economies of scale, the price will be $\$ 10$ per month by the end of the century.

Up to this point, the assumptions have been the same for both markets. This is not the case with elasticities. In the residential market, the price elasticity (it is assumed) will start at -2 . It will remain at this value until 1988. During the recession, it will decrease to -4 . Thereafter, it will taper off to -.75 . Income elasticity will follow a similar pattern. However, its values will be affected much more by the recession; i.e., 4 before, 10 during, 2 afterward.

In the business market, the price elasticity will be more volatile than its residential counterpart. Following the same pattern, its values will be 4 before, 8 during, and taper off to 3 afterward. Technology will also vary in this market. Most companies will view this service as a luxury. Due to the recession, very few will subscribe. This is reflected in the technology variable having a constant value of .00001

Electronic Mail. In the residential market, it is assumed the government will not allow the service to be implemented. This is based on the assumption that the Congress will continue its current stand that the United States Postal Service should not be allowed to "go electronic." The Congress currently feels the United States Postal Service would be an unfair competitor.

Given this assumption, the others become irrelevant. If the service is never implemented, the demand will be zero. Nevertheless, the other assumptions are summarized below. It may be that a forecaster would like to change the government assumption as part of a scenario test. 
The technology and cost factors are the same as the electronic newspaper. The technology value is one for the entire forecast. The cost variable will increase by 5 percent a year prior, remain the same during, and increase by 1 percent a year after the recession.

Energy will force a 25 percent increase during the recession. Before, its effect will be nominal. Afterward, it will stimulate a 2 percent increase. The price will be set by the United States Postal Service at $\$ 1$ per letter prior to 1989. Afterward, it will rise to $\$ 1.25$. The price and income elasticities will be -1 and 1.5 before, -3 and 3.5 during, and -.5 and .75 after the recession, respectively.

Within the business market, private electronic mail systems will develop. These will be primarily intracompany. Most large corporations will have "intelligent" PBXs. These machines will be used to distribute the mail electronically. Between companies, the teletype network (Western Union) will provide the communications.

The technology variable will grow (from zero) to 50 percent before the recession. It will remain there through the 1990 s.

The government will not be involved in this service since it is intracompany. Thus, the government variable will be one. Cost will also be one. The cost of the PBX will not significant because of this feature.

Energy will not impact the usage rate. The effect of competition will be significant. The PBX market, it is assumed, will be quite competitive. As a byproduct, most PBXs will have an electronic mail feature. This will increase the implementation process by 50 percent prior to the recession. Thereafter, it will be zero.

The price will be quite low, $\$ .50$ per letter. Elasticity, on the other hand, 
will be high. Most decision makers will view this as a luxury. Prior to the recession, it will be -3 . Thereafter, it will be -5 .

Travel Reservations. Due to the recession and energy crisis, travel will substantially decline. This, in turn, will keep this service from being implemented in either the residential or business market. The assumptions for each variable are: technology 1, government 1 , cost 1 , energy 1 , competition 0 , price $\$ .50$ per reservation, price elasticity -3 , and income elasticity 4 . These assumptions are for both markets.

POTS. Plain 이 Telephone Service will remain the communication mainstay for the duration of this century. Given the current ubiquity, implementation variables (technology, government, cost) will remain at one. Neither the energy crisis or the recession will substantially impact the service. Thus, energy will be zero. Due to the monopolistic nature of POTS, competition will also be zero.

Price will remain low--\$15 per month. Both income and price elasticities will also be low; -.2 and .02 , respectively. These assumptions hold for both residential and business customers, except for price. Business customers will pay $\$ 25$ per month.

Cellular Mobile System. This is one of the most expensive services to implement. Millions of local transmitters and controlling computers are required. Due to the cost, this service will not be implemented. The specific assumptions are: technology 0 to 20 percent prior to the recession, no growth thereafter; government 0 prior to 1985,1 thereafter; cost 0 ; energy 0 before, -.5 during, 0 after the recession; competition 0 , price $\$ 100$ per month; price elasticity -1.5 ; and income elasticity 2. These assumptions apply to both the residential and business markets. 
Consumer Advisory Service. This service will be offered primarily by the government. It is intended to provide information on consumer products and services. As a government, its implementation is independent of the recession. The specific assumptions are: technology 1 , government 10 percent increase a year until completely implemented, cost 1 , energy 0 , and competition 0 . The price will be only for the terminal, the service is free. The government will pay for program origination and distribution to metropolitan centers. From each metropolitan center, the service will be distributed over the telephone network. The price is assumed to be $\$ 15$ per month. Price and income elasticities are 3 and 4, respectively. These values are the same for both residential and business markets.

Video Library. This is a wide-band service. As such, it requires (as a minimum) wide-band capacity to the customer and narrow-band back to the originator. Neither CATV nor the telephone network have this abilitly. Moreover, the two distribution systems combined could only provide this service to a very limited degree. CATV does not have the capacity to provide each of its customers with a unique wide-band channel. The solution to this problem is to replace the local loop with fiber optics. The author, however, assumes the cost of replacement will prohibit this from happening. The assumptions for each variable are: technology 0 through $1991, .05$ per year increase thereafter; government 1; cost 0 through 1993, .01 per year increase thereafter; energy 0; and competition 0 through 1992, 10 percent thereafter.

Price will start at $\$ 25$ per month. During the recession, it will drop to $\$ 20$ per month and remain there. Elasticities will be -1.5 for price and 2 for income.

In that this is an entertainment service, the demand will come from the residential market. In fact, the assumptions above are for the residential market. 
The business market, it is assumed, has the same elasticities and price values. The difference is in technology (.001 in the business model).

Restaurant Guide, Reservations, and Menus. Due to the harsh economic assumptions, this serice will not be offered in either market. The specific assumptions are: technology 1 , government 1 , cost 0 , energy 0 , competition 0 , price $\$ 10$ per month, price elasticity -3 , and income elasticity 3 .

Video Games. There will be three means (sources) by which consumers may access this service; a central computer accessed through the network, home computers, and specialized devices which play only a few games. The latter source is currently most popular. The forecast herein, however, is for the first source. Competition will be keen among all three sources. The specific user assumptions are: technology 1; government 1; cost increase by .05 until the recession, .005 during, .01 after; energy 0 ; and competion .3 before the recession, .1 during, .2 after.

Price will be $\$ .50$ per hour of connect time. Price elasticity is -3 before the recession, -5 during, and -4 after. Income elasticity will follow a similar pattern; 4 before, 6 during, and 5 after.

This service will not be implemented or demanded in the business market. The cost variable will be zero. All other values are the same as above.

Network Television. Prior to the recession, this service will grow relatively fast. it is assumed the FCC will foster this as competition to the three major broadcasting companies. The proliferation of the CATV network will provide an excellent distribution system. Only satellite capacity will impede this service's growth.

During and after the recession, the service will not grow. The specific assumptions are technology, starting at . 3 it will increase by .075; government 1 ; 
cost 1; energy 0; competition .1; price $\$ 10$ per month; elasticity -2 before the recession, -4 during, and -3 after; and income elasticity 3 before, 5 during, and 4 after.

This service will not have any demand in the business market. Technology is assumed to be 0 , all other assumptions are the same.

Electronic Library. This service will undergo an unexpected growth spurt during the recession. It is assumed that the change in values (caused by the economic colapse) will result in a literary revival. Many households will seek literature as a source of entertainment. This, in turn, will drive up the demand for this service. The specific service assumptions for the residential market are: technology 1; government 1; cost .05 increase per year prior to 1988, no increase during the recession, . .1 during, and 0 after; and competition 0 . Price will be $\$ .50$ per hour, elasticity will be -3 prior to the recession, -.01 (reflecting revival) during, and.- .3 after. Income elasticity will follow a similar pattern ( 4 prior, .02 during, .4 after).

The economic decline will not have the same impact on the business market. In this case, the recession will reduce the demand. The reduction is reflected in the following assumptions: energy .01 reduction during the recession, 0 before and after; price elasticity -2 prior, -6 during, and -3 after. All other assumptions are the same as the residential market.

Outpatient Treatment. This service, like many of the others, will have a modest demand. The price of the service will be the limiting factor. Special devices will be required to monitor blood pressure, pulse, and respiration rates. This equipment will drive up th eprice. The specific assumptions are: technology 1 ; government 1 ; cost 1 ; energy 0 ; and competition 0 . The price will be 
$\$ 50$ per hour. Price elasticity is assumed to be -1 before the recession, -2 during, and -1.5 after. Income elasticity will be 1.5 before, 2.5 during, and 2 after.

This service will not be implemented in the business market. This is reflected in a technology of 0 . All other assumptions are the same as those above.

Diagnosis. Due to the implementation cost, this service will not be implemented. In order to implement this service, a private two-way video conferencing system is necessary. In addition, a multitude of specialized diagnostic equipment would be needed.

The specific assumptions for this service are: technology 1; government 1; cost 0 ; energy 0 ; competition 0 ; price $\$ 1,000$ per hour; elasticity -1 for price and 1 for income. These assumptions hold for both markets.

Emergency Services. Similar to the diagnosis service, this will not be implemented. The cost is the crucial factor. The specific assumptions are: technology 1; government 1; cost 0 ; energy 0 ; and competition 0 . Price, it is assumed, will be $\$ 1,000$ per hour. Price elasticity is -1 while income is 1 .

Computer Tutoring. The change in societies value system will reduce the demand for this service. Higher education will be considered a luxury. The specific assumptions are: technology 1; government 1; cost 1; energy 0 ; and competition 0 . The price will be $\$ 5$ per hour of assistance. Price elasticity will vary with the recession; before it will be -1 , during -5 , and after -4 . Income elasticity will follow a similar pattern, 1 before, 4 during, and 3 after.

The business market will have a slightly higher demand. This service will be cheaper than sending an employee to school. The price elasticity reflects this difference; -3 before, -5 during, and -4 after. All other assumptions are the same.

Correspondence School. The assumptions about this service are similar to computer tutoring. The assumptions are: technology 1; government 1; cost 1; 
energy 0; and competition 0 . Price will be $\$ 100$ per course. Price elasticity is -1 before the recession, -5 during, and -4 after. Income elasticity is assumed to be 1 before, 4 during, and 3 after.

The business market will have a price elasticity of -3 before, -5 during, and -4 after. All other assumptions are the same.

Electronic Meetings. It is assumed this service will be implemented in the business market as a replacement for travel. It will not be demanded in the residential market.

The energy crisis (driving up the cost of transportation) will positively impact both implementation and elasticity. This is one of the few services (under this assumption set) that will have an increased demand during the recession. The business market assumptions are: technology 1; government 1; cost .05 per year increase prior to the recession, 0 during, and .01 per year increase afterward; energy 0 before and after, .2 increase per year during; and competition 0 . Price will be $\$ 5$ per hour and price elasticity -3 prior, -1 during, and -2 afterward.

The residential market assumptions are the same, except for energy $(0)$.

Electronic Funds Transfer. This service will not be implemented because of government regulations. It is assumed that the Federal Reserve Board and the Federal Communications Commission would not agree such to such a service. The specific assumptions are: technology 1; government 0 ; cost .9; energy 0 ; competition 0; price .05 per transaction; price elasticity -7 ; and income elasticity 8. The assumptions hold for both markets.

Message Recording. This service (like the one above) will not be implemented. Recall, it was assumed the 1934 Communications Act would not be rewritten. The FCC would be making the major decisions about the industry's infrastructure. One aspect of critical concern is the boundary between the 
telecommunications and data processing industries. The FCC has ruled that message recording constitutes data processing and, therefore, cannot be provided through the switch. It is assumed that this ruling will not change.

The specific assumptions (for both markets) are: technology increase by .05 each year; government 0 ; cost 1 ; energy 0 ; competition 0 ; price $\$ 1$ per month; price elasticity -.5 before the recession, -2 during, and -1 after; and income elasticity .2 before, 3 during, and 2 after the recession.

Call Forwarding. Implementation of this service keyed to the replacement of old central offices with electronic switches for the residential market. The specific assumptions are: technology increase by .05 ; government 1 ; cost 1 ; energy 0 ; and competition 0 . Price will be $\$ .50$ per month and price elasticity -.5 before the recession, -2 during, and -1 after. Income elasticity will be .2 before, 3 during, and 2 after the recession.

The business market will have the same assumptions except for competition. PBX manufacturers will offer call forwarding as a regular feature of their product. The author has assumed that the competition variable will be .1 during the forecast period.

Video Conferencing. Due to the high implementation cost, this service will not be implemented in the residential market. Recall that all the wire in the local loop would have to be replaced with a wide-band medium.

In the business market, there will be minimal implementation. Larger corporations will lease satellite capacity to build a corporate communications system. The specific business assumptions are: technology starting at .2, increasing by .01 until the recession, 0 thereafter; government 1 ; cost .2 prior to the recession, .1 thereafter; energy .3 during the recession, 0 otherwise; 
competition 0; price $\$ 1,000$ per hour; and price elasticity -.2 prior to the recession and -1 thereafter.

These assumptions are the same in the residential market, except for cost which is 0 and income elasticity which i 1.

Appointment Calendar. The recession, it is assumed, will keep the demand quite low. Most comsumers will view this as an unnecessary luxury. The assumptions (for both markets) are: technology 1; government 1; cost 1; energy 0; and competition 0 . Price will be $\$ 10$ per month and price elasticity -1 before, -5 during, and -4 after the recession. Income elasticity will be 1 before, 2 during, and 1.5 after the recession.

Data Base Access. The government, fearing this will lead to a controlled society, will severely limit its implementation. The specific assumptions, for both markets, are: technology increasing by .1 each year prior to the recession, no change thereafter; government .1; cost 1; energy 0 ; and competition 0. Price will be \$1 per access; price elasticity -2; and income elasticity 3.

Word Processing. This is strictly a business market service. Smaller companies will rely on this as an inexpensive means of typing. The specific assumptions are: technology increase by .2 per year; government 1; cost increase by .4 per year; energy 0 ; and implementation 0 . Price will be $\$ 1$ per page and price elasticity -6 prior to the recession, -10 during, and -9 after.

The residential market will have the same assumptions.

Computer-To-Computer Communications. This is also a business service. Due to the recession, it will be severly limited. Only large corporations will use it. The specific assumptions are: technology increase by .2 per year; government 1; cost .05; energy 0 ; and competition 0 . Price will be $\$ 1,000$ per hour and price elasticity -1 prior to the recession, -5 during, and -1.5 thereafter. 
The residential market will have a price elasticity of -2 and an income elasticity of 2. All other assumptions are the same.

\section{Terminal Equipment Assumptions}

This section delineates specific assumptions for each of the three terminal types. Basically, these are assumptions about price and elasticities.

Voice Terminals. The most common example of this type of terminal is the telephone. Assumptions about the residential market are: there will be a maximum of five terminals per household prior to the recession, thereafter it will decline by .1 per year. The price fo the terminal will be $\$ 35$. Price elasticity will be -1 prior to the recession, -3 thereafter. Income elasticity will be .75 prior and 3 after the recession. Recall, these assumptions are for extension only (see terminal equation in Chapter III).

The business market will have higher prices due to the additional cost of multiline instruments. The price will be $\$ 100$ per terminal. Price elasticity will be -.75 prior to the recession and -4 thereafter. Fixed business investment elasticity will be .5 prior to the recession and 4 thereafter.

Data Terminals. The assumptions for the residential market are: terminals per household 5 prior to the recession, decline by .2 per year thereafter. The price will be $\$ 500$ per terminal; price elasticity -3 prior and -5 afterward; and income elasticity 2 prior and 6 afterward.

The business market will have a higher demand. This is reflected in the price elasticity (-.25 prior to the recession and -.75 afterward). The price will remain at $\$ 500$ per terminal. Business investment elasticity will also vary with the recession (.75 before, 3 during, and 2 after).

Video Terminals. This type will be more sensitive to changes in the economy, energy, and social values. The residential market assumptions are: price 
$\$ 1,000 ;$ price elasticity -3 prior, -10 during, and -5 after the recession; and income elasticity .9 prior, 15 during, and 10 after the recession.

The business assumptions are the same. The fixed business investment elasticity is .9 before, 4 during, and 3 after the recession.

\section{Forecasting Technique Assumptions}

For each of the general, service, and terminal equipment assumptions, there is a corresponding forecasting technique assumption. In fact, due to the recession assumption, many of the other assumptions have three different forecasting technique assumptions. Disposable income, for example, will follow the logistics curve prior to the recession, decline exponentially during the recession, and grow linearly afterward. Thus, three different techniques will be used to forecast disposable income. The multiple technique was used (in this assumption set) to emphasize the effect of the recession. A linear decline during the recession, for example, would not have been as dramatic.

The author has provided four forecasting techniques. In addition to the three listed above, the forecaster can select the technique of no change--constant value. In addition (also as shown above), different techniques can be used for different time intervals.

The specific forecasting technique assumptions are delineated in the following tables. 
TABLE IV

FORECASTING TECHNIQUE ASSUMPTION FOR SET I--GENERAL

\begin{tabular}{|c|c|c|c|}
\hline \multirow{2}{*}{ Variable } & \multicolumn{3}{|c|}{ Forecasting Technique } \\
\hline & $\begin{array}{c}\overline{\text { Before }} \\
\text { Recession }\end{array}$ & $\begin{array}{c}\text { During } \\
\text { Recession }\end{array}$ & $\begin{array}{c}\text { After } \\
\text { Recession }\end{array}$ \\
\hline $\begin{array}{l}\text { Disposable Income } \\
\text { Fixed Business Investment } \\
\text { Information Handlers } \\
\text { Population } \\
\text { Children Per Household } \\
\text { Divorce Rate } \\
\text { Dwelling Size } \\
\text { Migration }\end{array}$ & $\begin{array}{l}\text { S } \\
\text { S } \\
\text { C } \\
\text { L } \\
\text { L } \\
\text { L } \\
\text { C } \\
\text { L }\end{array}$ & $\begin{array}{l}E \\
E \\
C \\
L \\
E \\
E \\
E \\
E\end{array}$ & $\begin{array}{l}\text { L } \\
\text { L } \\
\text { C } \\
\text { L } \\
\text { C } \\
\text { C } \\
E, C\end{array}$ \\
\hline $\begin{array}{l}\text { C--Constant } \\
\text { E--Exponential } \\
\text { L--Linear } \\
\text { S--Logistics (S) Curve }\end{array}$ & & & \\
\hline
\end{tabular}


TABLE V

FORECASTING TECHNIQUE ASSUMPTION FOR SET I--SERVICES

\begin{tabular}{|c|c|c|c|c|c|c|c|c|}
\hline Service & $\begin{array}{l}\text { Tech- } \\
\text { nology }\end{array}$ & $\begin{array}{l}\text { Govern- } \\
\text { ment }\end{array}$ & Cost & $\begin{array}{l}\text { Energyx } \\
\text { Percent }\end{array}$ & $\begin{array}{l}\text { ompetition } \\
\text { Percent }\end{array}$ & Price & $\begin{array}{c}\text { Price } \\
\text { Elastic. }\end{array}$ & $\begin{array}{l}\text { Income } \\
\text { Elastic. }\end{array}$ \\
\hline $\begin{array}{l}\text { Electronic } \\
\text { Newspaper } \\
\text { Residential } \\
\text { Business }\end{array}$ & $\begin{array}{l}\mathrm{L} \\
\mathrm{L}\end{array}$ & $\begin{array}{l}\mathrm{C} \\
\mathrm{C}\end{array}$ & $\begin{array}{l}\text { LC } \\
\text { LC }\end{array}$ & $\begin{array}{l}\mathrm{C} \\
\mathrm{C}\end{array}$ & $\begin{array}{l}\mathrm{C} \\
\mathrm{C}\end{array}$ & $\begin{array}{l}\text { CS } \\
\text { CS }\end{array}$ & $\begin{array}{l}\mathrm{CL} \\
\mathrm{CL}\end{array}$ & CS \\
\hline $\begin{array}{l}\text { Electronic Ma } \\
\text { Residential } \\
\text { Business }\end{array}$ & $\begin{array}{l}\text { ail } \\
\mathrm{C}\end{array}$ & $\begin{array}{l}\mathrm{C} \\
\mathrm{C}\end{array}$ & $\begin{array}{l}\text { LC } \\
\text { LC }\end{array}$ & $\begin{array}{l}\mathrm{C} \\
\mathrm{C}\end{array}$ & $\begin{array}{l}\mathrm{C} \\
\mathrm{C}\end{array}$ & $\begin{array}{l}\mathrm{C} \\
\mathrm{C}\end{array}$ & $\begin{array}{l}\mathrm{C} \\
\mathrm{C}\end{array}$ & C \\
\hline $\begin{array}{l}\text { Travel Reser } \\
\text { Residential } \\
\text { Business }\end{array}$ & $\begin{array}{l}\text { vations } \\
\text { C }\end{array}$ & $\begin{array}{l}\mathrm{C} \\
\mathrm{C}\end{array}$ & $\begin{array}{l}\mathrm{C} \\
\mathrm{C}\end{array}$ & $\begin{array}{l}\mathrm{C} \\
\mathrm{C}\end{array}$ & $\begin{array}{l}\mathrm{C} \\
\mathrm{C}\end{array}$ & $\begin{array}{l}\mathrm{C} \\
\mathrm{C}\end{array}$ & $\begin{array}{l}\mathrm{C} \\
\mathrm{C}\end{array}$ & C \\
\hline $\begin{array}{l}\text { POTS } \\
\text { Residential } \\
\text { Business }\end{array}$ & $\begin{array}{l}\mathrm{C} \\
\mathrm{C}\end{array}$ & $\begin{array}{l}\mathrm{C} \\
\mathrm{C}\end{array}$ & $\begin{array}{l}\mathrm{C} \\
\mathrm{C}\end{array}$ & $\begin{array}{l}\mathrm{C} \\
\mathrm{C}\end{array}$ & $\begin{array}{l}\mathrm{C} \\
\mathrm{C}\end{array}$ & $\begin{array}{l}\mathrm{C} \\
\mathrm{C}\end{array}$ & $\begin{array}{l}\mathrm{C} \\
\mathrm{C}\end{array}$ & C \\
\hline $\begin{array}{l}\text { Cellular Mobi } \\
\text { System } \\
\text { Residential } \\
\text { Business }\end{array}$ & $\begin{array}{l}\text { ile } \\
\text { S } \\
\text { S }\end{array}$ & $\begin{array}{l}\mathrm{C} \\
\mathrm{C}\end{array}$ & $\begin{array}{l}\mathrm{C} \\
\mathrm{C}\end{array}$ & $\begin{array}{l}\mathrm{C} \\
\mathrm{C}\end{array}$ & $\begin{array}{l}\mathrm{C} \\
\mathrm{C}\end{array}$ & $\begin{array}{l}\mathrm{C} \\
\mathrm{C}\end{array}$ & $\begin{array}{l}\mathrm{C} \\
\mathrm{C}\end{array}$ & C \\
\hline $\begin{array}{l}\text { Consumer Ad } \\
\text { Service } \\
\text { Residential } \\
\text { Business }\end{array}$ & $\begin{array}{l}\text { dvisory } \\
\text { C } \\
\text { C }\end{array}$ & $\begin{array}{l}\mathrm{L} \\
\mathrm{L}\end{array}$ & $\begin{array}{l}\mathrm{C} \\
\mathrm{C}\end{array}$ & $\begin{array}{l}\mathrm{C} \\
\mathrm{C}\end{array}$ & $\begin{array}{l}\mathrm{C} \\
\mathrm{C}\end{array}$ & $\begin{array}{l}\mathrm{C} \\
\mathrm{C}\end{array}$ & $\begin{array}{l}\mathrm{C} \\
\mathrm{C}\end{array}$ & C \\
\hline $\begin{array}{l}\text { Video Library } \\
\text { Residential } \\
\text { Business }\end{array}$ & ${ }_{\mathrm{C}}^{\mathrm{CL}}$ & $\begin{array}{l}\mathrm{C} \\
\mathrm{C}\end{array}$ & $\begin{array}{l}\mathrm{CL} \\
\mathrm{CL}\end{array}$ & $\begin{array}{l}\mathrm{C} \\
\mathrm{C}\end{array}$ & $\begin{array}{l}\mathrm{CL} \\
\mathrm{CL}\end{array}$ & $\begin{array}{l}\mathrm{C} \\
\mathrm{C}\end{array}$ & $\begin{array}{l}\mathrm{C} \\
\mathrm{C}\end{array}$ & C \\
\hline $\begin{array}{l}\text { Restaurant G } \\
\text { Residential } \\
\text { Business }\end{array}$ & $\begin{array}{l}\text { Suide } \\
\text { C } \\
\text { C }\end{array}$ & $\begin{array}{l}\mathrm{C} \\
\mathrm{C}\end{array}$ & $\begin{array}{l}\mathrm{C} \\
\mathrm{C}\end{array}$ & $\begin{array}{l}\mathrm{C} \\
\mathrm{C}\end{array}$ & $\begin{array}{l}\mathrm{C} \\
\mathrm{C}\end{array}$ & $\begin{array}{l}\mathrm{C} \\
\mathrm{C}\end{array}$ & $\begin{array}{l}\mathrm{C} \\
\mathrm{C}\end{array}$ & C \\
\hline $\begin{array}{l}\text { Video Games } \\
\text { Residential } \\
\text { Business }\end{array}$ & $\begin{array}{l}\mathrm{L} \\
\mathrm{C}\end{array}$ & $\begin{array}{l}\mathrm{C} \\
\mathrm{C}\end{array}$ & $\begin{array}{l}\mathrm{L} \\
\mathrm{L}\end{array}$ & $\begin{array}{l}\mathrm{C} \\
\mathrm{C}\end{array}$ & $\begin{array}{l}\mathrm{C} \\
\mathrm{C}\end{array}$ & $\begin{array}{l}\mathrm{C} \\
\mathrm{C}\end{array}$ & $\begin{array}{l}\mathrm{C} \\
\mathrm{C}\end{array}$ & C \\
\hline $\begin{array}{l}\text { Network Tele } \\
\text { Residential } \\
\text { Business }\end{array}$ & $\begin{array}{c}\text { evision } \\
\text { LC } \\
\text { C }\end{array}$ & $\begin{array}{l}\mathrm{C} \\
\mathrm{C}\end{array}$ & $\begin{array}{l}\mathrm{C} \\
\mathrm{C}\end{array}$ & $\begin{array}{l}\mathrm{C} \\
\mathrm{C}\end{array}$ & $\begin{array}{l}\mathrm{C} \\
\mathrm{C}\end{array}$ & $\begin{array}{l}\mathrm{C} \\
\mathrm{C}\end{array}$ & $\begin{array}{l}\mathrm{C} \\
\mathrm{C}\end{array}$ & C \\
\hline
\end{tabular}


TABLE V (Continued)

FORECASTING TECHNIQUE ASSUMPTION FOR SET I--SERVICES

Tech- Govern-

Service
EnergyCompetition

Cost Percent Percent $\underline{\text { Price }}$
Price Income

Elastic. Elastic.

\section{Electronic Library}

Residential C

Business

$\begin{array}{ll}\text { C } & \mathrm{Cl} \\ \mathrm{C} & \mathrm{CL}\end{array}$

C

C

C

C

C

Outpatient Treatment

Residential C

Business

C C

C

C

C

C

C

C

C

Diagnosis

Residential

Business

C

C

C

C

C

C

C

C

C

C

C

C

Emergency Services

Residential C

Business C

C C

C

C

C

C

C

C

C

C

C

Computer Tutoring

Residential C

Business

$\begin{array}{ll}\text { C } & \text { C } \\ \text { C }\end{array}$

C

C

C

C

C

Correspondence

School

Residential C

Business

C C

C

C

C

C

C

C

C

Electronic Meeting

Residential C

Business

C

C

L

L

L

C

C

C

C

C

Electronic Funds

Transfer

Residential

Business

C C

C

C

C

C

C

C

C

Message Recording

Residential $L$

Business

$\begin{array}{ll}\mathrm{C} & \mathrm{C} \\ \mathrm{C} & \mathrm{C}\end{array}$

C

C

C

C

C

Call Forwarding

Residential L

Business

$\begin{array}{ll}c & C \\ \text { C } & \text { C }\end{array}$

C

C

C

C

C 
TABLE V (Continued)

\section{FORECASTING TECHNIQUE ASSUMPTION FOR SET I--SERVICES}

\begin{tabular}{|c|c|c|c|c|c|c|c|c|}
\hline Service & $\begin{array}{l}\text { Tech- } \\
\text { nology }\end{array}$ & $\begin{array}{l}\text { Govern- } \\
\text { ment }\end{array}$ & Cost & $\begin{array}{l}\text { Energyx } \\
\text { Percent }\end{array}$ & $\begin{array}{l}\text { ompetitio } \\
\text { Percent }\end{array}$ & Price & $\begin{array}{c}\text { Price } \\
\text { Elastic. }\end{array}$ & $\begin{array}{l}\text { Income } \\
\text { Elastic. }\end{array}$ \\
\hline \multicolumn{9}{|c|}{ Video Conferencing } \\
\hline Residential & $\mathrm{L}$ & C & C & C & C & C & C & C \\
\hline Business & $\bar{L}$ & $\mathrm{C}$ & C & C & C & C & C & \\
\hline \multicolumn{9}{|c|}{ Appointment Calendar } \\
\hline Residential & C & C & C & C & C & C & C & C \\
\hline Business & C & C & C & C & C & C & C & \\
\hline \multicolumn{9}{|c|}{ Data Base Access } \\
\hline Residential & $\mathrm{C}$ & C & $\mathrm{C}$ & C & C & C & C & C \\
\hline Business & C & C & C & C & C & C & C & \\
\hline \multicolumn{9}{|c|}{ Word Processing } \\
\hline Residential & $\mathrm{C}$ & C & $\mathrm{L}$ & C & C & C & C & C \\
\hline Business & $\mathrm{L}$ & $\mathrm{C}$ & $\mathrm{L}$ & C & C & C & $\mathrm{C}$ & \\
\hline \multirow{2}{*}{\multicolumn{9}{|c|}{$\begin{array}{l}\text { Computer-To-Computer } \\
\text { Communications }\end{array}$}} \\
\hline & & & & & & & & \\
\hline Residential & C & C & $\mathrm{L}$ & C & C & C & C & C \\
\hline Business & $\mathrm{L}$ & C & L & C & C & C & C & \\
\hline
\end{tabular}


TABLE VI

FORECASTING TECHNIQUE ASSUMPTION FOR SET I--TERMINAL EQUIPMENT

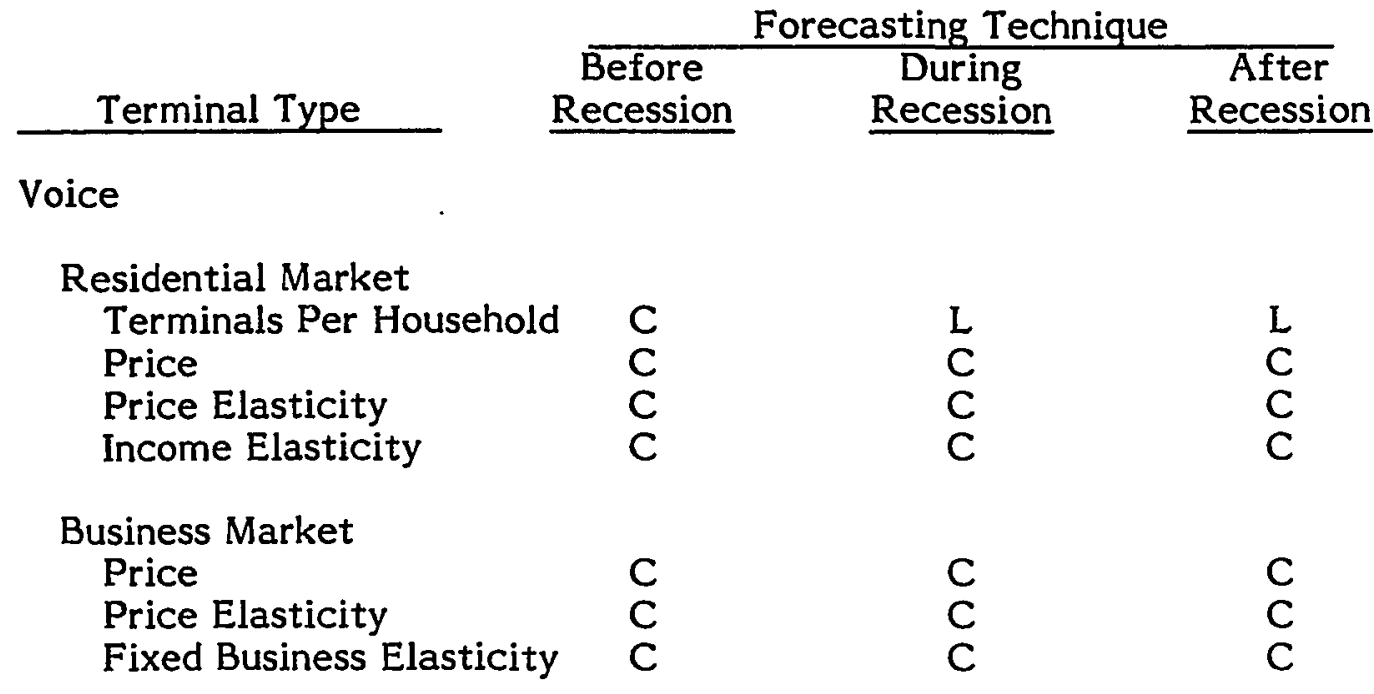

Data

Residential Market

Terminals Per Household

Price

Price Elasticity

Income Elasticity

C

C

C

L

C

C

L

C

C

C

Business Market

Price

Price Elasticity

Fixed Business Elasticity

C

C

C

C

C

C

Video

Residential Market Terminals Per Household Price Price Elasticity Income Elasticity

C

C

C

L

C

L

C

C

C

Business Market

Price

Price Elasticity

C

C

Fixed Business Elasticity

C

C

C

C

C 


\section{ASSUMPTION SET II--MODEST GROWTH}

The assumptions in this set reflect a middle-of-the-road outlook. The future will be devoid of any major wars, famines, or periods of exceptional prosperity. Socially, efforts will be made to maintain the status quo. The demographic factors (birth, death, divorce rates, etc.) will remain at their current levels. Although comsumers will want more sophistication, the demand will be modest. Moreover, it will favor enhancements in existing services, as opposed to demanding radically new services.

Both the economy and energy costs will grow. Fixed business investment and disposable income will grow at rates slightly below the current trends. Energy, on the other hand, will grow at a slightly higher rate.

Congress will rewrite the 1934 Communications Act. The rewrite will selectively deregulate portions of the network. The rewrite will also make it possible for most of the services to be implemented. It will also foster competition in the deregulated areas. As a general rule, services in the deregulated area will grow faster than those still regulated.

and complete list of the assumptions and an analysis of their impacts is given in the following sections.

\section{General Assumptions}

The assumptions described in this section are applicable to all services and terminals. These assumptions are listed below.

\section{Economy}

- Mild growth will continue through the end of the century. There will be no recessions or excessive growth periods. 
- Disposable income will grow at a rate of $\$ 45$ per year.

- $\quad$ Fixed business investment will grow at an annual rate of $\$ 20$ trillion.

- The percentage of information handlers will grow by .1 percent per year.

\section{Energy}

- The price of energy will continue to rise.

- $\quad$ Energy costs will reduce the migratory trend to the suburbs.

- Energy saving services will, in general, have faster implementation rates.

\section{Social Change}

- The population will continue to grow at an annual rate of 2.2 million.

- The divorce rate will remain at 6 percent of the population.

- The number of children per household will stay at 1.5 .

- Dwelling size will not change.

- Migration from the central cities will drop to zero (and remain there) by 1990.

- Consumers will demand more sophistication.

\section{Govermental Regulations}

- The 1934 Communications Act will be rewritten.

- Competition (wherever possible) will be used to regulate the industry.

- The local loop and central offices will remain regulated.

- Interexchange and terminal markets will be deregulated.

- Regulated services will be priced low.

In this assumption set, the primary assumptions are social. The author has assumed the society will not want any significant changes. Most people will feel their life-styles are comfortable. They will not want to change. As a result, 
efforts will be made to maintain the status quo. All the social parameters (divorce rate, etc.) will remain at their current levels, with the exception of migration. It is assumed the migration will dwindle to zero by 1980 . The price of energy plays a role here. Energy will continue to be more expensive. The cost of commuting will rise to the breakeven point. Those living in the central cities will feel the benefit of living in the suburbs will be counteracted by the cost of transportation. As a result, they will stay in the central cities.

The economy will continue to modestly grow. Fixed business investment and disposable income will grow at $\$ 20$ trillion and $\$ 45$ per year, respectively. The income per household will grow at a rate slightly less than the recent past. This reflects a slowdown in the number of additional incomes per household. Recall in the previous assumption set, many wives were assumed to enter the work force. In this set, the assumption is that most of these people are already in the work force. Those that are not will remain in the home. Thus, the disposable income per household will not grow due to additional incomes.

Fixed business follows a similar growth pattern. Consumers will spend modestly (due to their social outlook and disposable incomes), resulting in modest demand. This, in turn, will keep business growth modest.

The 1934 Communications Act rewrite will address the interexchange and terminal portions of the network. It is assumed these will be completely deregulated. An access charge will be established as a replacement for division of revenues. This is necessary in order to maintain universal service. Recall rural investment is quite high and had to be subsidized by division of revenues. The new mechanism will most likely have a fixed connection charge plus some type of usage charge. 
The local loop and central offices will remain regulated. This is necessary in order to meet the universal service mandate. The rewrite will also keep the rate of return reward system intact.

Terminal equipment will be completely deregulated. Anyone will be able to connect any terminal to the network as long as it meets certain electrical standards.

The rewrite will not address broadcasting. This is due to the divergent points of view between broadcasters, CATV, and telephone companies. However, competition will be encouraged through the FCC.

Within the network, the local loop and exchanges will continue to evolve as they have in the past, with one exception; wide-band capacity will be introduced.

Although wire will continue to dominate the local loop, there will be a move towards fiber optics. In urban (and suburban) centers, worn-out wire will be replaced by fibers. This, however, will be a slow process due to the extremely long life (50 years) of wire. Most of the growth in fibers will be due to new construction and increased corporate demands. Corporations will rely more and more on telecommunications as a replacement for travel. They will also have larger data transmission needs. It is interesting to note that this is one of the ironies of partial deregulation. It is, in fact, competition that will stimulate the telephone companies to introduce wide-band capacity. Although the local loop is a monopoly, private communications systems can provide end-to-end communications. If the telephone companies do not provide wide-band capacity, the private systems will.

It is important to note that this only holds true for the business market; residential customers will not have wide-band through the telephone companies.

In addition to the wide-band capacity, most of the central offices will be electronic by the end of the century. However, the central offices will not engage 
in any type of data processing. It is assumed the rewrite will not allow telephone companies to process data in their exchanges. This would give them an unfair advantage. They will, however, offer many expanded services. Call forwarding and automatic answering will be very prevalent. Automatic answering will be a necessity in many households. It is necessary because customers may have the lines tied up for long periods of time, while using services such as electronic newspapers or electronic games. The computer at the central office will tell the calling party the line is busy and ask for a message. Some computers will even interrupt the electronic game to let the subscriber know he has a call.

The interexchange portion of the network will grow faster than the regulated portion. New carriers will emerge, providing both voice and enhanced nonvoice. There will also be data processing companies which will work through carriers to provide teleprocessing. These companies will not provide communications, only data processing.

Outside the network, private systems will also develop. These are described in the next section.

\section{Technological Assumptions}

As a general rule of thumb, the technologies which improve existing services will be more prevelant than those that offer new services. This follows from the social assumptions. Consumers, in their effort to maintain status quo, will demand improvements of existing offerings over new services.

Listed below is a specific analysis of each technology.

Satellites. In that this technology can be used extensively to enhance existing services, it will have a moderate growth. The most common uses will be interexchanged communications and CATV distribution. Some larger corporations 
will use satellites for private communication networks. This, however, will be limited due to the high cost.

Electronic Publishing Technology. The services provided by this technology are new. Thus, the implementation will be low. This is somewhat contradictory in that most of the technology is already in place. What is missing is the origination computers. It will be these machines which will have a low implementatin rate.

Digital Transmission. By the end fo the century, all transmission will be digital, with the exception of portions of the local loop. This technology, due to its distortion-free characteristic, will enhance existing services. Thus, it will be in high demand. By the late 1980s, all interexchange transmission will be digital. The conversion within the central offices will take a few years longer. This rate is dependent upon the conversion to electronic switches (see below). Most of the local loop will remain analog, this is due to the replacement cost (and long life) of wire.

Packet Switching. Packet switching will undergo the most dramatic growth of all the technologies. Due to its low cost (compared to long distance), businesses will rely upon it for computer-related communications. The demand in the residential market, on the other hand, will be quite small. Most households will not be involved in data processing.

Another factor driving up the implementation rate is the telephone companies. They will view this as a less expensive means of increasing their capacity. Recall, more data can be transmitted per second using packet switching than over ordinary telephone lines.

Transmission Media. This area will have growth in fiber optics and coaxial cable. Fibers will replace almost all interexchange wire by the early 1990 s. Most larger corporations will have fibers directly to their premises. Fibers will be 
implemented in the local loop on a replacement basis. This will keep the implementation rate low.

Coaxial cable will continue to be used by CATV companies. Since this is an integral part of the CATV technology, it will be discussed in that section. The other media (lasers, waveguides, wire, and microwave) will not have significant implementation.

CATV. This technology will continue its current implementation rate. By the late 1980s, virtually every household will be connected to the system. Only a few rural customers will not have service, in that this technology is used to provide a primary residential service, the business demand will be minimal.

Cellular Mobile System. This system will be implemented on a very limited basis. It will be located only in metropolitan centers. Business will be exclusive users of this technology. Residential consumers will view this as too much sophistication and, hence, not demand it.

Electronic Switches. These switches will be implemented on a replacement and growth basis. All new switches will be electronic. In addition, old switches which will be upgraded or replaced will have electronic technology for its replacement. The conversion will be completed by the end of the century.

\section{Service Assumptions}

The specific assumptions for each service are listed below.

Electronic Newspaper. This service, like most of the others, fall into the new category; therefore, its growth will be moderate. The residential market assumptions are: starting at 0 , technology will reach 100 percent by the end of the century; government 1 ; and cost will increase 10 percent each year. Energy will not have an effect until the 1990s; then, it will increase to 10 percent a year. 
Competition, on the other hand, will have its impact in the 1980s. It will start at .5 and decline to 0 by the end of the decade.

Price will decline as implementation becomes large enough to capitalize on economies of scale. It will start at $\$ 15$ per month, eventually dropping to $\$ 10$. Price elasticity will follow a similar pattern. As the service becomes more common, it will become part of the norm. When this happens, consumers will try to maintain it (demand) as part of the status quo. Initially, price elasticity will be -5 , dropping to -.75 by 1995 . It will remain constant thereafter. Income elasticity will follow a similar pattern. Starting at 4 , it will drop to .5 .

The business market will have a much higher price elasticity, resulting in lower demand. It is assumed that most businesses will not view newspaper subscription as necessary to the company operations. The elasticity will remain constant at 5. All other assumptions are the same as the residential market.

Electronic Mail. Due to governmental indecision, this service's implementation will be delayed. Congress will not approve it until 1986. The residential assumptions are: technology and cost will both grow to 1 by 1990; and government 0 prior to 1986,1 thereafter. Energy will not have an impact until the 1990s. Then, it will increase to 10 percent a year. In that this is a governmental service, competition will not be allowed.

The price will start at $\$ 1$ per letter, dropping to $\$ .50$ by 1995 . Price elasticity will drop from -6 to -.75 . Income elasticity will follow a similar pattern starting at 5 and dropping to .5 .

The price elasticity will be lower in the business market. Starting at -2 , it will drop to -.25 by 1990 . This reflects the business market's need for rapid delivery and ability to absorb slightly higher costs. All other assumptions are the same for both markets. 
Travel Reservations. This service will be implemented in the business, but not resident, market. Consumers will want to continue to go to travel agencies as opposed to doing it themselves. The business market assumptions are: technology increase by .1 each year; goverment 1 ; and cost increase by .2 each year. Both energy and competition will be 0 . Price will be $\$ 5$ per reservation, dropping to $\$ 1$ by 1990 . Price elasticity will remain at -2 .

In the residential market, technology will be 0 . This reflects the assumption that the service will not be offered. All other assumptions are the same. In addition, income elasticity will drop from 4 to 2 .

POTS. This will continue to be as it has in the past--the mainstation of telecommunications. All the implementation variables (technology, government, and cost) will remain at 1 . Energy and competition will be 0 . Price will drop from $\$ 15$ per month to $\$ 10$. Price and income elasticities will be -.2 and .02 , respectively. These assumptions apply to both markets.

Cellular Mobile System. Due to the high cost, this service will be implemented only in the business market. The business assumptions are: technology .05 increase per year; government 1; and cost will grow at a rate of .02 per year. Both energy and competition will remain at 0 . Price will decline from $\$ 100$ per month to $\$ 50$. Price elasticity will remain constant at -1 . The cost variable in the residential market will be 0 . All other assumptions are the same. Income elasticity will be .5 .

Consumer Advisory Service. Being predominantly a consumer service, this will be implemented only in the residential market. The specific assumptions are: technology will reach .75 by the end of the century; government 1; cost 1; energy 0 ; and competition will start at .5 and dwindle to 0 by 1990 . The price will 
start at $\$ 25$ per month and decline to $\$ 5$ by 1990 . Price elasticity will remain at -2. Income elasticity will be 1.5 .

Within the business market, the technology variable will be 0 . All other assumptions are the same.

Video Library. This service will be offered to consumers in metropolitan centers (and suburbs--see CATV assumption). It will be available, but not demanded, in the business market. The specific residential assumptions are: technology will increase to .8 by 1990 ; government 1 ; and cost will increase by .1 a year. Energy will increase implementation, but not until the 1990s. Prior to 1990 , it will be 0 , thereafter it will increase by .02 per year. Competition will be influential during the $1980 \mathrm{~s}$. It will increase to .5 by 1985 , then drop to 0 by 1990 .

The initial price will be high, $\$ 20$ per movie; this, however, will drop to $\$ 10$ by 1990 . Both elasticities will follow the same pattern as the price. Initially, the price and income elasticities will be -2 and 1.5, respectively. By 1990, they will drop to -1 and .5 .

The demand in the business market will essentially be zero. Ths is reflected in the price elasticity $(2,000)$. All other assumptions are the same.

Restaurant Guide. Contrary to what one might think, this service will have a greater demand in the business market. Due to its newness, consumers will shy away from it. Business, on the other hand, will view it as an excellent tool for arranging luncheons, banquets, as well as business lunches and dinners. The business market assumptions are: technology will reach 1 by 1990 ; government 1; and cost will increase by .2 a year. Neither energy nor competition will have an effect. Price will be $\$ 1$ per reservation, dropping to $\$ .50$ by 1990 . The price elasticity will remain at .5 . 
Within the residential market, the price elasticity will be -500 . Income elasticity will be 100. All other assumptions are the same as above.

Video Games. This is totally a residential service. The specific assumptions are: technology will increase by .1 a year; government 1 ; and cost will rise to .8 . Energy will not impact implementation. Competition will start at .4 and decline to 0 by 1988 . The price will start at $\$ 3$ per hour, dropping to $\$ .50$. Price elasticity will remain constant at -1.5 . Income elasticity will be 1 . Price elasticity for the business market will be $-2,000$. All other assumptions are the same.

Network Television. This, like video games, is a residential service. Its implementation is keyed to CATV. Recall, CATV will be distributing this service. The specific assumptions are: technology will increase to 1 by 1990 ; government 1 ; cost increase by .2 per year; and energy will be 0 prior to $1990, .2$ thereafter; and competition 0. The price will start at $\$ 25$ per month, dropping to \$5 by 1988 . Price elasticity will remain constant at -1 . Income elasticity will be .8 . The price elasticity in the business market will be $-2,000$.

Electronic Library. Institutions will be the primary users of the service. Universities, research groups, etc., have already begun to use preliminary versions of this in the form of computerized literature search. The business market assumptions are: technology will increase by .02 each year; government 1 ; and cost will increase by .04 each year. Energy and competition will both be 0 . Price will start at $\$ 25$ per hour and drop to $\$ 50$. Price elasticity will be -.75 . In the residential market, the price elasticity will be -100 . Income elasticity will be 75 .

Outpatient Treatment. This service will be rather expensive in that specialized "hardware" is required. Monitors will be needed as well as a data or voice terminal. The price will keep implementation and demand low. The residential assumptions are: technology will grow to 1 by 1990; government 1; and 
cost will grow to .5 by 1990 . Energy will be 0 prior to 1990 ; thereafter, it will increase by .02 éach year. Competition will be 0 . The price will be quite high. Initially, it will be $\$ 50$ per hour. This will eventually drop to $\$ 10$ per hour. Price elasticity of demand will remain at -3 . Income elasticity will be 5 .

This service will not be implemented in the business market. The price elasticity (reflecting this assumption) will be $-2,000$.

Diagnosis. Due to the high implementation cost, this service will have a very limited implementation. Moreover, due to its nature, it will only be implemented in the business market. The specific assumptions are: technology will increase by .02 each year; government 1 ; and cost will increase by .01 each year. Both energy and competition will be 0 . Price will be $\$ 1,000$ per hour, dropping to $\$ 500$ by the end of the century. Price elasticity will be -7 .

In the residential market, the price elasticity will be $-2,000$. Income elasticity will also be high, 1,500 .

Emergency Services. This, like the previous service, will have a limited implementation due to the high cost. The specific assumptions for the business market are: technology will increase by .02 each year; goverment 1 ; and cost will increase by .01 each year. Both energy and competition will be 0 . Price will be $\$ 1,500$ per hour, dropping to $\$ 1,000$ by 1990 . Price elasticity will be -8 .

The price elasticity in the residential market will be quite high, $-2,000$. Income elasticity will be 1,500 .

Computer Tutoring. This service will have a limited demand in the residential market. Businesses, on the other hand, will view this as an expedient way to train new employees. The difference between the two assumptions are in the elasticities. The residential price elasticity will be -8 . The business elasticity will be -2. All other assumptions are: technology will increase to .8; 
government 1; and cost will increase to .75. Energy and competition will be 0 . The price will drop from $\$ 20$ per hour to $\$ 2$. Income elasticity will remain at 6 .

Correspondence School. During the 1980s, this (like the other educational services) will have limited demand. With the increased cost of gasoline during the 1990s, however, this trend will reverse. Students will find the transportation cost of going to school will alter their attitudes toward educational services. The residential assumptions are: technology will increase .8; government 1; and cost will increase to .75 . Energy will be 0 prior to 1990 . Thereafter, it will increase by .03 each year. Competition will be 0 . The price will start at $\$ 100$ per credit hour, dropping to $\$ 10$. Price elasticity will also start high $(-7)$ and drop (-.75). Income elasticity will drop from 6 to 2.

The business market will not utilize this service to the same extent. The price elasticity will remain constant at -7 .

Electronic Meetings. The business market, especially the academic sector, will demand this service. Residentially, it will not be significant. The dominant factor is energy. Increased fuel cost will drive up the cost of transportation. This, in turn, will stimulate companies to seek alternatives. This service is a prime candidate. The specific business assumptions are: technology will increase to 1 by 1995; government 1; and cost will reach 1 by 2000 . Energy will increase by .05 each year. Competition will increase to .4 by 1990 , then decline to 0 . The price will start at $\$ 20$ per hour and drop to $\$ 2$. Price elasticity will start at -10 and drop to -4 . Income elasticity will remain at 6 . The residential price elasticity will also remain constant $(-50)$. All other residential assumptions are the same as above.

Electronic Funds Transfer. This service will be impacted by governmental regualtions. It is assumed that state and local banking laws will inhibit implementation. The specific assumptions are: technology will increase by .05 
each year; government will start at .3 and increase by .01 each year; and cost will be .8. Energy will remain at 0 . Competition among banks will increase implementation by 10 percent each year. Price will be quite low, $\$ .02$ per transaction. Price elasticity will start at -8 adn drop to -1.5 . Income elasticity will remain at 5 . The assumptions are applicable to both markets.

Message Recording. This will be one of the mose demanded services in this set. The assumptions, applicable to both markets, are: technology will increase by .05 each year and government and cost will be 1. Energy and competition will both be 0 . Price will remain at $\$ 200$ per month. Both price and income elasticities will be inelastic, -.75 and .5 , respectively.

Call Forwarding. This, like message recording, will be in high demand. The assumptions are: technology will increase by .05 each year and government and cost 1. Both energy and competition will be 0 . Price will remain at $\$ 1.50$ per month. Price and income elasticities will be -.8 and .6 , respectively.

Video Conferencing. Due to the implementation cost, this service will only be demanded by larger corporations. The residential market will not demand it at all. The business assumptions are: technology will increase by .01 each year; governement 1; and cost will increase by .005 each year. Energy will tend to increase the demand. Recall, this service is a substitute for travel. Energy will increase by .01 each year. Competition will remain at 0 . Price will be $\$ 1,000$ per hour. Price elasticity will remain high $(-7)$. In the residential market, the price elasticity will be -500 . Income elasticity will be slightly lower, 250 . All other residential assumptions are the same as above.

Appointment Calendar. This service will have a modest demand. The assumptions for both markets are: technology will increase by .01 each year; government 1; and cost will increase by .1 each year. Both energy and competition 
will be 0 . Price will be $\$ 10$ per month. Price and income elasticities will be -6 and 5 , respectively.

Data Base Access. Many companies will share some of their data. Buyers, for example, will be able to transmit directly to the seller's computer system, speeding up the processing time. Most industry associations will develop data bases of industry averages. Each company's computers will provide data and retrieve averages. Nationwide data bases and access to any company data base will be offered. Corporations will not share their "sensitive" data. Moreover, the government will prohibit the release of data on individuals. Congress will maintain this is a violation of privacy.

The assumptions are: technology will increase to .1; government .3; cost .5; energy 0 ; competition 0 ; price $\$ 50$ per month; elasticity -8 ; and income elasticity 7.

Word Processing. This will become very common in the business market. Almost every company will use some form of it. The specific assumptions are: technology will eventually reach 1; government 1; cost will increase to .8; energy 0 ; competition 0 ; cost $\$ 1$ per page; and price elasticity -6 , dropping to -.5 . Within the residential market, the services will be offered on a very limited basis. This is reflected in the technology variable (.005). Income elasticity will be 6 . All other assumptions are the same as above.

Computer-To-Computer Communications. This service will greatly expand. The assumptions are: technology will increase by .2 each year; government 1 ; cost will increase by .15; energy 0 ; competition 0 ; price starting at $\$ 1,000$ per hour, it will drop to $\$ 100$ by 1990 ; and price elasticity -.9. The residential market will not be offered this service. The technology variable will be 0 . Income elasticity will be 8 . All other assumptions are the same as above. 
Terminal Equipment Assumptions

This section delineates specific assumptions about terminals. These assumptions are primarily about price and elasticities.

Voice Terminals. These will continue to remain the mainstay of the telecommunications market. Every household and business will have voice terminals. The residential assumptions are: maximum of 5 terminals per household; price will remain at $\$ 35$; price elasticity -.01 ; and income elasticity .02 . Within the business market, the price will be higher, $\$ 100$ each. Fixed business investment elasticity of demand will be low (.02).

Data Terminal. This terminal type will substantially grow in both markets. The specific assumptions are: 5 terminals per household; price $\$ 500$ each; price elasticity starting at -3 , dropping to -.7 by 1990 ; income elasticity 2 ; and fixed business investment elasticity will start at 2 and drop to .5 by 1990 .

Video Terminals. The demand will be lower than data terminals. This is a result of service demand. Recall, there are many more data services than video. In addition, data services had a higher demand. The specific assumptions are: 5 terminals per household; price $\$ 1,500$ per terminal; price elasticity -6 ; income elasticity 5; and fixed business elasticity of demand start at 4, drop to 1 by 1990 .

\section{Forecasting Technique Assumptions}

Within this set, a variety of different techniques are used. The specific techniques are listed in the following tables. 
TABLE VII

FORECASTING TECHNIQUE ASSUMPTIONS FOR SET II--GENERAL

Variable

Disposable Income

Fixed Business Investment

Information Handlers

Population

Children Per Household

Divorce Rate

Dwelling Size

Migration

*C--Constant

E--Exponential

L--Linear

S--Logistics (S) Curve
Forecasting Technique

L*

L

L

L

C

C

C

S 
TABLE VIII

FORECASTING TECHNIQUE ASSUMPTIONS FOR SET II--SERVICES

Tech- Govern-

$\underline{\text { Service }}$ nology ment

EnergyCompetition

Percent Percent Price
Price Income

Elastic. Elastic.

Electronic

Newspaper

Residential $S$

Business $\quad \mathrm{S}$

C

C

C

S

S

$\mathrm{S}$
$\mathrm{S}$

$\mathrm{S}$

Electronic Mail

Residential S

Business

C S

C S

S

C S

C S

S

Travel Reservations

Residential r.

Business

L

C

L C

C

C

C

S

$\mathrm{S}$

C

C

S

POTS

Residential C

C c

C

C

L

C

C

Business C

C

C

C

C

Cellular Mobile

System

Residential L

Business

L

C

C

C

$\begin{array}{ll}\text { C } & \text { L } \\ \text { C }\end{array}$

C

C

Consumer Advisory

Service

$\begin{array}{lllllllll}\text { Residential } & \text { S } & \text { C } & \text { C } & \text { C } & \text { S } & \text { S } & \text { C } & \text { C } \\ \text { Business } & \text { C } & \text { C } & \text { C } & \text { C } & \text { S } & \text { S } & \text { C } & \end{array}$

Video Library

Residential

Business

$\begin{array}{ll}C & \text { L } \\ \text { C } & \text { L }\end{array}$

CL

$\mathrm{CL}$

CL

S

S

S

Restaurant Guide

Residential S

Business C

$\begin{array}{ll}\text { C } & \text { L } \\ \text { C } & \text { L }\end{array}$

C

C

$\mathrm{S}$
$\mathrm{S}$

C

C

Video Games

Residential

Business

C S

C $\quad$ S

$\mathrm{S}$
$\mathrm{S}$

C

C

Network Television

$\begin{array}{ll}\text { Residential } & \text { S } \\ \text { Business } & \text { C }\end{array}$

C L

C

C

C

S

C

C

C 
TABLE VIII (Continued)

FORECASTING TECHNIQUE ASSUMPTIONS FOR SET II--SERVICES

\begin{tabular}{|c|c|c|c|c|c|c|c|c|}
\hline Service & $\begin{array}{l}\text { Tech- } \\
\text { nology }\end{array}$ & $\begin{array}{l}\text { Govern- } \\
\text { ment }\end{array}$ & Cost & $\begin{array}{l}\text { Energy } \\
\text { Percent }\end{array}$ & $\begin{array}{l}\text { ompetitio } \\
\text { Percent }\end{array}$ & Price & $\begin{array}{c}\text { Price } \\
\text { Elastic. }\end{array}$ & $\begin{array}{l}\text { Income } \\
\text { Elastic. }\end{array}$ \\
\hline \multicolumn{9}{|c|}{ Electronic Library } \\
\hline Residential & $1 \mathrm{~L}$ & C & L & C & C & $\mathrm{S}$ & C & C \\
\hline Business & C & C & $\mathrm{L}$ & C & C & $\mathbf{s}$ & C & \\
\hline \multicolumn{9}{|c|}{ Outpatient Treatment } \\
\hline Residential & 15 & $C$ & $\mathbf{S}$ & $\mathrm{CL}$ & C & $\mathrm{S}$ & C & C \\
\hline Business & $\mathbf{S}$ & C & $\mathrm{S}$ & $\mathrm{CL}$ & C & $\mathrm{S}$ & C & \\
\hline \multicolumn{9}{|l|}{ Diagnosis } \\
\hline Residential & L & C & L & C & C & $\mathrm{S}$ & C & C \\
\hline Business & $\bar{L}$ & C & $\bar{L}$ & C & C & $\mathrm{s}$ & $\mathrm{C}$ & \\
\hline \multicolumn{9}{|c|}{ Energency Services } \\
\hline Residential & $1 \quad \mathrm{~L}$ & C & $\mathbf{L}$ & C & C & $\mathrm{S}$ & C & C \\
\hline Business & $\mathrm{L}$ & C & $\mathrm{L}$ & C & C & $\mathrm{S}$ & C & \\
\hline \multicolumn{9}{|c|}{ Computer Tutoring } \\
\hline Residential & $1 \mathrm{~S}$ & C & $\mathbf{S}$ & C & C & $\mathrm{S}$ & C & C \\
\hline Business & $\mathrm{S}$ & C & $\mathrm{S}$ & C & C & $\mathrm{S}$ & C & \\
\hline
\end{tabular}

Correspondence

School

$\begin{array}{lllllllll}\text { Residential } & \text { S } & \text { C } & \text { S } & \text { CS } & \text { C } & \text { S } & \text { S } & \text { S } \\ \text { Business } & \text { S } & \text { C } & \text { S } & \text { CS } & \text { C } & \text { S } & \text { C } & \end{array}$

Electronic Meeting

Residential S

Business $\mathrm{S}$

$\begin{array}{ll}\mathrm{C} & \mathrm{S} \\ \mathrm{C} & \mathrm{S}\end{array}$

$\begin{array}{ll}L & S \\ L & S\end{array}$

$\begin{array}{ll}S & S \\ S & S\end{array}$

C

Electronic Funds

Transfer

$\begin{array}{lllllllll}\text { Residential } & \text { L } & \text { L } & \text { C } & \text { C } & \text { C } & \text { C } & \text { S } & \text { C } \\ \text { Business } & \text { L } & \text { L } & \text { C } & \text { C } & \text { C } & \text { C } & \text { S } & \end{array}$

Message Recording

Residential L

Business

L

C C

C C

C C

C

C

C

C

Call Forwarding

Residential L

Business

$\begin{array}{ll}\mathrm{C} & \mathrm{C} \\ \mathrm{C} & \mathrm{C}\end{array}$

C

C

C

C

C 
TABLE VIII (Continued)

FORECASTING TECHNIQUE ASSUMPTIONS FOR SET II--SERVICES

Tech- Govern- EnergyCompetition Price Income Service nology ment Cost Percent Percent Price Elastic. Elastic.

Video Conferencing Residential $\mathrm{L}$

Business

$\begin{array}{lll}\mathrm{C} & \mathrm{L} & \mathrm{L} \\ \mathrm{C} & \mathrm{L} & \mathrm{L}\end{array}$

C

C

C

C

Appointment Calendar

Residential $\mathrm{L}$

Business

$\begin{array}{ll}\mathrm{C} & \mathrm{L} \\ \mathrm{C} & \mathrm{L}\end{array}$

C

C

C

$\mathrm{C}$

C

C

Data Base Access

Residential L

Business

$\mathrm{L}$

C

C

C

C

C

C

C

C

C

Word Processing

Residential

C

C

S

C

C

C

C

C

Business

C $\mathrm{S}$

C

C

C

C

C

Computer-To-Computer

Communications

Residential C

Business I

$\begin{array}{ll}\text { C } & \text { L } \\ \text { C } & \text { L }\end{array}$

C

C

C

$\mathrm{S}$

$c$
$c$

C

\author{
*C--Constant \\ E--Exponential \\ L--Linear \\ S--Logistics (S) Curve
}


TABLE IX

FORECASTING TECHNIQUE ASSUMPTIONS FOR SET II--TERMINAL EQUIPMENT

Terminal Type

Forecasting Technique

Voice

Residential Market

Terminals/Household

Price

Price Elasticity

Income Elasticity

$C^{*}$

C

C

Business Market

Price

Price Elasticity

Fixed Business

C

Elasticity

Data

Residential Market

Terminals/Household

Price

Price Elasticity

Income Elasticity

C

C

Business Market

Price

Price Elasticity

Fixed Business

Elasticity

\author{
C \\ C \\ $\mathrm{S}$ \\ C \\ C \\ S \\ $\mathrm{S}$
}

Video

Residential Market

Terminals/Household C

Price

Price Elasticity

C

Income Elasticity

C

C

Business Market

Price

Price Elasticity

Fixed Business

Elasticity

*C--Constant

E--Exponential

L--Linear

S--Logistics (S) Curve

C

C

$\mathrm{S}$ 


\section{ASSUMPTION SET III--EXPONENTIAL GROWTH}

The assumptions in this set are similar to those of forecasters outside the industry; e.g., Martin (1978), Martino (1979), and Straussmann (1980). The future, for them, is very robust. It is loaded with high technology, services, ang gadgets. Martin, for example, predicts a "wired society" with every member having access to a plethora of exotic services. Satellites, cellular mobile systems, and video conferencing will all be common.

In order to achieve this state of high technological growthj will have to be exponential. Most social and economic variables will grow exponentially. Life styles will become more technologically demanding. High technology will be "in." Within the industry, corporations will scramble to provide the high technology, each trying to out do the others.

Congress will give the industry a boost by deregulation. The 1934 Communications Act will be repealed. The FCC will be abolished. State regulators will follow the federal example. They, too, will abolosh their regulations.

\section{General Assumptions}

The assumptions described in this section are applicable to all services and terminals. An analysis follows the list.

\section{Economy}

- The economy will grow at an exponential rate.

- Disposable income will increase at an annual rate of 10 percent.

- $\quad$ Fixed business investment will grow at an annual rate of 15 percent.

- The percentage of information handlers will grow by .01 percent. 


\section{Energy}

New forms of energy will be developed, solving the energy problem.

- Energy will not affect the migratory trend to the suburbs.

- Energy conserving services will not be in demand.

\section{Social Change}

- Life styles will radically change.

- The traditional family unit will break down.

- There will be a substantial increase in the number of single parents.

- The divorce rate will increase by .1 annually.

- The number of children per household will drop to .5.

- Dwelling size will increase by .5 percent annually.

- Population will peak at 235 million.

- Migration from the central cities will accelerate. By 1995, only 5 percent of the total population will reside in the urban core.

- Consumer demand for more sophistication will grow at an exponential rate.

\section{Competition}

- $\quad$ Competition will be stiff.

- Many new services will be implemented due to competitive pressures.

- The implementation rate of most services will be impacted by competition.

\section{Corporate Change}

- Telephone companies will adopt a competitive philosophy.

- Most data processing companies will offer telecommunications hardware. In some cases, the larger companies will also offer services.

- Many new interconnect companies will emerge. The companies will offer services as well as communication channels. 
Forecasting Technique

- As a general rule, growth will be exponential.

\section{Governmental Regulations}

- The telecommunications industry will be completely deregulated.

- The 1934 Communications Act will be repealed.

- The FCC will be disolved.

An exponentially growing positive feedback loop will develop between consumers and corporations. Initially, people will demand higher technology. Corporations, responding to demand, will provide what the customers want. The new level of activity in the business market will provide capital for expansion. Even higher technology services will be offered. Consumers, responding to the new offerings, will consume them and, in turn, demand even greater sophistication. Thus, the loop has become a full circle.

The increase in consumer demand is a reflection of changing life styles. As the society becomes more affluent, it will become more liberal in its values. The traditional family will break down. The divorce rate will increase. There will be a substantial rise in the number of single-parent families. The number of children per household will decline, reflecting a drop in the birth rate. Partents will want fewer children so they can give more to the children they already have. Following this philosophy, many wives will enter the work force. Houses will become larger as more and more people move to the suburbs--where there is "room to roam."

The economy will grow for a variety of reasons. One of the major factors is the increase in consumer demand (described above). Another is energy. It is assumed new technologies will be developed which will eliminate the current energy shortage and reduce the cost. This will make it possible for business to 
expand without fear of brownouts or exorbitant prices. This will also, in effect, raise the disposable income.

Another factor is the availability of money. It is assumed the federal government, in its effort to keep the publich demand for more products satisfied, will keep the cost of money low. This will make money quite available. The government will also affect the overall economy (in a lesser way) by deregulating telephony.

In this set it is assumed both telephony and broadcasting will be completely de:egulated. The 1934 Communications Act will be repealed. The FCC will be abolished. State Commissions will initially oppose the change. They too, however, will eventually remove their regulations.

In order for this to happen, federal and state regulators (and legislators) will have to abandon their current approach to universal service. They will no longer be able to "regulate" universal service. Instead, they will have to let competition and demand be the motivating forces. At the federal level, this move has already begun. In many cases (interexchange and terminal equipment) the FCC has alread introduced competition. As previously stated, their intention was to let competition motivate the telephone companies--not regulations. In this set, it is assumed the Congress will carry this idea into all aspects of telephony. Congress will abolish all Federal regulations and the FCC.

On the state level, there will be an initial reluctance to completely deregulate. This is primarily due to the rural aspect of universal service. Due to the large capital requirement and low revenues, many state commissions will fear rural customers will not be provided telephone services. It is assumed, however, that new technologies will fill the gap. The Carterphone, for example, was 
designed to provide telephone service to oil platforms in the Louisiana Bayou--a service AT\&T would not provide.

It is worth digressing for a moment to note the motivating forces behind the development of these technologies. When the Congress repeals the 1934 Communications Act it will also abolish the division of revenues. This will cut off a major source of revenues for most rural telephone companies. The telephone companies will be forced to increase their rates in order to avoid bankruptcy. In many cases, this increase will be so high customers will not be able to afford a telephone. Moreover, the cost of installing new service (which often involves a crew installing miles of wire) will be out of reach for all but the wealthy. State regulators and telephone companies will encourage the development of new technologies as a solution to this problem. It is assumed that these technologies will be developed. Moreover, they will be more sophisticated and only slightly more expensive.

At this point, the initial reluctance to deregulate will be gone. For as we have seen, the best way to stimulate new technologies (within telephony) is to abolish excessive regulation. State commissions will see themselves as the major obstacle to universal service. Thus, they will be forced to deregulate many areas. Eventually, state legistatures will abolish the state commissions.

In addition to meeting rural needs, competition will significantly impact the implementation rate of many services. Many companies, fearing other corporations will implement their services first, will speed up the implementation rate. This will be especially true for high technology services. In order to meet this competitive challenge, most telephone companies will reorganize into a more competitive structure. 
Technological Assumptions

All of the technologies will be implemented. Those of a sophisticated nature will eventually have a greater implementation. Due to their higher cost, it will take longer to be completely implemented. Each technology is discussed below.

Satellites. This will become one of the most demanded technologies. Interexchange companies will employ them as part of the long-distance network. Broadcasters will lease transponders in order to distribute their programs. In some instances, the programs will be beamed directly to the subscriber. Many corporations will lease transponders as part of their private communications network. CATV companies will also rely heavily upon them.

Electronic Publishing Technology. Both view data and teletext will be in high demand. View data will be especially demanded because of its two-way capability. By the early 1990s, both view data and teletext will be available to every subscriber. Work will also begin on a wide-band view data. This will be implemented in the late 1990 s.

Digital Transmission. By the end of the century, all transmission will be digital. By the mid-1980s, all interexchange transmission will be digitalized. Broadcasting will be completely converted in the early 1990s. The local loop will not be completely converted until the mid-1990s. This is due to the capacity constraint of copper wire. This is further discussed in the transmission media section below.

Packet Switching. By the mid-1980s, all data transmission will be packetized. Improvement will be made to this technology allowing both voice and video to be packetized. This is not to say that these cannot already be used by this technology. However, under the existing circumstances, voice (or video) 
conversations may be delayed or interrupted due to a lost packet or busy circuit. These improvements will be completed by the late 1980s.

Transmission Media. Telephone companies will immediately begin installing fiber optics (as opposed to wire). All new installations will be fibers. Fibers will also replace wire when it is necessary to replace the wire. In some densely populated areas, telephone companies will install fiber cables even though the wire does not need replacement.

CATV companies will also switch to fibers. The change over, however, will be slower. Only new installations will be fibers. Due to the distribution system of CATV, fibers and coaxial cable cannot be mixed (see Background Chapter).

CATV. Implementation of this technology will grow at an exponential rate. By the mid-1980s to late 1980s, virtually every household will be connected. In addition, CATV will begin to connect to businesses. It is in this market that it will install fiber systems. By the mid-1990s, every business will be able to access the CATV system.

CATV will also become two-way. Both residential and business markets will have this capability. This will also allow the system to offer many more services, especially those of a wide-band nature.

Cellular Mobile System. This system will be implemented nationwide. Initially, it will be offered in metropolitan centers. By the early 1990s, it will be available everywhere, except isolated rural areas. The system will be connected to the telephone network.

Electronic Switches. In an effort to keep up with the competition, telephone companies will rapidly replace mechanical switches with wide-band electronic central offices. In many cases, this will occur even though the mechanical switches do not need replacement. 


\section{Service Assumptions}

The assumptions in this section, like those in the General and Technology Sections, will be robust. All of the new services will be implemented. Moreover, they will be implemented at a much faster rate than in Sets I and II (see Forecasting Technique Section).

Due to the assumptions about energy and government, their impact on implementation will be minimal. Unless specifically stated, government will be 1 and energy will be 0 .

The specific assumptions for each service are listed below.

Electronic Newspaper. This service will follow the pattern of most assumptions in this set--exponential growth. Technology and cost will grow at annual rates of .9 and 1 , respectively. Competition will impact implementation in the 1980s. Starting in 1983, competition will be .4. This will decline annually by a rate of .01 . Initially, the price will be $\$ 15$ per month. This will drop to $\$ 10$ by 1990. Price elasticity will start at -8 , increasing to -.5 by 1990 . Income elasticity will follow a similar pattern, starting at 7 and dropping to 6 . These values apply to both markets.

Electronic Mail. This service will be implemented rather rapidly in the business market. Both technology and cost will grow at a rate of 1.75. Competition will be present in the early 1980s. It will start at .5 , dropping to 0 by 1990. Price will begin at $\$ 2$ per letter, dropping to $\$ .20$ by 2000 . Price elasticity will start at -3 and increase to -.25 by 1988 .

The residential market will have a slower implementation rate and higher elasticities. Technology will grow at an exponential rate of .65 . Price and income elasticities will remain constant at -4 and 2, respectively. All other assumptions are the same. 
Travel Reservations. This service will be more prevelant in the business market. The specific assumptions are: Technology and cost will grow at .9 and .7, respectively. Competition will not be prevelant in that it is assumed that the service will be offered by a consortium of travel companies. The price will be nominal, $\$ 1$ per reservation. Price elasticity will be constant at -1 .

The residential market will have a lower implementation rate: Cost will grow at .65. Income elasticity will be 2 . All other assumptions are the same.

POTS. This is one of the few services that will actually decline. The new and more sophisticated services will replace POTS. The specific assumptions are: technology will decline (at a rate of .7); cost will be 1 ; and competition 0 . Price will remain at $\$ 15$ for residences and $\$ 25$ for businesses. Price and income elasticites will change from -.2 and .02 to -3 and 1.5 , respectively.

Cellular Mobile Systems. As a result of the cost of implementation, this service will gradually be implemented. The business market assumptions are: Technology and cost will grow at annual rates of 1 and .7, respectively. Competition will have only a marginal impact, -.01 per year. Price will drop from $\$ 100$ per month to $\$ 50$. Price elasticity will remain constant at -1.5 .

The residential market will have a lower implementation rate. The cost will increase at a rate of .6. Income elasticity will be constant at 4 .

Consumer Advisory Service. This service will be predominantly offered in the residential market. The assumptions are: Technology and cost will both grow at .8 and competition will start at 10 percent, dropping to 0 by 1990 . Price will drop from $\$ 25$ per month to $\$ 10$. Price and income elasticities will change from -5 and 4 to -1 and .5 , respectively.

This service will not be implemented in the business market. Technology will be 0 , all other assumptions will be the same. 
Video Library. This is another residential-only technology, and cost will grow at 2 and 1.5, respectively. Competition will start at .5, declining by .1 each year. Price will drop from $\$ 20$ per movie to $\$ 2$. Price and income elasticities will remain constant at -.9 and 1 , respectively.

Technologies in the business market will be 0 , all other assumptions will be the same.

Restaurant Guide. This service will have a modest growth in both markets. The technology and cost variables will grow at rates of .7 and .65 , respectively. Competition will icrease implementation by 1 percent each year. Price will remain low at $\$ 1$ per reservation. Price and income elasticities will also remain low at -.8 and .9 , respectively.

Video Games. This service, like video library, will have a very rapid implementation in the residential market, while not being implemented at all in the business market. The technology and cost assumptions will grow at 2 and 1.5, respectively. In the business market, technology will remain at 0 . Competition will be quite strong in the 1980 s, starting at .5 , it will drop by .05 each year. Price will also drop from $\$ 20$ per month to $\$ 2$. Price and income elasticities will remain at -.5 and .5 , respectively.

Electronic Library. This service will have a modest exponential growth. Technology and cost will grow at rates of .7 and .8 , respectively. Competition will remain at .1. Price, starting at $\$ 20$ per month will decline at a linear rate of $\$ .50$ per year. Price and income elasticities will also change at linear rates of -.01 and .02 , starting at -2 and 1.5 , respectively.

Outpatient Treatment. This service will also have a modest growth in the residential market. It will not be implemented in the business market. The assumptions are: Technology and cost will grow at .65 and .6 , respectively. In the 
business market, technology will remain 0 . Competition will also be 0 (in both markets). Price will drop from $\$ 50$ to $\$ 5$ per hour. Price and income elasticities will be -1 and 1 , respectively.

Diagnosis. Due to the specialized nature of this service, it will not be implemented in the residential market. In the business market, implementation will be limited. Technology and cost will grow at .55 and .6, respectively. Competition will be constant at .001 . Price will drop from $\$ 1,000$ per hour to $\$ 50$. Price and income elasticities will remain at -.3 and 5 , respectively. Technolgoy will be 0 in the residential market.

Emergency Services. This service, like diagnosis, will not be implemented in the residential market and only modestly in the business market. The assumptions are: Technology and cost will grow at .6 and .55 , respectively. Technology will be 0 in the residential market. Price will drop from $\$ 1,000$ to $\$ 500$ per hour. Price and income elasticities will remain constant at -.8 and 1 , respectively. Competition will be .0001 .

Computer Tutoring. This service will have a modest growth rate. Technology and cost will grow at rates of .5 and .55 , respectively. Competition will remain at .01 . Price wil remain at $\$ 2$ per session. Price and income elasticities will change from -3 adn 2 to -.9 and .8 , respectively. These assumptions are for both markets.

Correspondence School. This service will have a slightly higher usage than computer tutoring. Students will be able to take courses without attending classes. This will allow them the freedom of studying according to their schedule (as opposed to the university's). The specific assumptions are: Technology and growth will grow at rates of .55 and .6 , respectively. Competition will be present in the early years in that universities will view this as an inexpensive alternative to 
classroom lectures. Competition will start at .1 in 1983 and drop by .02 year year. The price will also drop from $\$ 250$ to $\$ 100$ per class (at increments of $\$ 50$ per year). Price and income elasticities will remain constant at -1 and 1 , respectively. This service will not be implemented in the business market. Due to the affluent economy, businesses will send their employees to seminars instead of using this service. Hence, the technology variable will be 0 .

Electronic Meetings. This service will have a substantial growth in the business market. The technology and cost variables will grow at annual rates of 1 and 1.5 , respectively. Competition will start at .1 , declining by .01 each year. Price will start at $\$ 20$ per hour, dropping to $\$ 2$. Price elasticity will follow a similar pattern, starting at -4 , it will increase to -.8 .

This service will not be implemented in the residential market. Technology will be 0 and income elasticity will drop from 4 to 1 .

Electronic Funds Transfer. This service will also have a substantial growth. By 1990, it will be completely implemented. The specific assumptions are: Technology and cost will grow at rates of 1.5 and 1 , respectively. The government, via federal and state banking laws, will tend to hinder the growth somewhat. Government will increase .8 each year. Competition among banks, on the other hand, will speed up implementation. Competition will be .2 per year. Price will drop from $\$ .05$ to $\$ .02$ per transaction. Price and income elasticities will follow similar patters, changing from -3 and 2 to -1 and 1 , respectively. These assumptions hold for both markets.

Message Recording. This service will also be implemented early. The assumptions are: Technology will grow at 2 and 1.5; government 0 ; competition .01 ; price \$2 per month; and price and income elasticities -.9 and .75 , respectively. Again, these are for both markets. 
Call Forwarding. This service, like message recording, will have an early implementation and high demand. The assumptions are: Technology and cost will grow at 2.5 and 3, respectively; government 0 ; competition 0 ; price $\$ .50$ per month; and price and income elasticities -.1 and .8 , respectively.

Video Conferencing. This service will ultimately replace POTS. By the end of the century, all householders will have access. Business will have it earlier. The residential assumptions are: technology and cost .69 and 7, respectively; competition ,05. The price will start at $\$ 1,200$ per month, dropping at an annual rate of $\$ 50$. Price and income elasticities will start at -4 and 5 , changing at annual rates of .15 and .18 , respectively.

The business market will have a faster implementation; technology and cost will grow at rates of 1 and 1.5 , respectively. All other assumptions are the same.

Appointment Calendar. This service will have one of the lowest implementation and demand rates in this set. It is assumed that the inconvenience of going to the terminal and requesting the service will outweigh any benefits. The assumptions are: Technology and cost will grow at .5 and .55 , respectively. Competition will be .01 . Price will remain constant at $\$ 5$ per month. Price and income elasticities will also remain constant at -2 and 3.

Data Base Access. This service will be highly demanded in the business market. Nationwide data bases will be established for many key factors such as stock market statistics, worker productivity, and financial information. Most corporate employees will find a need to access these data bases from time to time.

Within the residential market, there will be a similar demand. Sports statistics, congressional voting records, and weather data will all be available. The specific assumptions (for both markets) are: Technology and cost will grow at 1.5 
and 1 , respectively; competition .1 , price $\$ .50$ per access (dropping to $\$ .02$ ); and price and income elasticities .2 and 1.5 , respectively.

Word Processing. Within the business market, this service will grow very rapidly. All businesses will use some form of word processing. Larger corporations will have their own word processing centers; smaller companies will use the service as an alternative to a stenographer--in some cases, even as an alternative to a secretary. The business assumptions are: Technology and cost will grow at rates of .65 and .7 , respectively. Competition will increase by .1 a year prior to 1985 , thereafter dropping by .05 a year. Price will remain constant at $\$ 1$ per page. Price elasticity will increase from -4 to -.8 .

The residential market will have a much smaller demand. The technology variable will remain at .0001 . Income elasticity will be 2 . All other values are the same.

Computer-To-Computer Communications. This service will also grow very rapidly within the business market. Even though the demand will grow rapidly, the overall implementation will not exceed .5. This is due to the nature of this service. Recall, the basic unit of consumption is the mainstation. Since each management employee will have a mainstation, there will be many more mainstations than computers (and computer-to-computer circuits). Thus, the maximum implementation will be less than other services which each employee can access. The author has assumed, in this set, that the maximum rate will be 50 percent of the maximum number of mainstations. The other assumptions are: Technology and cost will grow at rates of .8 and .9 , respectively. Competition will be .01 . Price will drop from $\$ 1,000$ per hour to $\$ 100$. Price elasticity will increase from -3 to -.75 .

Within the residential market, home computers and offices in the home will 
require this service. It is assumed that the growth rate will be even higher (technology 1.5). The overall implementation, however, will be much lower, .01 . The price will also be lower because the demand will be for slower speeds, less capacity, and lower quality. The price will drop from $\$ 100$ per hour to $\$ 2$. Price elasticity will follow a similar pattern, starting at -8 , increasing to -3 . Income elasticity will remain at 6 .

\section{Terminal Equipment Assumptions}

This section delineates the assumptions about terminals. These assumptions are about price, elasticities, and the number of terminals per household.

Voice Terminals. By the end of the century, this type of terminal will not be used. This follows from the assumptions about POTS being replaced by video adn data communications (see the previous section). This is reflected in increased price (rising from $\$ 35$ to $\$ 70)$ and a decrease in price elasticity $(-.01$ to -10$)$. Income elasticity will remain constant at .02 . The number of terminals per household will also drop from 5 to 1 . This last assumption reflects the consumers' desire to reduce the number of extension voice terminals.

Within the business market, the decline will be even more dramatic. The price will rise from $\$ 100$ to $\$ 300$ and price elasticity will drop from -.-1 to -20 . Fixed business investment will remain at .02 .

Data Terminals. Initially, this type of terminal will have a high demand. However, as wide-band capacity increases, so will the demand for vido terminals. Recall, video terminals have the capabilities of data terminals and more. This increase in video terminal activity will, in turn, decrease the demand for the data type. This trend is reflected in the following assumptions.

Initially, the price will drop. Starting at $\$ 1,500$ per terminal, it will decline at an annual rate of $\$ 100$. This trend will continue until 1990 . From that point on, 
the price will remain constant. Price elasticity will follow a more cyclical pattern, starting at -5 , it will increase -1 by 1990 . Thereafter, it will decrease at an annual rate of 1. Fixed business investment will remain constant at 3 prior to 1990 . Thereafter, it will drop to .8 .

Within the residential market, the patterns will be similar. Price will drop, price elasticity will vary cyclically, and income elasticity will decline. The differences are that the turning points will come earlier. In the business market, for example, it was assumed that the price elasticity increased until 1990. In this market, it is assumed that customers will switch to video terminals earlier. The elasticity, starting at -8 , will increase (at an annual rate of .5) until 1985, thereafter it will decrease to -12 . Income elasticity will remain at 1.5. The number of terminals per household (starting at 5) will increase at an annual rate of .01 prior to 1985. Thereafter, it will decline to 1 (again reflecting the consumers' desire to reduce the number of extension data terminals.

Video Terminals. The demand for this type will grow quite high. Within the residential market, the price will drop from $\$ 1,500$ to $\$ 500$. Price elasticity will increase from -8 to -.3 . Income elasticity will decline slightly from 5 to 4 . The number of terminals per household (starting at 5) will grow exponentially at an annual rate of .04 .

Within the business market, the growth will also be very high. The price will be the same as above. Price elasticity will increase from -6 to -.01 . Fixed business investment elasticity will remain constant at 3.

Forecasting Technique Assumptions

As described inthe introduction to this set, exponential growth plays a key role. Tables $\mathrm{X}, \mathrm{XI}$, and $\mathrm{XII}$ delineate the forecasting technique assumptions. 
TABLE $X$

FORECASTING TECHNIQUE ASSUMPTIONS FOR SET III--GENERAL

Variable

Disposable Income

Fixed Business Investment

Information Handlers

Population

Children Per Household

Divorce Rate

Dwelling Size

Migration

*C--Constant

E--Exponential

L--Linear

S--Logistics (S) Curve
Forecasting Technique
$E^{*}$
E
E
S
$\mathrm{S}$
E
E
SC 
TABLE XI

FORECASTING TECHNIQUE ASSUMPTION FOR SET III--SERVICES

\begin{tabular}{|c|c|c|c|c|c|c|c|c|}
\hline Service & $\begin{array}{r}\text { Tech- } \\
\text { nology }\end{array}$ & $\begin{array}{c}\text { Govern- } \\
\text { ment }\end{array}$ & Cost & $\begin{array}{l}\text { Energyc } \\
\text { Percent } \\
\end{array}$ & $\begin{array}{l}\text { ompetitior } \\
\text { Percent }\end{array}$ & Price & $\begin{array}{c}\text { Price } \\
\text { Elastic. }\end{array}$ & $\begin{array}{l}\text { Income } \\
\text { Elastic }\end{array}$ \\
\hline \multirow{2}{*}{\multicolumn{9}{|c|}{ Electronic Newspaper }} \\
\hline & & 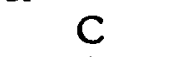 & E & C & L & $\mathrm{S}$ & $\mathrm{S}$ & $\mathrm{S}$ \\
\hline Business & $\mathrm{E}$ & C & $\mathrm{E}$ & C & $\mathrm{L}$ & $\mathrm{S}$ & $\mathrm{S}$ & \\
\hline \multicolumn{9}{|c|}{ Electronic Mail } \\
\hline Residenti & al E & C & $\mathrm{E}$ & C & $\mathbf{S}$ & $\mathrm{S}$ & C & C \\
\hline Business & E & C & $\mathrm{E}$ & C & $\mathrm{S}$ & $\mathrm{S}$ & $\mathrm{S}$ & \\
\hline \multicolumn{9}{|c|}{ Travel Reservations } \\
\hline Residenti & al E & C & $\mathrm{E}$ & C & $\mathrm{C}$ & $\mathrm{C}$ & C & C \\
\hline Business & $\mathrm{E}$ & C & $\mathrm{E}$ & C & C & $\mathrm{C}$ & $\mathrm{C}$ & \\
\hline \multicolumn{9}{|l|}{ POTS } \\
\hline Residenti & E & C & C & C & C & C & $\mathrm{S}$ & $\mathrm{S}$ \\
\hline Business & $\mathrm{E}$ & C & C & C & C & C & $\mathrm{S}$ & \\
\hline
\end{tabular}

Cellular Mobile

Systems

Residential E

Business $E$

E $\quad C \quad E \quad C$

C S

C $\quad \mathrm{C}$

Consumer Advisory

Service

$\begin{array}{lllllllll}\text { Residential } & \text { E } & \text { C } & \text { E } & \text { C } & \text { S } & \text { S } & \text { S } & \text { S } \\ \text { Business } & \text { C } & \text { C } & \text { E } & \text { C } & \text { S } & \text { S } & \text { S } & \end{array}$

Video Library

Residential E

Business $\mathrm{C}$

C $\mathrm{E}$

$\stackrel{\mathrm{C}}{\mathrm{C}}$

$\stackrel{L}{L}$

S

C

C

Restaurant Guide

Residential

Business E

C $\quad$ E

$\mathrm{C}$

C

C

C

C

Video Games

Residential E

Business

E C

C E

E

C

$\mathrm{CL}$

LC

C

C

Network Television

Residential $E$

Business

$\begin{array}{ll}C & E \\ C & \text { E }\end{array}$

$\begin{array}{ll}\text { C } & \text { LC } \\ \text { C } & \text { LC }\end{array}$

S

C

C 
TABLE XI (Continued)

FORECASTING TECHNIQUE ASSUMPTION FOR SET III--SERVICES

Tech- Govern-

Service
EnergyCompetition

Cost

Percent Percent
Price Income

Elastic. Elastic.
Electronic Library

Residential E

Business $\mathrm{E}$

Outpatient Treatment

Residential E

Business

E

C E

C

C

Residential $E$

Business

E

Emergency Services

Residential C

Business

E

C

C

E

C

$\begin{array}{ll}\mathrm{C} & \mathrm{E} \\ \mathrm{C} & \mathrm{E}\end{array}$

C

C

C

S

S

Business

E

C

C

C

C

C

L

L

.

Correspondence

\section{School}

Residential E

Business
C E

C E

C E

C

Residential

Business
C

E

Electronic Funds

Transfer

Residential $E$

Business

E

L

E

C

C

$S$

$\mathrm{S}$

Message Recording

$\begin{array}{ll}\text { Residential } & \mathrm{E} \\ \text { Business } & \mathrm{E}\end{array}$

$\begin{array}{ll}C & E \\ C & E\end{array}$

$\mathrm{C}$

C

C

C

C

Call Forwarding

Residential E

Business

$\begin{array}{ll}C & E \\ C & E\end{array}$

$\begin{array}{ll}\mathrm{C} & \mathrm{C} \\ \mathrm{C} & \mathrm{C}\end{array}$

C

C

C 
TABLE XI (Continued)

FORECASTING TECHNIQUE ASSUMPTION FOR SET III--SERVICES

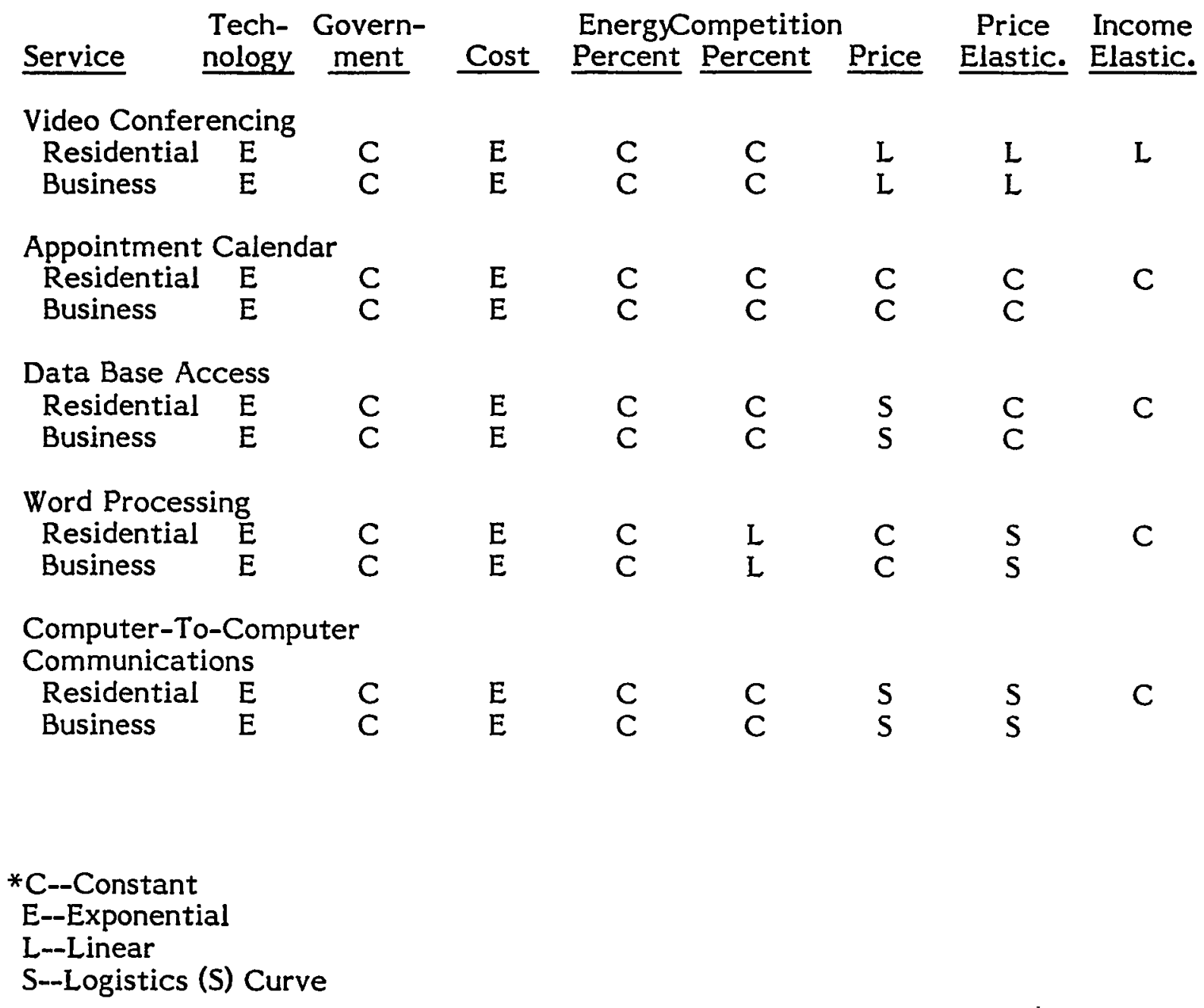


TABLE XII

FORECASTING TECHNIQUE ASSUMPTIONS FOR SET III--TERMINAL EQUIPMENT

Terminal Type

Forecasting Technique

Voice

Residential Market

Terminals Per Household

Price

Price Elasticity

Income Elasticity

$$
\begin{aligned}
& S^{*} \\
& S \\
& \text { C }
\end{aligned}
$$

Business Market

Price

$S$

Price Elasticity

S

Fixed Business Elasticity

C

Data

Residential Market

Terminals Per Household LS

Price

Price Elasticity

Income Elasticity

IS

LC

CS

Business Market

Price

Price Elasticity

Fixed Business Elasticity

L

SL

C

Video

Residential Market

Terminals Per Household E

Price S

Price Elasticity S

Income Elasticity S

Business Market

Price

Price Elasticity

Fixed Business Elasticity

\section{S}

S

*C--Constant
E--Exponential
L--Linear
S--Logistics (S) Curve 


\section{CHAPTER VII}

\section{THE COMPUTER PROGRAM}

Following the introduction, a user's guide is given. This guide describes how to enter a new assumption set, run the reports, and test scenarios. This is followed by an overview of the program from a data processing perspective. The chapter concludes with sections on the data base, reports, and the program's structure.

\section{INTRODUCTION}

The computer program ${ }^{1}$ is the third component of the FORTEL System. Its purpose is to synthesize the user assumptions with the demand models to produce the demand forecasts. It is important to specify the relationship between the computer program and FORTEL at the outset. There is often the tendency to confuse the two. FORTEL is an integrated man/machine forecasting system. The computer program is the machine component of FORTEL.

The program is documented from two different perspectives. The following section (Running The Program) is written from the user's perspective. The steps a forecaster would use are documented and illustrated. This program provides the user with a "how to use the program" manual.

The balance of the chapter is written from the data processing perspective. Documentation is provided on the data base, reports, and program structure. Detailed specifications such as program code, report layouts, and machine specifications are provided in a separate document (Black and Pound, 1981).

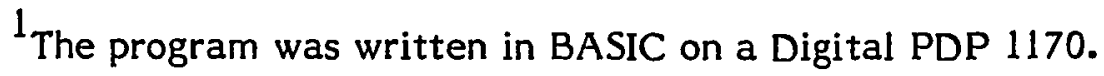




\section{RUNNING THE PROGRAM}

This section describes how to enter a new user assumption set, run the output reports, and test alternative scenarios.

The process of entering a new assumption set is quite involved. The other two options, however, are much simpler.

The discussions include illustrations of the program's prompts and user response. In all examples, user response is highlighted by bolded print.

\section{Entering A New User Assumption Set}

Prior to entering a new set, the forecaster must specify his assumptions (see Chapter VI). Once specified, the forecaster can use the work sheets (Appendix D) to translate the assumptions into a form compatible with the program.

After logging on and calling the program, the user is given an activity prompt:

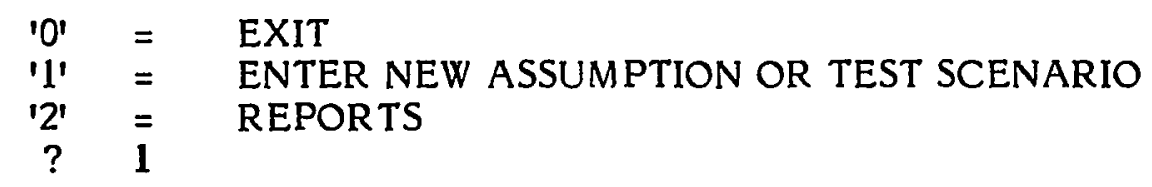

The next prompt identifies the desired user assumption set:

$\begin{array}{rll}{ }^{\prime} & = & \text { PREVIOUS PROMPT (EXIT) } \\ 1 & = & \text { ECONOMIC COLAPSE SET } \\ ' 2 ' & = & \text { MODEST GROWTH SET } \\ 13 & = & \text { EXPONENTIAL GROWTH SET } \\ 1{ }^{\prime} & = & \text { CREATE A NEW SET } \\ ? & 4 & \end{array}$

In this case, 4 is selected. One of the other sets would have been selected had the forecaster wanted to test an alternative scenario. This is discussed in a following section.

Following the set selection, the user must identify the file to which the data is to be written. Each file corresponds to a demand model. In that a new set is 
being entered, ultimately every file will have to be selected. The file prompt is:

\begin{tabular}{ccl}
\multicolumn{3}{l}{ SELECT DESIRED FILE } \\
$' 0^{\prime}=$ & PREVIOUS PROMPT (EXIT) \\
$' 1 '$ & $=$ & RESIDENTIAL SERVICE \\
$' 2$ & $=$ & RESIDENTIAL TERMINAL \\
$'{ }^{\prime}$ & $=$ & BUSINESS SER VICE \\
$'{ }^{\prime}$ & $=$ & BUSINESS TERMINAL \\
$?$ & 1 &
\end{tabular}

Although there are four files, the process of entering the data is the same. The only differences are the variables. Each file contains a different set of variable forecasts. The process begins with selecting the desired variable, then forecast data is entered. Following this, the forecast is generated and written to the appropriate file. A detailed discussion for each file follows.

Residential Service File. The data on this file pertains to the residential service model. There are 14 variables for which forecasts must be generated. The program prints the following prompt:

\begin{tabular}{|c|c|c|}
\hline ' 1 ' & $=$ & POPULATION \\
\hline '2' & $=$ & CHILDREN PER HOUSEHOLD \\
\hline '3' & $=$ & DIVORCE RATE \\
\hline $14^{\prime}$ & $=$ & URBAN SEGMENT \\
\hline 151 & $=$ & DISPOSABLE INCOME PER HOUSEHOLD \\
\hline '6' & $=$ & TECHNOLOGY \\
\hline '7' & $=$ & GOVERNMENT \\
\hline '8' & $=$ & $\operatorname{cosT}$ \\
\hline '9' & $=$ & ENERGY $\%$ \\
\hline '10' & $=$ & COMPETITION \% \\
\hline '11' & $=$ & PRICE \\
\hline$' 12 '$ & $=$ & PRICE ELASTICITY--SER VICE \\
\hline$' 131$ & $=$ & INCOME ELASTICITY--SER VICE \\
\hline '14' & $=$ & TERMINAL TYPE \\
\hline '0' & $=$ & PREVIOUS PROMPT (EXIT) \\
\hline ? & 1 & \\
\hline
\end{tabular}

This step identifies the variable to be forecasted. Like the files, all 14 variables will have to be evaluated. Entering a 1 indicates the population variable is to be forecasted. 
The next five prompts are designed to input forecast data about the selected variable. The first identifies the forecasting technique.

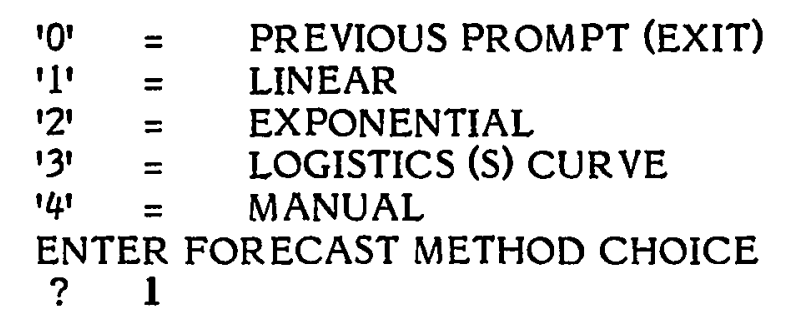

Following the method choice, the program queries for the beginning and ending years to be forecasted. This provides the forecaster with the flexibility of using different methods for different periods of time. The author, for example, used this option extensively in the economic colapse assumption set. The prompt is:

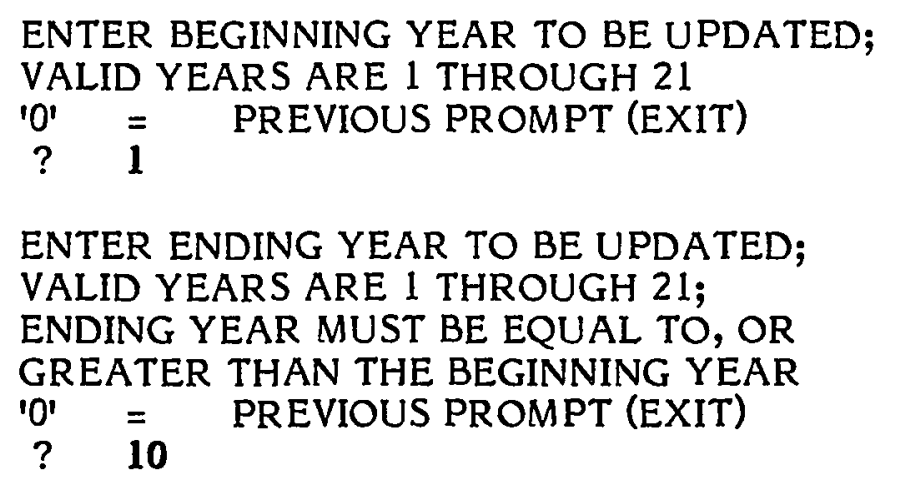

In this illustration, the linear method will be used in the period 1980 through 1989. Next, the beginning (1980) value and slope are entered.

\section{ENTER BEGINNING VALUE \\ ? $\quad 226.4$ \\ ENTER GROWTH RATE \\ ? $\quad 2.2$}

The program then calculates the forecast. In this example, the population will start at 226.4 (million) in 1980 and grow at an annual rate of 2.2 (million) for ten years. After completing the calculations, the forecast is written to the residential service data file. 
Control then returns to the forecast method prompt.

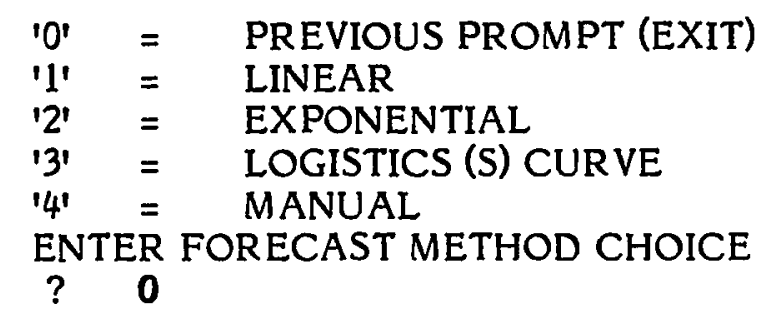

At this point, the user can either select another method or exit. Exiting (0) returns control to the variable prompt.

\begin{tabular}{|c|c|c|}
\hline '1' & $=$ & POPULATION \\
\hline '2' & $=$ & CHILDREN PER HOUSEHOLD \\
\hline '3' & $=$ & DIVORCE RATE \\
\hline '4' & $=$ & URBAN SEGMENT \\
\hline '5' & $=$ & DISPOSABLE INCOME PER HOUSEHOLD \\
\hline '6' & $=$ & TECHNOLOGY \\
\hline '7י & $=$ & GOVERNMENT \\
\hline ' 8 ' & $=$ & $\operatorname{cosT}$ \\
\hline '9י & $=$ & ENERGY \% \\
\hline 10 ' & $=$ & COMPETITION \% \\
\hline '11' & $=$ & PRICE \\
\hline '12' & $=$ & PRICE ELASTICITY--SER VICE \\
\hline '13' & $=$ & INCOME ELASTICITY--SER VICE \\
\hline '14' & $=$ & TERMINAL TYPE \\
\hline ' & $=$ & PREVIOUS PROMPT (EXIT) \\
\hline
\end{tabular}

Some of the variables ( 1 through 5 ) are applicable to all services, others (6 through 14) will vary from service to service. For these, the user must identify the specific service. The technology variable (6) was selected as an illustration. The program next requests the service (subelement) number.

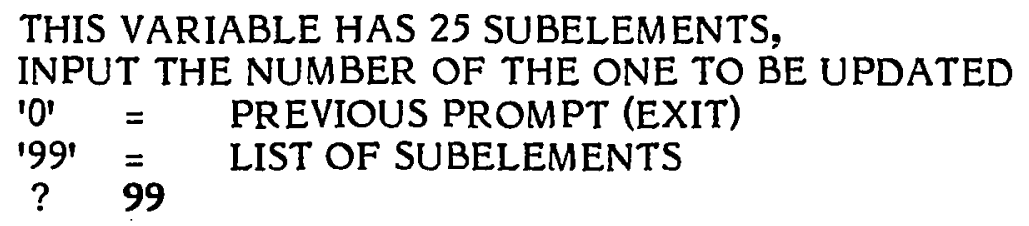

THIS VARIABLE HAS 25 SUBELEMENTS, INPUT THE NUMBER OF THE ONE TO BE UPDATED

${ }^{\prime}{ }^{\prime}=$ PREVIOUS PROMPT (EXIT)

$' 99 '=$ LIST OF SUBELEMENTS

? 99

The program (given the 99 response) next lists the services.

1--ELECTRONIC NEWSPAPER

2--ELECTRONIC MAIL

3--TRAVEL RESER VATIONS

4--PLAIN OLD TELEPHONE SER VICE 


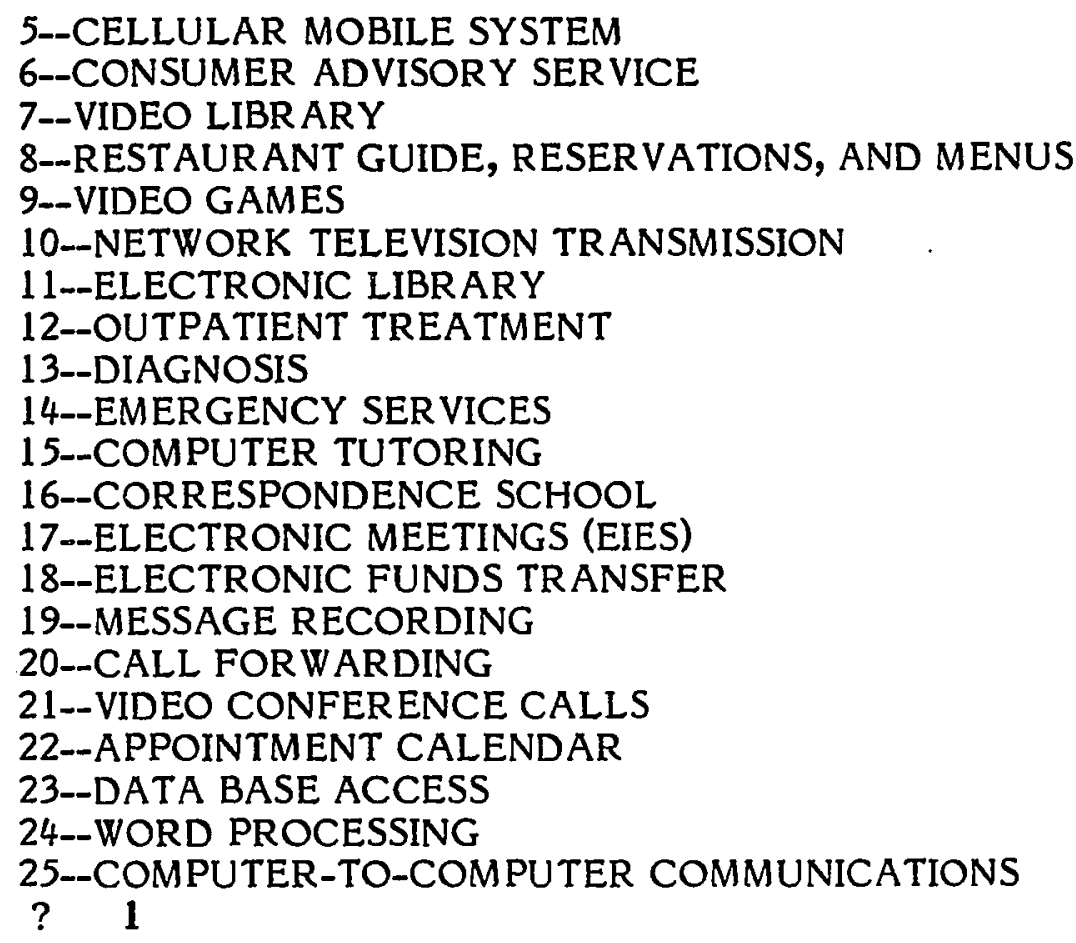

Selecting 1 indicates the data to be entered is for the electronic newspaper service. The program then prints the forecast method prompt.

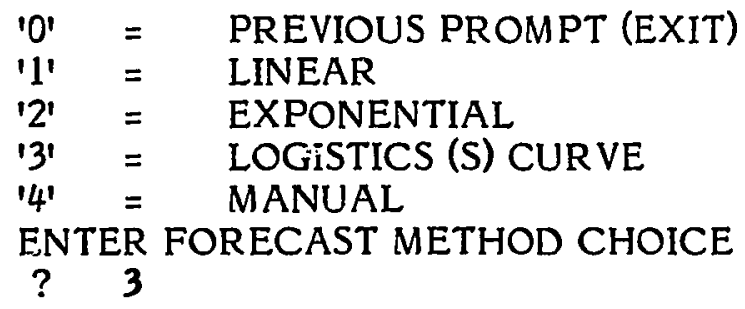

Following the method choice, the program queries about the beginning and ending years (as before). The prompts are:

ENTER BEGINNING YEAR TO BE UPDATED;

VALID YEARS ARE 1 THROUGH 21

${ }^{\prime}{ }^{\prime}=$ PREVIOUS PROMPT (EXIT)

? 1

ENTER ENDING YEAR TO BE UPDATED;

VALID YEARS ARE 1 THROUGH 21;

ENDING YEAR MUST BE EQUAL TO, OR

GREATER THAN THE BEGINNING YEAR

$'{ }^{\prime}{ }^{\prime}=$ PREVIOUS PROMPT (EXIT) 
Since the logistics method was selected, the remaining prompts are different than those described above. First, the type of curve (increasing or decreasing) must be specified. This is done in the following prompt:

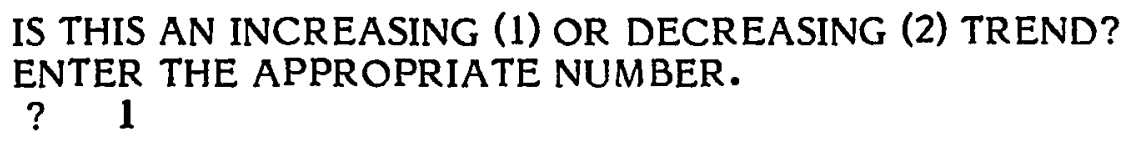

Next, the upper and lower limits of the curve must be enetered. The prompts are:

\section{ENTER UPPER LIMIT \\ ? $\quad .75$ \\ ENTER LOWER LIMIT \\ ? 0}

The program next calculates the technology variable forecast for the electronic newspaper service. The forecast starts at 0 (1980) and increases to .75 (2000) following a logistics curve. The forecast is then written to the residential service file, and the method prompt is again printed.

The process continues until the user has forecast all 14 residential service variables.

The next step in the process of entering a new assumption set is to enter the residential terminal file. This is done by entering 0 in each prompt until the file selection prompt is printed; then, a 2 is entered (as illustrated below).

\begin{tabular}{|c|c|c|}
\hline \multicolumn{3}{|c|}{ SELECT DESIRED FILE } \\
\hline ' & $=$ & PREVIOUS PROMPT (EXI \\
\hline ' 1 ' & & RESIDENTIAL SER VICE \\
\hline '2' & $=$ & RESIDENTIAL TERMINAL \\
\hline '3' & $=$ & BUSINESS SER VICE \\
\hline $\begin{array}{r}\text { '4' } \\
?\end{array}$ & $=$ & BUSINESS TERMINAL \\
\hline
\end{tabular}

Residential Terminal File. This file is much smaller than the Service File. It contains only four variables. Moreover, there are only three subelements per 
variable. Recall, the service variables had twenty-five--one for each service. The three subelements correspond to the three terminal types.

The following example illustrates how to forecast the price of a video terminal using an exponential curve. The forecast begins in 1980 and ends in 2000 with an inital price of $\$ 500$ and a growth rate of .25 .

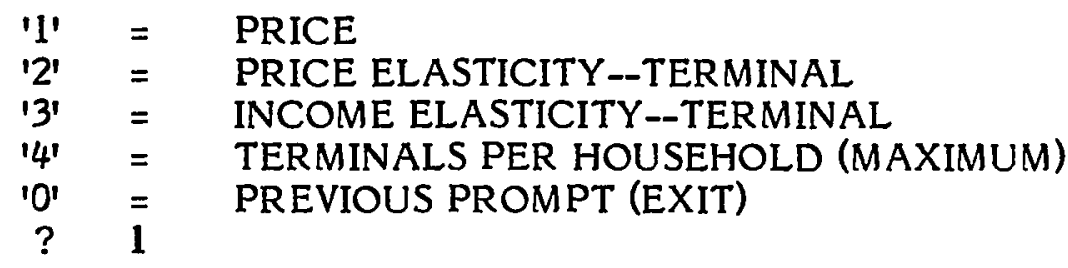

THIS VARIABLE HAS 3 SUBELEMENTS, INPUT THE NUMBER OF THE ONE TO BE UPDATED. ${ }^{\prime} \mathrm{O}^{\prime}=$ PREVIOUS PROMPT (EXIT)

$' 991^{\prime}=$ LIST OF SUBELEMENTS

? 99

1--VOICE TERMINAL

2--DATA TERMINAL

3--VIDEO TERMINAL

THIS VARIABLE HAS 3 SUBELEMENTS,

INPUT THE NUMBER OF THE ONE TO BE UPDATED.

${ }^{\prime}{ }^{\prime}=$ PREVIOUS PROMPT (EXIT)

$' 99 '=$ LIST OF SUBELEMENTS

? 3

${ }^{\prime} 0^{\prime}=$ PREVIOUS PROMPT (EXIT)

$'{ }^{\prime}=$ LINEAR

$' 2 '=$ EXPONENTIAL

$'{ }^{\prime}=$ LOGISTICS (S) CURVE

${ }^{\prime}{ }^{\prime}=$ MANUAL

ENTER FORECAST METHOD CHOICE

? 2

ENTER BEGINNING YEAR TO BE UPDATED;

VALID YEARS ARE 1 THROUGH 21

${ }^{\prime}{ }^{\prime}=$ PREVIOUS PROMPT (EXIT)

? 1

ENTER ENDING YEAR TO BE UPDATED;

VALID YEARS ARE 1 THROUGH 21;

ENDING YEAR MUST BE EQUAL TO, OR

GREATER THAN THE BEGINNING YEAR

${ }^{\prime}{ }^{\prime}=$ PREVIOUS PROMPT (EXIT) 


\section{ENTER BEGINNING VALUE \\ ? 500 \\ ENTER GROWTH RATE \\ ? $\quad .25$}

Like the service process, the forecaster must continue entering data until all the residential terminal variables have been forecasted.

This completes the residential market. A similar process must be used to enter the business market assumptions.

Business Service File. This file is quite similar to its residential counterpart. The only difference is the variables (this file has fewer). The process is the same, hence it will not be repeated in this section. For a list of the variables see Table XVII (Data Base Section).

Business Terminal File. This file is also similar to its residential counterpart. The variables are listed in Table XVIII.

This completes the discussion on entering a new user assumption set.

\section{Running The Reports}

The process begins with the activity prompt. This is the first prompt the user encounters after logging on. If a new set has just been entered, the user should enter ' $O$ ' to the prompts until the activity prompt is printed. This will also work if the user has been testing alternative scenarios. The prompt is:

$\begin{array}{lll}{ }^{\prime} & = & \text { EXIT } \\ 1 ' & = & \text { ENTER NEW ASSUMPTION OR TEST SCENARIO } \\ ' 2 ' & = & \text { REPORTS } \\ ? & \mathbf{2} & \end{array}$

Next, the program prompts for the desired report.

$$
\begin{aligned}
& \text { ENTER REPORT CHOICE } \\
& ' 1 '=\text { SER VICE DEMAND FORECAST } \\
& ' 2 '=\text { TERMINAL EQUIPMENT DEMAND FORECAST } \\
& ' 31=\text { SER VICE SEGMENT ANALYSIS } \\
& \text { ' } 4 \text { ' = TERMINAL SEGMENT ANALYSIS }
\end{aligned}
$$




$\begin{array}{rll}5^{\prime} & = & \text { USER ASSUMPTION COMPARISON--SER VICES } \\ '^{\prime} & =\text { USER ASSUMPTION COMPARISON--TERMINALS } \\ 7^{\prime} & =\text { SER VICE ASSUMPTIONS } \\ { }^{\prime} & =\text { TERMINAL ASSUMPTIONS } \\ { }^{\prime} & =\text { DEMOGRAPHIC AND BUSINESS FORECASTS } \\ { }^{\prime} & = & = \\ ? & 1 & \end{array}$

A detailed description of each report is given in the report section below. All of the reports (except the User Assumption Comparison--Services and its terminal counterpart) are based on a specified assumption set. The set is entered via the following prompt:

\begin{tabular}{|c|c|c|}
\hline \multicolumn{3}{|c|}{ ENTER VIEW CHOICE } \\
\hline ' 1 ' & $=$ & ECONOMIC COLAPSE (SET I) \\
\hline '2' & $=$ & MODEST GROWTH (SET II) \\
\hline '31 & $=$ & EXPONENTIAL GROWTH (SET III) \\
\hline 141 & $=$ & USER'S SET \\
\hline $\begin{array}{c}\text { ' } \\
?\end{array}$ & $=$ & PREVIOUS PROMPT (EXIT) \\
\hline
\end{tabular}

Next, an alignment prompt is printed.

\section{ALIGN PAPER AND PUSH 'RETURN' KEY ? (Return Key)}

This prompt ensures the report begins at the top of the page. After printing the report, the program returns to the report choice prompt. At this point, the user can either select another report or exit.

\section{Testing Alternative Scenarios}

The process of testing scenarios, as described in the Background Chapter, is a matter of changing user assumptions and running the reports. This process has, in fact, been documented in the previous sections.

Entering changes to an assumption set follows the same process as entering a new set; the only difference is that not every variable will be entered. The forecaster must select the appropriate variables for the scenario; then, he enters the changes just as he entered a new set. 
After entering the changes, the user runs the appropriate report. The report process was documented in the previous section.

\section{PROGRAM OVERVIEW --A DATA PROCESSING PERSEPECTIVE}

The program contains three modules. The input module is designed to input data and write it to the data base. This program also provides the user with the means to alter existing data; i.e., scenario testing. The second module calculates the forecasts (using the demand models) and prints the output on the appropriate report. The third module is a controller. When the user runs the system, this module is invoked. It polls the user as to which option he wants (input or reports). It then passes control to the appropriate module (see Figure 9).

The system was designed in a modular fashion to facilitate growth. As described in the follow-on research chapter, financial and public benefit modules would significantly enhance FORTEL. With this design, these modules could easily be "plugged in" to the existing program. 


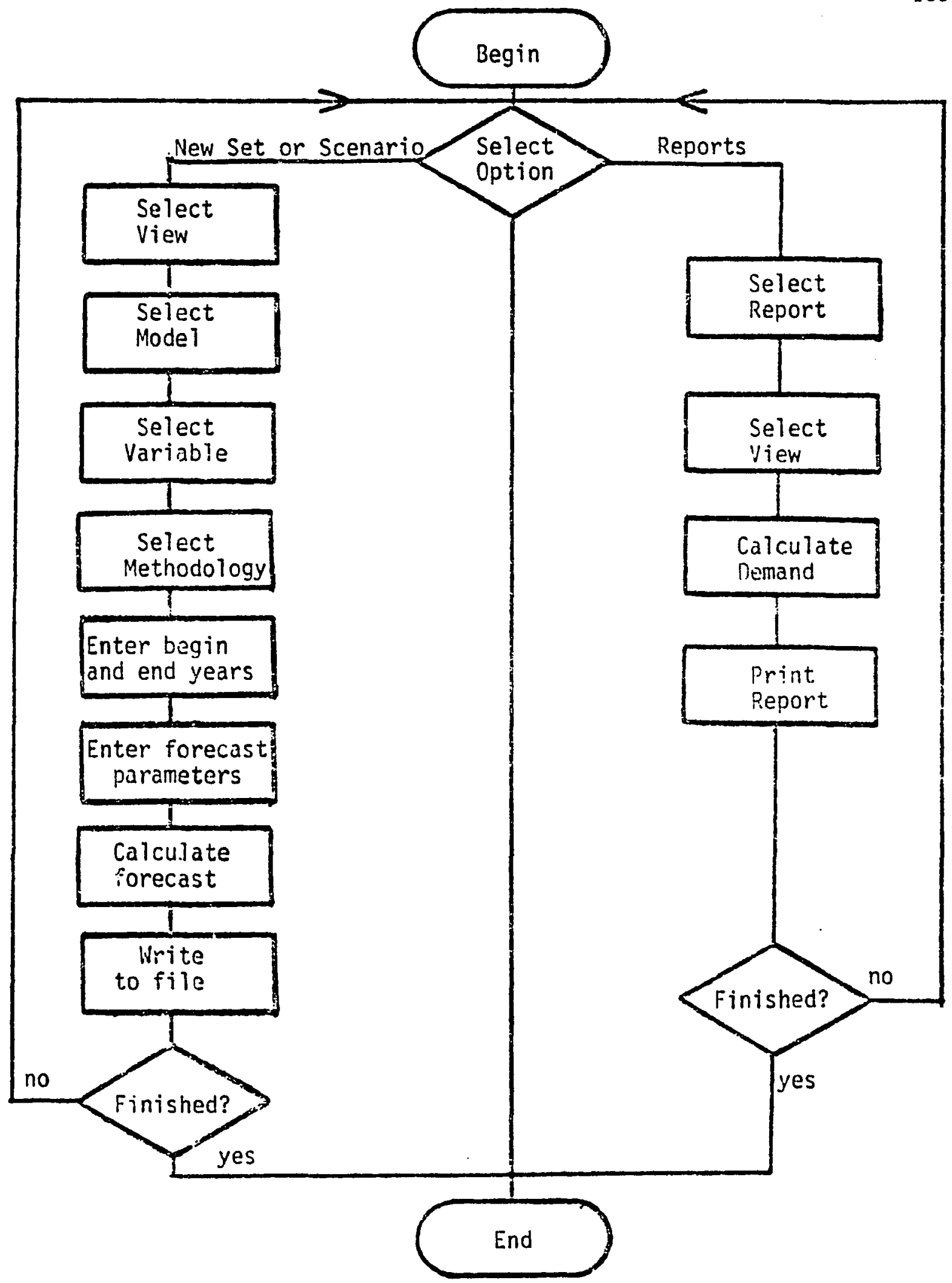

Figure 10. The computer program flowchart 


\section{DATA BASE}

The data base consists of four relative access files--one for each demand model. Each file contains the variable forecasts (which are inputs) for the associated model. Table XIII specifies this association as well as summarizes key factors of the data base.

TABLE XIII

DATA BASE SUMMARY

\begin{tabular}{|c|c|c|c|}
\hline & & \multicolumn{2}{|c|}{ Number of Fields Per } \\
\hline File Name & Model & & Record \\
\hline Resserv.Dat & Residential Service & 84 & 230 \\
\hline Resterm.Dat & Residential Terminal & 84 & 12 \\
\hline Busserv.Dat & Business Service & 84 & 177 \\
\hline Busterm.Dat & Business Terminal & 84 & 9 \\
\hline
\end{tabular}

In order to facilitate processing, the files have the same organization. Each file is organized by view (forecaster outlook) and year. The detail is specified in Table XIV.

TABLE XIV

FILE ORGANIZATION

\begin{tabular}{|c|c|c|}
\hline Records & Years & View (User Assumption Set) \\
\hline 1 through 21 & 1 through 21 & Economic Colapse \\
\hline 22 through 42 & 1 through 21 & Modest Growth \\
\hline 43 through 63 & 1 through 21 & Exponential Growth \\
\hline 64 through 84 & 1 through 21 & User's View \\
\hline
\end{tabular}


The files, then, are organized into four sections--one for each view. Within each section there are 21 records--one for each year. The fields within each record vary depending on the file. This is a result of the different input requirements for the models. The record descriptions for each file are given in the following tables.

TABLE XV

\begin{tabular}{|c|c|}
\hline Field Number & Description \\
\hline 1 & Population \\
\hline 2 & Children Per Household \\
\hline 3 & Divorce Rate \\
\hline 4 & Urban Population Percentage \\
\hline 5 & Disposable Income Per Household \\
\hline 6 through $30 *$ & Technology \\
\hline 31 through 55 & Government \\
\hline 56 through 80 & Cost \\
\hline 81 through 105 & Energy $\%$ \\
\hline 106 through 130 & Competition $\%$ \\
\hline 131 through 155 & Price \\
\hline 156 through 180 & Price Elasticity \\
\hline 181 through 205 & Income Elasticity \\
\hline 206 through 230 & Terminal Type \\
\hline
\end{tabular}

*There are 25 fields for these variables--one for each service. 
TABLE XVI

RESTERM.DAT FILE RECORD DESCRIPTION

Field Number

Description

1 through $3 *$

Price

4 through 6

Price Elasticity

7 through 9

Income Elasticity

10 through 12

Terminals Per Household

*There are three fields for these variables--one for each terminal type.

TABLE XVII

BUSSER V.DAT FILE RECORD DESCRIPTION

Field Number

Description

1

Fixed Business Investment

2

Information Handlers

3 through 27

Technology

28 through 52

Government

53 through 77

Cost

78 through 102

Energy \%

103 through 127

Competition \%

128 through 152

Price Elasticity

153 through 177

Price

TABLE XVIII

BUSTERM.DAT FILE RECORD DESCRIPTION

Field Number

Description

1 through 3

Price

4 through 6

Price Elasticity

7 through 9

Fixed Business Investment Elasticity 


\section{REPORTS}

A synopsis of the reports is given in Chapter III and samples in Appendix C. This section thoroughly documents the reports. There are three basic types of reports: those which pertain to services, terminals, and assumptions. The service and terminal types are similar in their format. Moreover, for each service report, there is a corresponding terminal report. This is a natural consequence of the relationship between services and terminals. Recall, the terminal is necessary to access the service. There are nine reports in all--four service, four corresponding terminal reports, and a summary report of the assumptions. Each report is discussed below.

\section{Service Demand Forecast}

This report summarizes service demand. For each of the twenty-five services, demand is projected through the end of the century. In order to run this report, the user must select a user assumption set. The program then calculates the residential and business demand for the selected set. These are delineated on the report along with a total (the sum of both markets). The report forecast demand is in millions; thus, a residential demand of five (say for electrionic newspaper) means 5 million households will subscribe to the service. Business (also in millions) refers to the number of mainstations subscribing to the service.

\section{Terminal Equipment Demand Forecast}

This is the terminal counterpart of the service demand report. For each of the three terminal types, residential and business demands are forecasted. This report does somewhat differ from the service report.

For each of the markets, demand is divided into mainstations and extensions. The service report forecasted, for example, residential demand. This 
report delineates residential mainstations, residential extensions, and total residential demand. Another difference is in the method of calculation. The service report was generated from the two service models. This report uses all four. Recall, the terminal models use, as input, service demand. The actual process begins with the forecaster selecting a user assumption set. The set is used as input to the service models. Next, the program calculates service demand (for each of the 25 services, residential and busiess demand is forecasted). This demand, along with the user assumption set, becomes input to the terminal models. The program next calculates terminal demand and writes the output to the report. The output, like service demand, is in millions.

\section{$\underline{\text { Terminal Segment Analysis }}$}

The urban and suburban/rural demands for each of the three terminal types are delineated in this report. The demand is further divided into mainstation and extension subdemands.

The process of calculating the demands begins, as the other reports do, with the user specifying the user assumptions. The service model then generates the urban and suburban/rural demands. These, along with the user assumptions, are used in the residential terminal market to generate the terminal forecast.

\section{User Assumption Comparison--Services}

The reports described thus far have been based on a specific assumption set designated by the user. This report compares the various assumption sets. For each service, the demand is calculated using all the assumption sets. For each set, then, there is a forecast.

The process is somewhat different in that it is iterative. It begins by calculating residential service demand using the residential model. Next, business 
service demand is calculated. The two forecasts are added together and printed on the report. The process then starts over for the next user assumption set. This continues until all sets have been analyzed.

User Assumption Comparison--Terminals

This report provides the forecaster with a comparison of the effect of different assumption sets upon terminal demand. The process is also iterative. However, all four models are involved (see Terminal Equipment Demand Report description).

\section{Service Assumptions}

This report is a printout of the data files. In this case, the user specifies an assumption set. The program then prints out the forecasts of the residential and business variables. The process is repeated for each service.

\section{Terminal Assumptions}

For each of the three terminal types, the variable forecasts are delineated. As above, the user must select an assumption set.

\section{Demographic and Business Forecasts}

Many of the assumptions are applicable to all the services (or terminals). This report delineates the forecasts of these variables.

\section{The Program Structure}

The program was designed in a modular fashion. This was done to easily facilitate expansion (see Chapter VIII). A narrative of each model follows. The narrative is in summary form. A detailed discussion, including the code, is provided in a separate document (Black and Pound, 1981). 
The Controller Module. The purpose of this module is to direct processing to the other modules. Based on user input, the activity is either directed to the input or report modules.

Input Module. This module is designed to input data and write it to the file. Its structure is a microcosm of the overall program. It, too, has a controller "module" (called the Main Loop Routine) and activity modules (subroutines).

The main loop begins by directing activity to a subroutine which opens the files. Next, activity is directed to several prompt subroutines. The first determines the user assumption set to be used. Next, the appropriate file is identified. This is followed by a subroutine which determines the variable to be forecasted. Then, the forecast method is entered. The beginning and ending year subroutine is called next, followed by the forecasting subroutine. In this routine, the user enters the appropriate parameters; e.g., beginning value and growth rate. Next, the subroutine forecasts the variable. It then calls a subroutine which writes the forecast to the file.

At this point, control is returned to the main loop routine. Based on user input, one of two courses will be followed. If the user wants to enter additional data, the controller directs activity to the appropriate subroutine. It may be, for example, the forecaster wants to use a different forecasting technique for the selected variables. In this case, control is passed to the method subroutine. On the other hand, a new variable may be desired; here activity will be directed to the variable identification subroutine.

The second option is to exit the input module. In this case, the main loop calls a routine which closes the file and then returns control to the controller module. 
Report Module. This module calculates the demand forecasts and prints the reports. Its structure is similar to the input module. It also has a main loop. The first activity of this loop is to call a subroutine which opens the files. Next, a report prompt is printed. The user enters the desired report. Due to the nature of most of the reports, the user must specify an assumption set. If the user selects one of these reports, an assumption set prompt is printed. Next, the user is given a prompt to align the paper. After this, control is passed to a subroutine which sets up the report header. The header is not printed at this time.

Calculating the forecast is the next step. There is a separate calculation subroutine for each report. It is important to note many of the reports require the same calculation. For example, the service demand reports require residential service demand calculations. These same calculations are needed for the service segment analysis report. As a result, there is a considerable degree of interaction between the subroutines.

The calculations are done by service (or terminal). All the calculations for a given service (or terminal) are performed at one time. In the service demand report, for example, the residential demand, business demand, and total demand are calculated at the same time. Some of the other reports have many more than three forecasts. The terminal demand forecast report has, for each terminal type, residential mainstation, extension, and subtotal forecasts (plus business mainstation, extension, and subtotal forecasts) along with a grand total (see Appendix C). In all, this report has seven forecasts for each terminal type. The calculations for all seven are done at one time. This is further explained below.

Although the calculations for each subroutine are different, the overall process is the same. After the main loop passes control to the appropriate calculating subroutine, one year of data is read into a buffer. The data is from all 
four files. Next, the forecasts are generated for that year. The forecasts are passed to an output matrix. The subroutine then reads the next year's data. This loop continues until all twenty-one years have been processed. Control is then passed to a print routine which prints the forecasts.

The main loop next checks to "see" if there are any additional services (or terminals) to be forecasted. If so, the control is passed to the appropriate calculating subroutine. Otherwise, the files are closed, and control is returned to the controller module. 


\section{CHAPTER VIII}

APPLICATIONS

There are four sections in this chapter. The first is an example of a forecasting session. The second section discusses the resultant forecasts (based on the user assumption sets). Validation is the third. The chapter concludes with forecast comparisons.

\section{EXAMPLE SESSION}

This section documents the responses of a first-time user of FORTEL. Emphasis is placed on the user's reactions. This section does not explain how to run the computer program. A step-by-step procedure is documented in Chapter VI.

The session began with an overview of the FORTEL System. The author spent approximately 30 minutes describing the forecasting process and the components of FORTEL. The user (a marketing research manager with an econometric background) was particularly interested in the demand models. The elements of each model were described along with their relationship to demand. Next, the author summarized the three preselected assumption sets. The user, a self-proclaimed optomist, said he would like to use the exponential growth set as a basis.

At this point, the user moved to the terminal and called up the program. The session is documented below. User responses are in bolded print.

\section{RUN FORTEL}

WELCOME TO FORTEL; A TELECOMMUNICATIONS FORECASTING SYSTEM 


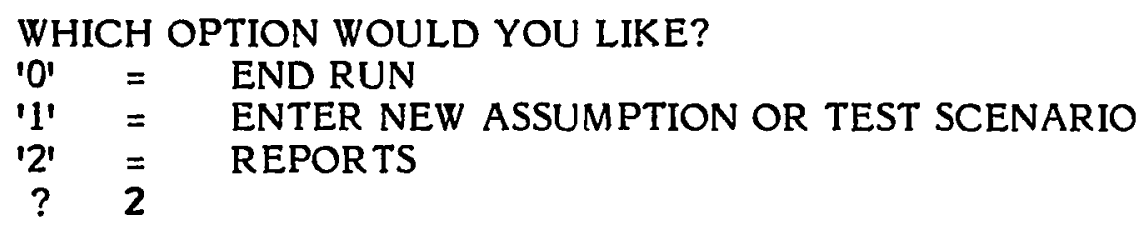

The author suggested a printout of the service demand and assumption reports would be helpful.

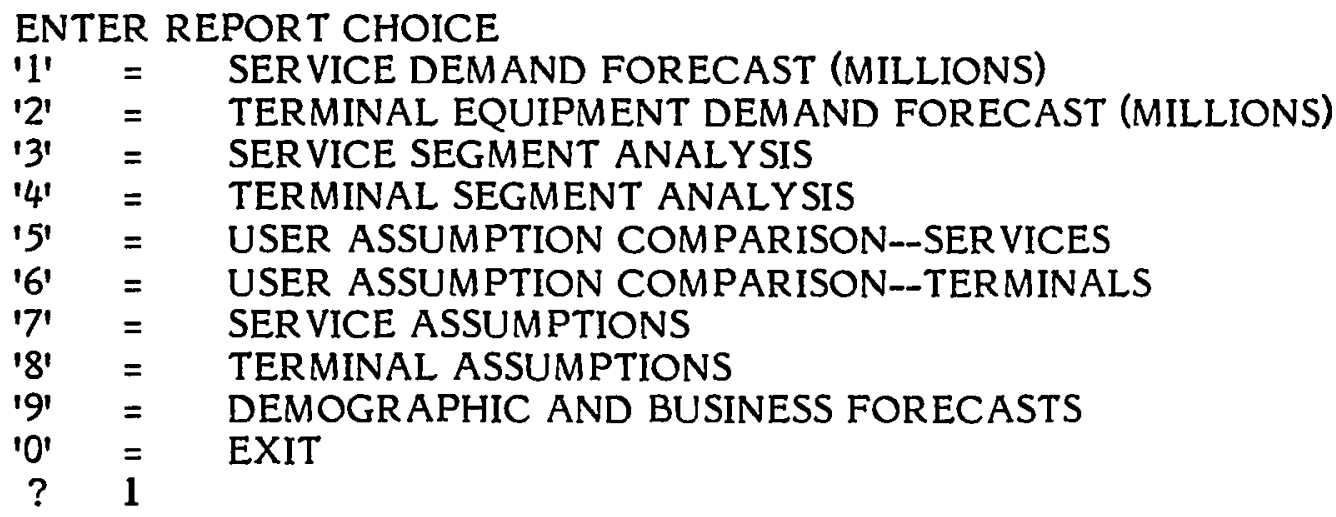

$\begin{array}{lll}\text { ENTER VIEW CHOICE } & \\ ' 1 '= & \text { ECONOMIC COLAPSE } \\ ' 2 '= & \text { MODEST GROWTH } \\ ' 31 & = & \text { EXPONENTIAL GROWTH } \\ ' 0 ' & = & \text { PREVIOUS PROMPT (EXIT) } \\ ? & 3 & \end{array}$

ALIGN PAPER AND PUSH THE 'RETURN' KEY ?

A print out of the service demand report is provided in Appendix E. The user was surprised at "just how many" twenty-five services really were. Initially, he had wanted to "look at" all. At this point, however, he decided to evaluate only the electronic newspaper service.

After printing the service demand report, the program returned to the report prompt.

$$
\begin{aligned}
& \text { ENTER REPORT CHOICE } \\
& ' 1 '=\text { SERVICE DEMAND FORECAST (MILLIONS) } \\
& '{ }^{\prime}{ }^{\prime}=\text { TERMINAL EQUIPMENT DEMAND FORECAST (MILLIONS) } \\
& { }^{\prime 3} 1=\text { SER VICE SEGMENT ANALYSIS } \\
& 14 \text { ' = TERMINAL SEGMENT ANALYSIS } \\
& '{ }^{\prime} \text { ' = USER ASSUMPTION COMPARISON--SERVICES }
\end{aligned}
$$




$\begin{array}{rll}16 ' & = & \text { USER ASSUMPTION COMPARISON--TERMINALS } \\ 17 ' & =\text { SER VICE ASSUMPTIONS } \\ ' 8 ' & =\text { TERMINAL ASSUMPTIONS } \\ 19 ' & =\text { DEMOGRAPHIC AND BUSINESS FORECASTS } \\ 10 ' & =\text { EXIT } \\ ? & 7\end{array}$

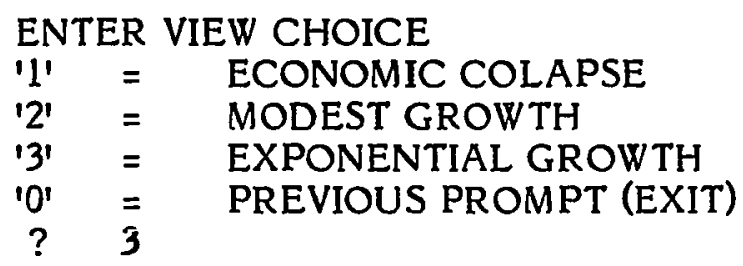

\section{ALIGN PAPER AND PUSH THE 'RETURN' KEY} ?

Here, the user had the service assumptions printed, then the demographic and business report. These two reports summarize the service assumptions.

After analyzing the assumptions, the user concluded that the fixed business investment growth rate ( 15 percent) was too low. He chose to double it. The variable was reforecasted, and the service demand report rerun.

The user was shocked when he saw how the demand had increased. In the year 2000, it increased from 7.45 million to 151 million. He had not expected such a dramatic rise. The user was faced with a dilemma. He believed in exponential growth and that a 30 percent growth rate was appropriate, yet he could not accept the tremendous increase. His response was to change the implementation variables until he arrived at a demand with which he felt comfortable.

Having done this, he concluded the session.

\section{RESULTANT FORECASTS}

For each of the three user assumption sets, there are twenty-five service forecasts and three terminal forecasts. These forecasts are delineated in Appendix E. 
In general, the forecasts coincide with what one would expect from the user assumptions. The demand under the economic colapse set, for example, is generally less than under the modest growth set.

There are, however, a few surprises. Most occurred in the economic colapse set. During the recession, the demand for several of the services actually increased. It was primarily services which were energy-efficient. Even though the general consumer trend was away from electronic "luxuries," the energy savings of these services increased their demand.

\section{VALIDATION}

In theory, one should be able to validate FORTEL by using the actual past values of the variables. If FORTEL is valid, the forecast will be close to the actual demand. As is often the case, however, in the process of applying theory, one encounters "difficulties." The process of validating FORTEL was no exception.

Of all the services forecasted by FORTEL, past data was only available for POTS (plain old telephone service). Moreover, the data was incomplete. Although actual demand data was available, past values of many of the variables were not. Elasticities, for example, were available at points in time, but not over a continuous period.

Nevertheless, the models were tested over the period for which demand data was available (1965 to 1980). Initially, the elasticities were assumed to be constant. Although this resulted in a reasonably accurate forecast (the largest error term was 7 percent of demand), there was a systematic bias. The error terms tended to increase with time. By varying the elasticities (over a range of .1 ), the bias was eliminated. It is interesting to note that these biases occurred in both the residential and business demand models. 
From this, one could conclude either the elasticities were in fact changing, and/or the models failed to capture the reality of the situation. Fortunately, the resolution of this problem is not central to the use of FORTEL. Assuming the worse case, the elasticities did not change over the test period, the error is small ( 7 percent over a 15-year period).

A similar test was conducted for the voice terminal (telephone). Recall, mainstation demand is synonymous with service demand. A distinction between the two is not possible. Extension demand, on the other hand, is distinct. The extension portion of the terminal models were tested over the 1965 to 1980 period. The results were the same as the service findings. The model (assuming constant elasticities) has the same systematic bias. By varying the elasticities, however, the bias was eliminated. ${ }^{1}$

Other methods of validation were considered, but none were found to be suitable for FORTEL. Most of the techniques described in the literature (e.g., Goldberger and Duncan, 1973, and O'Muircheartaigh and Payne, 1977) addressed statistical models.

\section{COMPARISON TO OTHER FORECASTS}

One question commonly posed by potential users is: What are the advantages of FORTEL? Stated alternatively, why should one use FORTEL, as opposed to other forecasts? It is the purpose of this section to compare FORTEL to other efforts and illustrate FORTEL's advantages.

Recall that in the Literature Search Section, the other forecasts fell into two categories. There were those of a broad nature. There were those of a broad nature.

${ }^{1}$ Thus, FORTEL tracked the actual data within a range of 7 percent of demand over the twenty-year period. 
These were tipified as having a telescopic nature, covering many services. The others were microscopic. They focus (in great detail) upon very few services. This is graphically illustrated in Figure 11.

The advantage of FORTEL is that it has both breadth and depth. It has all the detail of the econometric models. In addition, FORTEL has the detail of demographic, governmental, social, technological, and cost factors. On the other hand, FORTEL has the breadth of the "telescopic" forecasts. It forecasts the demand for as many (if not more) services as these broad types. Moreover, FORTEL has a scenario testing option which these do not. The user can integrate his opinions and ideas into the forecast. With the others, the forecast is fixed. The user must either accept it or reject it as is. It cannot be changed. 


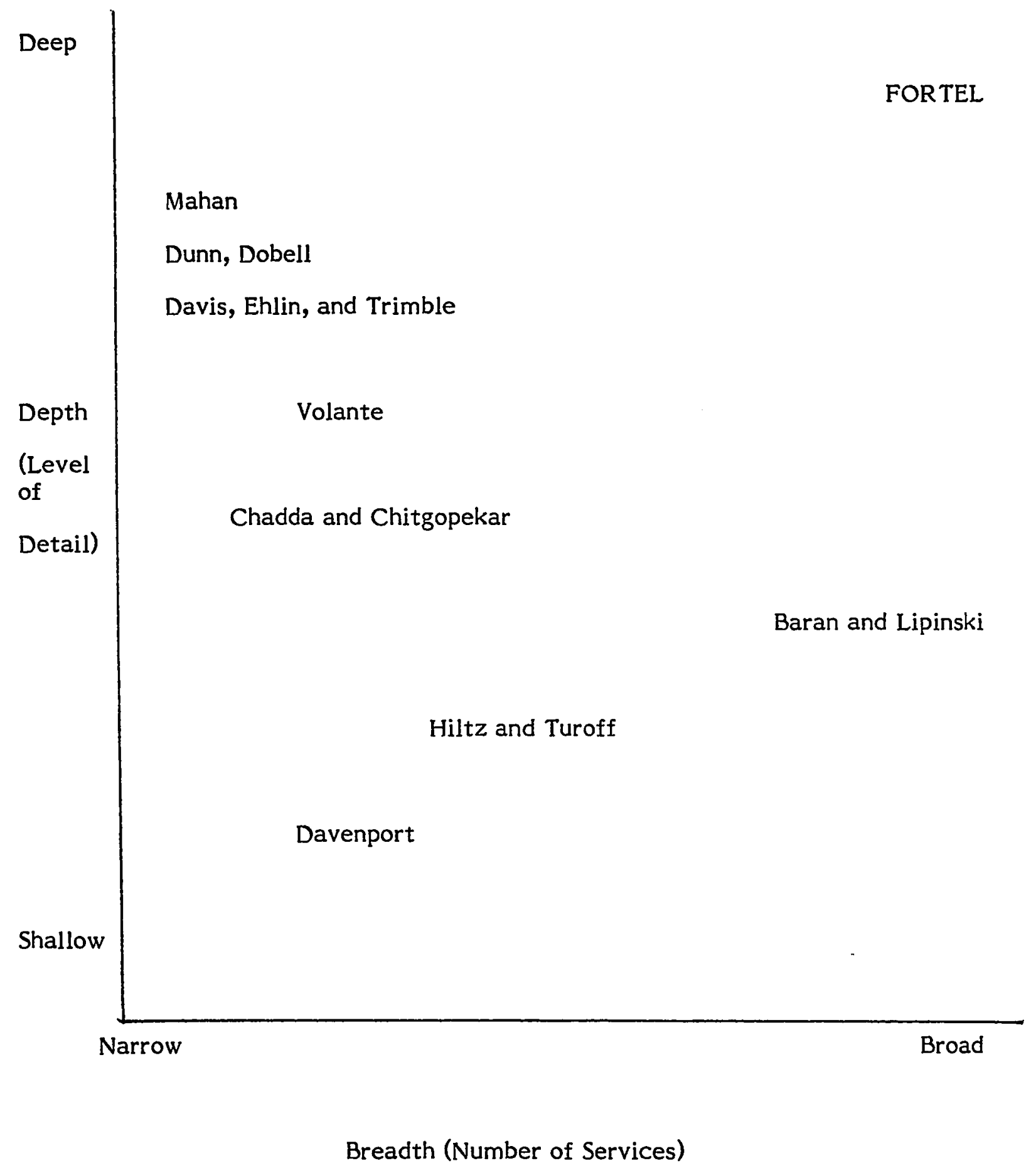

Figure 11. Forecast comparison 
Another dimension, relative to use, is complexity. Berlinski (1976) points out that often complex models are developed when a simple model would suffice. Ascher (1978), on the other hand, has found complex models are more likely to be used.

Had FORTEL been developed at a time when the telecommunications industry was not undergoing a metamorphic change, a more simple model would most likely suffice. In this era, however, it is essential that the forecasting system be able to examine the effects of alternative industry structures. This, of course, has added an additional degree of complexity to the model. 


\section{CHAPTER IX}

\section{FOLLOW-ON RESEARCH}

\section{TECHNOLOGY}

The technologies considered in FORTEL already exist. The focus has been on their implementation. Most of these have been developed over the last twenty years. Further research is needed to forecast technologies that have not yet been identified (discovered). If the recent past is any indication of the future, the quantity and quality of new technologies will be explosive. Their impact may even force another metamorphosis.

Since 1850 , communication capacity has grown at an exponential rate. In the recent past, the rate has become hyperexponential (Martin, 1977, page 22). If new technologies continue to be developed at this explosive growth rate, the capacity may be twenty orders of magnitude higher than today's.

Capacity is only one aspect of these technological innovations. A vast panorama of new services could evolve. Holography is but one example.

\section{FINANCIAL ANALYSIS}

In that the ultimate goal of every corporation is to make a profit, each new ventui: $=$ must be evaluated for its potential profitability. FORTEL provides half of the profitability analysis. From FORTEL, potential revenues can be determined; i.e., price multiplied by demand. Research needs to be conducted to determine the cost of providing the services and/or terminals. The difference, of course, is profit. 
The analysis will involve several of the implementation factors: technology, government, energy, and competition. These are in addition to the standard factors; e.g., cost of capital, depreciation rate, and taxes.

\section{SOCIAL BENEFIT}

Government regulators are charged with serving the public interest. In order to carry out their charge, they must know the social benefit of their decisions. FORTEL can predict demand; however, further research is needed to translate this into social benefit.

Deregulating the broadcasting industry may lead to a proliferation of socially damaging programming. A telecommunications system based on satellites is not militarily secure. Foreign powers could shoot them down. A nationwide computer system, as described by Martin (1978) could easily lead to Orwell's "1984" society.

Thus, a benefit analysis would be most appropriate for those regulators which will impact the outcome of the metamorphosis.

\section{ELASTICITY SURVEY}

The elasticities in FORTEL are products of the user assumptions, thus they will vary with different forecasters or different outlooks. Although this offers the advantage of forecaster input, it lacks the empirical verification of a statistical survey.

On the other hand, such a survey is a major undertaking. It would be necessary to interview a representative sample of the entire United States population, plus a representative sample of the business community. Nevertheless, such surveys would be of tremendous benefit. 


\section{CHAPTER $X$}

\section{CONCLUSION}

The telecommunications industry is undergoing a metamorphic change. A change which offers a future of great promise. A vast panorama of new services may emerge.

These services have the potential to greatly improve mankind's condition. The medical emergency services, for example, have the potential of saving thousands of lives by rapidly responding to the emergencies. The electronic publishing services have the potential to make available vast amounts of literature. On the other hand, these services, if misused, could easily result in Orwell's 1984 society. Through videoconferencing, for example, "big brother" could very easily be in every home, office, airport, even on every street corner.

Within the corporate world the potential is equally staggering. There are literally billions of dollars to be made. Many new corporations will emerge. Some of the older corporations have a potential for going bankrupt.

All will depend on the outcome of the metamorphosis, an outcome currently being determined by industry and government leaders.

Prior to FORTEL, these leaders did not have a systematic means of evaluating the effects of their decisions. Even more fundamental, however, they did not have a comprehensive means of formulating their decisions. In fact, without FORTEL, many of the pertinent variables would have been left out of the decision-making process. Great emphasis was placed on only a few factors (technology and government). Social change, on the other hand, was generally 
ignored. Thus, FORTEL is more than a mechanical decision making tool; it broadens the decision maker's horizon by incorporating many factors and relationships previously ignored.

The ultimate impact of FORTEL is difficult to access. It is being used. Within GTE, FORTEL has become part of the decision-making process. This is important for two reasons. First, it demonstrates system concepts can be used to solve "real world" problems. Second, the core assumptions (upon which the system was based) were selected on the criterion that the resultant system would be used. GTE's use of FORTEL validate the selected assumptions.

The fact that the system is used is obviously an important factor in accessing its impact. Uses in and of itself, however, do not imply a substantial impact. Although it must be used to have an impact, its true value lies in the degree to which it becomes integrated into the decision maker's process. Stated, alternatively, the degree to which it influences the decision maker's thinking by providing new possibilities. Only time will tell the degree to which this was accomplished.

The advantage of FORTEL is that it provides the decision makers with these new possibilities and a means of evaluating their impact. Prior to FORTEL this capacity did not exist.

It is equally important to point out FORTEL's limitations. First, FORTEL is only a tool to assist with the metamorphic change. The system, in and of itself, cannot determine the new infrastructure. It can only assist in the decision-making process. Another limitation is with the notion of core assumptions. The design of the models requires alternative assumptions to be entered at the systems level. That is, the models must be reprogrammed. A user, then, would not have the option. of changing core assumptions during an interactive session. If one 
subscribes to Ascher's conclusions (that core assumptions change over time), then FORTEL is for the short-term only. Another important aspect to note is that the preselected user assumptions were developed by the author, hence reflecting his bias. They are intended to be used as alternative scenarios. They do not necessarily reflect either the "truth" or the same degree of depth as the demand models.

To summarize, FORTEL is the product of system concepts applied to a real world problem. FORTEL is being used in the corporate world. However, more importantly, it suggests new futures and a means of evaluating the demand for services and terminals in these futures. 


\section{REFERENCES}

Anderson, L. 1980. "Telco Construction Spending To Top \$20 Billion In 180," Telephony, January 14, pp. 33-39.

Ascher, W. 1978. Forecasting--An Appraisal For Policy Makers and Planners, John Hopkins Press, Baltimore.

Baran, P. and Lipinski, A. 1970. "The Future of The Telephone Industry 1970-1985," Institute For The Future, Menlo Park, California.

Baran, P. 1971. "Potential Market Demand For Two-way Information Services To The Home: 1970-1990," Institute For The Future, Menlo Park, California.

Berlinski, D. 1976. On Systems Analysis, MIT Press, Cambridge, Massachusetts, pp. 81-83.

Black, J. and Pound, J. 1981. The FORTEL System Documentation Report, unpublished paper, General Telephone Company of the Northwest, Inc., Everett, Washington.

Black, R. 1980. General Telephone of the Northwest, Everett, Washington, Interview, November 17.

Bloch, A. 1970. "You Can Make The Systems Approach Work," Innovation, March, pp. 26-33.

Brophy, T. 1979. "Telephone Enters Its Promising Second Century," Telephony, November 26, p. 108.

Brophy, T. 1980. "All Must Speak Out For Free, Full Competition," Communications News, January, p. 34.

Brown, C. 1980. "Users Will Benefit From Expanded Choices In '80s," Communications News, January, 32-33.

Chadda, R. and Chitgopekar, S. 1971. "A Generalization of The Logistics Curves and Long-Range Forecasts (1966-1991) of Residence Telephones," Bell Journal of Economics and Management Science, Spring, pp. 542-560.

Churchman, C.W. 1968. The Systems Approach, Delta, New York, New York.

Davenport, L. 1978. Telecommunications For Metropolitian Areas: Opportunities For The 1980s, The National Academy of Sciences, Washington D.C.

Davis, B., Caccappolo, G., and Chaudry, M. 1973. "An Econometric Planning Model For American Telephone and Telegraph," Bell Journal of Economics and Management Science, Spring, pp. 29-56. 
Dobbs, A. 1976. "Highlights of History From Telephony," Telephony, July 19, pp. 50-51.

Dobell, A. 1972. Telephone Communications In Canada: "Demand Production and Investment Decisions," Bell Journal of Economics and Management Science, Spring.

Dunn, D., Williams, W., and Spivey, W. 1971. "Analysis and Prediction of Telephone Demand In Local Geographical Areas," Bell Journal of Economics and Managment Science, Spring, Pp. 561-576.

Ehlin, J., and Trimble, D. 1977. The Structure of Demand For Single-Line Telephones, unpublished papers, General Telephone Company of the Northwest, Everett, Washington.

Fay, T. 1980. "Teletext and Viewdata No Longer on the Horizon... They're Here Right Now!," Communications News, January, pp. 44-45.

Ferris, C. 1980. "Many Challenges, But Even Greater Opportunities," Communications News, January, p. 33.

Forrester, J. 1971. World Dynamics, Wright-Allen Press, Massachusetts.

Geller, H. 1980. "Change Holds Promise If We Prepare For It," Communications News, January, p. 32.

Goldberger, A. and Duncan, O. (eds) 1973. Structural Equation Models In The Social Sciences, Seminar Press, New York, New York.

Graham, G. 1977. "Adopting Inventory Precedures To New Telephone Technologies," Telephony, September 26, pp. 44-45.

Hall, A. 1962. A Methodology For Systems Engineering, Van Norstrand, New York, New York.

Henson, P. 1980. "Paul Henson Tells Where United Telecom Is Heading," Telephony, March 31, pp. 27-28.

Hiltz, S. and Turoff, M. 1978. "The Network Nation," Addison-Wesley, Reading, Massachusetts.

Hosselwonder, A. 1978. "Competing In The Terminal Equipment Marketplace: One Telco's Experience," Telephony, January 30, pp. 36+.

Irish, W. 1974. A Market Analysis of the Demand for Telephone Sets by Class of Service, unpublished paper, North Carolina Utilities Commission, Raleigh, North Carolina, December.

Jennings, L. 1979. "The Human Side of Tomorrows Communications," The Futurist, April, pp. 104-109. 
Kahn, H. et al., 1976. "The Next 200 Years," William Morrow Company, New York.

Linstone, H. and Turoff, M. (eds). 1975. The Delphi Method Techniques and Application, Addison-Wesley, London.

Mahan, G. 1979. The Demand For Residential Telephone Service. Michigan State University, Public Utilities Papers, East Lansing, Michigan.

Martin, J. 1976. Telecommunications and The Computer, Prentice Hall, Englewood Cliffs, New Jersey.

Martin, J. 1977. Future Developments In Telecommunications, Prentice Hall, Englewood Cliffs, New Jersey.

Martin, J. 1978. The Wired Society, Prentice Hall, Englewood Cliffs, New Jersey.

Martino, J. 1979. "Telecommunications In The Year 2000," The Futurist, April, pp. 95-103.

O'Muircheartaigh, C. and Payne, C. (eds) 1977. Model Fitting, Wiley adn Sons, New York, New York.

Rhyne, R. F. 1972. "Communicating Holistic Insights," Fields Within Fields, Vol. 5, No. 1, pp. 10-15.

Rowland, W. 1979. "The Effects of Technical Change On The Telecom Industry," Telephony, November 26, pp. 84-85.

Shannon, C. 1948. "Mathematical Theory of Communications," Bell System Technical Journal, July, p. 401.

Strassmann, P. 1980. "The Office of The Future: Information Management For The New Age," Technology Review, December/January, pp. 54-65.

Trimble, D. 1980. General Telephone and Electronics, Los Gatos, California, Interview, October 13.

U. S. Bureau of Census. 1979. Statistical Abstracts of The United States: 1979. (100 Edition) Washington D.C.

Van Deerlin, L. 1980. "Telephony Is Surely The Sleeper Medium of The 1980s," Communications News, January, pp. 33-34.

Volante, B. 1978. A Study of Trends and Demands For Future Services, Phase I, unpublished paper, General Telephone and Electronics, Stamford, Connecticut.

Wheeler, T. 1980. "CATV's Future Is In Program Diversity," Communications News, April, p. 63. 


\section{APPENDIX A}

\section{SER VICE DESCRIPTIONS}

\section{Electronic Newspaper}

Daily newspapers and magazines are constantly updated with current news. A customer could subscribe to several newspapers (getting different perspectives). Electronic Mail

United States mail provided via a view data technology. The mail could either be sent continuously or stored in a computer until requested by the customer.

Travel Reservation

This service is an expansion of the current airline reservation system. Anyone could access the system, as opposed to only airline personnel. The system would also include bus, train, boat, as well as hotel reservations.

POTS

Plain Old Telephone Service.

Cellular Mobile System

This is a mobile telephone system. Due to its cellular design (see Background Chapter), it has a nationwide capacity. Existing systems are quite limited.

\section{Consumer Advisory Service}

Similar to Consumer Report, this service will provide information on various projects (including ratings), companies, and institutions. 
Video Library

Plays, movies, and television shows would be available upon request.

\section{Restaurant Guide}

This will include restaurants, types of cuisine, specialties, prices, hours, and reservations.

Video Games

Similar to the video library, this service provides a multitude of games ranging from chess to sports to space games.

Network Television

This service is often referred to "superstations." These are local television stations which are distributed throughout the nation. They are competitors to the three major networks.

Electronic Library

Libraries would have their card catalogs as well as books on a time-share system. Users would access the "library" anytime of the day. Ultimately, all libraries could be combined into one central data bank.

Outpatient Treatment

A patient's vital signs and some routine lab work will be done in the home or in a neighborhood center. The results would be transmitted to the doctor who, in turn, could tell the patient the appropriate treatment.

\section{Diagnosis}

This service would provide a complete wide-band network to most hospitals and doctor offices. A doctor could transmit the symptoms over the system (complete with color pictures, electrocardiogram, results, etc.). Any doctor knowing the disease could then report back to the originating physician. 


\section{Emergency Services}

Many local ambulance companies, fire departments, and police departments have primitive versions of this service. The aid unit would have a wide-band communications system allowing all vital signs as well as many other monitor to be transmitted to the doctor on call. He, in turn, would use the network to instruct the emergency medical technicians to perform the appropriate procedures.

\section{Computer Tutoring}

The customer would select a program (on the desired subject) from a tutorial library. Through an interactive mode, a computer would coach the student.

\section{Correspondence School}

Similar to the television-type evening courses offered today, this service would provide a taped television lecture. Students would take tests and homework over a view data network. These courses would be offered for credit as well as audit.

\section{Electronic Meetings}

This service allows several paraticipants to conduct a meeting while being geographically and temporarily disbursed. Using a computer and the network, members can communicate to each other simultaneously (public), individually (private "conversations"). Hiltz and Turoff's (1978) EIES system is an example which is already in use (see the Technology Section of Chapter III). Electronic Funds Transfer

There are two types of funds transfer services; those between the consumer and the bank and those between banks. The former is forecasted herein. 
Message Recording

This service, provided by the central office, would allow a caller to leave a message. The message would be stored in the central office's computer (switch) until requested by the called party.

Call Forwarding

Like message recording, call forwarding will be provided through the central office. In addition, some PBXs will have this feature. Call forwarding automatically transfers a call from one telephone to another.

$\underline{\text { Video Conferencing }}$

This is a sophisticated version of AT\&T's videophone. Users would have both voice and video capacity.

Appointment Calendar

This service would replace the desk calendar. In addition, it can be programmed for wake-up calls or meeting reminders.

\section{Data Base Access}

This service would provide consumers (and businesses) access to government documents, results from statistical polls, corporate data bases, as well as medical records. Ultimately, this could result in a gigantic data base.

\section{Word Processing}

Dictation or written documents would be typed and edited (for grammar) by a remote word processor. This will be especially beneficial to smaller companies that do not have enough work to warrant a secretary. Larger corporations will have their own remote word processing centers, reducing the manpower requirements.

\section{Computer-To-Computer Communications}

This is a specialized, high-capacity service. Wide-band circuits will be used. 


\section{APPENDIX B}

\section{REGRESSION RESULTS}

\section{HOUSEHOLD SIZE}

\begin{tabular}{lc}
\multicolumn{1}{c}{ Variable } & .823 \\
Child & 1.57 \\
Divorce & 1.77 \\
Constant & \\
Statistics & \\
R Square .999 & \\
Residual Sum of Square .0003 \\
Degrees of Freedom 4 \\
Dependent Variable--Household Size
\end{tabular}

\section{Standard}

Error

.0345

.0281
$3,143.5$

F-Ratio

568.3

\section{BUSINESS MAINSTATIONS}

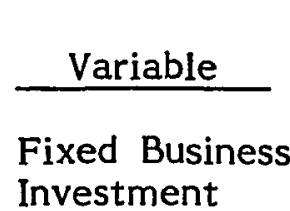

Coefficient

25.01

6,103
Standard

Error

.4334

Constant

$\underline{\text { Statistics }}$

R Square .998

Residual Sum of Squares 1,305,662

Degrees of Freedom 8

Dependent Variable--Business Mainstations 
APPENDIX C

SAMPLE REPORTS 
FOFIEL

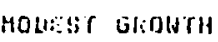

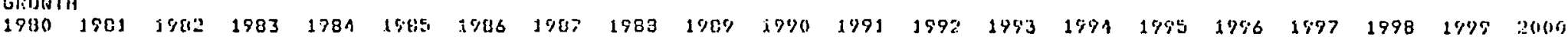
ELLCTi.,IILL HENSPAPEK

REETHEHTIAL

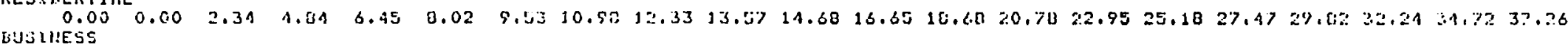

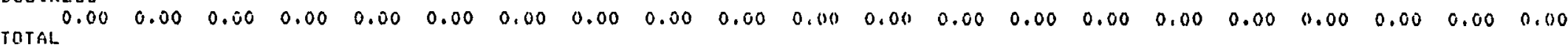

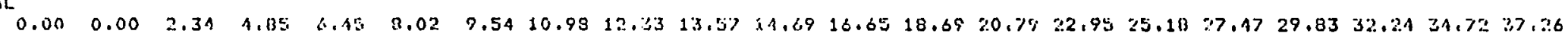

CLECTROMIC MÁIL

FESIUEWIIAL

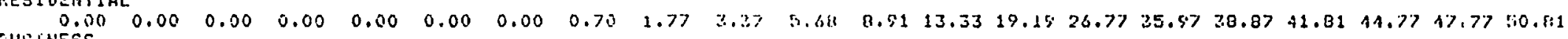

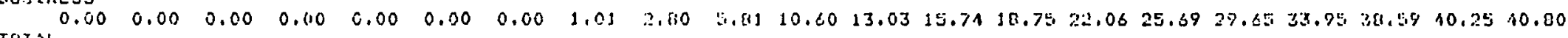

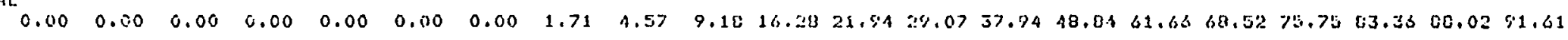

\section{TFSTILL FESEFHATIOHS}

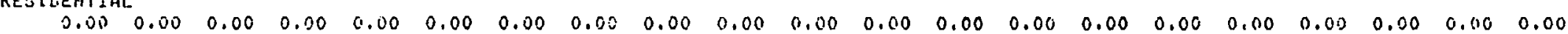

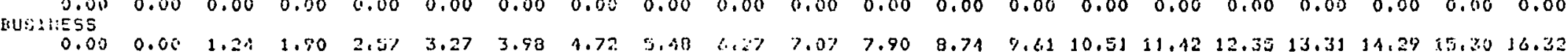
TOTAL

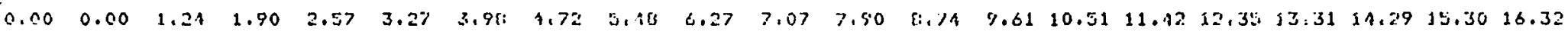

HAAII SLII TELEPHONE SEFUICE

RES I UEHITIAL

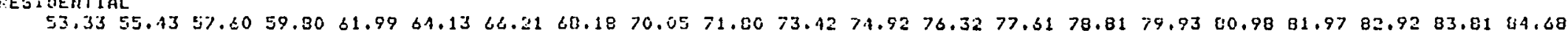
SUSIMLSS TOTAL

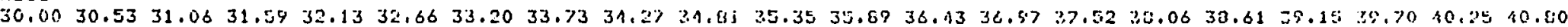

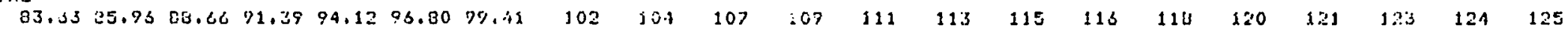
rELLLULF: HOULE SYSTEM

RECIAEUITISL

\begin{tabular}{|c|c|c|c|c|c|c|c|c|c|c|c|c|c|c|c|c|c|c|c|c|}
\hline $\begin{aligned} 0.00 \\
\therefore i s 5\end{aligned}$ & 0.00 & 0,00 & 0.00 & 0.00 & 0.00 & 0.00 & 0.00 & 0.00 & 0.00 & 0.00 & $\therefore, 00$ & 0.00 & 0.00 & 0.00 & 0.00 & 0.00 & 0.00 & 0.00 & 0.00 & 0.00 \\
\hline $1 \mathrm{AL}^{0.00}$ & 0.00 & 0.00 & 0.00 & 0.00 & 0.00 & 0.00 & 0.00 & 0.56 & 0.00 & 0.00 & 0.00 & 0.00 & 0.00 & 0.00 & 0.00 & 0.00 & 0.00 & 0.00 & 0.00 & 0.00 \\
\hline 0.00 & 0.00 & 0.00 & 0.00 & 0.00 & 0.00 & 0.06 & 0.00 & 0.00 & 0.00 & 0.50 & 0.00 & 0.00 & 0.00 & 0.00 & 0.00 & 0.00 & 0.00 & 0.00 & 0.00 & 0.00 \\
\hline
\end{tabular}

COAEUIILF GLUISOKY SERUICE

FESIOLIIILAL

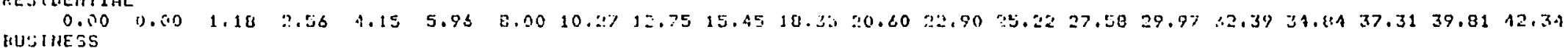

$\begin{array}{rlllllllllllllllllllllllll}0.00 & 0.00 & 0.00 & 0.00 & 0.00 & 0.00 & 0.00 & 0.00 & 0.00 & 0.00 & 0.00 & 0.00 & 0.00 & 0.00 & 0.00 & 0.00 & 0.00 & 0.00 & 0.00 & 0.00 & 0.00\end{array}$ Tuint

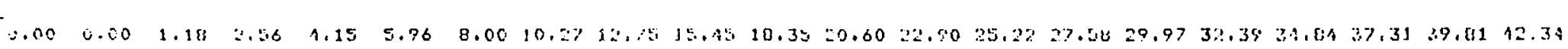


FORTLL.

TEFHIML DEMOMU) ROFECAST (HILI.IUHE;

MOLES GRUHTH

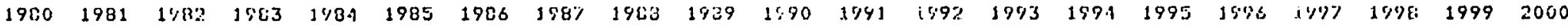
NOICE

TiESILENIITLL

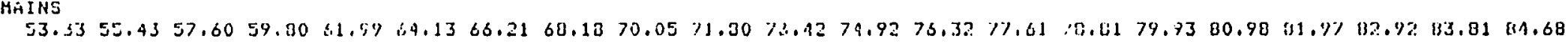

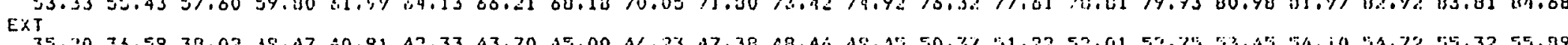

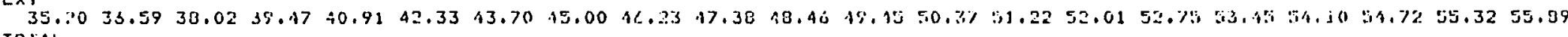

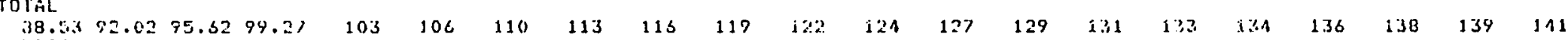
EUSIHESS

MAINS

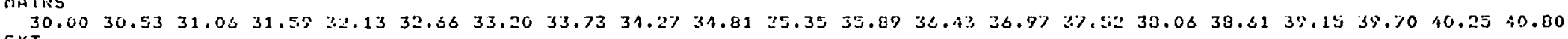
EXT 9 , ind

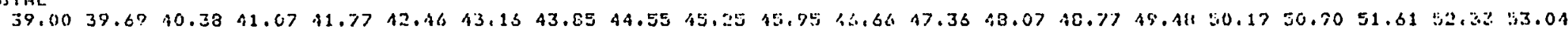

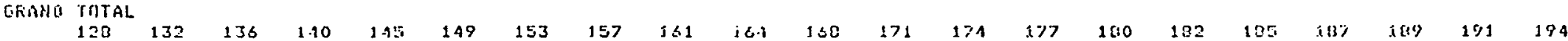
IIITA

RESIEENTIEL

\begin{tabular}{|c|c|c|c|c|c|c|c|c|c|c|c|c|c|c|c|c|c|c|c|c|}
\hline $\begin{array}{l}\text { MnINS } \\
1.07\end{array}$ & 1.11 & 1.15 & 1.20 & 1,21 & 1.28 & 1.32 & 1.36 & 1.10 & 1.11 & 1,47 & 1.50 & 1.53 & 1.55 & 1.58 & 1.30 & 1.62 & 1.64 & 1.66 & 1.68 & 1.69 \\
\hline $\begin{array}{c}\text { is. } 32 \\
\text { ToIAL }\end{array}$ & 0.33 & 0.315 & 0.36 & 0.37 & 0.33 & 0.10 & 0.11 & $0.4 \%$ & 0.43 & 0.41 & $0.4:$ & 0.16 & 0.17 & 0.47 & 0.48 & 0.19 & 0.47 & 0.50 & 0.50 & 0.51 \\
\hline $\begin{array}{c}1 \text { 1.37 } \\
\text { JIIESS }\end{array}$ & 1.14 & 1.50 & 1.55 & 1,51 & $1.2:$ & $1, \%$ & 1.77 & 1.82 & 1.07 & 3.51 & $1, \%$ & 1.90 & 2.02 & 2.05 & 2.00 & $2.1 x$ & 2.13 & 2.16 & 2.18 & 2.20 \\
\hline $\begin{array}{l}\text { MFILE } \\
\text { EXT } 0.20\end{array}$ & 0.61 & 0.52 & 0.63 & 0.84 & 0.65 & 0.65 & $0.6 \%$ & 0.59 & $0 . \%$ & 0.71 & 0.72 & 0.73 & 0.71 & 0.78 & 0.76 & 0.77 & 0.716 & 0.79 & 0.813 & 0.02 \\
\hline${ }_{\text {TUTAL }}^{0 . \mathrm{i}}$ & 0.10 & 0.15 & 0.18 & 0.19 & 0.20 & 0.20 & 0.20 & 0.21 & 0.21 & 0.21 & 0.22 & 0.22 & 0.22 & 0.23 & 0.23 & 0.23 & 0.22 & 0.24 & 0.21 & 0.24 \\
\hline 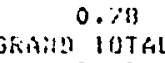 & 0.79 & 0.81 & 0.82 & 0.84 & 0.05 & 0.56 & 0.88 & 0.89 & 0.71 & $0 . \%$ & 0.5 .3 & 0.95 & 0.96 & 0.70 & $0.5 \%$ & 1.60 & i.0? & 1.03 & 1.05 & 1.03 \\
\hline 2.17 & 2.24 & 2.31 & $\therefore \therefore 0$ & $\therefore .5$ & 2.521 & 2.58 & 2.35 & 2.71 & 2.77 & $\therefore 83$ & 2.88 & 2.73 & : & 3.02 & 3.07 & 3.11 & 3.15 & $3.1 \%$ & 2.23 & 320 \\
\hline
\end{tabular}


FORTEL.

MOUEST GROWTH

SERUICE SEGMEMT ANILYSIS

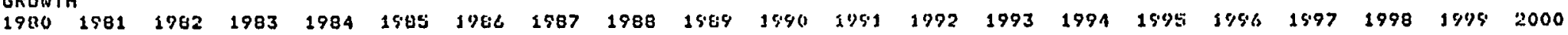
ELELTKOHIC NEUSPAPER

$\begin{array}{lllllllllllllllllllll}0.00 & 0.00 & 0.63 & 1.30 & 1.72 & 2.12 & 2.51 & 2.88 & 3.23 & 3.54 & 3.01 & 1.32 & 4.05 & 5.40 & 5.56 & 6.54 & 7.13 & 7.74 & 0.37 & 9.01 & 9.67\end{array}$

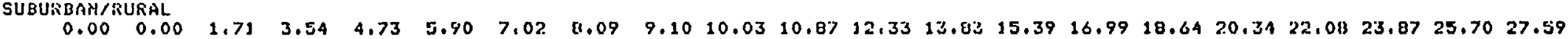
TOTAL

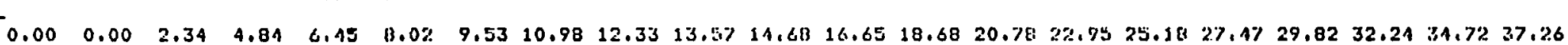
ELECTKONIC MAIL

URBAN

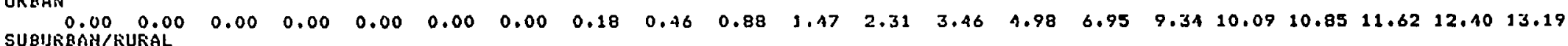

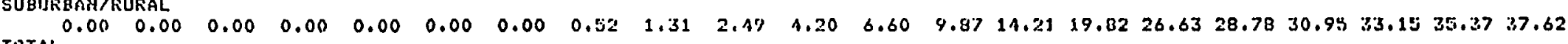
TUTAL

$\begin{array}{lllllllllllllllllllllllllll}0.00 & 0.00 & 0.00 & 0.00 & 0.00 & 0.00 & 0.00 & 0.70 & 1.77 & 3.37 & 5.68 & 8.91 & 13.33 & 19.19 & 26.77 & 35.97 & 38.87 & 41.81 & 44.77 & 17.77 & 50.81\end{array}$

TRGUEL KESERUATIOHS

URBAN

$\begin{array}{lllllllllllllllllllllllllll}0.00 & 0.00 & 0.00 & 0.00 & 0.00 & 0.00 & 0.00 & 0.00 & 0.00 & 0.00 & 0.00 & 0.00 & 0.00 & 0.00 & 0.00 & 0.00 & 0.00 & 0.00 & 0.00 & 0.00 & 0.00\end{array}$

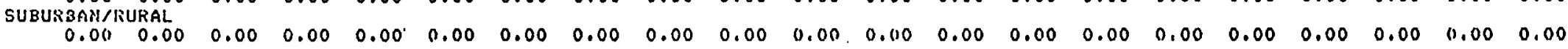
TOTAL

$\begin{array}{llllllllllllllllllllllllllllll}0.00 & 0.00 & 0.00 & 0.00 & 0.00 & 0.00 & 0.00 & 0.00 & 0.00 & 0.00 & 0.00 & 0.00 & 0.00 & 0.00 & 0.00 & 0.00 & 0.00 & 0.00 & 0.00 & 0.00 & 0.00\end{array}$

FLAIN OLD TELEFHUNE SERUICE

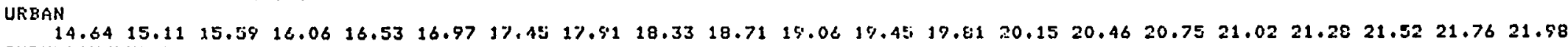
SUBUR 3AMI/RIJRAL

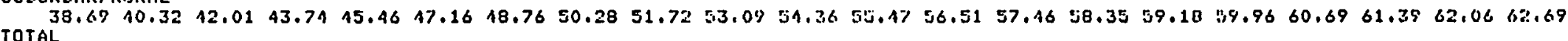

$53.3355 .4357 .6059 .8061 .9964 .1366 .2168 .1070 .0571 .0073 .4274 .9276 .3277 .6174 .8179 .9380 .5881 .97 \quad 132.9283 .8184 .68$ CELLULAR MOBILE SYSTEM

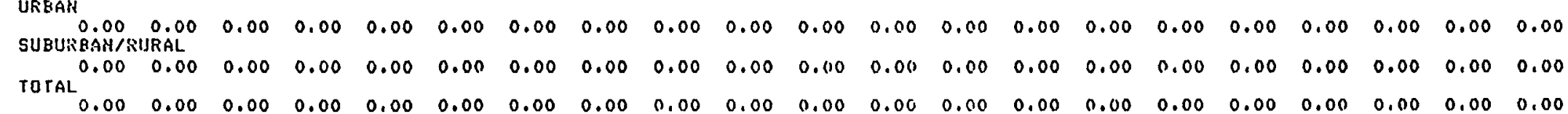
CONSUMER AIUISORY SEKUICE URBAR

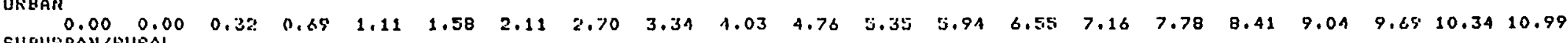

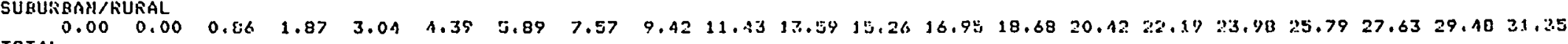
TOTAL

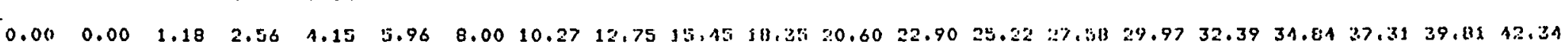


I JKREL

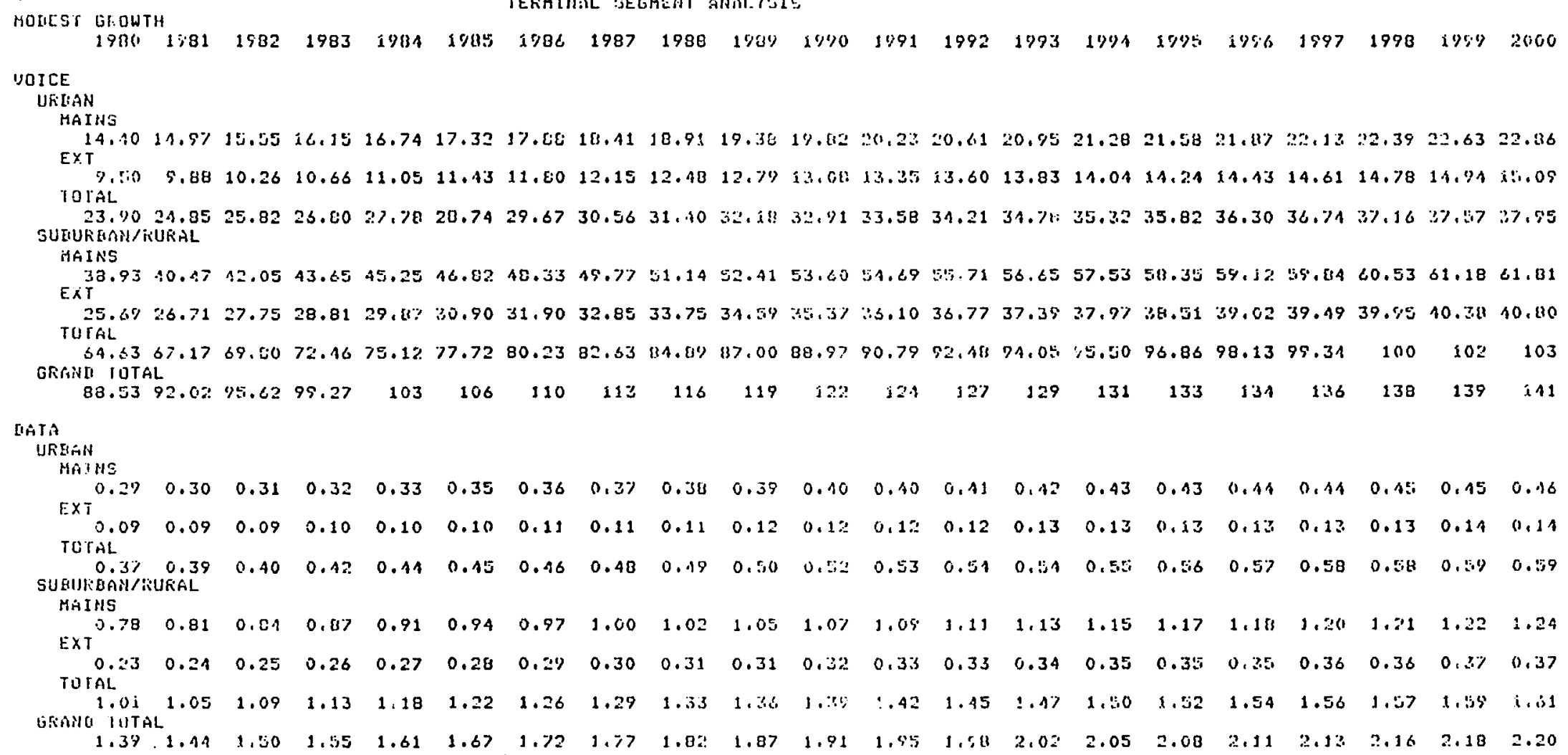


FOKIILL

MONEST GRUHTH

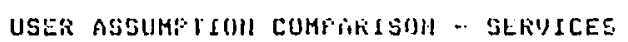

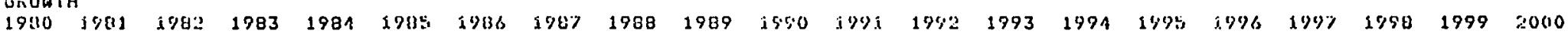

LLECTKUATC MEWSPHFER

ECUNOMIC COLLAFSE

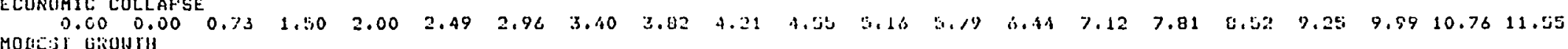
:ji livaluril

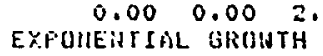

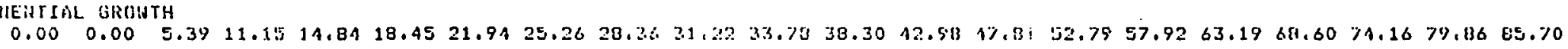

ELECTKOMIC IIAIL

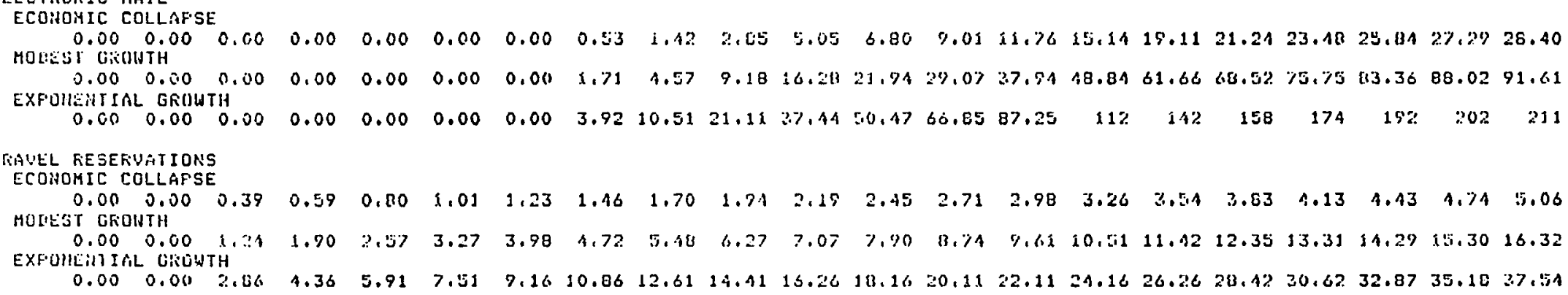

FLAIH OLI TELEFHONE SERUICE

cLUMUITL COLLAFSE

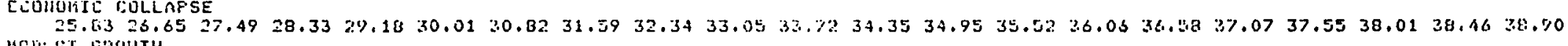
$\begin{array}{rllllllllllllllll}83.3385 .96 \quad 113.66 & 91.39 & 94.1296 .8099 .41 & 102 & 10.1 & 107 & 109 & 119 & 113 & 115 & 116 & 118 & 120 & 121 & 123 & 124 & 125\end{array}$

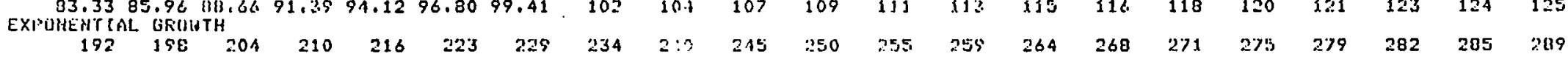

CELLULAIF MOHILE STSTEM

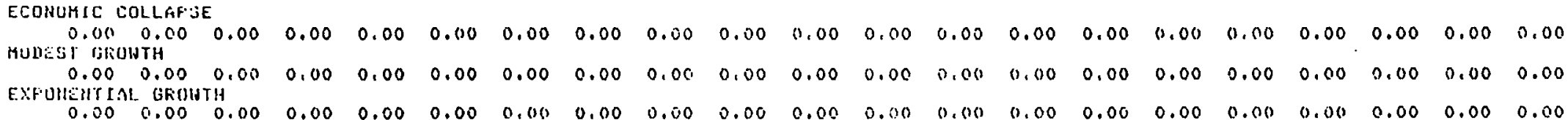

COI:SIMMEK NIUISORY SEKUICE

ECUHOMIL COLLAFSE

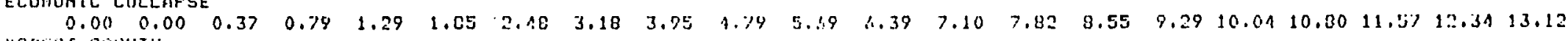
MOL::

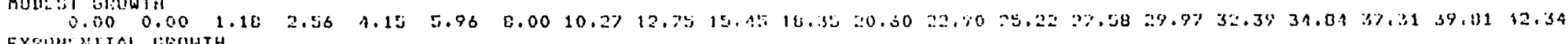
EXFunil!IIAL. LEROWTH

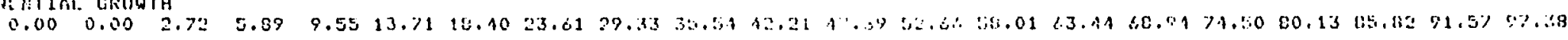


SHIEL

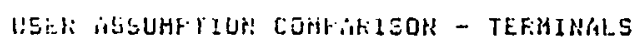

MODEST GRUNTH

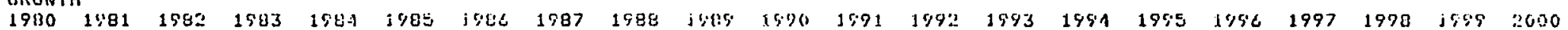
VOICE

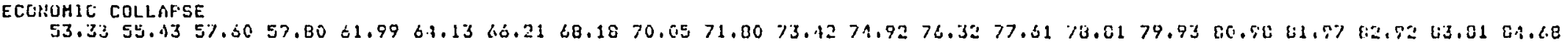
MOEEST CiKOWTH

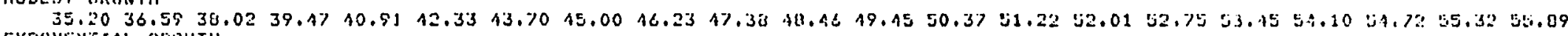

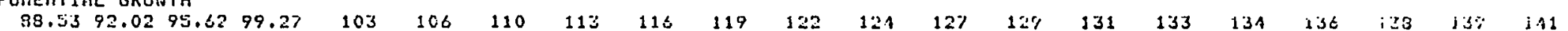
Intî.

ECORUMIC COLLAFSE

\begin{tabular}{|c|c|c|c|c|c|c|c|c|c|c|c|c|c|c|c|c|c|c|c|c|}
\hline moures $1.0 \%$ & $\begin{array}{l}\text { i.11 } \\
\text { NTii }\end{array}$ & 1.15 & i. 20 & 1.21 & i. 20 & 1.32 & 1.36 & 1.40 & 1.74 & 1.17 & 1.50 & 1,53 & 1.55 & 1.58 & 1.60 & 1.62 & 1.81 & 1.56 & j. 20 & 1.57 \\
\hline $\begin{array}{c}0.32 \\
\text { Exroumentsal }\end{array}$ & $\begin{array}{l}0.33 \\
1 . \quad \text { Candw }\end{array}$ & ${ }_{\mathrm{rH}}^{0.35}$ & 0.35 & 0.37 & 0.38 & 0.40 & 0.41 & 0.42 & 0.43 & 0.41 & 0.45 & 0.46 & 0.17 & 0.17 & 0.48 & 0.49 & 0.49 & 0.50 & 0.50 & $0 .: 1$ \\
\hline 1.35 & 1,14 & 1.50 & ت5 . 1 & 1.61 & 1.67 & 1.72 & 1.77 & 1.22 & $1.0 \%$ & i. 91 & 1.75 & 1.58 & 2.02 & 2.05 & .08 & & & 2.16 & $2, j a$ & 2.20 \\
\hline
\end{tabular}
UIDLO

ECOR:OHIC COLLRFE

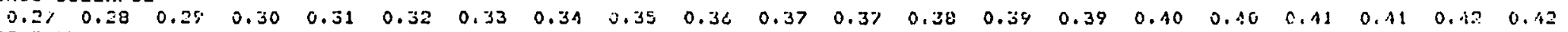
MOLEST SROHTH

$\begin{array}{lllllllllllllllllllllllll}0.05 & 0.06 & 0.06 & 0.06 & 0.06 & 0.06 & 0.07 & 0.07 & 0.07 & 0.07 & 0.07 & 0.07 & 0.00 & 0.00 & 0.08 & 0.08 & 0.03 & 0.06 & 0.08 & 0.08 & 0.08\end{array}$

EXFONEAIINL GSENT

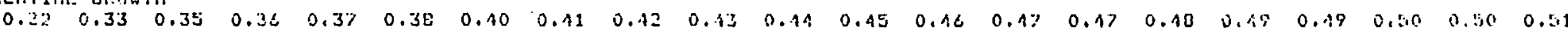


FDETEL

SERUILE NGSUMPTIOKE

MoLesi Li:JWrH

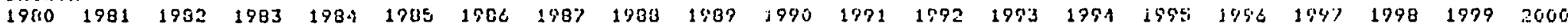
ELECTRUHIL NEWSAPAFER

RESIMENTIAL

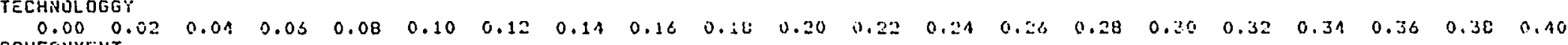

GOVERNMENT

$\cos \cos ^{1}$

$\begin{array}{lllllllllllllllllllll}1.00 & 1.00 & 1.00 & 1.00 & 1.00 & 1.00 & 1.00 & 1.00 & 1.00 & 1.00 & 1.00 & 1.00 & 1.00 & 1.00 & 1.00 & 1.00 & 1.00 & 1.00 & 1.00 & 1.00 & 1.00\end{array}$

NERGY

CCHFEYYTION

$\begin{array}{llllllllllllllllllllll}0.20 & 0.30 & 0.10 & 0.50 & 0.60 & 0.70 & 0.50 & 0.50 & 1.00 & 1.10 & 1.20 & 1.30 & 1.40 & 1.50 & 1.60 & 1.70 & 1.40 & 1.90 & 2.00\end{array}$

$\begin{array}{llllllllllllllllllllllllll}0.00 & 0.00 & 0.00 & 0.00 & 0.00 & 0.00 & 0.00 & 0.00 & 0.00 & 0.00 & 0.01 & 0.02 & 0.03 & 0.04 & 0.05 & 0.06 & 0.07 & 0.00 & 0.04 & 0.10\end{array}$

FRI ICE

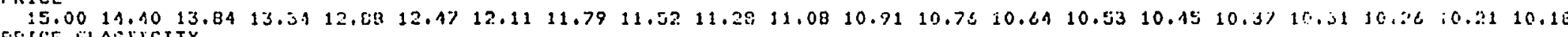

FRICE ELASTICITY

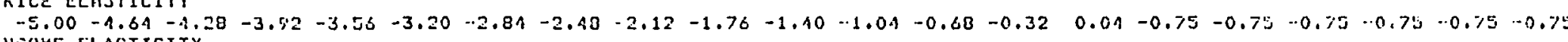

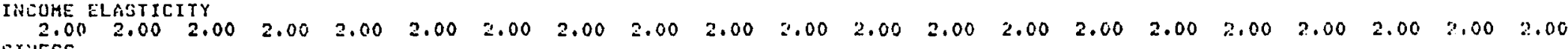
IUSTIESS

TECHAROLOCCY

$\begin{array}{llllllllllllllllllllllll}0.00 & 0.00 & 0.00 & 0.00 & 0.00 & 0.00 & 0.00 & 0.00 & 0.00 & 0.00 & 0.00 & 0.00 & 0.00 & 0.00 & 0.00 & 0.00 & 0.00 & 0.00 & 0.00 & 0.00 & 0.00\end{array}$

GOVEKHMENT

$\begin{array}{cllllllllllllllllllllllll}1.00 & 1.00 & 1.00 & 1.00 & 1.00 & 1.00 & 1.00 & 1.00 & 1.00 & 1.00 & 1.00 & 1.00 & 1.00 & 1.00 & 1.00 & 1.00 & 1.00 & 1.00 & 1.00 & 1.00 & 1.00\end{array}$

$\begin{array}{rllllllllllllllllllllllll}0.00 & 0.10 & 0.20 & 0.30 & 0.40 & 0.50 & 0.40 & 0.70 & 0.80 & 0.50 & 1.00 & 1.10 & 1.20 & 1.30 & 1.40 & 1.50 & 1.40 & 1.70 & 1.60 & 1.90 & 2.00\end{array}$

$\begin{array}{rlllllllllllllllllllllllllllll}0.00 & 0.00 & 0.00 & 0.00 & 0.00 & 0.00 & 0.00 & 0.00 & 0.00 & 0.00 & 0.00 & 0.01 & 0.02 & 0.03 & 0.01 & 0.05 & 0.06 & 0.0 \% & 0.08 & 0.08 & 0.10\end{array}$

$\begin{array}{llllllllllllllllllllll}0.30 & 0.45 & 0.10 & 0.35 & 0.30 & 0.25 & 0.20 & 0.15 & 0.10 & 0.05 & 0.00 & 0.00 & 0.00 & 0.00 & 0.00 & 0.00 & 0.00 & 0.00 & 0.00 & 0.00 & 0.00\end{array}$

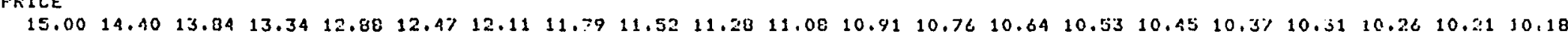

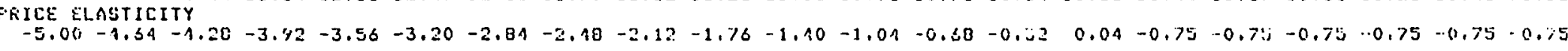


FOFiTi:

MODEST GKUUTH

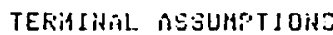

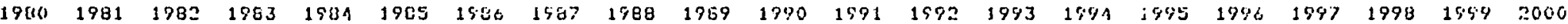

VDICE

FESIREMIXIML

FKICE

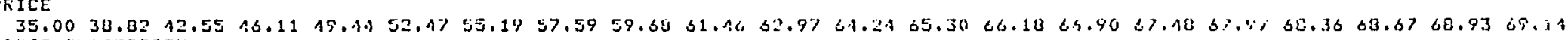

PRICE ELASTICITY

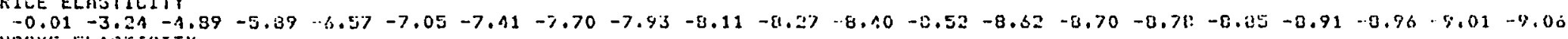
IHCOME ELASTILITY

$\begin{array}{lllllllllllllllllllllllll}0.02 & 0.02 & 0.02 & 0.02 & 0.02 & 0.02 & 0.02 & 0.02 & 0.02 & 0.02 & 0.02 & 0.02 & 0.02 & 0.02 & 0.02 & 0.02 & 0.02 & 0.92 & 0.02 & 0.02 & 0.02\end{array}$

ERMIMLS/HUUSEHOL

$\begin{array}{llllllllllllllllll}1.15 & 3.80 & 3.45 & 3.10 & 2.76 & 2.45 & 2.1 \% & 1.94 & 1.74 & 1.50 & 1.45 & 1.31 & 1.26 & 1.20 & 1.15 & 1.11 & 1.09 & 1.07\end{array}$

EUSTHESS

PRICE

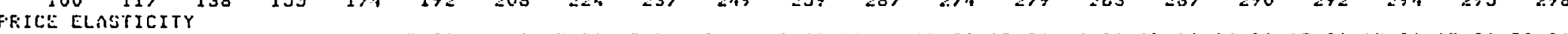

$-0.01-1.01-2.01-3.01-4.01-5.01-6.01-7.01-8.01-5.01-10.01-11.01-12.01-13.01-14.01-15.01-16.01-17.01-16.01-19.01-20.01$ FIXEA DUSIHESS IIIU ELASTICITY $\begin{array}{lllllllllllllllllllllllll}0.02 & 0.02 & 0.02 & 0.02 & 0.02 & 0.02 & 0.02 & 0.02 & 0.02 & 0.02 & 0.02 & 0.02 & 0.02 & 0.02 & 0.02 & 0.02 & 0.02 & 0.02 & 0.02 & 0.02 & 0.02\end{array}$ IATA

RESIDENTIAL

$\begin{array}{rllllllllllllllllllll}1500 & 1400 & 1300 & 1200 & 1100 & 1000 & 900 & 900 & 900 & 900 & 900 & 900 & 700 & 900 & 900 & 900 & 900 & 900 & 900 & 900 & 900\end{array}$ FRILE ELASTICITY $-8.00-7.50-7.00$

IVLOME ELASTECITY

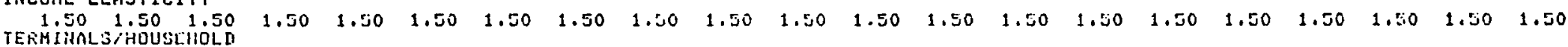
$\begin{array}{lllllllllllllllllllll}5.00 & 5.01 & 5.02 & 5.03 & 5.04 & 5.05 & 5.60 & 5.34 & 5.03 & 1.83 & 1.30 & 3.39 & 3.47 & 3.09 & 2.72 & 2.90 & 2.11 & 1.08 & 1.68 & 1.52 & 1.90\end{array}$ EUSIILES

$\begin{array}{rllllllllllllllllllllll}1500 & 1100 & 1300 & 1200 & 1100 & 1000 & 500 & 800 & 700 & 400 & 500 & 100 & 400 & 100 & 100 & 100 & 100 & 100 & 100 & 100 & 100\end{array}$ FFILE ELAETICITY

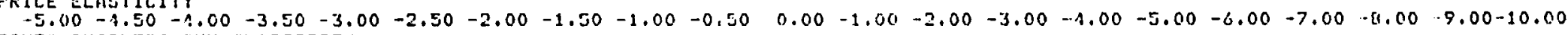
FIXEL BUSINESS INU ELASTICITY

$\begin{array}{lllllllllllllllllllll}3.00 & 3.00 & 3.00 & 3.00 & 3.00 & 3.00 & 3.00 & 3.00 & 3.00 & 3.00 & 2.83 & 5.65 & 2.96 & 2.26 & 2.06 & 1.67 & 1.69 & 1.53 & 1.40 & 1.38 & 1.18\end{array}$ 
TOF:TEL

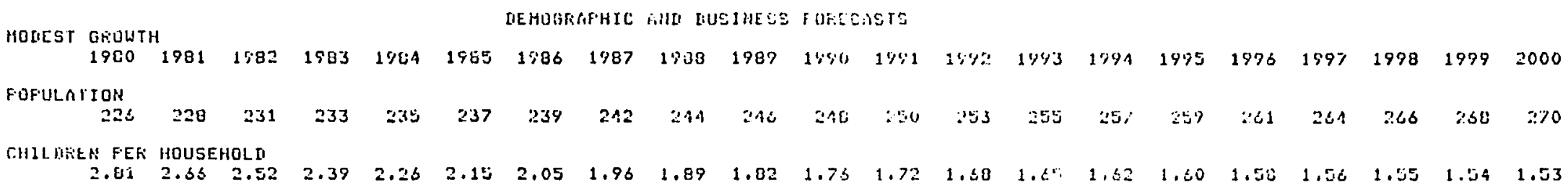
DIUURCE RATE

$10.0010 .0010 .0010 .0010 .0010 .0010 .0010 .0010 .0010 .0010 .0010 .0010 .00 \quad 10.0010 .0010 .0010 .0010 .0010 .0010 .0010 .00$ IISTOSAMLE INCOATE

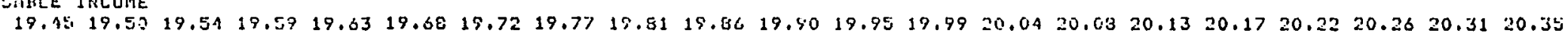
URHiN stiHiE!r(\%)

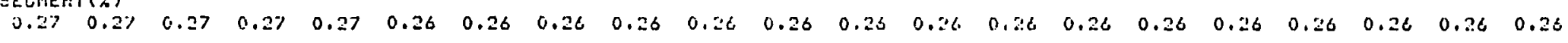

SUEULGAR:ARULAL SECMENT( $x)$

$\begin{array}{lllllllllllllllllllllllll}0.73 & 0.73 & 0.73 & 0.73 & 0.73 & 0.74 & 0.71 & 0.74 & 0.74 & 0.74 & 0.71 & 0.74 & 0.24 & 0.71 & 0.74 & 0.74 & 0.71 & 0.74 & 0.74 & 0.74 & 0.74\end{array}$

URBR:R HEUSEHOLIIS (IIILLIONS)

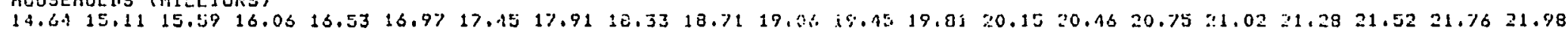
SUTSKHAHARURAL HGUSEHOLTS (MILLIONG)

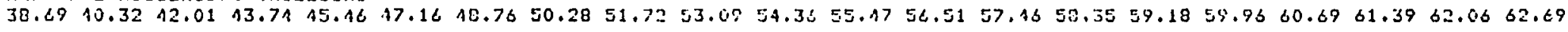

TOTHL HOUGEHGLIS (MILLIONS)

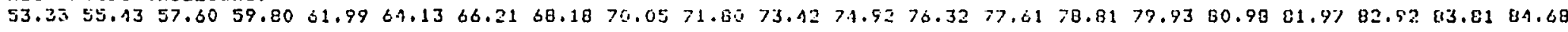

FIMEA BUSINESS INUESTMENT (TFILLIOHS)

$\begin{array}{llllllllllllllllllllll}1.50 & 1.52 & 1.54 & 1.56 & 1.58 & 1.60 & 1.62 & 1.64 & 1.65 & 1.68 & 1.70 & 1.72 & 1.74 & 1.96 & 1.08 & 1.100 & 1.82 & 1.84 & 1.06 & 1.08 & 1.90\end{array}$

IHH (HIHFTION HANLLERS $(\%)$

$\begin{array}{lllllllllllllllllllllll}0.00 & 0.00 & 0.00 & 0.00 & 0.00 & 0.01 & 0.01 & 0.01 & 0.01 & 0.01 & 0.01 & 0.01 & 0.01 & 0.01 & 0.01 & 0.02 & 0.02 & 0.02 & 0.02 & 0.02 & 0.02\end{array}$ 
APPENDIX D

USER ASSUMPTION WORK SHEETS

GENERAL ASSUMPTION WORK SHEET

ASSUMPTION SET I--ECONOMIC COLAPSE

\section{Variable \\ (Period) \\ Population (Millions) \\ 1 through 8}

9 through 21

\section{Children Per Household}

1 through 8

9 through 11

11 through 21

Divorce Rate

1 through 8

8 through 21

\section{Urban Segment}

1 through 8

8 through 11

11 through 21

\section{Income}

1 through 8

8 through 11

11 through 21
Forecasting

Technique

\section{Growth Rate/Limits}
L $\quad I=225.1$
$\mathrm{S}=$
2.2
L I $\quad$ I 241.5
$\mathrm{S}=$
5

$\begin{array}{lllll}\mathrm{L} & \mathrm{I}= & 2.81 & \mathrm{~S}= & -.02 \\ \mathrm{E} & \mathrm{I}= & 2.67 & \mathrm{~S}= & .2 \\ \mathrm{~L} & \mathrm{I}= & 4.84 & \mathrm{~S}= & .05\end{array}$

$\begin{array}{lllll}\mathrm{L} & \mathrm{I}= & 10 & \mathrm{~S}= & .19 \\ \mathrm{~L} & \mathrm{I}= & 2.4 & \mathrm{~S}= & .05\end{array}$

L $\quad I=\quad .27$

$\mathrm{S}=$

$-.0027$

$\mathrm{E} \quad \mathrm{I}=$

.26

.0025

I I $=$

.54

$-.001$

Fixed Business Investment

1 through 21

$\begin{array}{ll}\mathrm{S} & \mathrm{U}=30,000 \\ \mathrm{E} & \mathrm{I}=30,000 \\ \mathrm{~L} & \mathrm{I}=14,240\end{array}$

$L=19,450$

$\mathrm{S}=\quad-.25$

$\mathrm{S}=150$

$\mathrm{S}=$

\section{Fixed Business Investment}

Information Handlers

1 through 21

C $\quad I=226$

C $\quad I=\quad .1$ 
SER VICE ASSUMPTION WORK SHEET

ASSUMPTION SET I--ECONOMIC COLAPSE

SER VICE: ELECTRONIC NEWSPAPER

$\begin{array}{cccccc}\begin{array}{c}\text { Variable } \\ \text { (Period) }\end{array} & \begin{array}{c}\text { Forecasting } \\ \text { Technique }\end{array} & & & \\ \text { Growth Rate/Limits }\end{array}$

\section{BUSINESS MARKETY}

Price Elasticity

1 through 8

9 through 11

11 through 21

$\begin{array}{ll}\mathrm{C} & \mathrm{I}=-4 \\ \mathrm{C} & \mathrm{I}=-8 \\ \mathrm{~L} & \mathrm{I}=\end{array}$

Technology

1 through 21

C $\quad I=\quad .00001$ 
TERMINAL ASSUMPTION WORK SHEET

ASSUMPTION SET I--ECONOMIC COLAPSE

TERMINAL TYPE: VOICE

\begin{tabular}{ccc}
$\begin{array}{l}\text { Variable } \\
\text { (Period) }\end{array}$ & $\begin{array}{l}\text { Forecasting } \\
\text { Technique }\end{array}$ & Growth Rate/Limits \\
\hline
\end{tabular}

RESIDENTIAL MARKET

Price

1 through 21

C $\quad I=35$

Price Elasticity

1 through 8

9 through 21

C $\quad I=-1$

C $\quad I=.3$

Income Elasticity

1 through 8

9 through 21

C $\quad I=\quad .75$

C $\quad I=3$

Terminals Per Household

1 through 8

9 through 21

C I $\quad$ I 5

L $\quad I=5 \quad$ S $=\quad-.1$

BUSINESS MARKET

Price

1 through 21

C $\quad I=100$

Price Elasticity

1 through 8

9 through 21

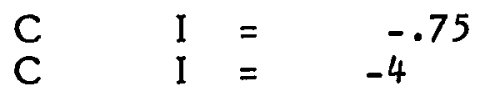

Fixed Business Investment

Elasticity

1 through 8

9 through 21

$\begin{array}{ll}C & I\end{array}=4^{-5}$ 


\section{APPENDIX E}

\section{SER VICE AND TERMINAL FORECASTS}




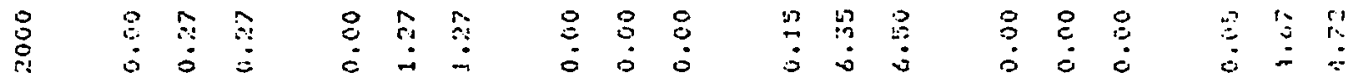

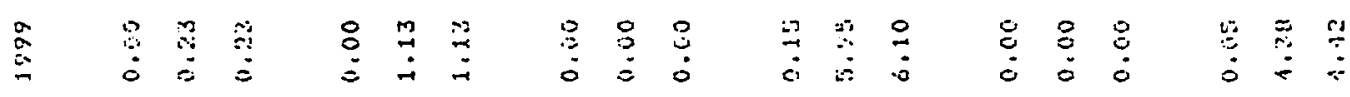

恖

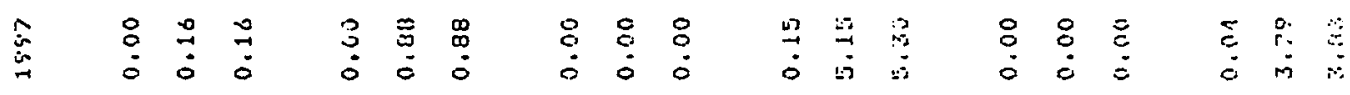

兽

莣

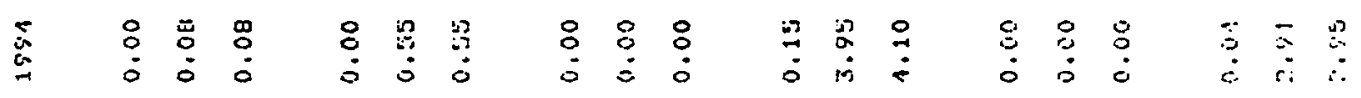

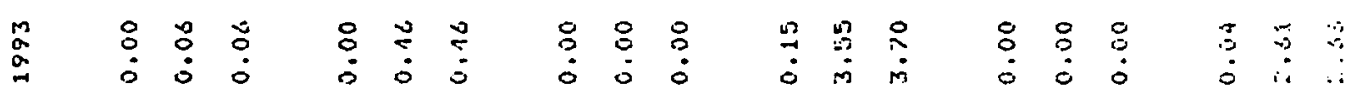

葛

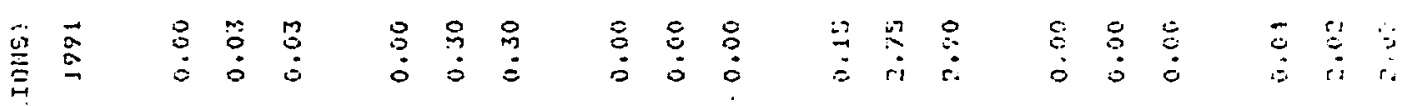

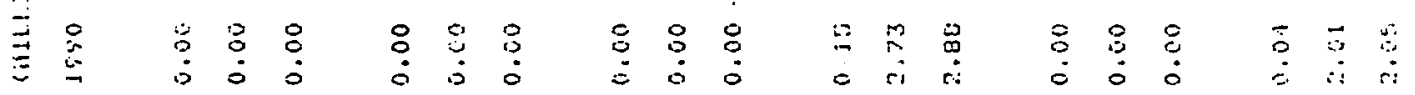

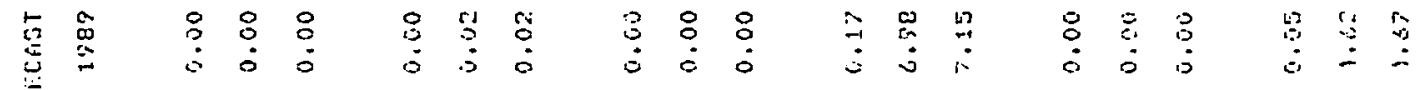

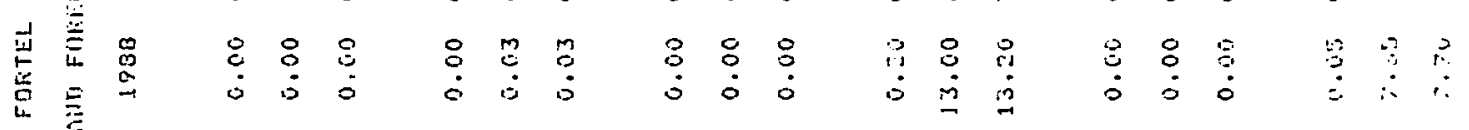

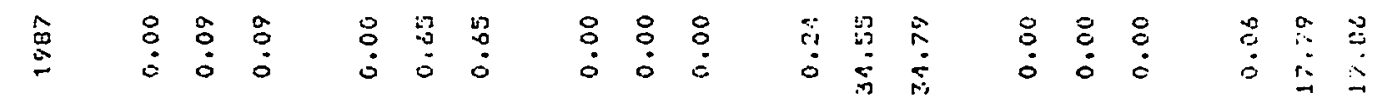

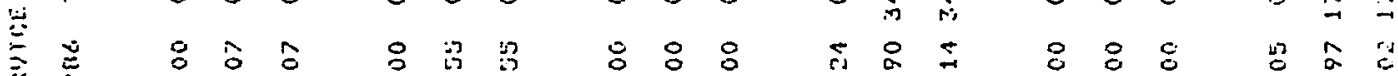

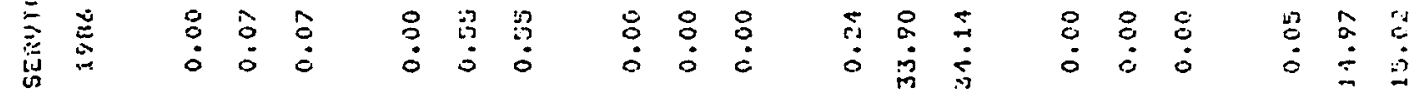

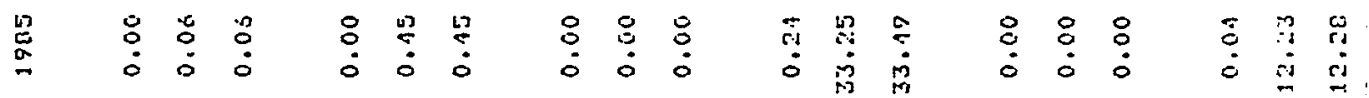

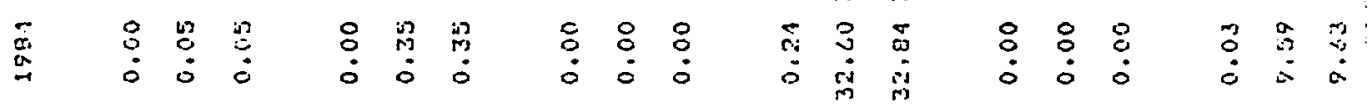

哭

总

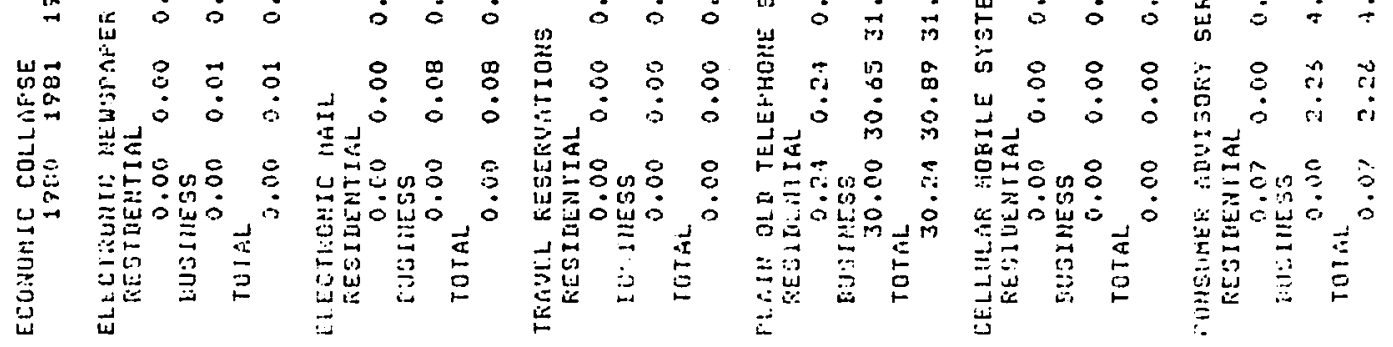


FOKTLL.

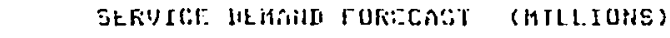

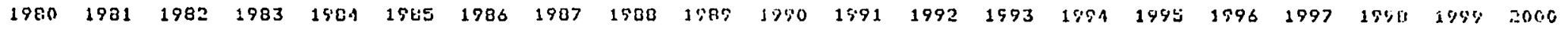

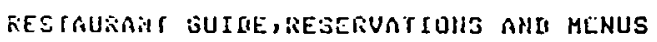

REETJUERIGL

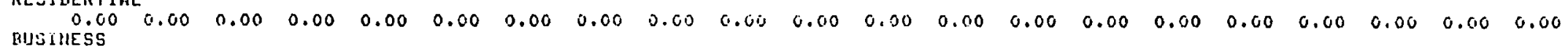

$\begin{array}{lllllllllllllllllllllllllllll}0.00 & 0.00 & 0.00 & 0.00 & 0.00 & 0.00 & 0.00 & 0.00 & 0.00 & 0.00 & 0.00 & 0.00 & 0.00 & 0.60 & 0.00 & 0.00 & 0.00 & 0.00 & 0.00 & 0.00 & 0.00\end{array}$

TOTAL

$\begin{array}{lllllllllllllllllllllllllllll}0.00 & 0.00 & 0.00 & 0.00 & 0.00 & 0.00 & 0.00 & 0.00 & 0.00 & 0.00 & 0.00 & 0.00 & 0.00 & 0.00 & 0.00 & 0.00 & 0.00 & 0.00 & 0.00 & 0.00 & 0.00\end{array}$

VII:CO CA:MES

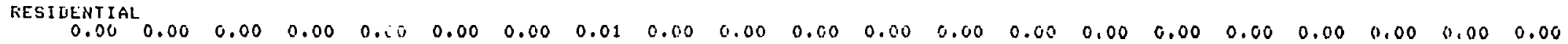

$\begin{array}{lllllllllllllllllllllllllll}0.00 & 0.00 & 0.00 & 0.00 & 0.00 & 0.00 & 0.00 & 0.00 & 0.00 & 0.00 & 0.00 & 0.00 & 0.00 & 0.00 & 0.00 & 0.00 & 0.00 & 0.00 & 0.00 & 0.00 & 0.00\end{array}$

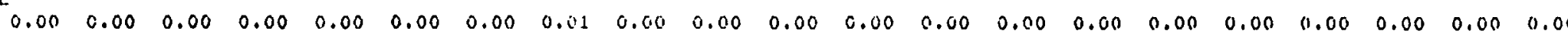

HEIUTRI. TELEUIGION TRRARSLISSION (SUFEHSTRTIONS)

RESIGENTIAL

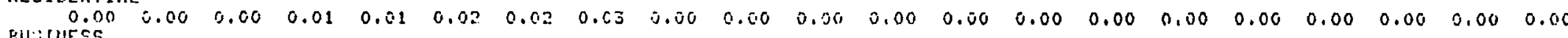

$\begin{array}{lllllllllllllllllllllllll}0.00 & 0.00 & 0.00 & 0.00 & 0.00 & 0.00 & 0.00 & 0.00 & 0.00 & 0.20 & 0.00 & 0.00 & 0.00 & 0.00 & 0.00 & 0.00 & 0.00 & 0.00 & 0.00 & 0.00 & 0.00\end{array}$

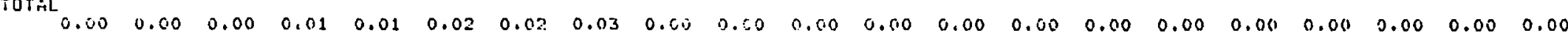

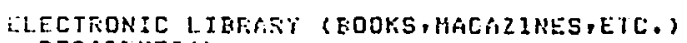

RESIDESTIAL-

$\begin{array}{cccccccccccccccccccccccc}0.00 & 0.00 & 0.00 & 0.00 & 0.00 & 0.00 & 0.00 & 0.00 & 0.00 & 0.00 & 0.00 & 0.00 & 0.00 & 0.00 & 0.00 & 0.00 & 0.00 & 0.00 & 0.00 & 0.00 & 0.00\end{array}$

$\begin{array}{lllllllllllllllllllllllll}0.00 & 0.00 & 0.00 & 0.00 & 0.00 & 0.00 & 0.00 & 0.00 & 0.00 & 0.00 & 0.00 & 0.00 & 0.00 & 0.00 & 0.00 & 0.00 & 0.00 & 0.00 & 0.00 & 0.00 & 0.00\end{array}$ $\begin{array}{llllllllllllllllllllllllllllllll}0.00 & 0.00 & 0.00 & 0.00 & 0.00 & 0.00 & 0.00 & 0.00 & 0.50 & 0.00 & 0.00 & 0.00 & 0.00 & 0.00 & 0.00 & 0.00 & 0.00 & 0.00 & 0.00 & 0.00 & 0.00\end{array}$

MUTFOTIENT TREATHEHT

FFESILENIIAL.

$\begin{array}{llllllllllllllllllllllll}0.00 & 0.00 & 0.00 & 0.00 & 0.00 & 0.00 & 0.00 & 0.00 & 0.00 & 0.00 & 0.00 & 0.00 & 0.00 & 0.00 & 0.00 & 0.00 & 0.00 & 0.00 & 0.00 & 0.00 & 0.00\end{array}$ E:U:THESS

$\begin{array}{lllllllllllllllllllllllll}0.00 & 0.00 & 0.10 & 0.00 & 0.00 & 0.00 & 0.00 & 0.00 & 0.00 & 0.00 & 0.00 & 0.00 & 0.00 & 0.00 & 0.00 & 0.00 & 0.00 & 0.00 & 0.00 & 0.00 & 0.00\end{array}$ $\begin{array}{lllllllllllllllllllllll}0.00 & 0.00 & 0.00 & 0.00 & 0.00 & 0.00 & 0.00 & 0.00 & 0.00 & 0.00 & 0.00 & 0.00 & 0.00 & 0.00 & 0.00 & 0.00 & 0.00 & 0.00 & 0.00 & 0.00 & 0.00\end{array}$ iricinosis

RESIDENTIAL

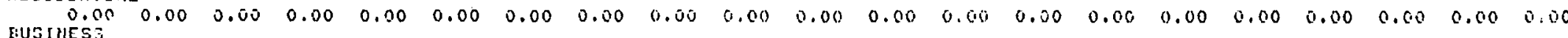

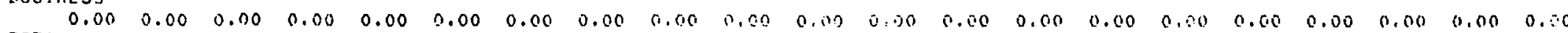

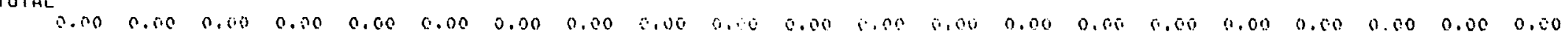


FOT:IEL

SERUICE DEHAHO FUREECAST (MILLIONS)

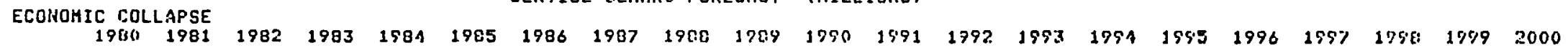
COMFUTER IHTURING

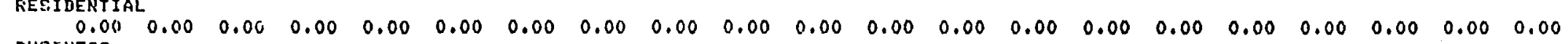
$\begin{array}{rlllllllllllllllllllllll}\text { BUSIMESS } & 0.3 \% & 0.34 & 0.35 & 0.35 & 0.38 & 0.37 & 0.37 & 0.30 & 0.02 & 0.01 & 0.00 & 0.02 & 0.02 & 0.02 & 0.03 & 0.03 & 0.03 & 0.03 & 0.04 & 0.01 & 0.04\end{array}$ TOTAL

$\begin{array}{llllllllllllllllllllllllll}0.33 & 0.34 & 0.35 & 0.35 & 0.36 & 0.37 & 0.3 \% & 0.38 & 0.02 & 0.01 & 0.00 & 0.02 & 0.0 \% & 0.02 & 0.03 & 0.03 & 0.03 & 0.03 & 0.04 & 0.04 & 0.04\end{array}$ COFFESPONDENCE SCHOOL

RESITENTIAL

$\begin{array}{llllllllllllllllllllllllllll}0.00 & 0.00 & 0.00 & 0.00 & 0.00 & 0.00 & 0.00 & 0.00 & 0.00 & 0.00 & 0.00 & 0.00 & 0.00 & 0.00 & 0.00 & 0.00 & 0.00 & 0.00 & 0.00 & 0.00 & 0.00\end{array}$ BUSIMES

$\begin{array}{lllllllllllllllllllllllllll}0.11 & 0.11 & 0.12 & 0.12 & 0.12 & 0.12 & 0.12 & 0.13 & 0.00 & 0.00 & 0.110 & 0.00 & 0.00 & 0.00 & 0.00 & 0.00 & 0.00 & 0.00 & 0.00 & 0.00 & 0.00\end{array}$ $\begin{array}{lllllllllllllllllllllllll}0.11 & 0.11 & 0.12 & 0.12 & 0.12 & 0.12 & 0.12 & 0.13 & 0.00 & 0.00 & 0.00 & 0.00 & 0.00 & 0.00 & 0.00 & 0.00 & 0.00 & 0.00 & 0.010 & 0.00 & 0.00\end{array}$

ELECTKOHIC MEETINGS (EIES)

RES I IEETI I AL

$\begin{array}{lllllllllllllllllllllllllll}0.00 & 0.00 & 0.00 & 0.00 & 0.00 & 0.00 & 0.00 & 0.00 & 0.00 & 0.00 & 0.00 & 0.00 & 0.00 & 0.00 & 0.00 & 0.00 & 0.00 & 0.00 & 0.00 & 0.00 & 0.00\end{array}$

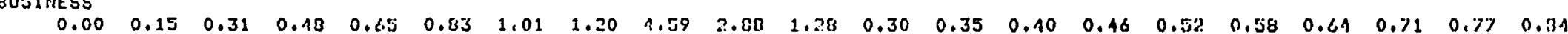
TOTAL

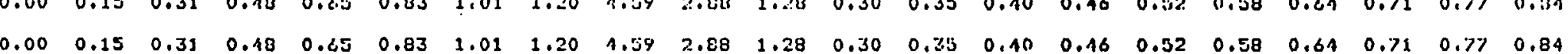

\section{ELECTRONIC FUNDS TRANSFERRING}

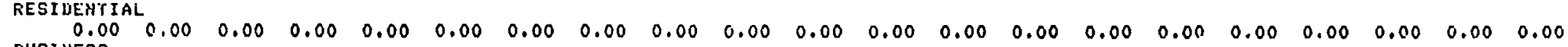
BUSIHESS

TOTAL

$\begin{array}{llllllllllllllllllllllllll}0.00 & 0.00 & 0.00 & 0.00 & 0.00 & 0.00 & 0.00 & 0.00 & 0.00 & 0.00 & 0.00 & 0.00 & 0.00 & 0.00 & 0.00 & 0.00 & 0.00 & 0.00 & 0.00 & 0.00 & 0.00\end{array}$

$\begin{array}{lllllllllllllllllllllllllll}0.00 & 0.00 & 0.00 & 0.00 & 0.00 & 0.00 & 0.00 & 0.00 & 0.00 & 0.00 & 0.00 & 0.00 & 0.00 & 0.00 & 0.00 & 0.00 & 0.00 & 0.00 & 0.00 & 0.00 & 0.00\end{array}$

MESENCE RECCRDING

RESIDENTIAL

$\begin{array}{cllllllllllllllllllllllll}0.00 & 0.00 & 0.00 & 0.00 & 0.00 & 0.00 & 0.00 & 0.00 & 0.00 & 0.00 & 0.00 & 0.00 & 0.00 & 0.00 & 0.00 & 0.00 & 0.00 & 0.00 & 0.00 & 0.00 & 0.00\end{array}$

$\begin{array}{rlllllllllllllllllllllllll}0.00 & 0.00 & 0.00 & 0.00 & 0.00 & 0.00 & 0.00 & 0.00 & 0.00 & 0.00 & 0.00 & 0.00 & 0.00 & 0.00 & 0.00 & 0.00 & 0.00 & 0.00 & 0.00 & 0.00 & 0.00\end{array}$

$\begin{array}{rlllllllllllllllllllllllll}\text { TOTAL } & 0.00 & 0.00 & 0.00 & 0.00 & 0.00 & 0.00 & 0.00 & 0.00 & 0.00 & 0.00 & 0.00 & 0.00 & 0.00 & 0.00 & 0.00 & 0.00 & 0.00 & 0.00 & 0.00 & 0.100 & 0.00\end{array}$

CALL FOKWARIIMO

RESI DENTI AL

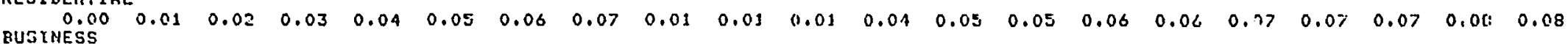

$\begin{array}{llllllllllllllllllllllll}0.00 & 1.53 & 3.13 & 1.79 & 6.52 & 8.31 & 10.1 \% & 12.09 & 1.11 & 0.05 & 0.37 & 1.11 & 1.3 \% & 1.70 & 2.03 & 2.40 & 2.00 & 3.2 .2 & 3.80 & 1.16 & 1.67\end{array}$

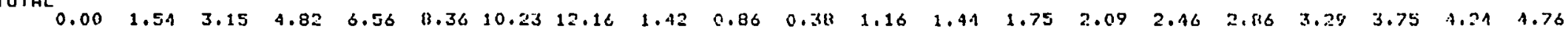


FOIITIL

E.CONOHIC COI.LAFSE

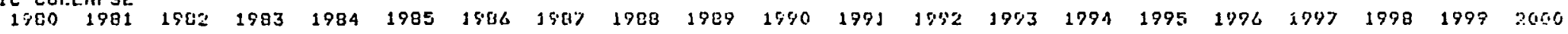

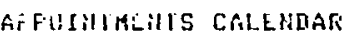

KESTMENIIGL

I:USTI: 0.00 TOTAL $\begin{array}{llllllllllllllllllllllllll}0.06 & 0.06 & 0.06 & 0.06 & 0.06 & 0.06 & 0.06 & 0.06 & 0.00 & 0.00 & 0.06 & 0.00 & 0.00 & 0.00 & 0.00 & 0.00 & 0.00 & 0.00 & 0.00 & 0.00 & 0.00\end{array}$

INTH EASE ACCESS

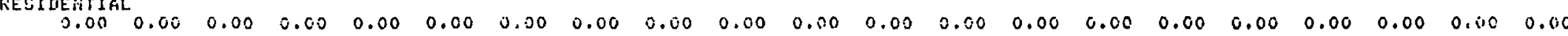

EUTSINESS

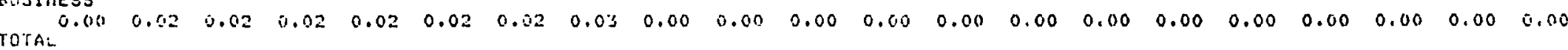

$\begin{array}{llllllllllllllllllllllllllll}0.00 & 0.02 & 0.02 & 0.02 & 0.02 & 0.02 & 0.02 & 0.03 & 0.00 & 0.00 & 0.00 & 0.00 & 0.00 & 0.00 & 0.00 & 0.00 & 0.00 & 0.00 & 0.00 & 0.00 & 0.00\end{array}$

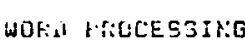

REZITREHTIAL

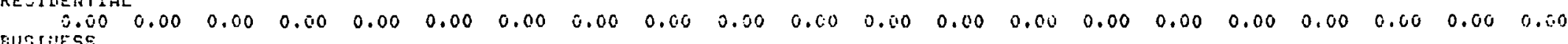

$\begin{array}{rlllllllllllllllllllll}0.01 & 0.02 & 0.02 & 0.02 & 0.02 & 0.02 & 0.02 & 0.02 & 0.00 & 0.00 & 0.00 & 0.00 & 0.00 & 0.00 & 0.00 & 0.00 & 0.00 & 0.00 & 0.00 & 0.00 & 0.00\end{array}$

$\begin{array}{lllllllllllllllllllllllllllllll}0.01 & 0.02 & 0.02 & 0.02 & 0.02 & 0.02 & 0.02 & 0.02 & 0.00 & 0.00 & 0.00 & 0.00 & 0.00 & 0.00 & 0.00 & 0.00 & 0.00 & 0.00 & 0.00 & 0.00 & 0.00 & 0.00\end{array}$

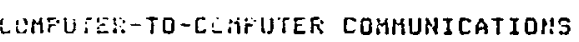

GESTCEITIAL

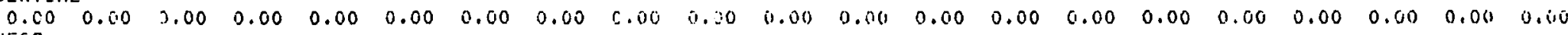

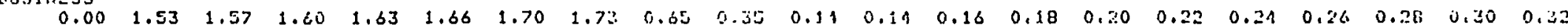

$\begin{array}{rlllllllllllllllllllllll}\text { TCTAL } & 0.00 & 1.53 & 3.57 & 1.60 & 1.33 & 1.64 & 1.70 & 1.73 & 0.05 & 0.35 & 0.14 & 0.14 & 0.16 & 0.18 & 0.20 & 0.22 & 0.24 & 0.24 & 0.28 & 0.30 & 0.32\end{array}$ 
FOKTEL

TERHINAL QEMAHE FOKECAST (KILI.IONS)

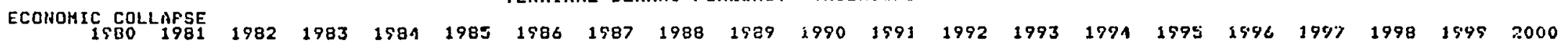
UOICE RESIIIENTIAL

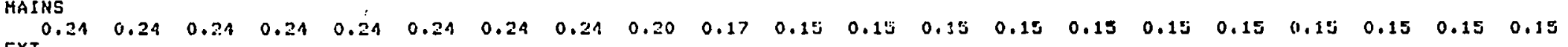
$\begin{array}{llllllllllllllllllllll}0.16 & 0.16 & 0.16 & 0.16 & 0.16 & 0.16 & 0.16 & 0.16 & 0.13 & 0.11 & 0.10 & 0.10 & 0.10 & 0.10 & 0.10 & 0.10 & 0.10 & 0.10 & 0.10 & 0.10 & 0.10\end{array}$

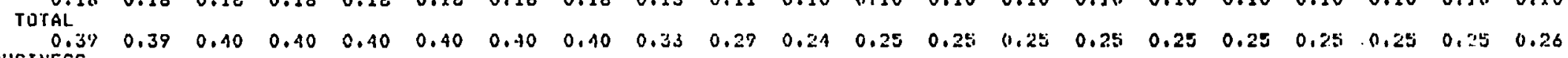
MAINS

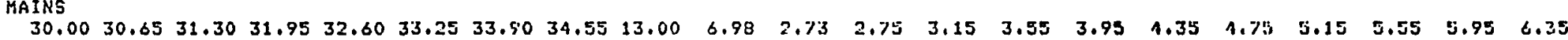

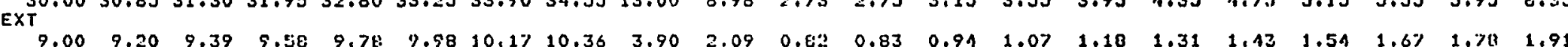
TOTAL

$\begin{array}{lllllllllllllllllllll}39.00 & 39.85 & 10.69 & 11.53 & 12.38 & 13.23 & 11.07 & 41.92 & 16.90 & 9.07 & 3.55 & 3.58 & 1.09 & 1.62 & 5.13 & 5.66 & 6.18 & 6.67 & 7.22 & 7.73 & 8.26\end{array}$ GRAND TUTAL

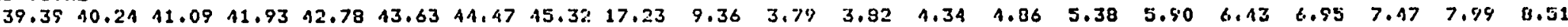
DATA

RESIIIENTIALL
MAINS

$\begin{array}{rlllllllllllllllllllllllll}0.00 & 0.00 & 0.00 & 0.00 & 0.00 & 0.00 & 0.00 & 0.00 & 0.00 & 0.00 & 0.00 & 0.00 & 0.00 & 0.00 & 0.00 & 0.00 & 0.00 & 0.00 & 0.00 & 0.00 & 0.00\end{array}$

EXT

$\begin{array}{llllllllllllllllllllllllll}0.00 & 0.00 & 0.00 & 0.00 & 0.00 & 0.00 & 0.00 & 0.00 & 0.00 & 0.00 & 0.00 & 0.00 & 0.00 & 0.00 & 0.00 & 0.00 & 0.10 & 0.00 & 0.00 & 0.00 & 0.00\end{array}$

$\begin{array}{lllllllllllllllllllllllllllllllllll}0.01 & 0.01 & 0.01 & 0.01 & 0.01 & 0.01 & 0.01 & 0.01 & 0.01 & 0.00 & 0.00 & 0.00 & 0.00 & 0.00 & 0.00 & 0.00 & 0.00 & 0.00 & 0.00 & 0.00 & 0.00\end{array}$

BUSIHESS

$\begin{array}{clllllllllllllllllllll}\text { MAINS } & 0.60 & 0.61 & 0.63 & 0.64 & 0.65 & 0.66 & 0.68 & 0.69 & 0.26 & 0.11 & 0.05 & 0.06 & 0.06 & 0.07 & 0.08 & 0.09 & 0.10 & 0.10 & 0.11 & 0.12 & 0.13\end{array}$

$\begin{array}{llllllllllllllllllllllllll}0.18 & 0.18 & 0.19 & 0.19 & 0.20 & 0.20 & 0.20 & 0.21 & 0.08 & 0.04 & 0.02 & 0.02 & 0.02 & 0.02 & 0.02 & 0.03 & 0.03 & 0.03 & 0.03 & 0.01 & 0.04\end{array}$

$\begin{array}{rlllllllllllllllllllll}0.78 & 0.80 & 0.81 & 0.83 & 0.85 & 0.86 & 0.88 & 0.90 & 0.31 & 0.18 & 0.07 & 0.07 & 0.08 & 0.09 & 0.10 & 0.11 & 0.12 & 0.13 & 0.11 & 0.15 & 0.17\end{array}$

$\begin{array}{lllllllllllllllllllllllll}\text { GRAND IUTAL } & 0.79 & 0.80 & 0.82 & 0.84 & 0.85 & 0.87 & 0.89 & 0.90 & 0.34 & 0.19 & 0.08 & 0.08 & 0.09 & 0.10 & 0.11 & 0.12 & 0.13 & 0.11 & 0.15 & 0.16 & 0.17\end{array}$ 
FOFTEL

Molis:st binthrt

SERUXIEE JEKAND FOFECAST (HILLIONS)

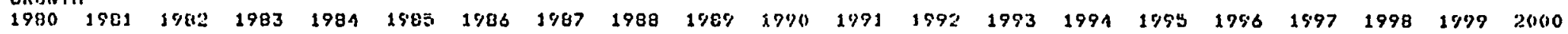
ELECTRUMTC MEWSPAPER

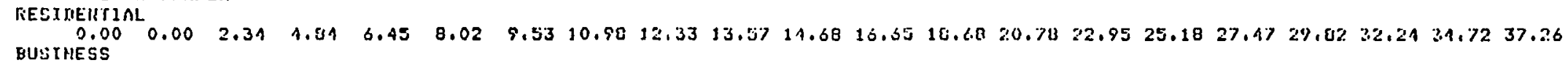
TOTAL

$\begin{array}{lllllllllllllllllllllllllllll}0.00 & 0.00 & 0.00 & 0.00 & 0.00 & 0.00 & 0.00 & 0.00 & 0.00 & 0.00 & 0.010 & 0.00 & 0.00 & 0.00 & 0.00 & 0.00 & 0.00 & 0.00 & 0.00 & 0.00 & 0.00\end{array}$

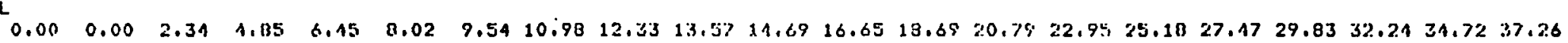
ELECTRONIC MAIL

RESI DENTIAL

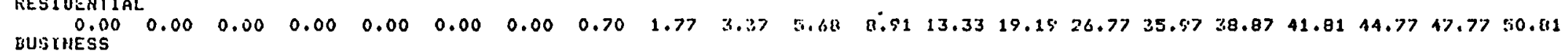

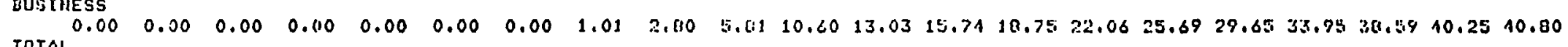
TOTAL

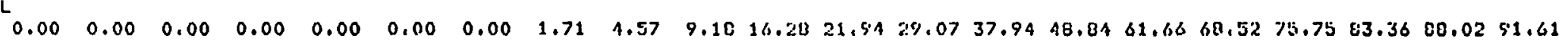

TRAUIEL RESERUATIONS

RESTUENTIAL

$\begin{array}{cllllllllllllllllllllllll}0.00 & 0.00 & 0.00 & 0.00 & 0.00 & 0.00 & 0.00 & 0.00 & 0.00 & 0.00 & 0.00 & 0.00 & 0.00 & 0.00 & 0.00 & 0.00 & 0.00 & 0.00 & 0.00 & 0.00 & 0.00\end{array}$

$\begin{array}{rlllllllllllllllllllll}0.00 & 0.00 & 1.24 & 1.50 & 2.57 & 3.27 & 3.98 & 4.72 & 5.43 & 6.27 & 7.07 & 7.90 & 9.74 & \% .41 & 10.51 & 11.42 & 12.35 & 13.31 & 14.29 & 15.30 & 16.32\end{array}$ TOTAL

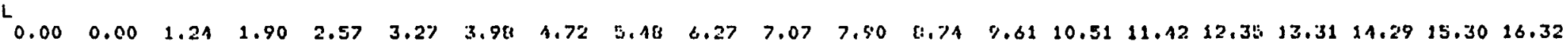

FLAIN TILU TELEPHONE SERUICE

RESIUEHIIAL

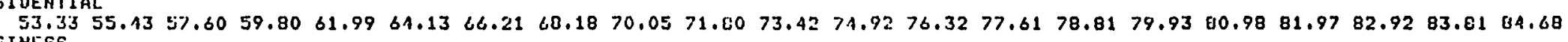

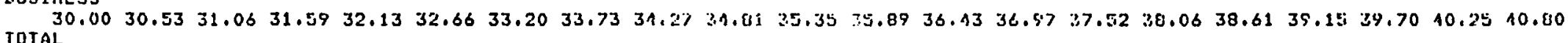

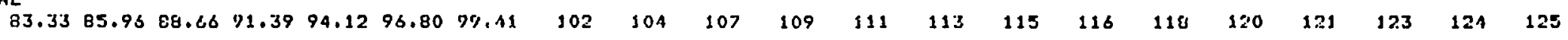
CELLULAR MOHILE SYSTEM

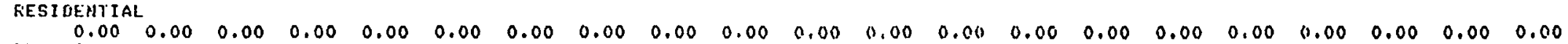
$\begin{array}{rlllllllllllllllllllll}\text { EUSINESS } & 0.00 & 0.00 & 0.00 & 0.00 & 0.00 & 0.00 & 0.00 & 0.00 & 0.00 & 0.00 & 0.00 & 0.00 & 0.00 & 0.00 & 0.00 & 0.00 & 0.00 & 0.00 & 0.00 & 0.00\end{array}$ $\begin{array}{rlllllllllllllllllllll}\text { TUTAL } & 0.00 & 0.00 & 0.00 & 0.00 & 0.00 & 0.00 & 0.00 & 0.00 & 0.00 & 0.00 & 0.00 & 0.00 & 0.00 & 0.00 & 0.00 & 0.00 & 0.00 & 0.00 & 0.00 & 0.00 \\ 0.00 & 0.00 & 0.00 & 0.10 & 0.00 & 0.00 & 0.00 & 0.00 & 0.00 & 0.00 & 0.00 & 0.00 & 0.00 & 0.00 & 0.00 & 0.00 & 0.00 & 0.00 & 0.00 & 0.00 & 0.00\end{array}$

CONSUHER ALUISORY SERUICE

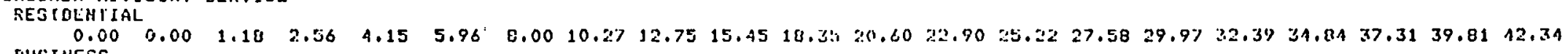
$\begin{array}{rlllllllllllllllllllllll}0.00 & 0.00 & 0.00 & 0.00 & 0.00 & 0.00 & 0.00 & 0.00 & 0.00 & 0.00 & 0.00 & 0.00 & 0.00 & 0.00 & 0.00 & 0.00 & 0.00 & 0.00 & 0.00 & 0.00 & 0.00\end{array}$

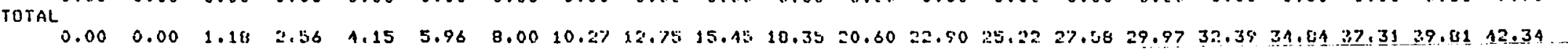


FOKTEL

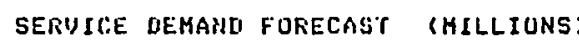

MODEST GROWTH

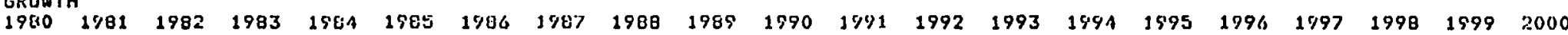
REsTAURANT GUIDE, KESERUATIOHS AHD MENUS

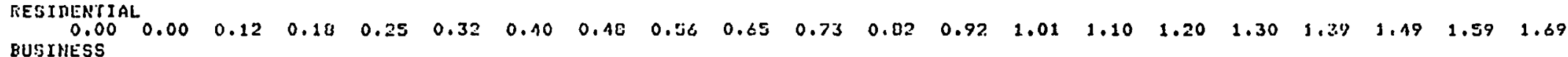
BUS IMESS

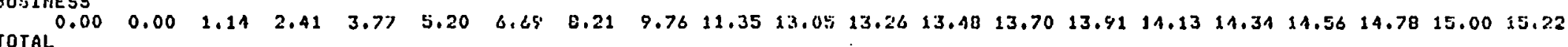

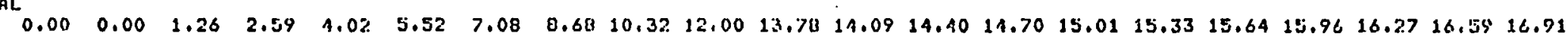

VIDEO GAMES

RESIDENTIAL

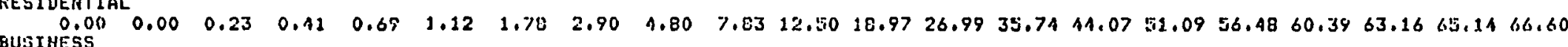

$\begin{array}{llllllllllllllllllllllllll}0.00 & 0.00 & 0.00 & 0.100 & 0.00 & 0.00 & 0.00 & 0.00 & 0.00 & 0.00 & 0.00 & 0.00 & 0.00 & 0.00 & 0.00 & 0.00 & 0.00 & 0.00 & 0.00 & 0.00 & 0.00\end{array}$

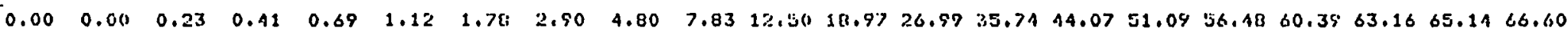

NETWOKK TELEUISION TR:ANSHISSION (SUPERSTATIONS)

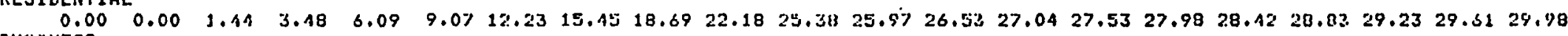
BUSTHESS TOTAL

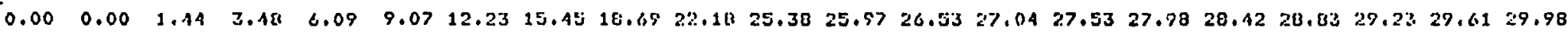

\section{ELECTKONIC LIBRARY (BOOKS, MACGZINESIETC.)}

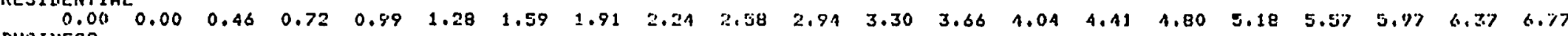

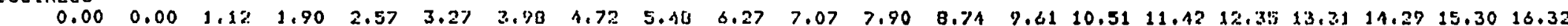

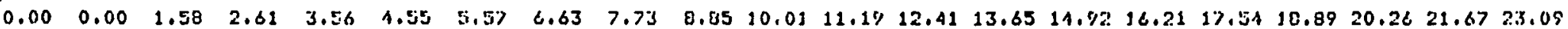

OUTMTIEMT TREATMENT

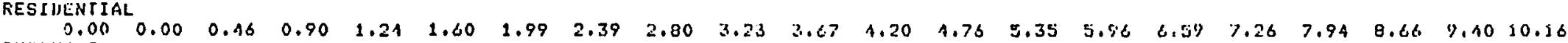

BUSTHESS

$\begin{array}{lllllllllllllllllllllllllll}0.00 & 0.00 & 0.00 & 0.00 & 0.00 & 0.00 & 0.00 & 0.00 & 0.00 & 0.00 & 0.00 & 0.00 & 0.00 & 0.00 & 0.00 & 0.00 & 0.00 & 0.00 & 0.00 & 0.00 & 0.00\end{array}$

$\begin{array}{rllllllllllllllllllll}\text { TOTAL }_{0.00} & 0.00 & 0.16 & 0.90 & 1.24 & 1.60 & 1.59 & 2.39 & 2.80 & 3.23 & 3.67 & 4.20 & 4.76 & 5.35 & 5.96 & 6.54 & 7.26 & 7.94 & 8.66 & 9.30 & 10.16\end{array}$

DIALNOSIS

RESIIENTIAL

$\begin{array}{lllllllllllllllllllllllll}0.00 & 0.00 & 0.00 & 0.00 & 0.00 & 0.00 & 0.00 & 0.00 & 0.00 & 0.00 & 0.00 & 0.00 & 0.00 & 0.00 & 0.00 & 0.00 & 0.00 & 0.00 & 0.00 & 0.00 & 0.00\end{array}$

BuSTHESS

TOTAL

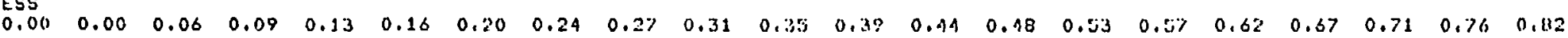

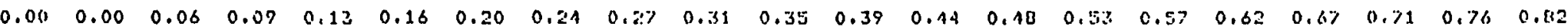


TEFTEL

SERUICE DEHAMD FORECAST (HILLIONS)

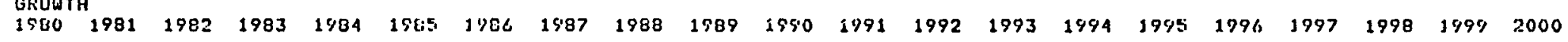

COKPUTER TUTURING

KESIDENTIAL.

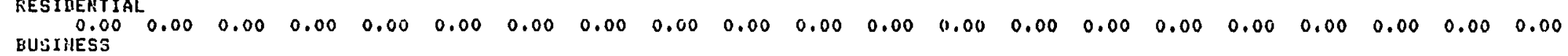

$\begin{array}{rllllllllllllllllllllllll}0.00 & 0.05 & 0.07 & 0.11 & 0.17 & 0.25 & 0.37 & 0.53 & 0.74 & 0.99 & 1.28 & 1.59 & 1.80 & 2.14 & 2.35 & 2.53 & 2.67 & 2.78 & 2.07 & 2.95 & 3.01\end{array}$

$\begin{array}{lllllllllllllllllllllllll}0.00 & 0.05 & 0.07 & 0.11 & 0.17 & 0.25 & 0.37 & 0.53 & 0.74 & 0.59 & 1.28 & 1.59 & 1.08 & 2.11 & 2.35 & 2.53 & 2.67 & 2.70 & 2.87 & 2.95 & 3.01\end{array}$

COKFESPONDENCE SCHOOL

RESI DEIIIIAL

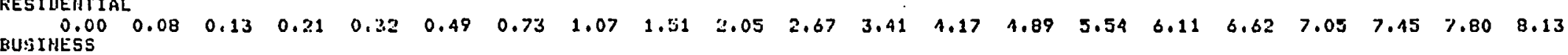

$\begin{array}{rllllllllllllllllllll}0.00 & 0.05 & 0.07 & 0.11 & 0.17 & 0.25 & 0.37 & 0.53 & 0.74 & 0.94 & 1.28 & 1.63 & 1.94 & 2.33 & 2.64 & 2.91 & 2.15 & 3.37 & 3.55 & 3.75 & 3.92\end{array}$

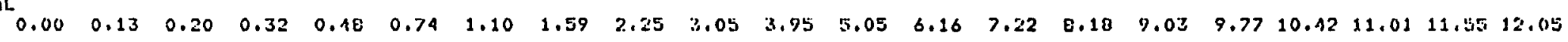

ELECTKINIC MEETINGS (EIES)

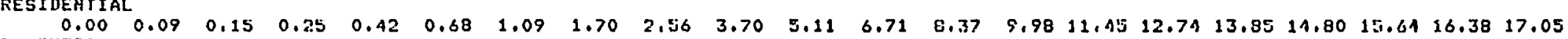

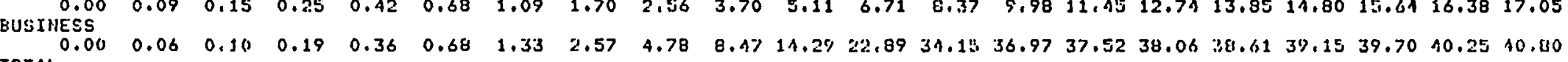

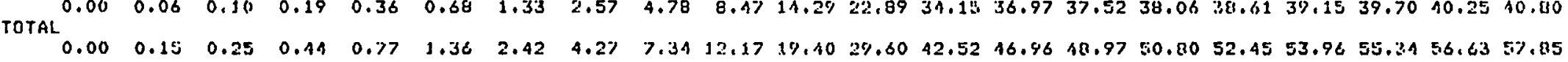

ELECTRONIC FUNDS TRAIISFERKING

RESIUIENTIAL

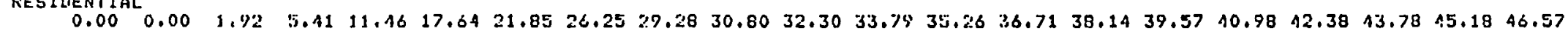

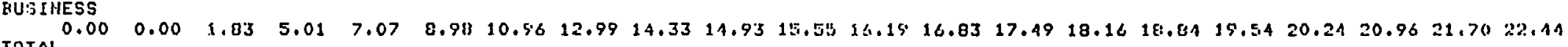

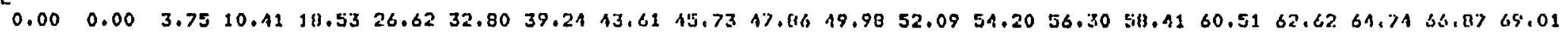

MESSACE RECDRUING

KESIDENTIAL

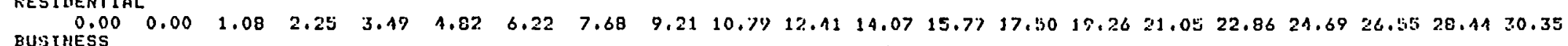

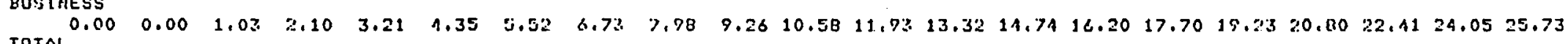
TOTAL

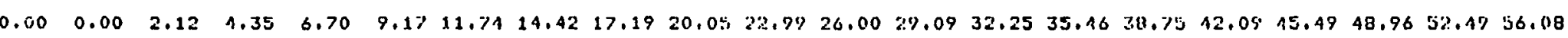

\section{CALL F DKWARIING}

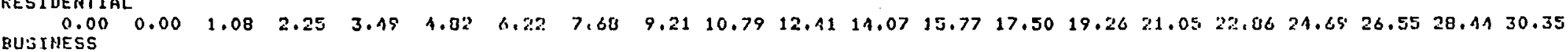

$\begin{array}{rlllllllllllllllllll}0.00 & 0.00 & 1.03 & 2.10 & 3.21 & 1.35 & 5.52 & 6.73 & 7.9 E & \% .26 & 10.5611 .93 & 13.32 & 11.71 & 16.20 & 17.70 & 19.23 & 20.80 & 22.11 & 24.05 & 25.73\end{array}$ TOTAL

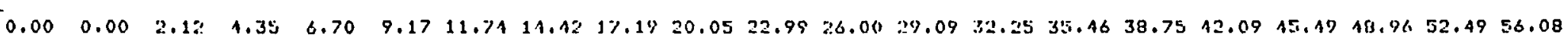




\section{FQRTEL.}

SERUILE DEMAMU TOKECNST (MILLIONS)

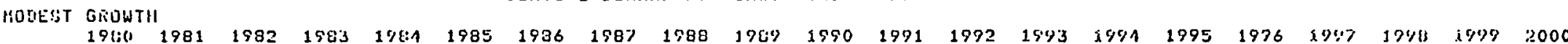
AFFOIMTKLITS CCILEHHAK

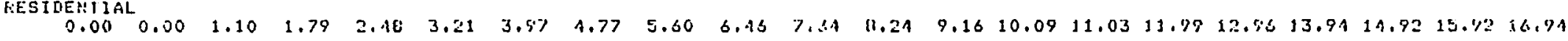
$\begin{array}{rllllllllllllllllllllll}\text { EUSHESS } & 0.00 & 0.62 & 0.45 & 1.2 \% & 1.63 & 1.99 & 2.36 & 2.71 & 3.13 & 3.53 & 3.95 & 4.37 & 4.613 & 5.25 & 5.71 & 6.10 & 6.66 & 7.15 & 7.45 & 8.16\end{array}$

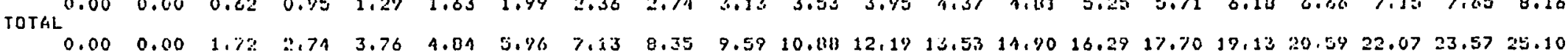
IIIIA BRSE ACCESS

TIESTDEM HCCES

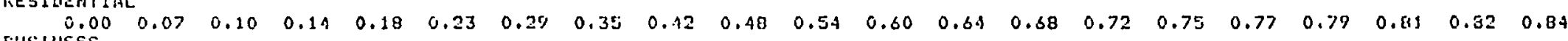

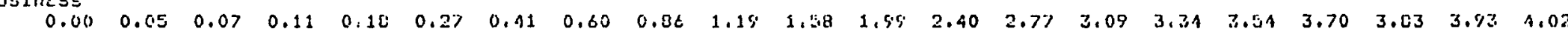

$\begin{array}{rllllllllllllllllllll}\text { TOTAL }_{0.00} & 0.12 & 0.17 & 0.25 & 0.32 & 0.50 & 0.70 & 0.95 & 1.08 & 1.67 & 2.12 & 2.57 & 3.05 & 3.46 & 3.81 & 1.09 & 4.31 & 4.19 & 1.04 & 4.28 & 1.85\end{array}$ WLKI FROCESSIKG

KEE'IILEMIIAL

$\begin{array}{llllllllllllllllllllllll}0.00 & 0.69 & 0.17 & 0.30 & 0.31 & 0.32 & 0.33 & 0.34 & 0.35 & 0.36 & 0.39 & 0.37 & 0.30 & 0.39 & 0.39 & 0.40 & 0.40 & 0.11 & 0.41 & 0.42 & 0.12\end{array}$

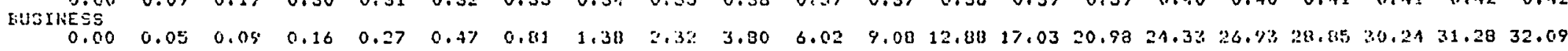
IUTRL

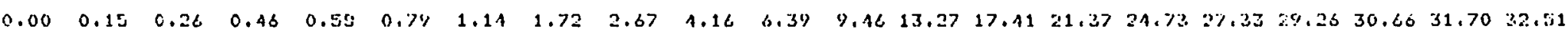

COHFURE-TO-COMFUTER COMHUNICATIONS

RESI IIEIITI I AL.

$\begin{array}{lllllllllllllllllllllllll}0.00 & 0.00 & 0.00 & 0.00 & 0.00 & 0.00 & 0.00 & 0.00 & 0.00 & 0.00 & 0.00 & 0.00 & 0.00 & 0.00 & 0.00 & 0.00 & 0.00 & 0.00 & 0.00 & 0.00 & 0.00\end{array}$

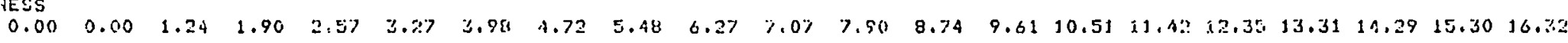

TOTAL

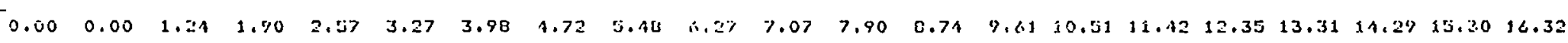


FOFTEL

TERMIHAL DEHAMM FORECNGT (KILI.IOHE:

HOLITST GREUWTH

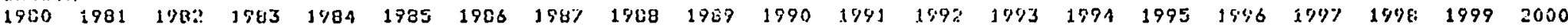
VOICE RESIIIENIIIIL

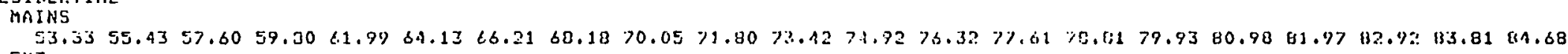
EXT TOIAL

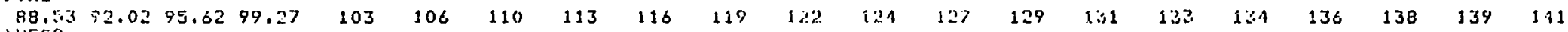
AU:IHESS

HAl 1 H:S

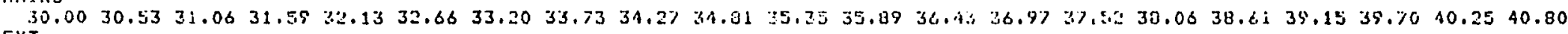
EXT

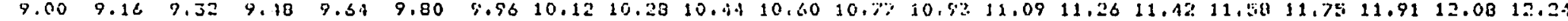
1) 17 in:

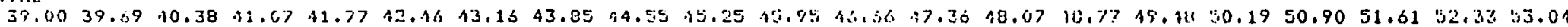
GRABIO TOTAL

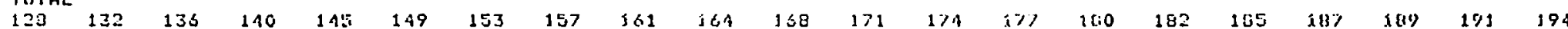
Intis

FESIDENTIAL
MAINS

\begin{tabular}{|c|c|c|c|c|c|c|c|c|c|c|c|c|c|c|c|c|c|c|c|c|}
\hline$E \times T^{1.0 ?}$ & $1 .: 1$ & 1.15 & 1.20 & 1.21 & $1 . .38$ & 1.32 & 1.36 & 1.40 & 1.91 & $i, i 7$ & 1.30 & 1,53 & 5.5. & 8ز5. & 1.20 & 1.52 & 1.64 & $1,<5$ & 1.68 & 1.69 \\
\hline IOIAL & 0.33 & 0.315 & 3.36 & 0.37 & 0.38 & 0.10 & 0.11 & 0.12 & 0.43 & 0.98 & 0.45 & 0.96 & 0.47 & 0.47 & 0.43 & 0.47 & 0.10 & 0.50 & 0.50 & 0.51 \\
\hline $\begin{array}{l}1.23 \% \\
\text { IMESS } \\
\text { HAIUS }\end{array}$ & 1.44 & 1.50 & 1.55 & .61 & .67 & .72 & 3.77 & 1.82 & 1.87 & 1.51 & שי" 1 & 1.23 & 2.02 & 2.05 & 2.00 & $2.1 i$ & 213 & 2.18 & 2.18 & 2.20 \\
\hline$E^{0.5 T^{0.50}}$ & 0.61 & .62 & .63 & . CA & .65 & .66 & 0.67 & 0.48 & 0.70 & .71 & 0.72 & $0.7 / 3$ & 0.74 & 0.75 & 0.78 & 0.77 & 0.78 & 0,70 & .81 & 0.132 \\
\hline$T_{\text {TiJ }}^{0.10}$ & 0.10 & .19 & 0.17 & 19 & 0.20 & . 20 & 0,20 & .21 & 0.21 & .21 & 0.22 & 1.22 & 122 & $0 .=3$ & .23 & 0.23 & 0,23 & 0,21 & 0.24 & 0.24 \\
\hline $\begin{array}{l}0.73 \\
\mathrm{IOTA}\end{array}$ & 0.7 & 0.81 & 0.32 & 0 & $0.8 \mathrm{~J}$ & .86 & 0.88 & 0.37 & 0.91 & $0 . \%$ & 0.3 .3 & 0.95 & 0.96 & 0.90 & $0.5,9$ & $i, 00$ & $i, 0 z$ & 1.03 & 1.05 & 1.06 \\
\hline 2.17 & & 2.31 & 2.30 & 2.75 & 2.62 & 2008 & 2.35 & 2.71 & 2.27 & $\therefore .33$ & 2.88 & $2.9 \%$ & 2.98 & 3.02 & $3.0 ?$ & 3.11 & 3.15 & 3.19 & 3,23 & 3.26 \\
\hline
\end{tabular}


FOFTEL

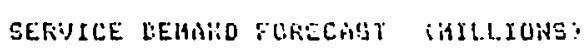

FXFUIEUTIRL GRUHTH

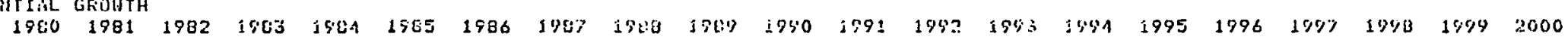
ELICINUARC MEWSPAFER

\begin{tabular}{|c|c|c|c|c|c|c|c|c|c|c|c|c|c|c|c|c|c|c|c|c|}
\hline $\begin{array}{c}0.00 \\
\text { EUSiLESS }\end{array}$ & 0.00 & 0.00 & 0.00 & 0.00 & 0.00 & 0.00 & 0.00 & 0.00 & 0.00 & 0.00 & 0.00 & 0.01 & 0.02 & 0.03 & 0.06 & 0.04 & 0.02 & 0.01 & 0.00 & 0.00 \\
\hline $\operatorname{TalAL}^{0.00}$ & 0.00 & 0.00 & 0.00 & 0.00 & 0.00 & 0.00 & 0.00 & 0.00 & 0.01 & 0.06 & $0.1 \%$ & 0.70 & 3.37 & 3.89 & 343 & 14.26 & 16.39 & 19.20 & 22,45 & 26.10 \\
\hline 0.00 & 0.00 & 0.00 & 0.00 & 0.00 & 0.00 & 0.00 & 0.00 & 0.00 & 0.01 & 0.06 & 0.17 & 0.90 & 1.37 & 3.93 & 313 & 34.29 & 16.61 & 19.31 & 22.15 & 26.10 \\
\hline $\begin{array}{c}\text { KESUIJEWI IAL } \\
0.00 \\
\text { EUSZIIESS }\end{array}$ & 0.00 & 0.00 & 0.00 & 0.00 & 0.00 & 0.00 & 0.00 & 0.00 & 0.00 & 0.00 & 0.00 & 0.02 & 0.01 & 0.11 & 0.27 & 0.7 .1 & 1.82 & 1.11 & 10.69 & 24.18 \\
\hline Tomal 0.00 & 0.00 & 0.00 & 0.00 & 0.02 & 0.18 & 1.61 & 13.51 & 82.11 & 122 & 145 & 172 & 106 & 240 & 201 & 320 & 385 & 450 & 52. & 611 & 711 \\
\hline
\end{tabular}

IFIRELL RESERVATIIIUHS

FE!SI DENIIIAL.

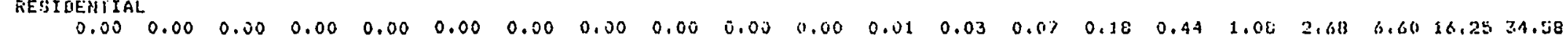

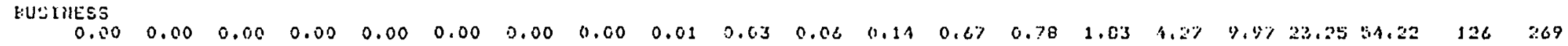

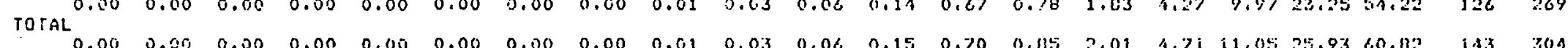

PLAII: OLE TELËFHLR:L GERUICE

RESI DEHIIAL

$\begin{array}{llllllllllllllllllllllll}53.33 & 23.61 & 10.51 & 1.20 & 2.12 & 0.96 & 0.13 & 0.20 & 0.0 \% & 0.04 & 0.02 & 0.00 & 0.00 & 0.00 & 0.00 & 0.00 & 0.00 & 0.00 & 0.00 & 0.00 & 0.00\end{array}$ Busmitiss

$\begin{array}{lllllllllllllllllllllll}30.00 & 15.45 & 7.54 & 4.05 & 2.06 & 1.05 & 0.53 & 0.27 & 0.13 & 0.07 & 0.03 & 0.02 & 0.05 & 0.00 & 0.00 & 0.00 & 0.00 & 0.00 & 0.00 & 0.00 & 0.00\end{array}$

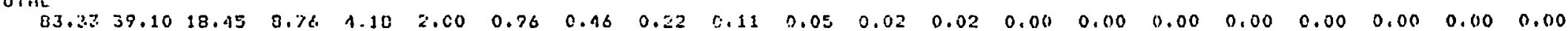

CILLLLLAE MOEILE SYSTEM

LESI IEEUT SAL

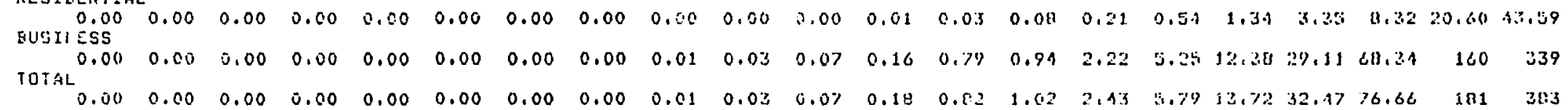

COM!'UUEF: AII!ISOKY SET:UICE

Fis Sxllicillitil

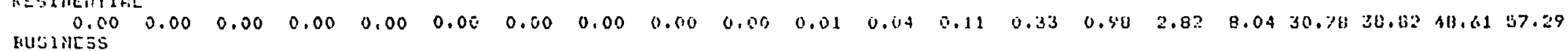

$\begin{array}{rlllllllllllllllllllllllllllllll}0.00 & 0.00 & 0.00 & 0.00 & 0.00 & 0.00 & 0.00 & 0.00 & 0.00 & 0.00 & 0.00 & 0.00 & 0.00 & 0.00 & 0.00 & 0.00 & 0.00 & 0.00 & 0.00 & 0.00 & 0.00\end{array}$ TUTh

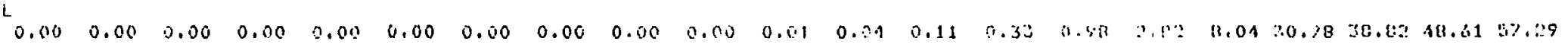


FOKILL

SERUILË DENAHD FUKECAST (IILLIUNS)

E*FUNEIIIIAL LEOWTH

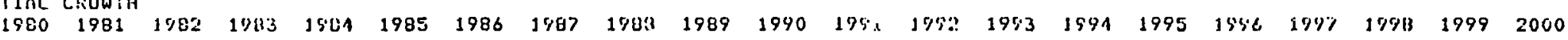

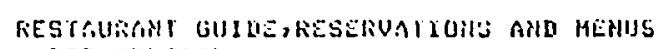

\begin{tabular}{|c|c|c|c|c|c|c|c|c|c|c|c|c|c|c|c|c|c|c|c|c|}
\hline 0.00 & 0.00 & 0.00 & 0.00 & 0.00 & 0.00 & .00 & 1.00 & 0.00 & .00 & 0.00 & .02 & 0.05 & .10 & 0.21 & 0.44 & 0.93 & 1.97 & A. IA & 8.70 & $1 \% .29$ \\
\hline 0.00 & 0.00 & 0.00 & 0.00 & 0.00 & 0.00 & 0.00 & 0.00 & 0.00 & 0.02 & 0.05 & 0.10 & 0.46 & 0.51 & 1.13 & 2.50 & 6 & 1236 & 27.38 & Co.c.E & 135 \\
\hline 0.00 & 0.00 & 0.00 & .00 & 0.00 & 1.00 & 0.00 & 1.00 & 0.00 & 0.02 & 0.05 & .12 & 0.50 & .60 & 1.3 .3 & 2.71 & 6.19 & 11.30 & 31.50 & 69.30 & 32 \\
\hline
\end{tabular}

VIDEUS Critit S

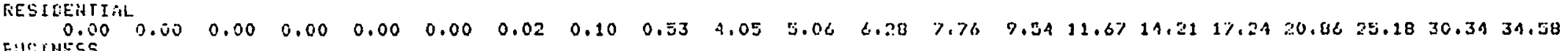
$\begin{array}{rlllllllllllllllllllllllll}0.00 & 0.00 & 0.00 & 0.00 & 0.00 & 0.00 & 0.00 & 0.00 & 0.00 & 0.00 & 0.00 & 0.00 & 0.00 & 0.00 & 0.00 & 0.00 & 0.00 & 0.00 & 0.00 & 0.00 & 0.00\end{array}$

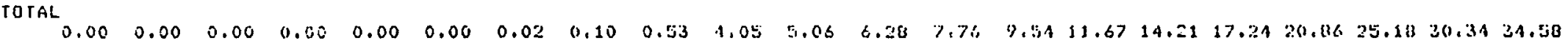
REYHOKK TLLLUISIOR TKANSHISSION (SUFERETATIONS)

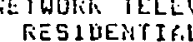

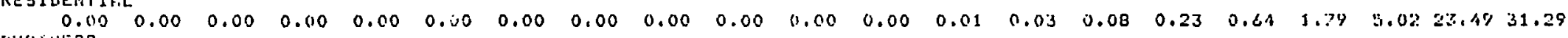

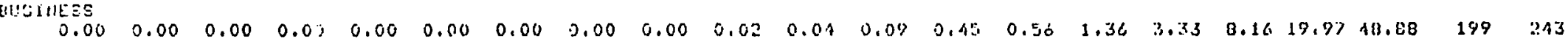

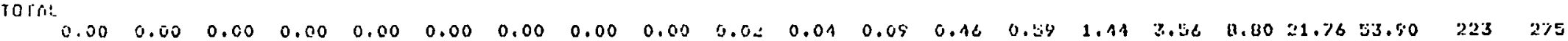

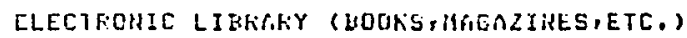

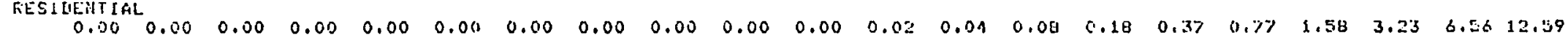
LLTIIILSS TOTAL.

$\begin{array}{llllllllllllllllllllllllllllllll}0.00 & 0.00 & 0.00 & 0.00 & 0.00 & 0.00 & 0.00 & 0.00 & 0.00 & 0.00 & 0.00 & 0.00 & 0.00 & 0.00 & 0.00 & 0.00 & 0.00 & 0.00 & 0.00 & 0.00 & 0.00\end{array}$

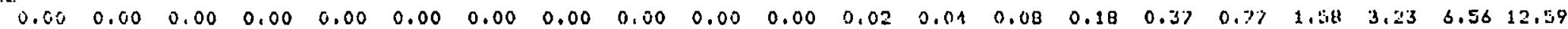
MJTHITEMT IKESTHLi:T

KESITEHIIAL

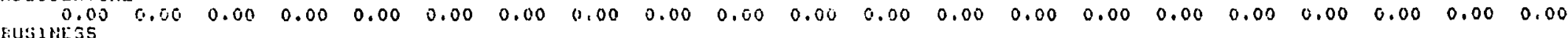

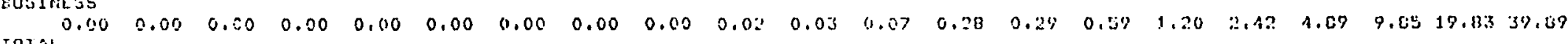
TOTAL

$\begin{array}{llllllllllllllllllllll}0.00 & 0.20 & 0.00 & 0.00 & 0.00 & 0.00 & 0.00 & 0.00 & 0.00 & 0.02 & 0.03 & 0.07 & 0.013 & 0.29 & 0.04 & 1.20 & 2.12 & 1.89 & 9.85 & 17.183 & 39.89\end{array}$

SInC:TOSIS

BESTHERTIFI.

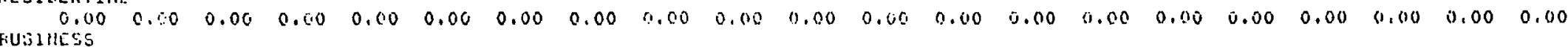

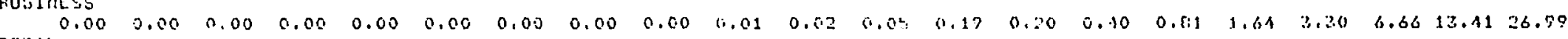
TCIAL

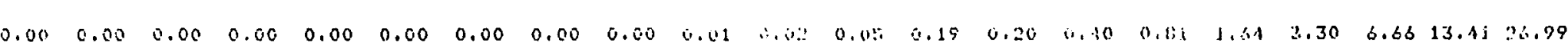


FOFTILL

SERUYIE UEHIMU FOKRCAST (MILLIUNS)

EXruit:HI GR. GROHTII

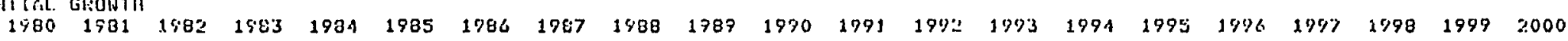
COMFUT:ir IUIOAING

FEETHEWTIOL

$\begin{array}{lllllllllllllllllllll}0.00 & 0.00 & 0.00 & 0.00 & 0.00 & 0.00 & 0.00 & 0.00 & 0.00 & 0.00 & 0.00 & 0.00 & 0.02 & 0.03 & 0.0 \% & 0.13 & 0.26 & 0.51 & 0.98 & 1.90 & 3.163\end{array}$

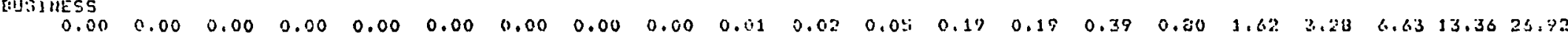

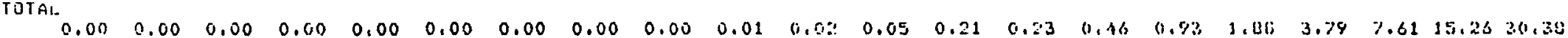

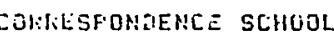

\begin{tabular}{|c|c|c|c|c|c|c|c|c|c|c|c|c|c|c|c|c|c|c|c|c|}
\hline US DHES & 0.00 & 0.00 & .00 & .00 & .00 & .00 & .00 & 0.00 & 0.00 & & 0.00 & & 0.00 & & 0.00 & 0.00 & 0.00 & 0.00 & 0.00 & \\
\hline & 0.00 & 0.00 & & & & & & 0.08 & & & 4.50 & & & & & & & & 537 & \\
\hline 0.00 & 0.00 & 0.00 & 0.00 & .00 & .00 & .00 & 0.02 & $0 . C 8$ & 0.32 & 1,28 & 1.90 & 35.92 & 157 & 201 & $2 \$ 1$ & 308 & 374 & 449 & 537 & \\
\hline
\end{tabular}

CLECTROHIC MEETINGS (EIES)

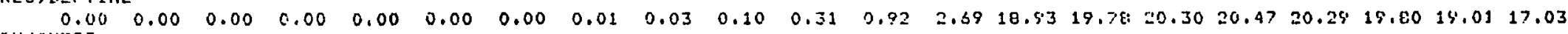

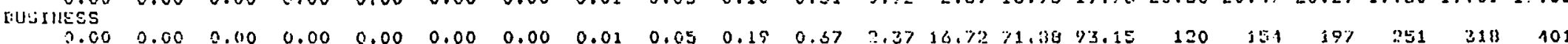
TOTAL

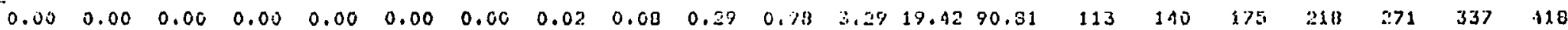

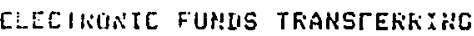

RESTILITISAL

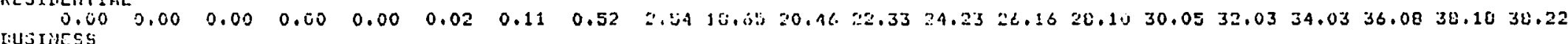

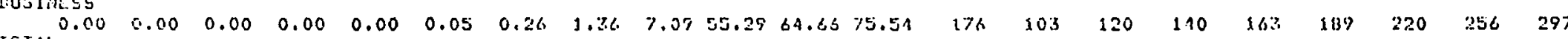
TCTA

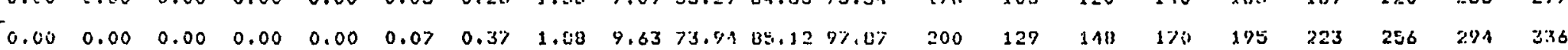

HI. SAIEL RECOFEIH!O

RiE:LiLilital

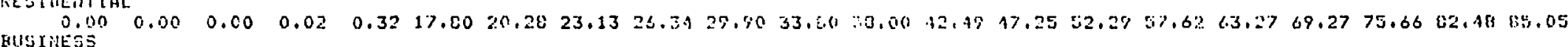

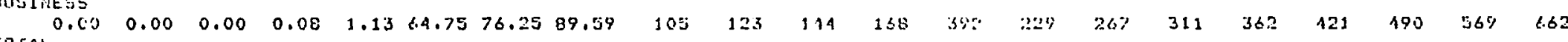

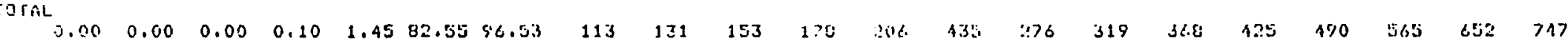

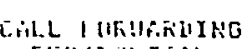

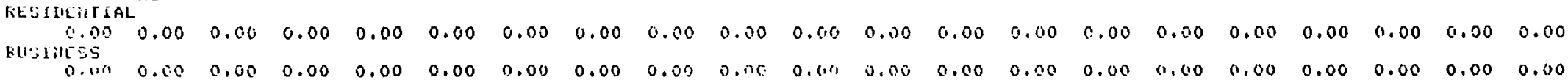


FOKTEL

SERUICE REMAMD FORECAST (MILLIOHS)

EXFONLHTIAL GROWTH

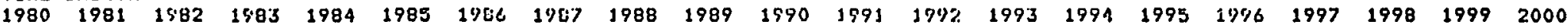
APPOIATMEHISS LALENIJAR

RESIMENTIIAL

GUSTNESS

TOTAL $\begin{array}{llllllllllllllllllllll}0.00 & 0.00 & 0.00 & 0.00 & 0.00 & 0.00 & 0.00 & 0.00 & 0.00 & 0.00 & 0.00 & 0.00 & 0.02 & 0.02 & 0.04 & 0.08 & 0.15 & 0.30 & 0.36 & 1.08 & 2.06\end{array}$ $\begin{array}{lllllllllllllllllllllll}0.00 & 0.00 & 0.00 & 0.00 & 0.00 & 0.00 & 0.00 & 0.00 & 0.00 & 0.00 & 0.00 & 0.00 & 0.02 & 0.02 & 0.04 & 0.08 & 0.17 & 0.32 & 0.62 & 1.20 & 2.32\end{array}$

DATA BASE ACCESS

RESTDENTIAL

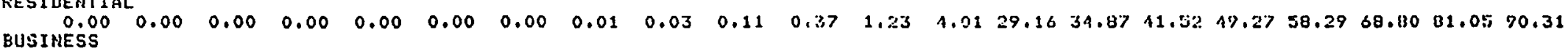

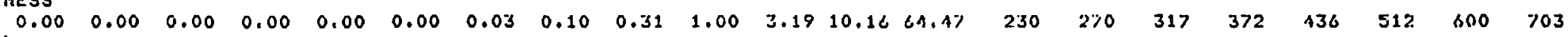

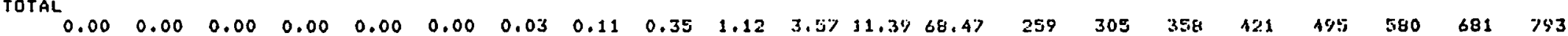

\section{WOFD FHOCESSIM!G}

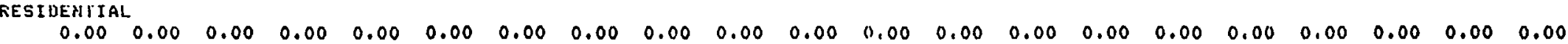

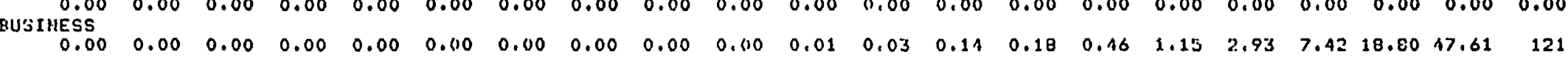

$\begin{array}{rllllllllllllllllllllll}\text { TOTAL } & 0.00 & 0.00 & 0.00 & 0.00 & 0.00 & 0.00 & 0.00 & 0.00 & 0.00 & 0.00 & 0.01 & 0.03 & 0.11 & 0.18 & 0.46 & 1.15 & 2.93 & 7.42 & 18.80 & 17.61 & 121\end{array}$

COMFUTER-TO-COMFUTEF COMMUNICATIONS

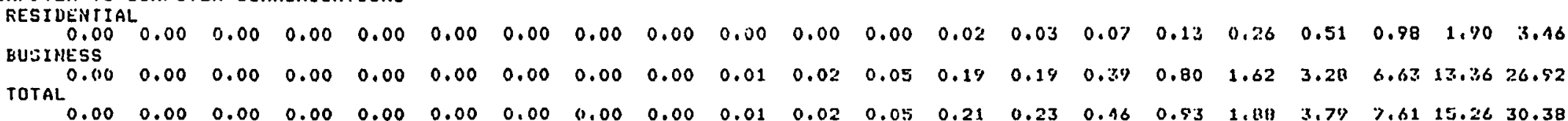


FOKTEL

TERYIHAL. DERAHD FORECAST (HILLIUASS)

EXPONEHTIML GRINTH

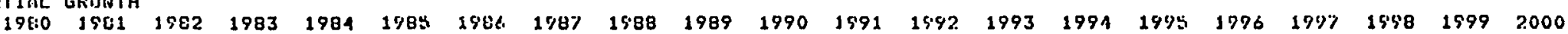
VOICE

REESTDEIITIAL

$\begin{array}{lllllllllllllllllllllll}\text { MAINS } & 23.33 & 23.61 & 10.5 i 1 & 1.70 & 2.12 & 0.96 & 0.43 & 0.20 & 0.09 & 0.04 & 0.02 & 0.00 & 0.00 & 0.00 & 0.00 & 0.00 & 0.00 & 0.00 & 0.00 & 0.00 & 0.00\end{array}$ EXT

$\begin{array}{lllllllllllllllllllllllll}35.20 & 15.59 & 6.54 & 3.10 & 1.10 & 0.63 & 0.29 & 0.13 & 0.06 & 0.03 & 0.01 & 0.00 & 0.00 & 0.00 & 0.00 & 0.00 & 0.00 & 0.00 & 0.00 & 0.00 & 0.00\end{array}$ TUTAL

$\begin{array}{lllllllllllllllllllllll}88.53 & 39.20 & 17.45 & 7.81 & 3.51 & 1.59 & 0.72 & 0.33 & 0.15 & 0.07 & 0.03 & 0.00 & 0.00 & 0.03 & 0.00 & 0.00 & 0.00 & 0.00 & 0.00 & 0.00 & 0.00\end{array}$ EUSIHESS

MAINS

$\begin{array}{llllllllllllllllllllllll}30.00 & 15.49 & 7.91 & 1.05 & 2.06 & 1.05 & 0.53 & 0.27 & 0.13 & 0.07 & 0.03 & 0.02 & 0.02 & 0.00 & 0.00 & 0.00 & 0.00 & 0.00 & 0.00 & 0.00 & 0.00\end{array}$ EXT

$\begin{array}{lllllllllllllllllllllll}9.00 & 1.65 & 2.38 & 1.22 & 0.62 & 0.31 & 0.16 & 0.08 & 0.04 & 0.02 & 0.01 & 0.01 & 0.01 & 0.00 & 0.00 & 0.00 & 0.00 & 0.00 & 0.00 & 0.00 & 0.00\end{array}$

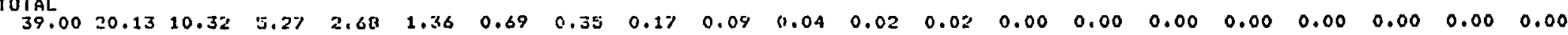
GRAND TUTAL

$\begin{array}{lllllllllllllllllllllll}120 & 59.33 & 27.77 & 13.08 & 6.19 & 2.94 & 1.41 & 0.67 & 0.32 & 0.15 & 0.07 & 0.0 \% & 0.02 & 0.00 & 0.00 & 0.00 & 0.00 & 0.00 & 0.00 & 0.00 & 0.00\end{array}$

IIATA

FESINENTIAL

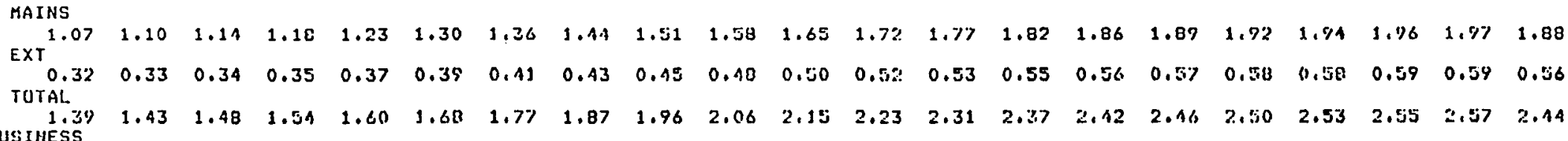
MAINS

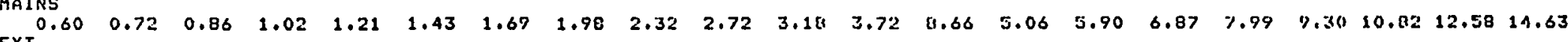

$\begin{array}{lllllllllllllllllllllll}0.18 & 0.22 & 0.26 & 0.31 & 0.36 & 0.43 & 0.51 & 0.59 & 0.70 & 0.82 & 0.95 & 1.11 & 2.60 & 1.52 & 1.77 & 2.06 & 2.40 & 2.79 & 3.25 & 3.78 & 1.39\end{array}$

$\begin{array}{rlllllllllllllllllllllll}\text { TOTAL } & 0.78 & 0.51 & 1.12 & 1.33 & 1.58 & 1.86 & 2.19 & 2.57 & 3.02 & 3.51 & 1.14 & 4.83 & 11.26 & 6.58 & 7.66 & 0.93 & 10.39 & 12.09 & 11.07 & 16.36 & 15.02\end{array}$

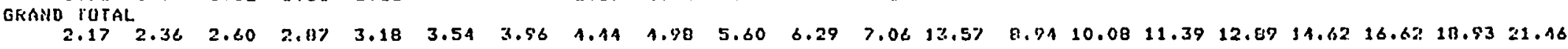




\title{
LIST OF ABBREVIATIONS
}

\author{
CATV Cable Television \\ CB Citizen Band \\ CO Central Office (Switch) \\ EFT Electronic Funds Transfer \\ EIES Electronic Information Exchange System \\ FCC Federal Communications Commission \\ GTE General Telephone and Electronics \\ GTNW General Telephone Company of the Northwest, Incorporated \\ MCI Microwave Communications, Incorporated \\ PBX Private Branch Exchange \\ POTS Plain Old Telephone Service \\ SBS Satellite Business System \\ STV Satellite Television \\ Telco A Telephone Operating Company
}

